\title{
Effectiveness of a multiple-strategy community intervention to reduce maternal and child health inequalities in Haryana, Nort India
}

Citation for published version (APA):

Gupta, M. (2016). Effectiveness of a multiple-strategy community intervention to reduce maternal and child health inequalities in Haryana, Nort India. [Doctoral Thesis, Maastricht University]. Maastricht University. https://doi.org/10.26481/dis.20161212mg

Document status and date:

Published: 01/01/2016

DOI:

10.26481/dis.20161212mg

Document Version:

Publisher's PDF, also known as Version of record

Document license:

Unspecified

Please check the document version of this publication:

- A submitted manuscript is the version of the article upon submission and before peer-review. There can be important differences between the submitted version and the official published version of record.

People interested in the research are advised to contact the author for the final version of the publication, or visit the DOI to the publisher's website.

- The final author version and the galley proof are versions of the publication after peer review.

- The final published version features the final layout of the paper including the volume, issue and page numbers.

Link to publication

\footnotetext{
General rights rights.

- You may freely distribute the URL identifying the publication in the public portal. please follow below link for the End User Agreement:

www.umlib.nl/taverne-license

Take down policy

If you believe that this document breaches copyright please contact us at:

repository@maastrichtuniversity.nl

providing details and we will investigate your claim.
}

Copyright and moral rights for the publications made accessible in the public portal are retained by the authors and/or other copyright owners and it is a condition of accessing publications that users recognise and abide by the legal requirements associated with these

- Users may download and print one copy of any publication from the public portal for the purpose of private study or research.

- You may not further distribute the material or use it for any profit-making activity or commercial gain

If the publication is distributed under the terms of Article $25 \mathrm{fa}$ of the Dutch Copyright Act, indicated by the "Taverne" license above, 
Effectiveness of a Multiple-Strategy Community Intervention to Reduce Maternal and Child Health Inequalities in Haryana, North India 
Colophon

(c) Copyright: Madhu Gupta, Maastricht 2016

Cover design: Madhu Gupta

Lay-out: Madhu Gupta

Production: IPSKAMP printing

ISBN: 978-94-028-0373-0

Maastricht 2016

The research presented in this dissertation was conducted at the School of Public Health, Department of Community Medicine, Post Graduate Institute of Medical Education and Research (PGIMER), Chandigarh, India. PGIMER is one of the Institutes of National Importance in India. In 2015, the British Medical Journal has adjudged it for having the best medicine experts in South Asia.

The studies presented in this dissertation were conducted in close collaboration with and supervision by researchers in the School for Public Health and Primary Care (CAPHRI) at Maastricht University, The Netherlands. CAPHRI is part of the Netherlands School of Primary Care Research (CARE), which has been acknowledged since 1995 by the Royal Netherlands Academy of Art and Sciences.

This research described in this dissertation was funded by the National Rural Health Mission, Haryana Government, India.

All rights are reserved. No part of this book may be reproduced or transmitted in any form or by any means, without the written permission from the author or, where appropriate, the publisher of the article. 


\title{
Effectiveness of a Multiple-Strategy Community Intervention to Reduce Maternal and Child Health Inequalities in Haryana, North India
}

\author{
DISSERTATION \\ To obtain the degree of Doctor at Maastricht University, \\ on the authority of the Rector Magnificus Prof. dr. R. M. Letschert \\ in accordance with the decision of the Board of Deans, \\ to be defended in public on Monday $12^{\text {th }}$ of December 2016, at 14.00 hours \\ by \\ Madhu Gupta
}




\section{Supervisors}

Prof. dr. C.P. van Schayck

Prof. dr. H. Bosma

\section{Co-supervisor}

Dr. F. Angeli

\section{Assessment committee}

Prof. dr. D. Ruwaard (voorzitter)

Prof. dr. B.S. Garg

Prof. dr. F. Feron

Dr. A. Krumeich

Prof. dr. S. Zodpey 


\section{Table of Contents}

$\begin{array}{llr}\text { CHAPTER } 1 \text { General Introduction } & 9\end{array}$

CHAPTER 2 Effectiveness of a multiple-strategy community intervention to reduce maternal and child health inequalities in Haryana, North India: A mixed-methods study protocol. Glob Health Action. 2015; 8: 25987. (Published online on 10 February 2015).

CHAPTER 3 Extent of implementation of a multiple-strategy community intervention for reducing maternal and child health inequalities in Haryana, India.

Submitted.

CHAPTER 4 Effectiveness of multiple-strategy community intervention in reducing geographical, socioeconomic and gender based inequalities in maternal and child health outcomes in Haryana, India.

Plos One. 2016; 11(3). (Published online on 22 March 2016).

CHAPTER 5 Qualitative study on the effectiveness of a multiple-strategy community intervention to reduce maternal and child health inequalities in Haryana, India.

Submitted.

CHAPTER 6 Effectiveness of a multiple-strategy community intervention to reduce maternal and child health inequalities in Northern India: mixed method study.

Submitted.

CHAPTER 7 General Discussion

Summary

Valorization

Acknowledgement

Curriculum Vitae

Appendices 


\section{List of Abbréviations}

\begin{tabular}{|c|c|}
\hline ANM & Auxillary Nurse Midwife \\
\hline ASHA & Accredited Social Health Activist \\
\hline CRM & Common Review Mission \\
\hline DLHS & District Level Household Survey \\
\hline FBNC & Facility Based Newborn Care \\
\hline FMR & Financial Monitoring Report \\
\hline HBNC & Home Based New Born Care \\
\hline IIPS & International Institute of Population Sciences \\
\hline IMNCI & Integerated Mangement of Neonatal and Childhood Illnesses \\
\hline IMR & Infant Mortality Rate \\
\hline IYCF & Infant and Young Child Feeding \\
\hline JRM & Joint Review Mission \\
\hline JSSK & Janani Shishu Suraksha Karayakaram \\
\hline JSY & Janani Suraksha Yojna \\
\hline MDR & Maternal Death Review \\
\hline MMR & Maternal Mortality Rate \\
\hline MMU & Mobile Medical Unit \\
\hline MOHFW & Ministry of Health and Family Welfare \\
\hline NRC & Nutritional Rehabilitation Center \\
\hline NRHM & National Rural Health Mission \\
\hline NHM & National Health Mission \\
\hline PIP & Program Implementation Plan \\
\hline
\end{tabular}


RCH Reproductive and Child Health

RGI Registrar General of India

RHS Rapid Household Survey

RKS Rogi Kalyan Samities

ROP Record of Proceedings

USD United States Dollar

VHND Village Health and Nutrition Days

VHNSC Village Health Nutrition and Sanitation Committees 


\section{Chapter 1}

General Introduction

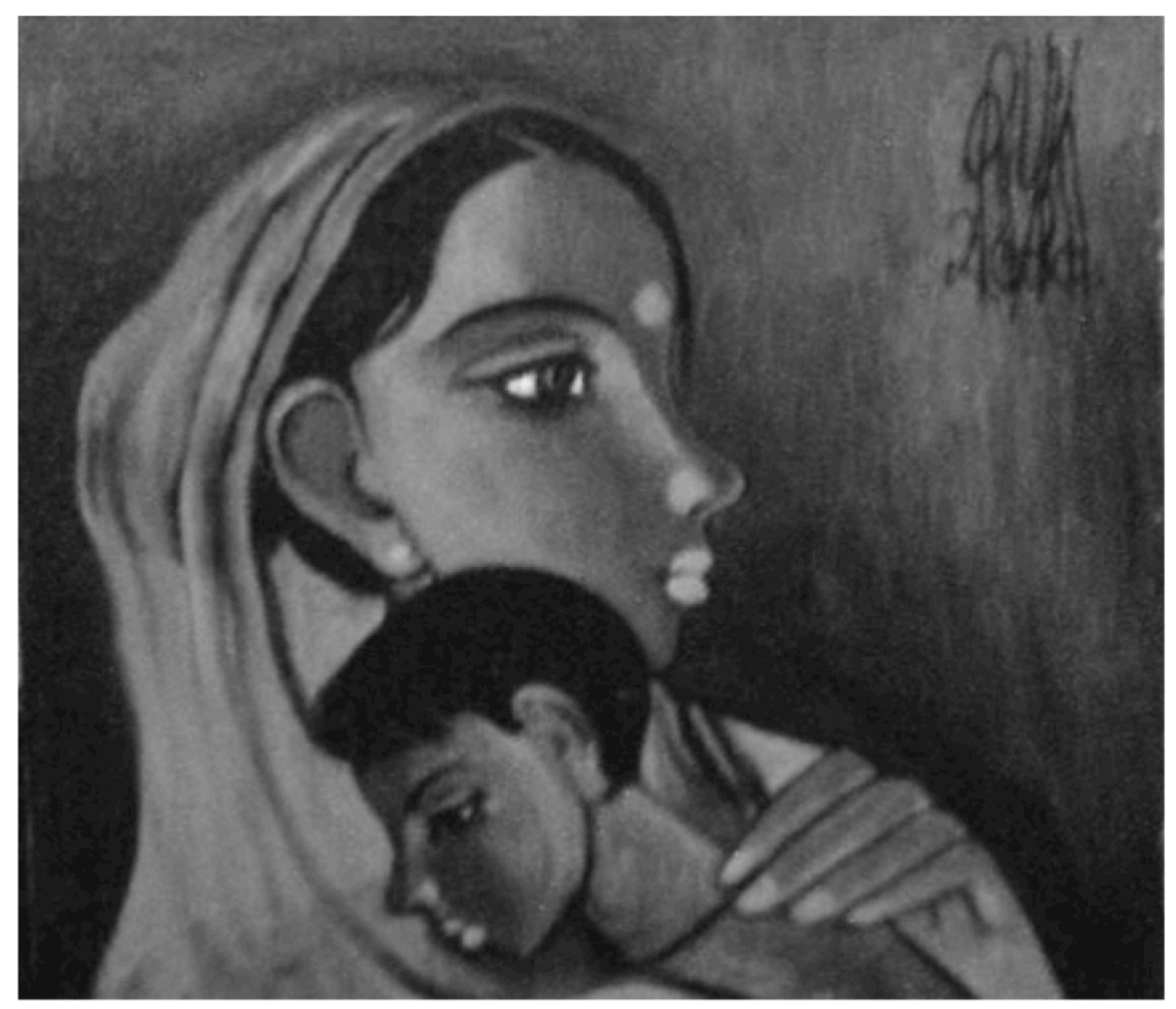




\section{General Introduction}

India is often described as an emerging economic super power and is one of the fastest growing major economies of the world [1]. The economic growth rate had increased up to $10 \%$ after economic reforms in 1990-92, and on an average remained at $6 \%$ per year [2]. Hence Indians now have more money to spend as compared to earlier times. However, the growing money circulating seems to be limited to the already wealthy sections of society and hence unequally distributed, making the rich richer and the poor poorer. This is leading to wide economic and social disparities across regions (western and southern part versus northern and eastern part of the country), geographical area (rural versus urban area) and gender (males versus females) in all the sectors including health [1,3]. Hence, health inequality in India is greater concern now as Indian economy is rising steadily. The health care delivery system has been sensitive and responsive to this but the extent of it still needs to be investigated.

Together women in the reproductive age group (15-49 years) and children account for about $60 \%$ of the total Indian population. Hence, health inequalities among this proportion of the population will largely affect the total health of the nation. India contributes to about $22 \%$ of all maternal deaths and to $20 \%$ of all under five deaths globally [4] Public health interventions to improve maternal and child health outcomes in India have been implemented since 1950's like National Family Welfare Program (1952), Acute Diarrheal Disease Control Program (1978), Acute Respiratory Infections Control Program (1978), Universal Immunization Program (1985), Safe Childhood and Safe Motherhood Program (1992), Reproductive and Child Health Program (RCH-1997-2005) [5, 6].

However, the pace of improvement of maternal and child health outcomes had been slow because these programs were not focusing on $\mathrm{MCH}$ inequalities. As per sample registration system bulletin [7], the maternal mortality rate (MMR) until 2005 was still as high as 3 maternal deaths per thousand live births and the infant mortality rate (IMR) was equal to 60 infant deaths per thousand live births [8]. Also Ram et al (2013) reported marked geographical inequality in maternal and child health outcomes, which continued to persist and even widened across states, between rural and urban areas, and within communities in India [9]. Gupta et al (2008) also reported marked reproductive and child health inequalities in a North Indian Union Territory [10]. It was observed that about $68 \%$ of the deliveries were at home and not assisted by skilled birth attendants (nurse, midwife, or doctor) in the slums, compared to $21 \%$ and $7 \%$ in rural and urban areas, respectively. Fully immunized children at the age of 2 years were $30 \%$ in slums as compared to $74 \%$ and $62.5 \%$ in urban and rural 
areas, respectively. Contraceptive prevalence was significantly more in urban (73\%) and rural areas $(75 \%)$ as compared to the slum areas $(53.4 \%)$.

To address this gap in the implementation, enhance the pace of improvement, and meet the millennium development goals, the government of India had launched a multiple-strategy community intervention known as National Rural Health Mission (NRHM) in the year 2005, to provide primary health care to all and to carry out necessary organizational changes in the basic health care delivery system so as to improve the availability of and access to quality health care by people, especially for those residing in rural areas, the poor, women and children. [11]. It was implemented till 2012 and later continued as part of National Health Mission to cover urban poor as well (2013 to 2017) [12].

\section{National Rural Health Mission (NRHM)}

The aim of the NRHM was to reduce the maternal and child health inequalities by improving the availability of and access to better-quality healthcare, especially for people residing in rural areas (to reduce geographical inequality), for the poor (to reduce socioeconomic inequality), and for women and children (to reduce gender inequality). NRHM had four major health sector plans to achieve its aims [13]. These are described below:

\section{Health system strengthening}

\section{Patients transport service}

Patients transport service (referral transport) was available and operating under dial number 108/102 as ambulance service. 102 ambulance services essentially consist of basic patient transport aimed to cater the needs of pregnant women and children though other categories are also taking benefit and were not excluded. Free transfer from home to facility; inter facility transfer in case of referral and drop back for mother and children were the key focus of 102 services. 108-ambulance service was predominantly an emergency response system, primarily designed to attend to patients of critical care, trauma and accident victims etc.

\section{Infrastructure strengthening}

Financial support was provided to the states to strengthen the public health system including up-gradation of existing or construction of new infrastructure. Under NRHM high focus states could spend upto $33 \%$ and other states up to $25 \%$ of their NRHM funds on infrastructure upgradation. 


\section{Human Resources}

Financial support was provided to strengthen the existing health system by increasing the availability of health care providers including engagement of nurses, doctors and specialist on contractual basis based on the appraisal of requirements proposed by the states in their annual programme implementation plans.

\section{Drugs and logistics}

States were being incentivized up to 5\% of their total outlay of NRHM's funds to prepare policy and establish systems for free distribution of essential drugs including preparation of essential drug list, standard treatment protocols, robust procurement system etc., for free distribution of essential medicines in Public Health facilities. Various program components under NRHM such as Maternal health, Child health, Family planning, Adolescent health and National disease control program prescribe specific drugs which are either centrally procured or funds are provided to States/ UTs for decentralized procurement. Apart from program specific drugs, funds were also provided for general drugs and supplies

\section{Mobile Medical Units}

Mobile Medical Unit was a mechanism to provide outreach services in rural and remote areas. This was not meant to transfer patients. Mobile Medical Units comprised of one/two or three vehicles varying state-wise. Where there was more than one vehicle then one vehicle was used for transport of medical and para-medical personnel, second was used for carrying equipment/ accessories and basic laboratory facilities, third vehicle carried diagnostic equipment such as X-Ray, ultrasound, ECG machine and generator. Each unit had one doctor, one nurse, one radiologist (if available), one lab attendant, one pharmacist and a helper and driver. There was provision of free medicines in the unit.

\section{Maternal health care strategies}

\section{Janani Suraksha Yojna (Financial incentives for institutional delivery)}

This scheme was launched in April 2005. Cash incentives were given to pregnant women on institutional deliveries. In low performing states all pregnant women were beneficiary, in high performing states pregnant women belonging to below poverty line were the beneficiaries. Schedule caste women were beneficiaries in both types of states.

Janani Shishu Suraksha Karyakaram (free institutional delivery and sick infant care in the hospitals) 
This initiative was launched in June 2011 and entitled all pregnant women delivering in public health institutions to absolutely free and no expense delivery, including caesarean section. The entitlements included free drugs and consumables, free diet up to 3 days during normal delivery and up to 7 days for $\mathrm{C}$-section, free diagnostics, and free blood wherever required. This initiative also provided for free transport from home to institution, between facilities in case of a referral and drop back home. Similar entitlements had been put in place for all sick newborns accessing public health institutions for treatment till one year after birth. The scheme aimed to eliminate out of pocket expenses incurred by the pregnant women and sick new born while accessing services at government health facilities.

\section{Child health care strategies}

For child health focus was given on providing newborn care units at the facility level by facility based new born care scheme, skilled management of under five illnesses by providing trainings of the doctors, staff nurses and strengthening of facilities under facility based management of childhood illnesses. Medical officers and ANMs were trained in communitybased management of newborns and children illnesses through integrated management of newborn and childhood illnesses and home based post natal care. Malnutrition was targeted through approaches like infant young child feeding practices and establishing nutritional rehabilitation centers for severely malnourished children. Since mortality due to diarrhea and pneumonia was very high among under 5 year olds hence targeted approach was followed for these two diseases. Supplementation of micronutrients was also provided. Immunizations coverage was improved in remote and rural areas through provision of alternate vaccinators and increasing the number of outreach immunization sessions.

\section{Communitization}

Panchayati Raj institutions (local governments) were involved to own, control and manage public health services from village to district level. At the village level, their representatives were members of village health nutrition and sanitation committees. Village head was involved in selection of accredited social health activists in the villages. In the public health facilities members of Panchayati Raj institutions were members of patient welfare committees.

\section{Accredited social health activist}

It included provision of a female accredited social health activist for each village who served as link between the community and health care delivery system. She belonged to the same village and had basic educational qualification (up to eighth standard, but in remote district up 
to fifth standard). She was given performance-based incentives for providing antenatal, postnatal and child-care. She was involved in behavior change communication with the antenatal, postnatal women or with potential decision makers in the families for antenatal care, immunization, and institutional delivery, post natal care etc.

\section{Village health nutrition and sanitation committees}

Members of local government (Panchayati Raj institutions) including village heads were involved by forming village health nutrition and sanitation committees so as to prepare village health action plan according to the needs or problems in the villages. This committee had been sanctioned a sum of Rs 10,000 to perform the activities annually. It got deposited in a joint bank account.

\section{Village health and nutrition days}

Maternal and child health services were provided through organization of village health and nutrition days each month in the village where antenatal care and immunization of children were mainly done.

\section{Patient welfare committees (Rogi Kalyan Samities)}

These were patient welfare committees, which were set up in health facilities for community management of hospitals.

\section{Untied fund}

Each sub-centre had an untied fund for local action of USD 15 (10,000 in Indian Rupees) per annum. This fund was deposited in a joint bank account of the auxiliary nurse midwife and village head (Sarpanch) and operated by auxiliary nurse midwife, in consultation with the village health committee.

\section{Study Area}

This study was conducted in Haryana, in Northern part of India. The state of Haryana has a population of $2,53,53,081$ as per census 2011 , crude birth rate of 21.8 and crude death rate of 6.5 per thousand mid year population [14]. Despite being one of the richer states, reporting the highest per capita income in the country at Rs 1,09,064 (USD 1947.6) during 2012-13, maternal and child health indicators are not the best in the country [15]. Although the maternal mortality rate has declined from 176 (for the year 1999-2001) [7] to 146 deaths per one hundred thousand live births (2010-12) [16], it fell behind the goal of reducing MMR below 100 by 2015 . There are marked geographical differences in maternal and child health 
like the infant mortality rate is higher in rural areas ( 46 per thousand live births) as compared to urban areas (33 per thousand live births) [17]. The child sex ratio at birth declined from 964 in the 2001 census to 830 females per thousand males in the 2011 census [14]. There is a clear problem of female feticide and poor health-seeking behavior for daughters [18-22]. Haryana state is also representative of other North Indian states with similar socioeconomic development and sociocultural factors, such as the preference to have sons, female feticide, lower sex ratios and lower social status of women. At the same time, Haryana represents a unique context by being a prosperous state with a rising economy but with unequal distribution of resources, which has led to wide intra-state and inter-district differences. All this provides us with an excellent opportunity to study inequalities in this state.

This state is governed through a Governor. The Chief Minister heads the organogram of the state rural health mission directorate at the state level and is vested with most of the executive and legislative powers. State Health Minister is responsible for implementing the NRHM in the state. Financial Commissioner cum Principal Secretary Government of Haryana assists the State Health Minister. Under Principal Secretary's supervision Mission Director, National Rural Health Mission works.

\begin{abstract}
Aim
The aim of this $\mathrm{PhD}$ research is to ascertain the extent of implementation of NRHM's health sector plans and its effectiveness in improving the maternal and child health outcomes and reducing geographical, socio-economical and gender based health inequalities in Haryana, North India.
\end{abstract}

\title{
Research Questions
}

1. What is the extent of implementation of NRHM plans in the public health sector in Haryana, North India?

2. To what extent did the NRHM implementation result in improving the maternal and child health outcomes and in reducing geographic, socioeconomic and gender-based health inequities in Haryana, North India?

\section{Objectives}

1. To quantify the extent of implementation of NRHM plans in the public health care sector in Haryana, North India. 
2. To quantify the extent to which NRHM implementation reduced geographical, socioeconomic and gender inequities in maternal and child health outcomes in Haryana by comparing the status pre and post NRHM implementation.

3. To ascertain qualitatively the extent to which NRHM plans were implemented in the public health care sector from the implementers' standpoint and from a societal perspective in Haryana.

4. To ascertain qualitatively the extent to which NRHM implementation reduced geographical, socioeconomic and gender inequities in maternal and child health outcomes in Haryana.

5. To give appropriate and evidence based recommendations to NRHM in bridging health inequities in Haryana.

\section{Outline of thesis}

This study used an explanatory sequential mixed method approach to ascertain the extent and effectiveness of NRHM's health sector plans in improving $\mathrm{MCH}$ outcomes and reducing geographical, socio-economical and gender based $\mathrm{MCH}$ inequalities. The detailed study protocol is presented in Chapter 2. The quantitative estimation of extent of implementation of various NRHM's health sector plans under four major components of NRHM i.e., health system strengthening, communitization, maternal and child health care strategy is described in Chapter 3. The quantitative estimation of effectiveness of NRHM's plans in improving MCH outcomes and reducing geographical, socio-economical and gender based $\mathrm{MCH}$ inequalities is given in Chapter 4. Chapter 5 describes the methodology and findings of the qualitative study investigating the extent of implementation of various NRHM's health sector plans and effectiveness of NRHM's plans in improving $\mathrm{MCH}$ outcomes and reducing geographical, socio-economical and gender-based $\mathrm{MCH}$ inequalities. Finally, the findings of the quantitative and qualitative study were mixed at the interpretation level to enhance, validate and provide explanation of the quantitative findings by using a mixed method approach. Mixed method findings are given in Chapter 6. Chapter 7 presents the general discussion and future recommendations for effective implementation of the intervention not only in Haryana but other Indian states as well. 


\section{References}

1. Kurian NJ. Widening economic and social disparities: Implications for India. Indian J Med Res. 2007; 127; 374-80.

2. Ministry of Statistics and Program Implementation. Available at http://mospi.nic.in/Mospi_New/site/inner.aspx?status=2\&menu_id=21. Accessed 3 May 2016.

3. Kurian NJ. Widening Regional Disparities in India: Some Indicators. Economic and Political Weekly. 2000; 35(7): 538-550.

4. Hill K, Thomas K, AbouZahr C et al. Estimates of maternal mortality worldwide between 1990 and 2005: an assessment of available data. Lancet 2007;370:1311-1319. doi: 10.1016/S0140-6736(07)61572-4.

5. Paruthi R, Dutta PK. Reproductive and child health programme. Indian J Public Health 2002;46(3):72-7.

6. MOHFW. Ministry of Health and Family Welfare. Child health program in India. 2000. Available at http://mohfw.nic.in/WriteReadData/1892s/6342515027file14.pdf. Accessed on 27 November 2014.

7. Registrar General of India. Special Bulletin on Maternal Mortality in India. Sample Registration System 2001-03.

8. Registrar General of India. Sample Registration System Bulletin. 2005. http://www.censusindia.gov.in/vital_statistics/SRS_Bulletins/SRS_Bulletins_links/SRS_Bulle tin_April_2005.pdf. Accessed on 15 July 2013.

9. Ram F, Singh A, Ram U. Human rights approach to maternal \& child health: Has India fared well? Indian J Med Res 2013;137(4): 721-727.

10. Gupta M, Thakur JS, Kumar R. Reproductive and child health inequities in Chandigarh Union Territory of India. J Urban Health. 2008;85(2):291-299.

11. Hota P, Dobe M. National Rural Health Mission. Indian J Public Health 2005; 49(3):107-10.

12. Ministry of Health and Family Welfare. National Health Mission. [http://nrhm.gov.in/nhm/nrhm/nrhm-framework-for-implementation.html.] Accessed on 16 January 2014.

13. Ministry of Health and Family Welfare. NRHM mission document. Available at http://www.mohfw.nic.in/NRHM/Documents/Mission_Document.pdf. Accessed on 16 January 2014.

14. Census 2011. [http://censusindia.gov.in/2011census/censusinfodashboard/index.html.] Accessed on 16 July 2013.

15. Department of Economic and Statistical Analysis Haryana: Economic Survey of Haryana. Government of Haryana. 2012-13. Available at http://web1.hry.nic.in/budget/Esurvey.pdf. Accessed on 16 July 2013.

16. Registrar General of India. Special Bulletin on Maternal Mortality in India. Sample Registration System 2010-12. Available at http://www.censusindia.gov.in/vital_statistics/SRS_Bulletins/Final-MMR\%20Bulletin-200709_070711.pdf. Accessed on 16 July 2013.

17. Registrar General of India. Sample Registration System. Registrar General of India. Available at

http://censusindia.gov.in/Vital_Statistics/SRS/Sample_Registration_System.aspx. Accessed 10 November 2011.

18. Prusty RK, Kumar A. Socioeconomic dynamics of gender disparity in childhood immunization in India, 1992-2006. Plos One. 2014;15:9(8):e104598. doi: 10.1371/journal.pone.0104598.

19. Kaur M. Female Foeticide-A sociological perspective. The Journal of Family Welfare. 1998;39(1):40-43.

20. Sabu G, Dahiya M, Ranbir S. Female foeticide in rural Haryana. Economic and Political Weekly. 1998;33(32):2191-98.

21. Kumar R, Gupta M, Prinja S. Illness burden, care seeking and treatment cost among less than 2-year-olds in rural Haryana. Indian J Pediatr. 2014. Available at http://www.ncbi.nlm.nih.gov/pubmed/24874811. Accessed 1 December, 2014.

22. Sharma S. Child health and nutritional status of children: the role of sex differentials. Population Research Center. Institute of Economic Growth. Available at http://www.iegindia.org/workpap/wp262.pdf. Accessed 1 December 2014. 


\section{Chapter 2}

Effectiveness of a multiple-strategy community intervention to reduce maternal and child health inequalities in Haryana, North India: A mixed-methods study protocol.

Madhu Gupta, Federica Angeli, Onno CP van Schayck, Hans Bosma.

Glob Health Action. 2015, 8: 25987 - http://dx.doi.org/10.3402/gha.v8.25987

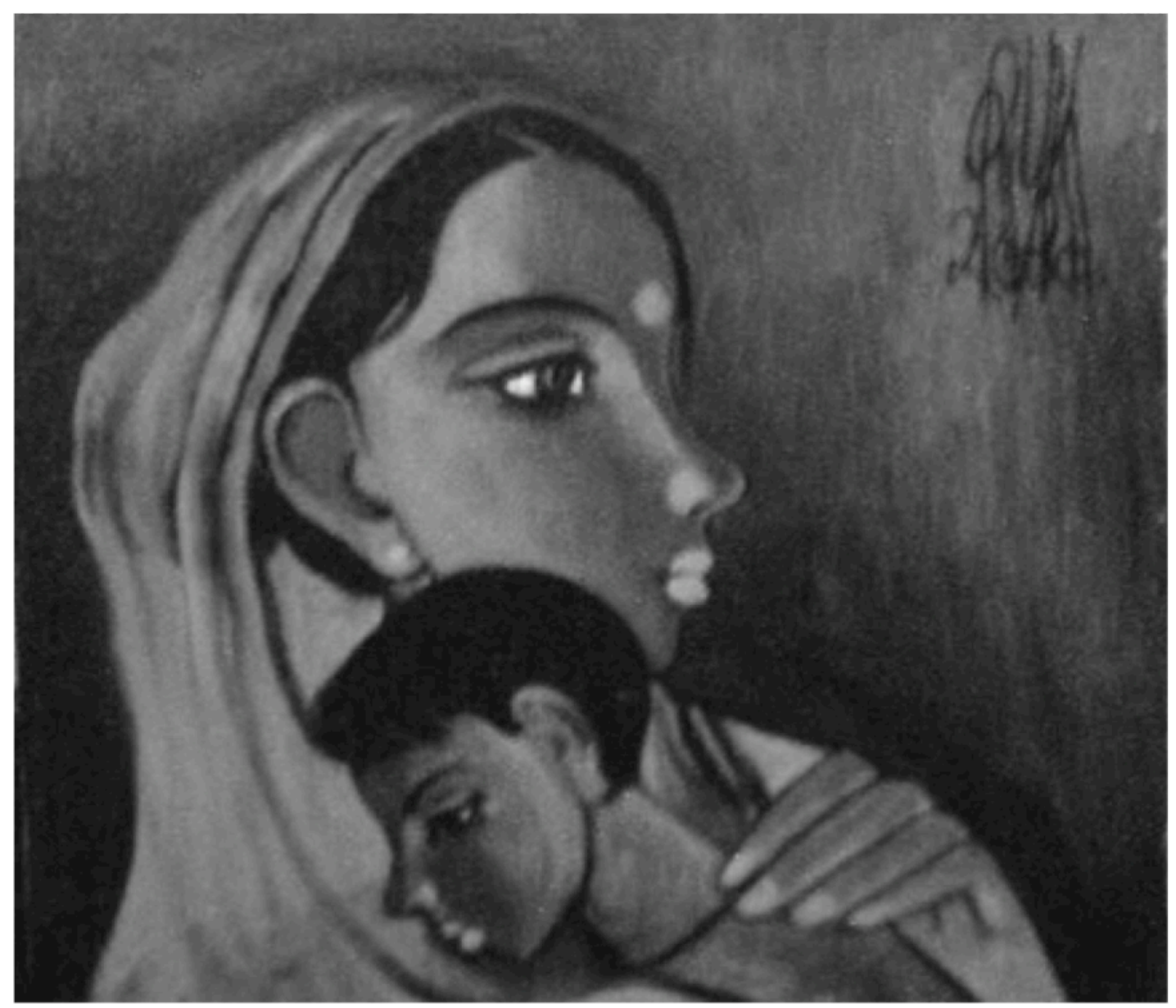




\begin{abstract}
Background

A multiple-strategy community intervention, known as National Rural Health Mission (NRHM), launched in India to improve the availability of and access to better-quality healthcare, especially for rural, poor mothers and children. The final goal of the intervention is to reduce maternal and child health inequalities across geographical areas, socioeconomic status groups, and gender of child. Extensive, in-depth research is necessary to assess the effectiveness of NRHM, on multiple outcome dimensions. This paper presents the design of a new study, able to overcome the shortcomings of previous research.
\end{abstract}

\title{
Objective
}

To propose a comprehensive, methodologically sound protocol to assess the extent of implementation and the effectiveness of NRHM measures to improve maternal and child health outcomes and reduce maternal and child health inequalities.

\section{Design}

A mixed-methods approach (quantitative and qualitative) is proposed for this study in Haryana, a North Indian State. NRHM's health sector plans included health system strengthening, specific maternal and child healthcare strategies, and communitization. Mission documents and reports on progress, financial monitoring, common and joint review will be reviewed in-depth to assess the extent of the implementation of plans. Data on maternal and child health indicators will be obtained from demographic health surveys held before, during, and after the implementation of the first phase of the NRHM (2005 to 2012) and compared over time. Differences in maternal and child health indicators will be used to measure maternal and child health inequalities; these will be compared pre- and post-NRHM. Focus group discussions with service providers and in-depth interviews with program managers, community representatives, and mothers will be conducted until data saturation is achieved, in two districts of Haryana. Using Nvivo software, an inductive qualitative content analysis will be performed to search for the broader themes across the interviews and focus group discussions. Ethical approval was obtained from the Ethics Committee of the Post Graduate Institute of Medical Education and Research. 


\section{Introduction}

Achieving millennium development goals 4 and 5 - i.e., reducing under-five child mortality by two thirds and maternal mortality by three quarters between 1990 and 2015 - is among the highest priorities on India's national health agenda [1]. Between 2005 and 2012, India's total spending on health increased from $0.9 \%$ of gross domestic product to nearly $2 \%$, but maternal and child health indicators have not improved correspondingly [2].

\section{Problem statement}

The maternal mortality rate (MMR) is still as high as 178 maternal deaths per hundred thousand live births $\left[{ }^{3}\right]$ and the infant mortality rate (IMR) is 42 infant deaths per thousand live births $\left[{ }^{4}\right]$. There is geographical inequality in maternal and child health outcomes. For example, IMR is higher in rural as compared to urban areas (48 against 28 deaths per thousand live births) [4]. Large geographical and socioeconomic inequalities in maternal and child health status and access to health services continue to persist in India and have even widened across states, between rural and urban areas, and within communities [5]. Singh et al reported inequality regarding advice during the antenatal period and the coverage of essential postnatal care, which is provided disproportionately more frequently among the rich [6,7]. Nayar (2007) reported maternal and child health inequalities across different caste groups [scheduled castes (SC), scheduled tribes (ST) and other backward castes (OBC) and general castes] in India. SC/ST/OBC (lower castes) represent communities belonging to lower socioeconomic groups with a poor maternal and child health status as compared to higher castes [8]. Pathak et al reported a disproportionately concentrated malnutrition burden among poor children and slow changes in child malnutrition in India during 1992-2006, coupled with a concomitant rise in economic inequalities [9]. Pradhan et al reported that poor household economic status (46\%), mother's illiteracy (35\%) and rural residence (15\%) explained 96\% of the total socioeconomic inequalities in child survival at the national level [10]. Gender inequality among children is another area of concern, especially among North Indian states, 
involving a strong preference for sons, female feticide, and declining sex ratio at birth [11]. Gender disparity in immunization programs favoring males has been reported in urban areas, developed states and Muslim communities in India [12]. Better healthcare-seeking behaviors of caregivers for sick male children as compared to sick female children further add to the gender-related health inequalities.

This persistence of maternal and child health inequalities highlights the need to assess how the existing national health programs or policies on maternal and child health are being implemented. Simultaneously, it indicates the need for studies on the effectiveness of these programs, as these are highly resource-intensive. Such assessments can inform policy makers in resource-constrained countries like India on ways to improve the policy or implementation strategy of these interventions.

\section{Study population}

Studying maternal and child health inequalities in the Indian state of Haryana is worthwhile as it is representative of other North Indian states with similar socioeconomic development and sociocultural factors, such as the preference to have sons, female feticide, lower sex ratios and lower social status of women. At the same time, Haryana represents a unique context by being a prosperous state with a rising economy but with unequal distribution of resources, which has led to wide intra-state and inter-district differences in terms of provision of basic infrastructure like water, roads, schools, hospitals etc. Despite being one of the richer states, reporting the highest per capita income in the country at Rs $1,09,064$ (USD 1947.6) during 2012-13, maternal and child health indicators are not the best in the country [13]. Although the maternal mortality rate has declined from 176 (for the year 1999-2001) [14] to 146 deaths per one hundred thousand live births (for the year 2010-12) [3], it still lags behind the goal of reducing it to below 100 by 2015 [1]. There are marked geographical differences in maternal and child health: the infant mortality rate is higher in rural areas (46 per thousand live births) 
compared to urban areas (33 per thousand live births) [4]. The child sex ratio at birth declined from 964 in the 2001 census to 830 per thousand males in the 2011 census [11]. There is a clear problem of female feticide and poor health-seeking behavior for daughters. [15-18]. All this provides us with an excellent opportunity to study inequalities in this state.

\section{Current and past interventions/current state, new interventions}

Past interventions to improve maternal and child health were initially implemented as vertical programs, like the Family Welfare Program (1952), Acute Diarrheal Disease Control Program (1978), Acute Respiratory Infections Control Program (1978) and Universal Immunization Program (1985). These initiatives were later merged, initially as the Safe Childhood and Safe Motherhood Program (CSSM, 1992) and then as the Reproductive and Child Health Program (RCH I, 1997-2005), as it was realized that improving maternal health is imperative to improving child health [19]. However the main objective in these earlier programs was to improve the maternal and child health indicators and increase their survival, and not much emphasis was put on reducing inequalities. Realizing this gap in implementation, a national multiple-strategy community intervention was launched, known as the National Rural Health Mission (NRHM), by the Ministry of Health and Family Welfare of the Government of India [started during 2005 in the $11^{\text {th }}$ health plan (2005 to 2012), and continued in $12^{\text {th }}$ health plan (2012 to 2017)] with the aim to reduce health inequalities by improving the availability of and access to better-quality healthcare, especially for people residing in rural areas (to reduce geographical inequality), for the poor (to reduce socioeconomic inequality), and for women and children (to reduce gender inequality) [20] NRHM's health sector plans included health system strengthening, specific maternal and child healthcare strategies/schemes (RCH-II), and communitization (delegating powers to and empowering the community to monitor the healthcare delivery system) [21]. Details of these plans are given in chapter 1. Briefly, health system strengthening included making available mobile medical units (MMUs) and patient transport services, strengthening the health infrastructure, providing free drugs and logistics, 
and providing telemedicine facilities. Maternal and child health schemes included cash incentives for hospital deliveries, free delivery services for pregnant women and treatment of neonatal illnesses in hospitals, reimbursements of travel cost to hospitals and appointing Accredited Social Health Activists (ASHAs) to promote the access to improved healthcare at household level in villages. The intention was to reduce the infant mortality rate to 30/1,000 live births, maternal mortality to 1/1,000 live births, and the total fertility rate to 2.1 by 2012 . It was further realized that NRHM strategies were not covering the urban poor, whose condition was even worse than that of the rural population. Hence, NRHM was renamed National Health Mission (2012), and now covers the slum population as well.

\section{Previous assessments and their strengths/weaknesses}

The planning commission of India had the NRHM schemes evaluated in seven states (Uttar Pradesh, Madhya Pradesh, Jharkhand, Orissa, Assam, Jammu and Kashmir and Tamil Nadu) during the fourth year of its implementation (2009-10) and assessed the availability, adequacy and utilization of maternal and child health services [22]. They conducted cross-sectional surveys, focus group discussions and in-depth interviews with stakeholders. They observed some improvements in the availability and utilization of maternal and child health services in rural areas, and recommended further strengthening of health facilities. The strength of their study lies in the inclusion of a qualitative assessment of the program that gave insight into the implementation process. However, their evaluation was limited by the lack of assessment of the extent of implementation of NRHM schemes, including budget sanctioned and spent on NRHM schemes, the lack of comparison of results with the situation before the implementation of the NRHM, the lack of measurement of maternal and child health inequalities, and the lack of interpretation of quantitative data and qualitative data by a mixedmethods approach. Since NRHM had two more years to go at the time of the planning commission's evaluation, it represented a mid-term evaluation. The present study intends to overcome the above limitations by assessing the extent of implementation of NRHM schemes 
in the maternal and child health care sector, including the budgetary outlays for maternal and child health schemes through the NRHM period (2005-12) and its effectiveness, by comparing the situation before, during and after the implementation of the NRHM using a mixed-methods approach. In another study by Mukherjee et al, 100 rural doctors from the states of Orissa, Assam, Jharkhand and Chattisgarh were interviewed to analyze the effectiveness of the NRHM in improving the availability and accessibility of health services in rural areas. They concluded that it was not $100 \%$ effective and there were inefficiencies in terms of infrastructure and manpower [23]. Earlier surveys did report on the effectiveness of health services, but none reported on maternal and child health inequalities. Also, no previous study has been conducted in Haryana state. State-specific information is necessary, as each state is different, having its own unique cultural, social, and demographic backgrounds and problems. Since the causes of maternal and child health inequalities vary across states, solutions to bridge the gaps thus have to be tailor-made $[24,25]$.

It is against this background that the present mixed-methods study was designed, to quantify the extent of implementation of NRHM's maternal and child health-related plans in the healthcare sector, to quantify NRHM's effectiveness in terms of reducing geographical, socioeconomic, and gender inequalities and improving the overall maternal and child health outcomes, as well as to qualitatively ascertain the extent to which maternal and child health strategies in the NRHM were implemented and were effective in tackling the inequalities and outcomes, and to formulate evidence-based recommendations for bridging the health inequalities in Haryana state.

\section{Study Design}

A mixed-methods approach will be used in this study, involving a partially mixed sequential equal status design in terms of the Leech classification [26]. Partially mixed design implies that mixing of qualitative (QUAL) and quantitative (QUAN) data will be done at 
interpretation level (i.e. the quantitative data will be linked to and explained by qualitative results); sequential means that the qualitative data will be collected after the quantitative data collection; and equal status denotes that both qualitative and quantitative data will be given the same importance at the time of interpretation. The quantitative part of the mixed-method study will reveal the trends and differences in rates for maternal and child health outcomes and inequalities before, during, and after NRHM implementation, whereas the qualitative study will provide explanations for these findings, which will be used to formulate evidencebased recommendations for implementing the program in a more effective way, so as to achieve the intended maternal and child health goals.

\section{Setting}

This study will be done in Haryana state in India. A state is divided into many administrative districts, which include several administrative blocks. The Chief Medical Officer (CMO) is the overall person in charge of implementing national health programs at the district level. There are several program officers, one for each program, who report to the CMO. There is a three-tier system of health care infrastructure in each district: at grass-root level, there is a sub-center catering for a population of 5,000, a primary health center (PHC) catering for a population of 30,000 , and a community health center ( $\mathrm{CHC}$ ) catering for a population of 100,000. Above the CHC (block) level, there is either a sub-district or district hospital. A doctor is available at the PHC level and above. At the sub-health center, an Auxiliary Nurse Midwife (ANM) is responsible for implementing maternal and child health programs. She is assisted by an Accredited Social Health Activist (ASHA) and a child care volunteer called Anganwadi Worker (AWW) for each village or population of 1,000. Community groups include Panchayati Raj Institutions, village health committees, and self-help groups in villages $[27,28]$. 
Haryana has 21 districts, and has a population of 25,353,081 (70\% rural), a birth rate of 21.6 and a mortality rate of 6.4 deaths per thousand mid-year population $[4,11]$. For the qualitative study, we will select a well performing (Ambala) and a poorly performing district (Mewat) of Haryana. This selection will allow us to obtain a better contextual understanding of two extreme situations and to learn which scheme works better in a particular situation, by exploring the perceptions and beliefs of service providers, community representatives, and mothers regarding the implementation status and effectiveness of NRHM's maternal and child health schemes. (Figure 1).

Figure 1. Map of Haryana showing districts selected for qualitative study, 2013

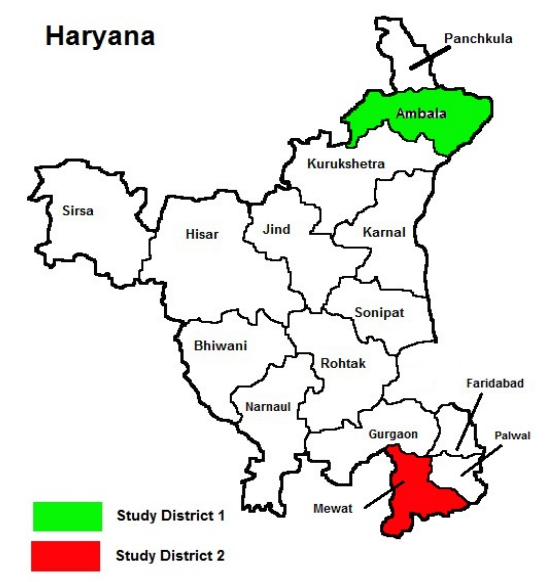

Criteria for labeling the district as well or low performing are based on the District Level Household Survey 3 (DLHS-3, 2007-08) [29]. Maternal and child health indicators for comparison included age at marriage below 18 years (3\% in Ambala v/s 43\% in Mewat), teenage pregnancies (0.9\% in Ambala v/s 9.3\% in Mewat), availability of antenatal care (83\% in Ambala v/s in 53\% Mewat), institutional births (55\% in Ambala v/s 15\% in Mewat), availability of postnatal care (70\% v/s 34\%), and fully immunized children (92\% Ambala v/s $20 \%$ Mewat). About $51 \%$ of the population of Ambala have a high standard of living index, compared to $11 \%$ in Mewat. Although differing in the above characteristics, the Ambala and 
Mewat districts have a similar population size (Ambala 1,128,350; Mewat 1,089,263) and density (Ambala 717; Mewat 723 per sq km).

\section{Data Collection and Analyses}

Quantitative study

\section{Extent of implementation of NRHM plans}

Information will be obtained via an in-depth review of the NRHM mission document [21], the progress reports of the NRHM, approved state program implementation plans, and financial monitoring reports (FMRs), in order to obtain information on budgets approved and spent for each activity planned in the financial years 2005 to 2012. Independent evaluation reports, such as those by the Common Review Mission (CRM) [30] and Joint Review Mission (JRM) [31] will also be reviewed. CRM reports are an important component of the overall monitoring and evaluation framework envisaged in the NRHM implementation framework. The CRM undertakes spot appraisal of the health system and reflects on the success of the strategies and policies with the aim of identifying the need for potential midcourse corrections in implementation. Seven such reviews have been conducted so far, as and Haryana state was covered in the $3^{\text {rd }}, 5^{\text {th }}$ and $7^{\text {th }}$ CRMs. Data pertaining to maternal and child health indicators in these documents will be recorded on a predesigned form to avoid selection bias. This will prevent rejection or acceptance of "bad" data on arbitrary grounds instead of according to previously stated criteria as listed in predesigned form.

\section{Effectiveness of NRHM plans}

Information on the status of maternal and child health indicators will be obtained from the District Level Household Survey [DLHS 2 (2002-03), the DLHS 3 (2007-08), and the DLHS 4 (2012-13)] [29]. DLHS 2 represents the situation before, DLHS 3 that during and DLHS 4 that after NRHM implementation. These surveys provide consistent and reliable estimates of fertility, mortality, family planning, utilization of maternal and child healthcare services, and 
other related indicators at both the national and state levels. Maternal and infant mortality rates at the Haryana state level will be obtained from the Sample Registration System $[3,4]$.

\section{Variables}

Implementation variables include NRHM health sector measures (Table 1), while sociodemographic variables include wealth index, education, caste, and religion, as available from demographic surveys. Outcome variables for this study are listed in Table 2. These include maternal and child health indicators, maternal and child health inequalities across the socioeconomic, geographical, and gender gradients and indicators on the access/availability of maternal and child health services.

Table 1. Implementation status of NRHM health sector plans.

\begin{tabular}{ll}
\hline NRHM Plans & \multicolumn{2}{c}{ Implementation status } \\
(Independent variables) & Full Partial None
\end{tabular}

\section{Health System Strengthening}

Mobile medical units with access to hard-to-reach areas

Patient transport service/referral services

Infrastructure development and strengthening

Human resources: availability of additional nurses, doctors, specialists, ANMs, administrative staff on a contractual basis

Drugs and logistics (free essential medicines at all healthcare facilities)

Telemedicine

\section{Communitization}

Accredited Social Health Activist (ASHA)

Village health nutrition and sanitation committees

Village health and nutrition days

Rogi Kalyan Samities (patient welfare committees in the hospitals with members also deriving from the community) 


\section{Maternal Healthcare Strategies \\ JSY- Janani Suraksha Yojna \\ JSSK-Janani Shishu Suraksha Karyakaram \\ Increased number of delivery points with provision of $24 / 7$ delivery services \\ Provision of safe MTP services}

\section{Child Health Care Strategies}

Specialized care for newborns - facility-based neonatal care

Facility-based integrated management of neonatal and childhood illnesses

Integrated management of childhood illnesses

Home-based neonatal care

Infant and young child feeding

Nutritional rehabilitation centers for malnourished children

Immunization

\section{Quantitative Data Analysis}

The implementation status of the NRHM's health sector plans will be categorized into fully implemented, partially implemented, or not at all implemented, depending upon the utilization of the budget sanctioned for implementation of that plan at the end of 2012. (Table 1). The implementation status of the overall NRHM plan will be based upon the status of individual health sector plans. If all the plans have been fully implemented, the overall NRHM plans will also be considered fully implemented, if partially then partial, if not implemented at all then not at all. Health sector plans will also be differentiated according to whether these resulted in desired action or not, so as to find out which policy measures are effective. The maternal and child health indicators will be compared before, during and after the introduction of the NRHM, from 2002 to 2012, to assess improvements in maternal and child health outcomes in Haryana. Since the NRHM is implemented in all areas in Haryana, 
the situation during the pre-NRHM implementation period will serve as a control. Impact indicators like mortality rates (maternal mortality ratio and child mortality rates) will be compared at state level for Haryana. The main variables to be compared between 2005 and 2012 are shown in Tables 1 and 2.

Table 2. List of outcome variables indicating availability/accessibility of health services, maternal and child health status, and inequalities.

\begin{tabular}{|c|c|c|c|}
\hline $\begin{array}{l}\text { Availability/Accessibility } \\
\text { of services }\end{array}$ & Maternal Health & Child Health & $\begin{array}{l}\text { Maternal and } \\
\text { Child Health } \\
\text { Inequalities }\end{array}$ \\
\hline
\end{tabular}

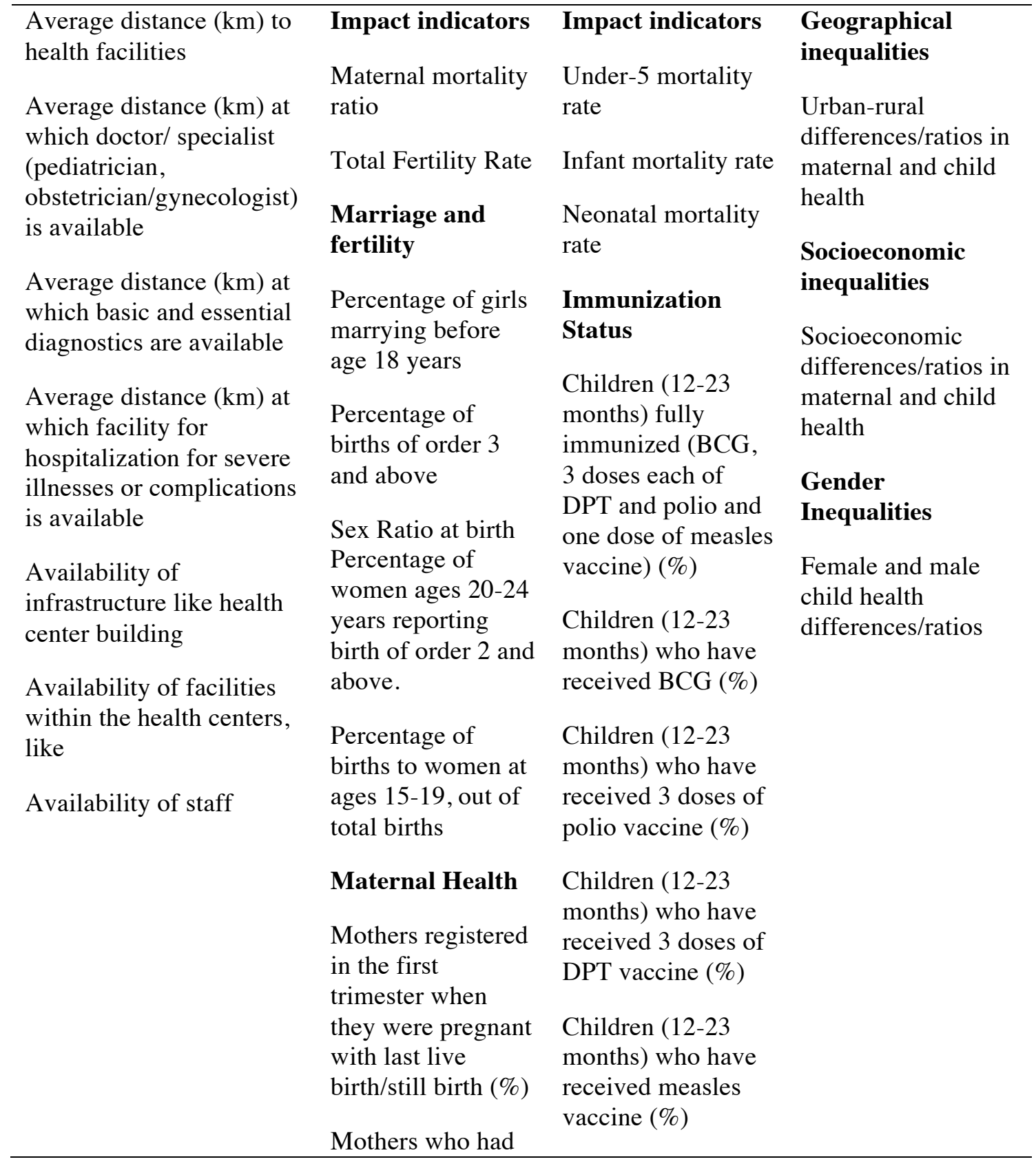




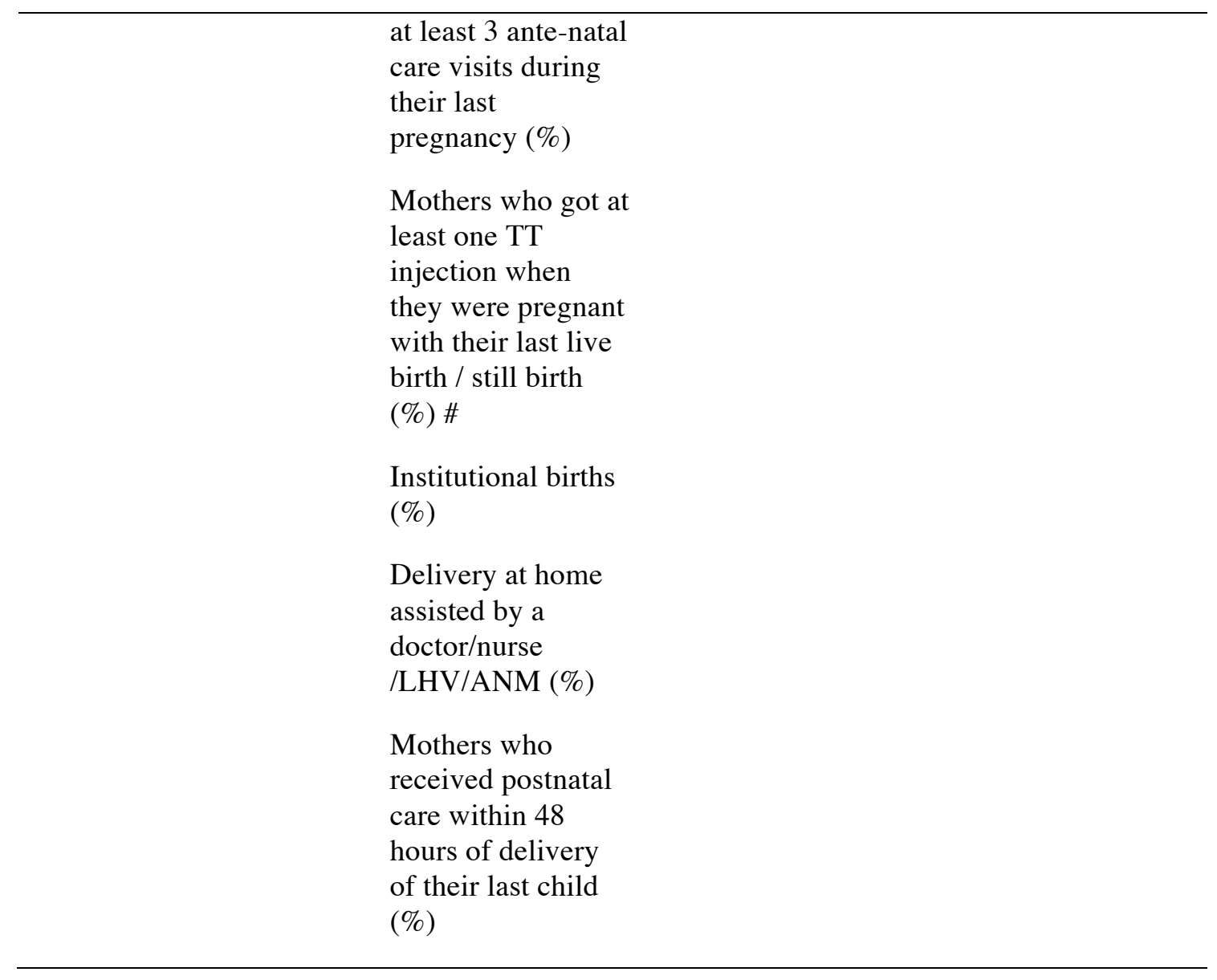

Geographical, socioeconomic, and gender inequality in maternal and child health will be assessed by estimating the relative and absolute differences (range) in maternal and child health indicators between urban and rural areas, between the most advantaged and least advantaged socioeconomic groups (excluding maternal and child mortality indicators), and between male and female children. Overall rates and inequalities expressed in terms of ratios and rate differences will be compared across the relevant time period before, during, and after the NRHM. The P-value will be considered significant at 95\% confidence intervals. Data will be analyzed using Excel and SPSS version 16. Using predesigned methods to extract data from the available documents will minimize bias. In the time period covered (including the introduction of the NRHM), inequalities in child and maternal health indicators may have decreased, but time-dependent changes (other than the introduction of the NRHM) may have occurred simultaneously (e.g. decreased income inequality, increased gross domestic product, other policies/regulations). Hence, potential confounders include socio-demographic variables 
like wealth index and education status. Since we only have a pre-versus-post comparison, 'trends' of possible confounders will also be identified. Information pertaining to confounding variables will be extracted from demographic health surveys, and multivariate logistic regression analyses will be done.

The findings of the QUAN and QUAL parts of study will be combined during the interpretation stage, using the QUAL data to explain the results of the QUAN study.

Qualitative study

Extent of implementation and effectiveness of NRHM plans

The perceptions of program managers, service providers, community, and target group will be explored regarding the extent of implementation of NRHM plans, the affordability and accessibility of healthcare services, and the extent of improvement in geographical, socioeconomic, and gender differences in maternal and child health outcomes during the year 2013-14. The study sample used for the interviews and focus groups will include the Mission Director of NRHM, Haryana; Program Managers (State/District Maternal and Child Health Officers or NRHM Nodal Officers); community/opinion leaders including religious leaders, group leaders, village heads or priests etc.; mothers with children aged under five; and service providers including Senior/Medical officers, Auxiliary Nurse Midwives (ANMs), and Accredited Social Health Activists (ASHAs).

The sampling method will be purposive. One $\mathrm{CHC}$, one $\mathrm{PHC}$, one sub-center, one village from a rural area, and a city/town and a slum from an urban area will be selected from the Ambala and Mewat districts. As there is variability within the districts regarding maternal and child health status, with certain blocks performing better than others, we will select wellperforming and poorly performing health centers within the Ambala and Mewat districts. Focus group discussions (FGDs) will be held with the service providers at each level, i.e., 
ASHAs at the village level, ANMs at the sub-center level, medical officers at the PHC level and senior medical officers at the CHC level. Each FGD will include 5-10 participants. Indepth interviews will be conducted with the Mission Director of NRHM of the state, the program managers of maternal and child health at the state and district level, the community leaders, and at least two mothers at each level (district, CHC, PHC, sub-center/village). FGDs and in-depth interviews will be conducted until data saturation is achieved.

The approach to be used in the qualitative study will be based on grounded theory. Guides for the in-depth interviews and FGDs will be prepared and used after pretesting in the community (Appendix 1). All the FGDs and in-depth interviews will be audio- and video-recorded after obtaining written informed consent, so that verbal and non-verbal responses can be recorded. Manual recording will also be done as a backup.

\section{Qualitative Data Analysis}

All the information obtained from the FGDs and in-depth interviews will be first transcribed in Hindi/local language using the audio and video recordings and the manual recordings. The transcribed version will then be translated into English. Memos will be assigned and two independent coders (authors) who are trained in qualitative analysis will identify codes. Thematic analysis of the content will then be done either manually or using Nvivo statistical software to identify the patterns.

\section{Recommendations}

Based upon the evidence obtained through this mixed-methods study, appropriate recommendations will be made for policy makers and program managers regarding implementing strategies for maternal and child healthcare and to reduce the health inequalities in Haryana as well as India as a whole. 


\section{Ethics and dissemination}

Ethical approval has been obtained from the Post Graduate Institute of Medical Education and Research (PGIMER) Ethics Committee. A study information sheet will be provided and written informed consent will be obtained from participants of the focus group discussions and in-depth interviews.

\section{Discussion}

The results of this study will provide important information on the trends in the implementation of NRHM's health sector plans and its effectiveness in improving maternal and child health outcomes and reducing geographic, socioeconomic, and gender inequalities in maternal and child health. The evidence will be collected through a novel and rigorous mixed-methods study conducted in Haryana, so that the findings can guide the effective implementation of NRHM plans to reduce these inequalities in maternal and child health and achieve the intended maternal and child health goals. We chose a mixed-methods approach as the use of quantitative as well as quantitative methods will enable us to not only estimate the extent of implementation and effectiveness of the multiple strategy intervention in reducing maternal and child health inequalities in Haryana (QUAN study findings) but also explain the possible causes of these results (from the QUAL study findings). The partially mixed sequential equal status design will afford us the flexibility to use existing quantitative data from demographic surveys held before, during, and after the NRHM implementation [DLHS 2 (2004-05), DLHS 3 (2007-08), DLHS 4 (2012-13)] for trend analysis. The qualitative study will be performed last, so as to ascertain the status of implementation of NRHM at its flag end [26]. The aim of this approach is to ascertain the status of implementation of NRHM plans objectively as per the amount of budget spent on various health sector plans, as well as from the perspective of providers, managers, and the community; and to assess the status of maternal and child health indicators and inequalities across geographical, socioeconomic, and gender domains after the implementation of the NRHM. 
Most of the previous studies on maternal and child health inequalities in India have used the data of demographic health surveys collected prior to the implementation of the NRHM, so we do not know the present status of these inequalities after the targeted intervention (NRHM). Pathak and colleagues (2010) reported that, despite several governmental efforts to increase access and coverage of delivery services to the poor, the poor did not use skilled birth attendance (SBA), and even if they used SBA, they were more likely to use the private providers. These authors, however, provided no suggestions to increase public sector facilities utilization [24]. Goli et al recommended adopting different health policy interventions, in accordance with the pattern of varying contributions of socioeconomic factors to child health inequalities, between more developed southern Indian states and less developed states [32]. Pallikadavath and colleagues (2013) performed a quantitative assessment of maternal and child health inequalities 'within' and 'between' states. They emphasized that a policy and programming was needed to address 'within-state' inequalities as a priority (aimed at ensuring the availability of all-weather roads and primary schools), as these, more than 'between-state' inequalities affected maternal and child health inequalities by influencing the availability and accessibility of these services [25]. All these studies suggest that state specific actions are necessary to deal with inequalities.

The planning commission's evaluation of the NRHM during its implementation does not include Haryana state, and did not measure maternal and child health inequalities. The advantage of the current study is that it will use an approach for program assessment that is more holistic in nature, and will be helpful in identifying the barriers and facilitators for implementing the strategies, as compared to one-time assessments, which are generally crosssectional in nature, and provide no explanations for the findings. Recommendations based upon holistic program assessments are likely to deliver a more complete and complex picture, and hence to be more relevant for policy making. Additionally, by qualitatively comparing the implementation status in well performing and poorly performing districts, issues and 
bottlenecks in poorly performing districts can be brought to the attention of the policy makers, so that immediate action can be taken to overcome these barriers. The results of our study will not only benefit Haryana, but might also help the whole nation to improve the planning and implementation of services aimed at improving maternal and child health and reducing the major geographical, socioeconomic, and gender-related inequalities in health in India. 


\section{References}

1. Millenium development goals and beyond 2015. Available at http://www.un.org/millenniumgoals/maternal.shtml. Accessed on August 26, 2014.

2. Hota P. National Rural Health Mission. Indian J Pediatr 2006; 73:195-195.

3. Registrar General of India. Special Bulletin on Maternal Mortality in India. Sample Registration System 2010-12. Available at http://www.censusindia.gov.in/vital_statistics/SRS_Bulletins/Final-MMR\%20Bulletin-200709_070711.pdf. Accessed on 16 July 2013.

4. Registrar General of India. Sample Registration System. Available at http://censusindia.gov.in/Vital_Statistics/SRS/Sample_Registration_System.aspx. Accessed on 15 July 2013

5. Ram F, Singh A, Ram U. Human rights approach to maternal \& child health: Has India fared well? Indian J Med Res 2013;137(4): 721-727.

6. Singh A, Pallikadavath S, Ram F, Ogollah R. Inequalities in Advice Provided by Public Health Workers to Women during Antenatal Sessions in Rural India. PLoS One 2012; 7(9): e44931. doi: 10.1371/journal.pone.0044931

7. Singh A, Padmadas SS, Mishra US, Pallikadavath S, Johnson FA, Matthews Z. Socioeconomic inequalities in the use of postnatal care in India. PLoS One 2012; 7(5):e37037. doi: 10.1371/journal.pone.0037037. Epub 2012.

8. Nayar KR. Social exclusion, caste and health: A review based on the social determinants framework. Indian J Med Res 2007;126:355-363.

9. Pathak PK, Singh A: Trends in malnutrition among children in India: growing inequalities across different economic groups. Soc Sci Med 2011; 73(4):576-85.

10. Pradhan J, Arokiasamy P. Socioeconomic inequalities in child survival in India: A decomposition $\quad$ analysis. $\quad$ Health 2010 . DOI: http://dx.doi.org/10.1016/j.healthpol.2010.05.010

11. Census 2011. [http://censusindia.gov.in/2011census/censusinfodashboard/index.html.] Accessed on Accessed on 16 July 2013.

12. Prusty RK, Kumar A. Socioeconomic dynamics of gender disparity in childhood immunization in India, 1992-2006. Plos One. 2014;15:9(8):e104598. doi: 10.1371/journal.pone.0104598.

13. Department of Economic and Statistical Analysis Haryana: Economic Survey of Haryana. Government of Haryana. 2012-13. Available at http://web1.hry.nic.in/budget/Esurvey.pdf. Accessed on 16 July 2013.

14. Registrar General of India. Sample Registration system. Matermal Mortality in India:19972003. Trends causes and risk factors. 2006:12-15.

15. Kaur M. Female Foeticide-A sociological perspective. The Journal of Family Welfare. 1998;39(1):40-43.

16. Sabu G, Dahiya M, Ranbir S. Female foeticide in rural Haryana. Economic and Political Weekly. 1998;33(32):2191-98.

17. Kumar R, Gupta M, Prinja S. Illness burden, care seeking and treatment cost among less than 2-year-olds in rural Haryana. Indian J Pediatr. 2014. Available at http://www.ncbi.nlm.nih.gov/pubmed/24874811. Accessed 1 December, 2014.

18. Sharma S. Child health and nutritional status of children: the role of sex differentials. Population Research Center. Institute of Economic Growth. Available at http://www.iegindia.org/workpap/wp262.pdf. Accessed 1 December 2014.

19. Child health program in India. Available http://mohfw.nic.in/WriteReadData/1892s/6342515027file14.pdf. Accessed on 27 November 2014.

20. Hota P, Dobe M. National Rural Health Mission. Indian J Public Health 2005; 49(3):107-10.

21. National Health Mission. [http://nrhm.gov.in/nhm/nrhm/nrhm-framework-forimplementation.html.] Accessed on 16 January 2014.

22. Evaluation study of National Rural Health Mission (NRHM) in seven states. Programme Evaluation Organisation. Planning Commission. Government of India. Available at http://planningcommission.nic.in/reports/peoreport/peoevalu/peo_2807.pdf. Accessed on 29 June 2014.

23. Mukherjee S. A study on effectiveness of NRHM in terms of reach and social marketing initiatives in rural India. European Journal of Scientific Research 2010; 42(4):573. 
24. Pathak PK, Singh A, Subramanian SV. Economic inequalities in maternal healthcare: prenatal care and skilled birth attendance in India, 1992-2006. PLoS One 2010; 27:5(10):e13593. doi: 10.1371/journal.pone.0013593.

25. Pallikadavath S, Singh A, Ogollah R, Dean T, Stones W. Human resource inequalities at the base of India's public healthcare system. Health Place 2013; 23:26-32.

26. Leech NL, Onwuegbuzie AJ. A typology of mixed method research designs. Qual Quant 2009; 43:265-275.

27. Rural healthcare in System in India structure and current scenario. http://mohfw.nic.in/Rural\%20Health\%20Care\%20System\%20in\%20India.pdf. (accessed 20 April 2014).

28. Panchayati Raj Ministry of Panchayati Raj. Government of India. http://panchayat.gov.in/index.do?siteid=101\&sitename=Government $\% 20$ of $\% 20$ India $\% 20 \% 3 \mathrm{C}$ br\%3E\%20Ministry\%20of\%20Panchayati\%20Raj. (accessed 20 April 2014).

29. International Institute of Population Sciences. District Level Household Surveys. Reproductive and Child Health Project. Ministry of Health and Family Welfare. New Delhi. India. Available at http://www.rchiips.org/ARCH-1.html. Accessed 10 July 2013.

30. Common Review Mission. Available at http://nrhm.gov.in/monitoring/common-reviewmission/1st-common-review-mission.html]. Accessed 4 September, 2013.

31. Joint Review Mission. Available at http://nrhm.gov.in/monitoring/joint-review-mission.html. Accessed 4 September, 2013.

32. Goli S, Doshi R, Arokiasamy P. Pathways of economic inequalities in maternal and child health in Urban India: A decompostition analysis. Plos ONE 2013; 8(3): e58573. doi:10.1371/journal.pone.0058573 


\section{Chapter 3}

Extent of implementation of a multiple-strategy community intervention for reducing maternal and child health inequalities in Haryana, India.

Madhu Gupta, Federica Angeli, Hans Bosma, Shankar Prinja, Manmeet_Kaur, Onno

CP van Schayck

Global Health Action (submitted, 2016).

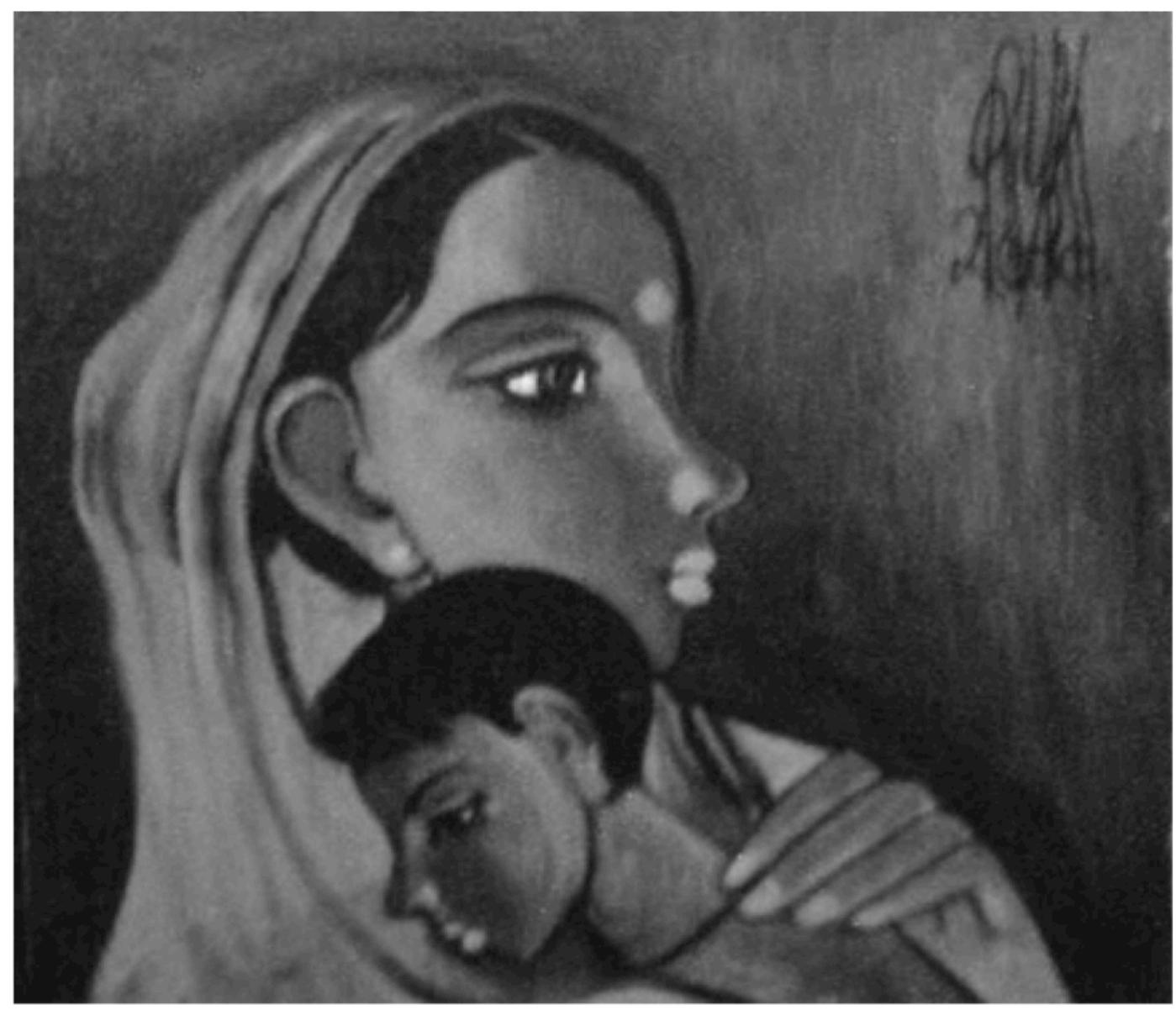




\begin{abstract}
Background

To facilitate the decline of maternal and child mortality and bridge geographical and socioeconomic inequalities related to maternal and child health, a multiple-strategy community intervention known as national rural health mission (NRHM) was launched in India in 2005. This study examines the extent of implementation of NRHM's maternal and child health sector plans, including health system strengthening, maternal and child health care strategies, and communitization from 2005 to 2012 in Haryana, India.
\end{abstract}

\title{
Methods
}

We estimated the amount of budget approved and spent on each of the plans. Total funds sanctioned and spent under each maternal and child health sector plan of NRHM in a given financial year were obtained from state records and financial monitoring reports. The proportion of unspent budget and budget utilization rate of each health plan was calculated to have an indirect estimation of the extent of implementation of the planned activity. If utilization rate for implementing a health plan is $100 \%$ or above then it is considered fully implemented, if less than $100 \%$ its partial, if $0 \%$ then not implemented at all at the end of financial year 2012-13.

\section{Results}

The overall budget for maternal and child health sector plans increased from USD 6.6 million (2005-06) to USD 66.7 million (2012-13). Budget utilization rate increased from $20.6 \%$ (2007-08) to $89 \%$ (2012-13). Funds were overspent for patient referral services (-11.5\%), human resources $(-10.8 \%)$, drugs and logistics $(-71 \%)$, Accredited Social Health Activists (ASHA) [-32.2\%], immunization (-5.4\%). Additional budget on implementing these activities was obtained from state health budget.

\section{Conclusions}

Overall the extent of implementation of NRHM maternal and child health plans was partial in Haryana. Referral services, human resources, drugs, ASHA scheme, and immunization were fully implemented; and all other schemes were only partially implemented. 


\section{Introduction}

India contributes to about $22 \%$ of all maternal deaths and to $20 \%$ of all under five deaths globally [1]. Public health interventions to improve maternal and child health outcomes in India have been implemented since 1950's like National Family Welfare Program (1952), Acute Diarrheal Disease Control Program (1978), Acute Respiratory Infections Control Program (1978), Universal Immunization Program (1985), Safe Childhood and Safe Motherhood Program (1992), Reproductive and Child Health Program (RCH-1997-2005) $[2,3]$. However, the pace of achievement of maternal and child health outcome was slow. As per sample registration system bulletin [4], the maternal mortality rate (MMR) until 2005 was still as high as 3 maternal deaths per thousand live births and the infant mortality rate (IMR) was equal to 60 infant deaths per thousand live births [5]. Also Ram et al (2013) reported marked geographical inequality in maternal and child health outcomes, which continued to persist and even widen across states, between rural and urban areas, and within communities in India [6].

The reasons identified for the slow decline of maternal mortality and infant mortality were a high proportion of home deliveries (up to $70 \%$ ), the lack of trained skilled birth attendants, the lack of an adequate number of auxiliary nurse midwives (ANMs) to provide domiciliary care during home visits following delivery, the poor quality of services in the health facilities due to the lack of an adequate number of trained staff nurses and doctors to provide round the clock basic emergency obstetric care or essential new born care [7], the lack of an adequate number of specialists to provide comprehensive emergency obstetric care services or sick newborn/child care services, the lack of an adequate number of health facilities with equipment, blood storage units or drugs and logistics, and the lack of involvement of the community in the planning and monitoring of the national program $[8,9]$. 
To address this gap in the implementation, enhance the pace of improvement, and meet the millennium development goals, a multiple-strategy community based intervention known as National Rural Health Mission (NRHM) has been implemented in India from 2005 to 2012 by the central government. The aim of NRHM was to improve the availability of and access to better quality health care especially for poor mothers and children. Organizational improvements in the health care delivery system were initiated, so as to reduce the maternal and child health inequalities and improve the overall maternal and child health status. To meet this aim, four major NRHM's health sector plans were implemented. These plans included health system strengthening, specific maternal and child health care strategies/schemes $(\mathrm{RCH}-$ II), and communitization (delegating powers to and empowering the community to monitor the healthcare delivery system) [10]. The details of the plans described in a previous protocol study [11].

Briefly, health system strengthening included strengthening the health infrastructure with more ANMs, staff nurses, doctors on contractual basis to provide around-the-clock services, providing free drugs and logistics, availability of mobile medical units (MMUs) and patient transport services, and providing telemedicine facilities. Maternal and child health schemes included cash incentives to pregnant women for hospital deliveries under Janani Suraksha Yojna (JSY) scheme; free delivery services for pregnant women and treatment of neonatal and infant illnesses in hospitals, reimbursements of travel cost to hospitals under Janani Sishu Suraksha Karyakaram (JSSK), implementation of integrated management of neonatal and childhood illnesses (IMNCI), infant young child feeding (IYCF), facility and home based newborn care (FBNC/HBNC), establishing nutritional rehabilitation centers (NRCs), maternal death review (MDR); and appointing Accredited Social Health Activists (ASHAs) in all villages or for 1000 population to promote the access to improved healthcare at the household level in villages, forming village health nutrition and sanitation committees (VHNSCs) at the village level and Rogi Kalyan Samities (RKS) in health facilities for patient welfare (with 
representation from members of local government), celebration of village health and nutrition days (VHNDs) every month under communitization. The intention was to reduce the infant mortality rate to $30 / 1,000$ live births, maternal mortality to $1 / 1,000$ live births, and the total fertility rate to 2.1 by 2012 . These health sector plans were adopted based upon existing literature on strategies to reduce maternal and child mortality by the government of India [12$16]$.

Since maternal mortality did not decrease below 1/1,000 live births (MMR 1.46/1,000 live births) and infant mortality below 30/1,000 (IMR 40/1,000 live births) in Haryana after seven years (2005-12) of implementation of maternal and child health sector plans of NRHM, it becomes pertinent to assess the of scale of implementation of NRHM's maternal and child health sector plans. An intervention cannot have its impact unless it is being implemented up to a certain extent and for a minimum time period. The goal of this study is to quantify the extent of implementation of various NRHM's maternal and child health sector plans from 2005 to 2012 in Haryana, North India, by estimating the amount of budget approved and spent on each of the planned activities. The results of this study might be useful for improving the implementation of maternal and child health care strategies in Haryana, but might also be of help for policy makers and researchers working with similar strategies in other states of India or in other low- and middle income countries.

\section{Methods}

The authors received ethical approval from their institute.

Study area

This study was conducted in Haryana state in India, as it is representative of other North Indian states with similar a socioeconomic development and sociocultural factors, such as the preference to have sons, female feticide, lower sex ratios, and a lower social status of women. 
Haryana has 21 districts. A detailed description of the health care delivery system within the state can be found in study protocol [11].

\section{Institutional arrangements for implementing NRHM at state and district level}

A mission steering group headed by the Union Minister of Health and Family nationally guides the implementation of NRHM. At the state level, the State Health Mission, chaired by the Chief Minister and co-chaired by the Health Minister of the State, guide its implementation. The functions of the NRHM are carried out through the State Health Society. A state Mission Director, NRHM (Indian Administrative Services, Officer) is appointed for its implementation. Maternal and Child health divisions were created in addition to permanently appointed state health care staff. At the district level, the district Health Mission functions under the leadership of the District Collector with the District Chief Health Officer as the convener [17].

Planning and budgeting for implementing maternal and child health sector plans under NRHM

A state program implementation plan (PIP), a decentralized planning document (planned at the district level and compiled at the state level) is prepared annually. It includes all the activities to be implemented under NRHM along with the budget required for implementing the activities during the next financial year. Broadly it has five major parts. Part A includes $\mathrm{RCH}$ technical strategies and budget (labelled as RCH flexible pool). RCH flexible pool has further subheads of maternal health, child heath, family planning, adolescent health, infrastructure (minor civil works) and human resources, program management, and institutional strengthening and training. Part B includes the budgetary outlay for communitization, hospital strengthening, new constructions, mobile medical units, referral transport, and procurement etc (labelled as mission flexible pool). Part $\mathrm{C}$ is on immunization, part $\mathrm{D}$ on other disease control programs (national health programs other than $\mathrm{RCH}$ ) and part 
E on funds required for convergence with other sectors (social welfare, women and child development etc). For this study, we have restricted ourselves to part A, B and C, as these cover all the maternal and child health strategies under NRHM.

The budget for the activities depends upon the utilization rate of the activity/service during previous years with some expected increases in the following year (up to $25 \%$ increase). On approval from the central government, funds are released to the states. The state contributes up to $25 \%$ of the total NRHM budget on health in addition to the central government budget. NRHM provides flexible financing of the health sector plans/schemes so that states can prioritize the expenditure based upon their needs; unspent funds left under one scheme can be reallocated to other scheme.

\section{Data collection methods}

Information on various maternal and child health sector plans implemented in the Haryana state was obtained by an in-depth review of the mission document. Implementation status of various activities was obtained from yearly progress reports of NRHM, Haryana. Total funds sanctioned under each maternal and child health activity of NRHM in a given financial year were obtained from records of proceedings (ROP) of meetings conducted for approval of state PIP, by Ministry of Health and Family Welfare, Government of India [18]. The amount of budget spent under each activity of NRHM during a given financial year was obtained from financial monitoring reports (FMRs) from 2005-06 to 2012-13. FMRs are proofs of expenditure incurred, as these are duly audited financial statements by an external agency.

Independent evaluation reports of NRHM, such as the Common Review Mission (CRM) and Joint Review Mission's reports (JRM) were also reviewed so as to compare the findings of this study with the national level evaluation $[19,20]$. Seven CRM reviews and eight JRMs 
have been conducted since and Haryana state was covered in the $3^{\text {rd }}, 5^{\text {th }}$ and $7^{\text {th }} \mathrm{CRMs}$ and $2^{\text {nd }}$, $3^{\text {rd }}$ and $6^{\text {th }}$ JRMs.

\section{Data analysis}

The implementation status of the NRHM's health sector plans categorized into fully implemented, partially implemented, or not at all implemented, depending upon the utilization rate of the budget sanctioned for implementation of that plan at the end of financial year 2012-13. Sanctioned budget is the budget approved by the central government to implement a given health plan. Budget spent is the expenditure incurred on implementing a given health plan in a financial year. Budget utilization rate is proportion of the expenditure incurred out of total budget sanctioned by the central government for implementing a given health plan. If utilization rate for implementing a health plan is $100 \%$ or above then it is considered fully implemented, if less than $100 \%$ its partial, if $0 \%$ then not implemented at all. Budget utilization rate under each activity provides an indirect estimation of the implementation of the planned activity. The proportion of the budget left unspent for each health plan was calculated by subtracting the budget spent from the budget sanctioned and then dividing from budget sanctioned for each health plan. The overall trend of budget utilization rate and the proportion of the budget left unspent was registered from 2005-06 to 2012-13, so as to reflect upon the state's health priorities and capacity to deal with funds.

Certain measurable achievements of NRHM include increase in number of patients referred through referral transport, beneficiaries registered under JSY scheme, institutional delivery rate, availability of ASHAs, better immunization status of children. Hence correlation between such selected NRHM health sector plans and corresponding budget utilization rate was also estimated. 


\section{Results}

As per the mission document of Haryana, Government of Haryana signed a memorandum of understanding with the central government in June 2005. Regarding the budgetary outlay, Haryana state initially contributed $10 \%$ of the state budget in the overall NRHM budget; this increased to about $15 \%$ later. The total amount of budget sanctioned and spent under the health system strengthening, specific maternal and child health care strategies/schemes (RCHII), and communitization from the year 2005-06 to 2011-12 is given in Table 1 .

Table 1: Total funds received and spent on implementing maternal and child health sector plans under NRHM from financial year 2005-06 to 2012-13 in Haryana.

\begin{tabular}{cccc}
\hline Year & $\begin{array}{c}\text { Amount received } \\
\text { (million USD) }\end{array}$ & $\begin{array}{c}\text { Actual expenditure } \\
\text { (million USD) }\end{array}$ & $\begin{array}{c}\text { Utilization rate } \\
(\boldsymbol{\%})\end{array}$ \\
\hline $2005-2006$ & 6.6 & 5.7 & 87.2 \\
$2006-2007$ & 13.8 & 7.6 & 54.8 \\
$2007-2008$ & 32.1 & 6.6 & 20.6 \\
$2008-2009$ & 27.4 & 22.9 & 83.7 \\
$2009-2010$ & 39.1 & 44.2 & 113.2 \\
$2010-2011$ & 50.0 & 47.3 & 94.7 \\
$2011-2012$ & 46.9 & 47.5 & 101.3 \\
$2012-2013$ & 66.7 & 59.3 & 89 \\
\hline
\end{tabular}

During 2005-06, the state received about 6.6 million USD, out of which $87 \%$ could be utilized. During the year 2005-06, funding was mainly based upon previous activities covered under the RCH-II program and limited funds were dedicated to newer schemes under NRHM like ASHA. From 2006-07 onwards, state PIP included funding provisions for NRHM's new health sector plans like ASHA, Janani Suraksha Yojna (JSY), infrastructure strengthening, human resources especially additional ANM in the sub centers, drugs and logistics. Hence sanctioned budget increased to 13.8 million USD during 2006-07. However, the state spent only $55 \%$ of allocated funds in that financial year. 
During 2007-08, the state received about USD 32 million, but spent about $20 \%$ of it. Total budget sanctioned and spent increased thereafter (Figure 1). By 2011-12, total funds sanctioned increased to USD 47 million with an almost 100\% utilization rate. However, it again declined to $89 \%$ during $2012-13$, though the sanctioned budget was more than previous years. During the year 2012-13, the sanctioned budget was more than the previous year (additional 20 million USD) and budget spent was also more (addition 12 million USD) in 2012-13 as compared to the previous year. However, state could not fully exhaust the additional budget in hand, hence budget utilization rate in 2012-13 was lower than the previous year.

Figure 1. Trend of budget utilization rate of maternal and child health sector plans under National Rural Health Mission from financial year 2005-06 to 2012-13 in Haryana, India.

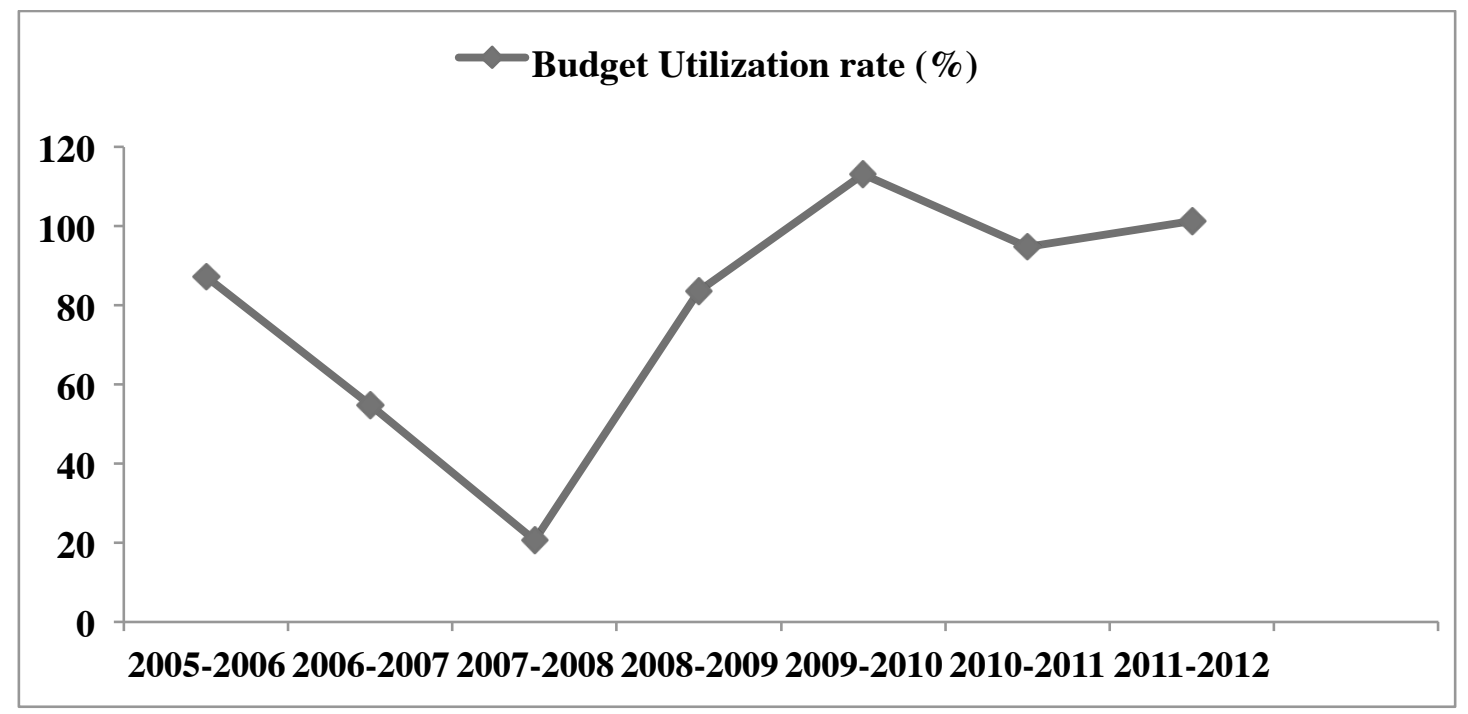

Scheme wise financial monitoring reports of NRHM's implementation were available from the year 2007-08 onwards. Yearly allocation of funds, expenditure incurred and proportion of budget left unspent under each scheme from financial year 2007-08 to 2012-13 is presented in Table 2. Initially the focus of the state was on improving the health system strengthening mainly through the provision of drugs and logistics. Later, infrastructure strengthening, more human resources were promoted and referral services were introduced. Under communitization, the states' main focus was on implementing the ASHA scheme. Although they initially implemented the village health nutrition scheme, it seems the state could not 
maintain its implementation. From the year 2008-09 onwards, planning under NRHM improved considerably with allocation of funds on other schemes like mobile medical units, patient referral transport, and telemedicine under health system strengthening; abortion services under maternal health; 
Table 2. Year wise distribution of budget sanctioned, expenditure incurred (in million USD) and percentage of budget left unspent for NRHM's maternal and child health sector plans from the financial year 2007-08 to 2012-13.

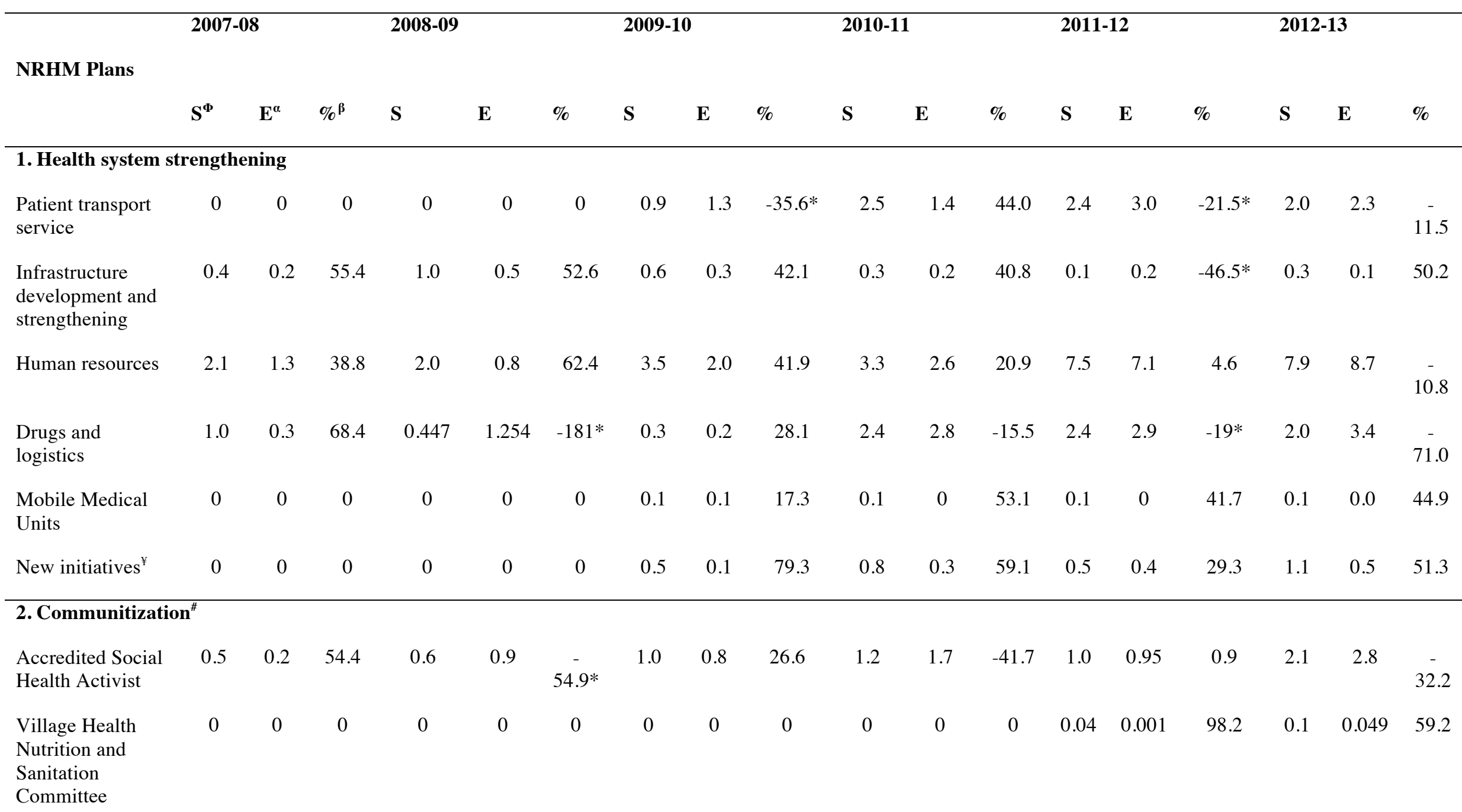




\begin{tabular}{|c|c|c|c|c|c|c|c|c|c|c|c|c|c|c|c|c|c|c|}
\hline $\begin{array}{l}\text { Village Health } \\
\text { and Nutrition Day }\end{array}$ & 0.04 & 0.01 & 80.3 & 0.02 & 0.002 & 85.0 & 0 & $\begin{array}{c}0.00 \\
1\end{array}$ & 0 & 0 & 0 & 0 & 0 & 0 & 0 & 0.0 & 0.0 & 0.0 \\
\hline $\begin{array}{l}\text { Rogi Kalyan } \\
\text { Samities }\end{array}$ & 0 & 0 & 0 & 0 & 0 & 0 & 0.9 & 0.9 & $-2.3^{*}$ & 0.9 & 0.8 & 8.7 & 0.9 & 0.8 & 9.2 & 0.8 & 0.9 & -5.0 \\
\hline \multicolumn{19}{|c|}{ 3. Maternal Health Care Strategies } \\
\hline $\begin{array}{l}\text { Janani Suraksha } \\
\text { Yojna }\end{array}$ & $\begin{array}{c}0.00 \\
3\end{array}$ & 0 & & 0.8 & 0.5 & 37.0 & 0.9 & 0.7 & 19.8 & 0.8 & 0.7 & 14.4 & 1.1 & 0.8 & 20.8 & 1.0 & 0.8 & 19.8 \\
\hline $\begin{array}{l}\text { Janani Sishu } \\
\text { Suraksha } \\
\text { Karayakaram }\end{array}$ & 0 & 0 & 0 & 0 & 0 & 0 & 0 & 0 & 0 & 0 & 0 & 0 & 0 & 0.14 & 0 & 3.8 & 1.9 & 48.4 \\
\hline $\begin{array}{l}\text { Delivery points } \\
\text { with } 24 \times 7 \\
\text { delivery services }\end{array}$ & 0 & 0 & 0 & 0.005 & 0 & 100.0 & 0.03 & 0.01 & 65.8 & 0 & 0 & 0 & $\begin{array}{c}0.03 \\
4\end{array}$ & 0.02 & 43.7 & 0 & 0.002 & $\begin{array}{c}- \\
100\end{array}$ \\
\hline $\begin{array}{l}\text { Provision of safe } \\
\text { abortion services }\end{array}$ & 0 & 0 & 0 & 0 & 0 & 0 & 0 & 0 & 0 & 0.04 & 0 & 99.5 & 0 & 0.001 & 0 & 0.004 & 0.002 & 54.8 \\
\hline \multicolumn{19}{|c|}{ 4. Child Health Care Strategies } \\
\hline $\begin{array}{l}\text { Facility based } \\
\text { new born care }\end{array}$ & 0 & 0 & 0 & 0 & 0 & 0 & 0 & 0 & 0 & 0.3 & 0.2 & 35.7 & 0.5 & 0.4 & 18.2 & 0.48 & 0.15 & $\begin{array}{r}69 \\
.1\end{array}$ \\
\hline $\begin{array}{l}\text { Integrated } \\
\text { management of } \\
\text { neonatal and } \\
\text { childhood } \\
\text { illnesses }\end{array}$ & 0.03 & 0 & 100 & 0.03 & 0.001 & 97.4 & 0.05 & 0.01 & 81 & 0.03 & 0.005 & 79.8 & $\begin{array}{c}0.03 \\
1\end{array}$ & 0.04 & -14.7 & $\begin{array}{c}0.03 \\
2\end{array}$ & 0.012 & $\begin{array}{r}62 \\
.9\end{array}$ \\
\hline $\begin{array}{l}\text { Home based new } \\
\text { born care }\end{array}$ & 0 & 0 & 0 & 0 & 0 & 0 & 0 & 0 & 0 & 0 & 0 & 0 & 0.13 & 0.01 & 91.1 & $\begin{array}{c}0.00 \\
7\end{array}$ & 0.034 & - \\
\hline
\end{tabular}




\begin{tabular}{|c|c|c|c|c|c|c|c|c|c|c|c|c|c|c|c|c|c|}
\hline $\begin{array}{l}\text { Infant and young } \\
\text { child feeding }\end{array}$ & $\begin{array}{c}0.00 \\
1\end{array}$ & 0 & 100 & 0.05 & 0.002 & 96.3 & 0.04 & 0.02 & 57.4 & 0 & 0 & 0 & 0.02 & 0.01 & 54.2 & $\begin{array}{c}0.00 \\
9\end{array}$ & 0.005 \\
\hline \multirow{2}{*}{$\begin{array}{l}\text { Nutritional } \\
\text { rehabilitation } \\
\text { centers }\end{array}$} & 0 & 0 & 0 & 0 & 0 & 0 & 0.003 & 0 & 100 & 0 & 0 & 0 & $\begin{array}{c}0.00 \\
4\end{array}$ & $\begin{array}{c}0.000 \\
2\end{array}$ & 95.5 & $\begin{array}{c}0.01 \\
7\end{array}$ & 0.0001 \\
\hline & 0.3 & 0.2 & 46.8 & 0.46 & 0.22 & 54.1 & 0.7 & 0.37 & 47.1 & 2.4 & 1.9 & 22.1 & 0.75 & 0.49 & 34.0 & 3.1 & 3.3 \\
\hline Immunization & & & & & & & & & & & & & & & & & \\
\hline
\end{tabular}

$\alpha$ sanctioned; $\beta$ Expenditure done; $\gamma$ percentage of funds left unspent; *Extra budget is received from state budget. More than $100 \%$ utilization is because of using the state budget in addition to central government grant in aid for implementing NRHM schemes. 
FBNC, HBNC, and NRCs under child health. The yearly trend of proportion of unspent funds under health system strengthening is given in Figure 2. State exhausted the funds allocated for human resources, patient referral and transport services and drugs and logistics in 2012-13, under health system strengthening.

Figure 2. Trend of proportion of unspent budget of strategies under health system strengthening component of National Rural Health Mission from 2007-08 to 2012-13.

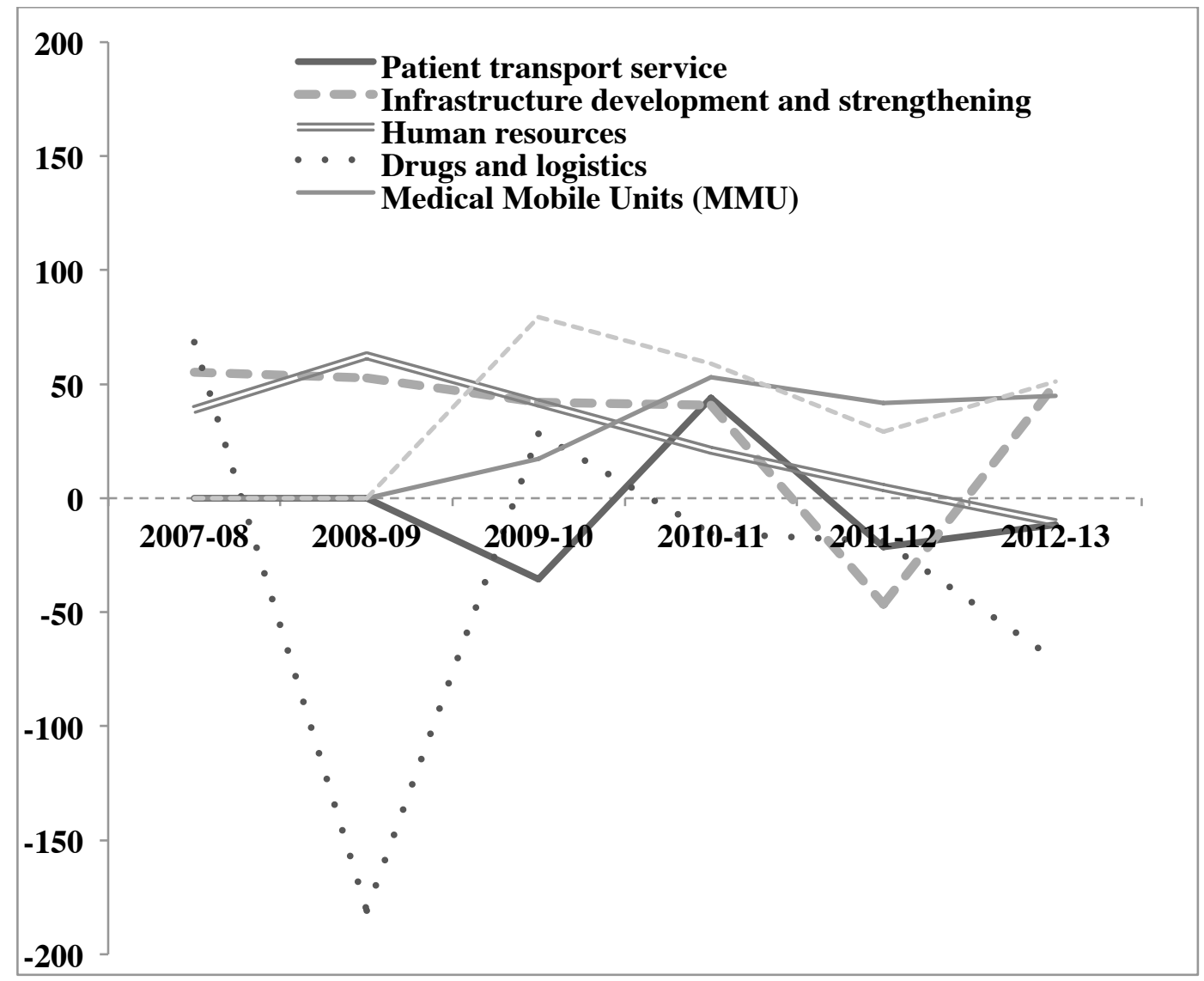

Under communitization, the state over spent on ASHA scheme and patient welfare committees in the hospitals (RKS). However, a large amount of the budget is instead left unspent under the VHNSC (98\% in 2011-12 and 59\% in 2012-13) scheme. Funds sanctioned under VHND scheme were nil after 2009-10. (Figure 3).

Figure 3. Trend of proportion of unspent budget of strategies under communitization component of National Rural Health Mission from 2007-08 to 2012-13. 


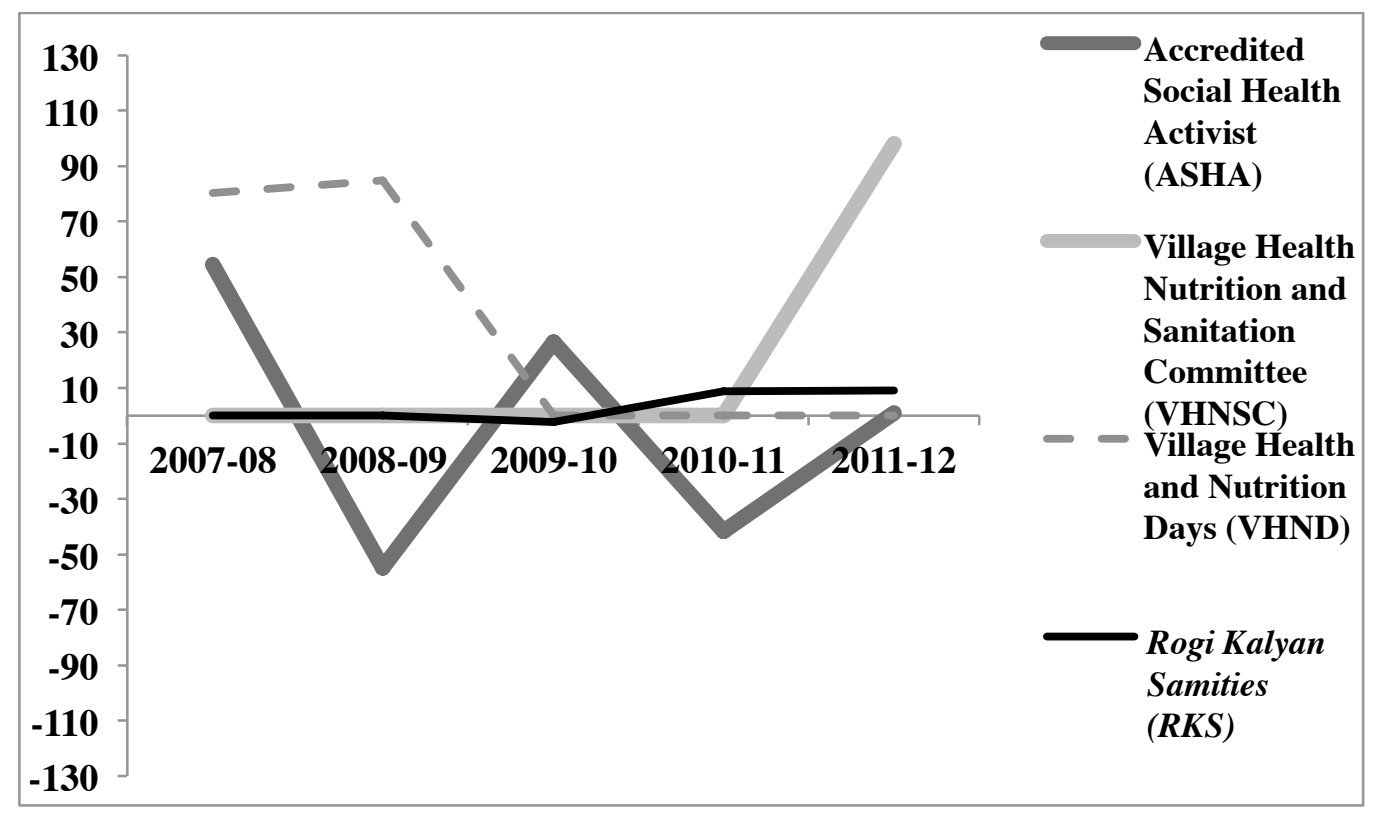

For maternal health care strategies, almost all the schemes' budget is left unutilized. (Figure 4). About $44 \%$ of the budget remained unutilized for strengthening delivery points with 24 hours services during 2011-12. No funds allocated under this scheme next year, however FMRs show expenditure under this scheme during 2012-13. A steady decline in unspent budget was observed for the JSY scheme. Unspent funds dedicated for JSY decreased from $100 \%$ to $20 \%$ from $2007-08$ to $2012-13$.

Figure 4. Trend of proportion of budget left unspent under maternal health care strategies of National Rural Health Mission from 2007-08 to 2012-13.

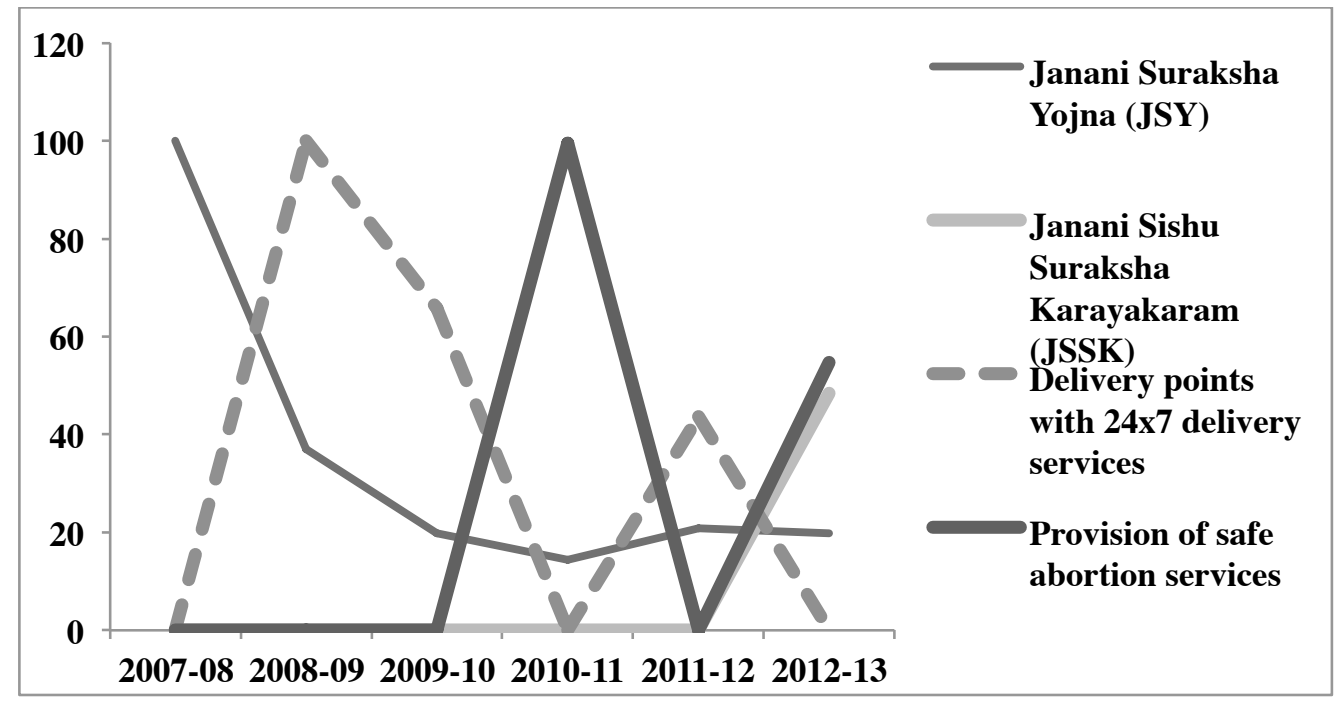

Under child health care strategies, funds were being sanctioned for implementing IMNCI, IYCF and immunization since 2005. (Figure 5). However, utilization was slow. The unspent 
budget decreased from 100 to $62.9 \%$ for IMNCI implementation, $100 \%$ to $43.6 \%$ for IYCF and $47 \%$ to $-5.4 \%$ for immunization, from 2005-06 to 2012-13, respectively. Unspent budget under HBNC declined drastically from 91\% during 2011-12 to -370\% during 2012-13. The almost maximum unspent budget is left for implementing NRCs (99.4\%)

Figure 5. Trend of proportion of budget left unspent under child health care strategies component of NRHM from 2007-08 to 2012-13.

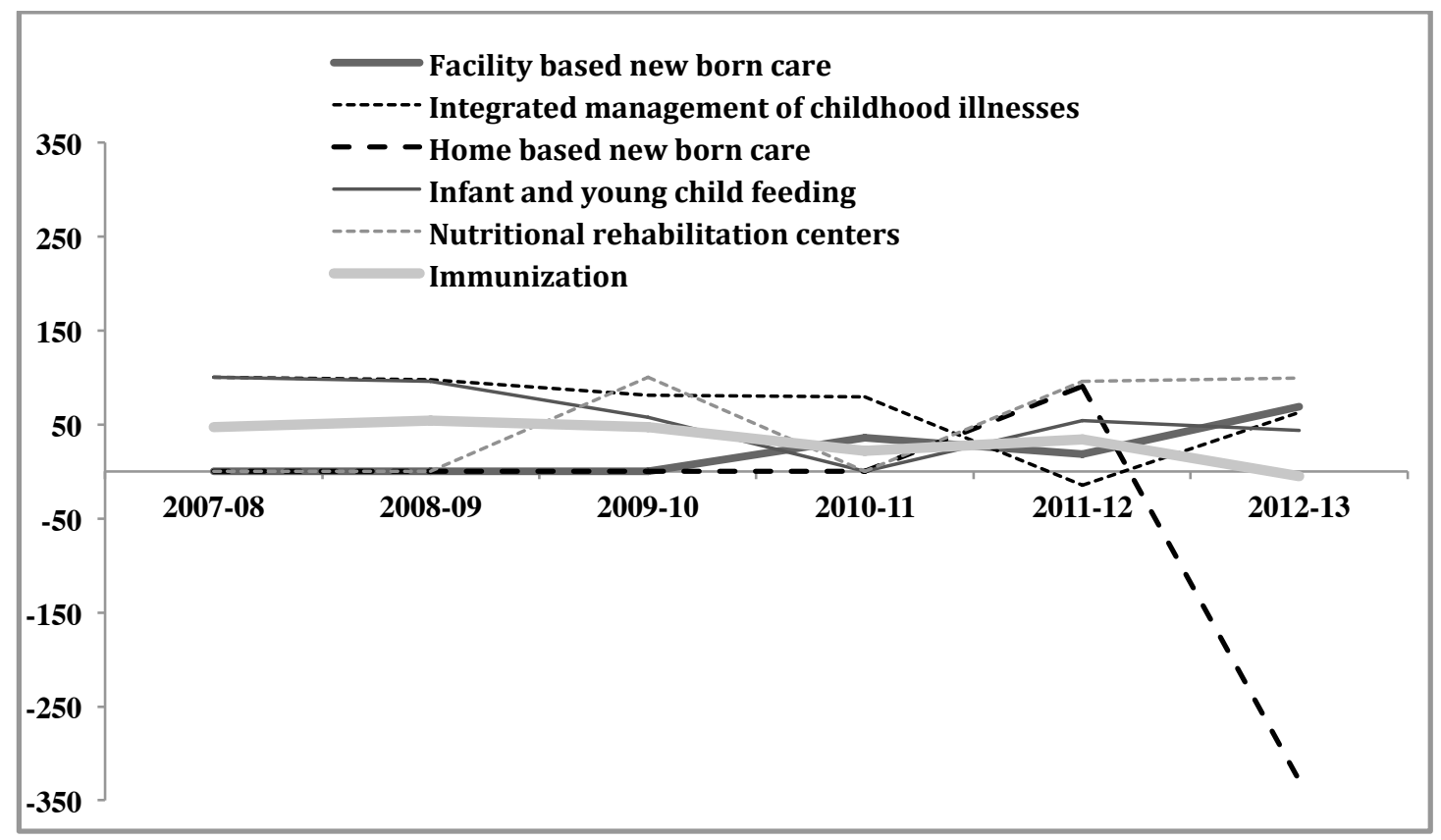

More than $100 \%$ utilization indicates the use of the state's health budget in addition to the central governmental grant in aid for implementing NRHM schemes. Not all schemes were implemented throughout the NRHM phase (2005-06 to 2012-13). Infrastructure strengthening, provision of drugs and logistics, human resources, ASHA scheme, immunization for children and pregnant mothers, IYCF, IMNCI and JSY were implemented throughout. However, patient transport services, MMUs, patient welfare committees (RKS) and delivery points with round the clock services were implemented during the last four years, VHSC, facility based new born care and home based new born care during last two years. The VHND scheme has not been implemented after 2009-10. Free treatment of neonatal illness and pregnant mothers (JSSK) launched in 2011.

As per state's progress report of NRHM, there has been an increase in the number of health facilities and health care providers. (Table 3). 
Table 3. Status of health facilities and health care providers in Haryana.

\begin{tabular}{llll}
\hline Health Facilities & $\mathbf{2 0 0 5 - 2 0 0 6}$ & $\mathbf{2 0 0 7 - 2 0 0 8}$ & $\mathbf{2 0 1 2 - 2 0 1 3}$ \\
\hline District hospitals & 19 & 20 & 21 \\
Sub-district hospitals & 24 & 23 & 25 \\
CHCs & 81 & 83 & 110 \\
PHCs & 408 & 420 & 440 \\
SCs & 2433 & 2465 & 2630 \\
\hline ASHA recruitment status & $\mathbf{2 0 0 5 - 0 6}$ & $\mathbf{2 0 0 7 - 0 8}$ & $\mathbf{2 0 1 1 - 1 2}$ \\
& 3639 & 11108 & 13787 \\
\hline Health care providers (as in 2011) & $\mathbf{R e g u l a r}$ & $\mathbf{C o n t r a c t u a l}$ & Total \\
Doctors & 2239 & 113 & 2352 \\
Specialists & 475 & 246 & 721 \\
Paramedics & 697 & 18 & 715 \\
Staff Nurses & 1554 & 1295 & 2849 \\
ANMs & 2077 & 2532 & 4609 \\
\hline CHC: Con & & & \\
\hline
\end{tabular}

CHC: Community Health Centers, PHCs: Primary Health Centers, SCs: Subcenters; Source: Progress report of NRHM, Haryana.

The number of pregnant women who availed referral transport services increased from 25,891 (2009-10) to 143,046 (2012-13). Positive correlation observed between budget utilization rate and institutional delivery rate $(\mathrm{r}=0.3)$, ASHA scheme $(\mathrm{r}=0.4)$ and Janani Suraksha Yojna $(\mathrm{r}=0.6)$. Small negative correlation observed with referral transport $(\mathrm{r}=-0.2)$ scheme and large negative correlation with full immunization $(\mathrm{r}=-0.8)$ status of children (Table 4).

Table 4. Correlation between budget utilization rate and selected NRHM health sector plans.

\begin{tabular}{cccc}
\hline Financial year & $\begin{array}{c}\text { Budget Utilization } \\
\text { rate }(\%)\end{array}$ & $\begin{array}{c}\text { NRHM Health } \\
\text { Sector Plans }\end{array}$ & $\begin{array}{c}\text { Correlation Coefficient } \\
(\mathbf{r})\end{array}$
\end{tabular}

\begin{tabular}{lccc}
\hline Number of patients referred through referral Transport (N) & \\
$2009-2010$ & 135.6 & 25891 & -0.26 \\
$2010-2011$ & 56 & 99075 &
\end{tabular}




\begin{tabular}{lccc}
\hline \multicolumn{2}{l}{ Institutional delivery rate*\$(\%) } & & \\
$2007-08$ & 63 & 46.9 & 0.3 \\
$2009-2010$ & 100 & 63.3 \\
$2012-2013$ & 80.2 & 76.9
\end{tabular}

\begin{tabular}{lccc}
\hline Number of ASHAs recruited $(\mathbf{N})$ & & \\
$2007-08$ & 45.6 & 11108 \\
$2008-09$ & 154.9 & 12152 \\
$2009-2010$ & 73.4 & 12753 \\
$2010-2011$ & 141.7 & 12861 \\
$2011-2012$ & 99.1 & 13787 \\
$2012-2013$ & 132.2 & 14622
\end{tabular}

\begin{tabular}{lccl}
\hline Number of beneficiaries registered under Janani Suraksha Yojna (N) & \\
$2007-08$ & 0 & 48076 & 0.64 \\
$2010-2011$ & 85.6 & 63171 \\
$2011-2012$ & 79 & 41758
\end{tabular}

Proportion of fully immunized children between 12-23 months\$ (\%)

$\begin{array}{llll}2007-08 & 53.2 & 59.6 & -0.79\end{array}$

2009-2010

71.7

2012-2013

105.4

52.1

*Institutional delivery rate compared with budget utilization rate for implementing Janani Suraksha Yojna. \$: IIPS 2007-08, Unicef 2009, IIPS 2012-13

Based upon the budget sanctioned and spent on various maternal and child health schemes, the extent of implementation of NRHM plans are summarized in Table 5. The patients' referral transport services, human resources and provision of drugs and logistics under health system strengthening; the ASHA and RKS scheme under communitization; and immunization and HBNC under child health care strategies were fully implemented. Nutrition rehabilitation center scheme was only minimally implemented hence placed in not implemented category and all other schemes were partially implemented. 
Table 5. Extent of Implementation on NRHM's maternal and child health sector plans in Haryana.

\begin{tabular}{lccc}
\hline NRHM Plans & \multicolumn{3}{c}{ Extent of Implementation } \\
\cline { 2 - 4 } & Fully & Partially & Not Implemented \\
\hline 1. Health System Strengthening & $\checkmark$ & - & - \\
Patient transport service/referral services & - & - & - \\
Infrastructure development and strengthening & $\checkmark$ & - & - \\
Human resources & $\checkmark$ & - & - \\
Drugs and logistics & - & - & - \\
Mobile medical units & - & - & \\
New Initiative &
\end{tabular}

\section{Communitization}

Accredited Female Health Activist

Village health and sanitation committees

Village health and nutrition days

Rogi Kalyan Samities

\section{Maternal Health Care Strategies}

Janani Suraksha Yojna

Janani Shishi Suraksha Karyakaram

Delivery points with provision of $24 \times 7$ delivery services

Provision of safe MTP services

\section{Child Health Care Strategies}

Facility based new born care

Integrated management of childhood illnesses

Home based new born care

Infant and young child feeding

Nutrition Rehabilitation Centers

Immunization 


\section{Discussion}

As derived from the budget allocated and spent on implementing the NHRM-related activities, the results of this study show that the extent to which national rural health mission's maternal and child health sector plans have been implemented in Haryana has been mostly partial, except for patients' referral transport services, human resources, drugs and logistics, ASHA, patient welfare committees at health facilities (RKS), immunization and HBNC. There is evidence of an increased utilization of funds throughout the NRHM implementation period (from 2005-12) and a decline in maternal and child mortality, but the decline was not as expected (which was a decrease to a maternal mortality ratio of less than 1 per 1,000 live births and a decrease of infant mortality rate to 30/1000 live births).

From the trend statistics regarding the proportion of unspent budget (Figures 2 to Figure 5), it can be learnt that the focus of the state was not only on implementing specific maternal and child health care strategies but also on health system strengthening and communitization. Haryana state focused on the implementation of some of the key interventions, like providing free patient referral services to improve the access to health facilities, increased manpower, drugs and logistics, the availability of local lady as a link between the community and the health facility, and trained manpower to implement IMNCI and HBNC. It also needs to place more emphasis on infrastructure development and strengthening; putting in place 24 hours delivery services, treatment of sick children at health facilities and implementing infant and young child feeding, village health and sanitation committees, and village health and nutrition day celebrations. Improvement in institutional delivery rate from $29 \%$ during 2005-06 [8] to $76.9 \%$ in 2012-13 [21] could be because of these health sector plans. This is also evident from the positive correlation seen in this study with budget utilized on implementing schemes like JSY and ASHA that focus on improving institutional delivery. Prinja et al reported a positive effect of referral transport service on increasing institutional deliveries and suggested that it needs to be backed up with adequate supply of basic and emergency obstetric care at health 
facilities [22]. The small negative correlation with referral transport seen in this study can be overlooked because budget spent is more than 100\%. Although NRHM's funds were utilized fully under immunization head yet, fully immunized children (age 12-23 months) declined from $65.3 \%$ during $2005-06$ [8] to $52.1 \%$ in 2012-13 [21]. This could be because of other operational issues at the level of implementation like tracking of all children, micro planning for immunization sessions etc., which probably were not addressed simultaneously. Partial implementation of maternal and childcare interventions could be the reason for slow pace of decline of maternal and child mortality.

Singh in his systematic review on the relationship between public health spending and population health outcomes concluded that financial investments in public health have the potential to improve community health [23]. Simultaneously, Singh suggested additional research to explore the pathways that mediate this relationship. The present study may not completely answer this, but definitely add to the existing literature. Bekemeier et al pointed out that need-based allocations of the funds for programs on maternal and child health are better for improving services [24]. Farag et al examined the relationship between a country's health spending and child health (infant and child mortality) among low- and middle-income countries and observed that government health spending has a significant effect on reducing infant and child mortality [25]. Direct correlation between the level of public health spending and its impact on improving equitable utilization of health services has also been shown in India [26]. Further, the inequitable impact on utilization of services is also seen with higher out-of-pocket expenditures [27].

Another important issue that emerges from the results of this study might the power dynamics at the national/state level that influence the program implementation. Colenbrander et al examined the priority setting process in the health sector in Uganda and reported that the decision to implement which strategy and which not lie in the hands of few men mainly from 
Ministries of health, bilateral donors, and multilateral development agencies [28]. A similar explanation might be true for Indian states.

The methodology used in this study is an indirect estimation of the extent of implementation of maternal and child health sector plans under NRHM, by estimating the rate of utilization of funds allocated for a particular activity. This has been based on the fact that states cannot implement an activity unless it utilizes the allocated budget to provide resources/logistics to implement that activity. Resources could be in terms of manpower, performance based incentives for health service providers/community volunteers, incentives for using the services, referral transport, drugs and logistics etc. How much the state could spend on these activities gives us an indirect estimation of the extent of implementation. As per WHO, the basic building blocks of a health system include leadership/governance, service delivery, health workforce, health information systems, access to essential medicines, and financing [29]. In this study, we ascertained the status of financing as it affects the availability of sufficiently large health workforce and essential medicines which impact service delivery and ultimately the mortality indicators.

FMRs capture the detailed expenditure on an activity starting from the level of the village to the district. The annual utilization certificate and the state of expenditure audited internally and externally can be considered reliable sources for estimating the budget utilization [30]. We looked at the surrogate parameter budget spent for maternal and child health care, while it would be better to evaluate the actual care. An alternative method to measure the extent of implementation of NRHM maternal and child health sector plans is a field survey, which, however, is costly and time-consuming. Adam $\mathrm{T}$ et al in their review of health system evaluation studies in low- and middle-income group countries also pointed out that possible barriers for a comprehensive evaluation is the lack of funding and inadequate time frames etc [31]. The advantage of using our indirect method is the feasibility and the ease with which 
existing information can be used for ultimately having a better implementation of health plans in the future.

Witter et al studied the health care financing system of Sierra Leona that has poor maternal and child health indicators [32]. A target of allocating at least $15 \%$ of annual budget to health sector improvement (Abuja target) by African governments was fixed. To measure this target, it was suggested to focus on actual expenditure rather than budgets (which are only theoretical) and which captures areas of spending that are subject to government discretion. In the present study also we have tried to look at how much of the budget is spent to reflect upon the implementation status of maternal and child health sector plans of the multiple-strategy community intervention.

Budget utilization rates of implementing maternal and child health sector plans under NRHM from financial year 2005-06 to 2011-12 have shown a lot of variation. This is, because initially funding was mainly based on the previously implemented RCH-II program during 2005-06; that program had fewer funds, but more utilization. It could also be because of the health sector reforms program focus on $\mathrm{RCH}$ since 1999 in the state [33]. In later years, planning and budgeting for NRHM activities was done under newer interventions like infrastructure development, human resources, patient referral services, ASHA, RKS, JSY, and delivery points, IMNCI etc., which caused a considerable increase in the sanctioned budget. The utilization rate was only $20 \%$ during $2007-08$, which increased to almost $100 \%$ by 2011 12. The change in leadership during 2009, a new Mission Director joined the state, might also have contributed to above change. Under his stewardship and vision, the state annually not only received more budget, but the utilization also increased. Brinkerhoff et al (2014) emphasized that good governance is crucial for health system strengthening [34]. This is also demonstrated from the local context where the reforms for decentralization in Haryana between 2002 and 2004 were strongly influenced by local leadership [35]. 
The results of this study provide insight into the utilization of the central government funds by the state government; this has not been documented so far. It raises several issues related to over- or underutilization of funds. The possible explanation for the discrepancies in utilization could be either there is no adequate budget estimation or there is no adequate registration of the actual costs made or there is a more efficient use of resources than originally planned or there is less money spent for mother and health care leading to an insufficient decline in maternal and child mortality.

The underlying reasons for the partial implementation and underutilization of the budget could be the insufficient capacity of the state to spend the budget, the late release of funds by the central government as states usually send the PIP in the last quarter of a financial year (January-March) and the budget is approved in the first quarter of the next financial year (April-June, improper planning for implementation of activities like activity implemented at the end of the year, lack of adequate number of program managers like one program manager looking after many other programs who could not optimally plan to implement a particular plan, differential priorities set by the state to implement the health sector plan so that one plan gets the priority over other and also due to lack of regular monitoring and supervision of implementation of activities and utilization of funds [36]. CRM and JRM reports have also documented partial implementation status of NRHM activities and mentioned that there certainly is scope for improvement.

Brixi $\mathrm{H}$ et al analyzed the government expenditure on health in the context of China's decentralization and intergovernmental model to assess whether national, provincial and subprovincial public resource allocations and local government accountability relationships are aligned to reduce maternal and child health inequalities [37]. They observed that government expenditure on health at sub-national levels, which accounts for $90 \%$ of total government 
expenditure on health, is increasingly regressive across and within provinces. Public expenditure at sub-national levels was not aligned with national priorities. The unsynchronized budget cycle and expenditure cycle leads to a delay in budget execution and complicates the program implementation [38].

Since the JSSK scheme was launched during the year 2011, it was too early to comment on its implementation based upon utilization of funds. Overutilization of funds on certain schemes like referral transport, infrastructure development etc., could be because of the flexibility provided with NRHM funds: the state can choose to provide additional funds from the state's health budget. Nearly $15 \%$ of the total NRHM funds come from state share (in addition to central aid in grant).

Earlier planning commission did an evaluation of NRHM in seven states in India with the objective to assess the availability, adequacy and utilization of health services in the rural areas. However, no efforts were done to look into how the planning for the program implementation has been done and how funds were allocated and utilized [39]. As per the systems approach in health management, there are input, process, output, outcome and impact indicators that are used to evaluate a program [40]. In this study by measuring the amount of funds utilized for performing an activity, we have tried to look into the input and process indicators related to maternal and child health sector plans, which forms the basis for output and outcome indicators. Zanakis et al (1995) have reviewed about 306 articles on program evaluation to conclude that few publications deal with both evaluation and allocation as an integrated process [41]. This study is an attempt in this direction.

The findings of this study are useful for policy makers and program managers working on improving program implementation and aiming at achieving the intended maternal and child health outcomes. It is emphasized that underlying in our argument is the assumption that all 
separate measures and the amount sanctioned to them are equally important/effective in reducing maternal and child mortality. We need more research to find out whether some measures with different amounts sanctioned and spent might be more effective. Future research may be longitudinal or prospective in nature to see which strategy is being implemented and how funds are being spent on implementing that strategy, with which outcomes. One could even speculate whether a model could be made that estimates the actual care delivered on the basis of measured budget spent.

Based on the overall results of this study, it is recommended, firstly, that defined annual targets regarding budget expenditures on maternal and child health interventions should be set at the state level and, secondly, that regular monitoring and evaluation by an independent agency should be done to strengthen the program implementation at the state level. 


\section{References}

1. Hill K, Thomas K, AbouZahr C et al. Estimates of maternal mortality worldwide between 1990 and 2005: an assessment of available data. Lancet 2007;370:1311-1319. doi: 10.1016/S0140-6736(07)61572-4.

2. Paruthi R, Dutta PK. Reproductive and child health programme. Indian J Public Health 2002;46(3):72-7.

3. Ministry of Health and Family Welfare. Child health program in India. 2000. Available at http://mohfw.nic.in/WriteReadData/1892s/6342515027file14.pdf. Accessed on 27 November 2014.

4. Registrar General of India. Special Bulletin on Maternal Mortality in India. Sample Registration System 2001-03.

5. Registrar General of India. Sample Registration System Bulletin. 2005. http://www.censusindia.gov.in/vital_statistics/SRS_Bulletins/SRS_Bulletins_links/SRS_Bulle tin_April_2005.pdf. Accessed on 15 July 2013.

6. Ram F, Singh A, Ram U. Human rights approach to maternal \& child health: Has India fared well? Indian J Med Res 2013;137(4): 721-727.

7. Nolan T, Angos P, Cunha AJ, Muhe L, Qazi S, Simoes EA et al. Quality of hospital care for seriously ill children in less-developed countries. Lancet 2001; 357(9250):106-10.

8. International Institute of Population Sciences. National Family Health Survey-3. Ministry of Health and Family Welfare. New Delhi. India. 2005-06. Available at: http://www.nfhsindia.org/factsheet.html. Accessed 4 May 2015.

9. Rural health statistics report 2004-15. Available at https://data.gov.in/catalog/rural-healthstatistics-india-2005\#web_catalog_tabs_block_10. Accessed 27 April 2015.

10. Ministry of Health and Family Welfare. National Health Mission. 2005-12. Available at http://nrhm.gov.in/nhm/nrhm/nrhm-framework-for-implementation.html. Accessed on 16 January 2014.

11. Gupta M, Angeli F, van Schayck OCP, Bosma H. Effectiveness of a multiple startegy community intervention to reduce maternala and child health inequalities in Haryana, North India: a mixed methods study protocol. Glob Health Action 2015; 8: 25987 http://dx.doi.org/10.3402/gha.v8.25987

12. Campbell OM, Graham WJ, Lancet Maternal Survival Series, steering group. Strategies for reducing maternal mortality: getting on with what works. Lancet 2006;368(9543):1284-99.

13. Jones G, Steketee RW, Black RE, Bhutta ZA, Morris SS, Bellagio Child Survival Study Group. How many child deaths can we prevent this year? Lancet 2003;362: 65-71.

14. Mosley WH, Chen LC. Child Survival: strategies for research. Popul Dev Rev 1984; 10: (Suppl).

15. Rustein OS. In: Setty-Venugopal V, Upadhyay UD, eds. Birth spacing: three to five saves lives. Population Reports, 2002 Series L (13). Baltimore: Johns Hopkins Bloomberg School of Public Health, Population Information Program. 2002.

16. Rustein OS. Factors associated with trends in infant mortality in developing countries during 1990s. Bull World Health Organ 2000;78: 1256-68.

17. National Health Mission. Organization structure of the Scheme. National Health Mission Haryana. 2005-12. Available at http://www.nrhmharyana.gov.in/page.aspx?id=57. Accessed 25 March 2014.

18. National Rural Health Mission. Record of Proceedings to approve PIP of Haryana. 2005-12. Avaialble at http://www.nrhmharyana.gov.in/files/ROP\%202009-10.pdf. Accessed on 6 April 2015.

19. Common Review Mission. Ministry of Health and Family Welfare. Government of Inida. New Delhi. 2005-12. Available at http://nrhm.gov.in/monitoring/common-review-mission/1stcommon-review-mission.html. Accessed on 4 September, 2013.

20. Joint Review Mission. Ministry of Health and Family Welfare. Government of Inida. New Delhi. 2005-12. Available at http://nrhm.gov.in/monitoring/joint-review-mission.html. Accessed on 4 September, 2013.

21. International Institute of Population Sciences. District Level Household survey-4. State Fact Sheet Haryana. Ministry of Health and Family Welfare. New Delhi. India. 2012-13.

22. Prinja S, Jeet S, Kaur M, Aggarwal AK, Manchanda N, Kumar R. Impact of referral transport system on institutional deliveries in Haryana, India. Indian J Med Res 2014; 139(6):883-891. 
23. Singh SR. Public health spending and population health: a systematic review. Am J Prev Med 2014;47(5):634-40. doi: 10.1016/j.amepre.2014.05.017. Epub 2014 Jul 29.

24. Bekemeier $\mathrm{B}^{1}$, Dunbar $\mathrm{M}$, Bryan $\mathrm{M}$, Morris ME. Local health departments and specific maternal and child health expenditures: relationships between spending and need. JPublic Health Manag Pract. 2012;18(6):615-22.

25. Farag $\mathrm{M}^{1}$, Nandakumar AK, Wallack S, Hodgkin $\mathrm{D}$, Gaumer G, Erbil C. Health expenditures, health outcomes and the role of good governance. Int J Health Care Finance Econ 2013;13(1):33-52. doi: 10.1007/s10754-012-9120-3.

26. Prinja S, Kumar M, Pinto AD, Jan S, Kumar R. Equity in Hospital Services Utilization in India. Economic and Political Weekly. 2013; XLVIII (2): 52-58.

27. Prinja S, Kanavos P, Kumar R. Health Care Inequities in North India: Role of Public Sector in Universalizing Health Care. Indian J Med Research. 2012; 136: 145-55.

28. Colerbranber S, Birungi C, Mbonye AK. Consensus and contention in the priority setting process: Examining the health sector in Uganada. Health Policy Plan 2015;30(5):555-65.

29. Shenghelia B, Murray CJL, Adams OB et al. Beyond access and utilization: defning and measuring health system coverage. In: Murray CJL, Evans DB, eds. Health systems performance assessment: debates, methods and empiricism. Geneva, World Health Organization. 2003:221-235.

30. Concurrent Audit of NHM Haryana at District Level. 2014-15. Available at http://www.nrhmharyana.gov.in/Writereaddata/userfiles/file/pdfs/concurrent_audit_2014_15_ districts.pdf. Accessed on 25 March 2015.

31. Adam T, Hsu J, Savigny de D, Lavis JN, Rottingen JA, Bennett S. Evaluating health systems strengthening interventions in low-income and middle-income countries: are we asking the right questions? Health Policy Plan 2012 ; 27 (suppl 4): iv9-iv19.

32. Witter S, Jones A, Ensor T. How to (or not to).....measure performance against the Abuja target for public health expenditure. Health Policy Plan 2014; 29:450-455. doi: 10.1093/heapol/czt031

33. Berman P. Health sector reform: making health development sustainable. Health Policy 1995;32(1-3):13-28.

34. Brinkerhoff DW, Bossert TJ. Health governance: principal-agent linkages and health system strengthening. Health Policy Plan 2014;29(6):685-93.

35. Kaur M, Prinja S, Kumar P, Kumar R. Decentralization of health services in India: barriers and facilitating factors. WHO South-East Asia Journal of Public Health 2012;1(1):94-104.

36. Rao KS, Selvaraju S, Nagpal S, Sakthivel S. Financing of Health in India. Financing and Delivery of Health Care Services in India. 2005. Available at http://aksocculthelp.yolasite.com/resources/Health_Financing_of_Health_in_India.pdf. Accessed on 6 May 2015.

37. Brixi H, Mu Yan, Targa B, Hipgrave D. Engaging sub-national governments in addressing health equities: challenges and opportunities in China's health system reform. Health Policy Plan 2013; 28:809-824 doi:10.1093/heapol/czs120.

38. World Bank. China 2030: Building a Modern, Harmonious, and Creative High-Income Society. Washington DC: The World Bank. 2012.

39. Planning Commission. Evaluation study of National Rural Health Mission (NRHM) in seven states. Programme Evaluation Organization. Government of India. 2011. Available at http://planningcommission.nic.in/reports/peoreport/peoevalu/peo_2807.pdf. Accessed on 29 June 2014.

40. Leonard SC. Systems approach - what is it? In: Introduction to the systems approach. Reprinted from Educational Technology Magazine. New Jersey. USA. 1973:1-2.

41. Zanakis SH, Tomislav Mandakovic T, Gupta SK, Sahay S, Hong S. A review of program evaluation and fund allocation methods within the service and government sectors. SocioEconomic Planning Sciences 1995;29(1):59-79. 


\section{Chapter 4}

Effectiveness of multiple-strategy community intervention in reducing geographical, socioeconomic and gender based inequalities in maternal and child health outcomes in Haryana, India.

Madhu Gupta , Federica Angeli, Hans Bosma, Monica Rana, Shankar Prinja, Rajesh Kumar, Onno CP van Schayck

Plos One. 2016; 11(3): e0150537. doi:10.1371/journal.pone.0150537.

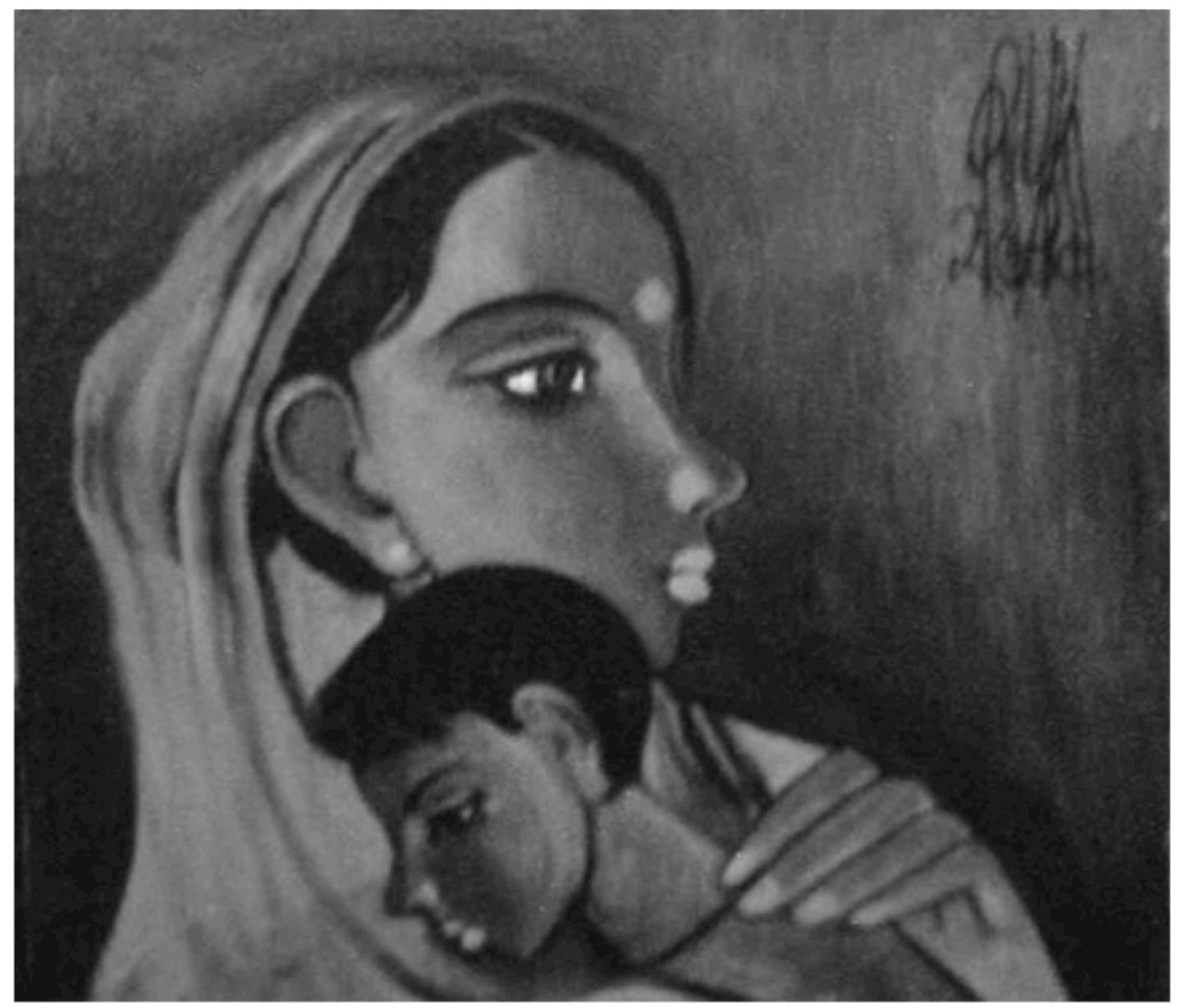




\begin{abstract}
Objective: The implemented multiple-strategy community intervention National Rural Health Mission (NRHM) between 2005 and 2012 aimed to reduce maternal and child health (MCH) inequalities across geographical, socioeconomic and gender categories in India. The objective of this study is to quantify the extent of reduction in these inequalities pre- and post-NRHM in Haryana, North India.
\end{abstract}

Methods: Data of district-level household surveys (DLHS) held before (2002-04), during (2007-08), and after (2012-13) the implementation of NRHM has been used. Geographical, socioeconomic and gender inequalities in maternal and child health were assessed by estimating the absolute differences in $\mathrm{MCH}$ indicators between urban and rural areas, between the most advantaged and least advantaged socioeconomic groups and between male and female children. Logistic regression analyses were done to observe significant differences in these inequalities between 2005 and 2012.

Results: There were significant improvements in all $\mathrm{MCH}$ indicators $(\mathrm{p}<0.05)$. The geographical and socioeconomic differences between urban and rural areas, and between rich and poor were significantly $(\mathrm{p}<0.05)$ reduced for pregnant women who had an institutional delivery (geographical difference declining from $22 \%$ to $7.6 \%$; socioeconomic from $48.2 \%$ to $13 \%)$, post-natal care within 2 weeks of delivery ( $2.8 \%$ to $1.5 \% ; 30.3 \%$ to $7 \%$ ); and for children with full vaccination (10\% to $3.5 \%, 48.3 \%$ to $14 \%$ ) and who received oral rehydration solution (ORS) for diarrhea (11\% to $-2.2 \% ; 41 \%$ to $5 \%)$. Inequalities between male and female children were significantly $(\mathrm{p}<0.05)$ reversed for full immunization $(5.7 \%$ to $-0.6 \%)$ and BCG immunization $(1.9$ to -0.9 points $)$, and a significant $(\mathrm{p}<0.05)$ decrease was observed for oral polio vaccine $(4.0 \%$ to $0 \%)$ and measles vaccine $(4.2 \%$ to $0.1 \%)$.

Conclusions: The implemented multiple-strategy community intervention National Rural Health Mission (NRHM) between 2005 and 2012 might have resulted in significant reductions in geographical, socioeconomic and gender inequalities in $\mathrm{MCH}$ in Haryana, as causal relationships cannot be established with descriptive research. 


\section{Introduction}

Maternal and child health (MCH) inequalities across socioeconomic, geographical and gender gradient is a public health concern worldwide [1,2]. This gap is much more widened in the low and middle-income group countries because of unequal distribution of resources and health facilities. In a retrospective review done by using demographic health surveillance data from 54 countries, marked $\mathrm{MCH}$ inequalities in low and middle-income group countries including India were observed $[3,4]$. In India, the maternal mortality ratio (MMR) is still as high as 167 per hundred thousand live births [5] and the infant mortality rate (IMR) is 40 deaths per thousand live births [6]. There is geographical inequality in $\mathrm{MCH}$ outcomes, like IMR is higher in rural (44 per thousand live births) as compared to urban areas (27 per thousand live births) [6]. Large geographical and socioeconomic inequalities in $\mathrm{MCH}$ status and access to $\mathrm{MCH}$ services continue to persist in India and have even widened across states, between rural and urban areas, and within communities [7]. There are MCH interventions available to improve $\mathrm{MCH}$ outcomes and reduce inequalities, however because of the issues at the level of implementation of these interventions that influence the accessibility and availability of health services especially to the most needy, these inequalities are not reduced. [8-10].

This persistence of MCH inequalities indicates the need to assess how the existing national health programs or policies on $\mathrm{MCH}$ are being implemented to tackle this issue in India. Simultaneously, it indicates the need for studies presenting evidence on the effectiveness of these programs, as these are highly resource-intensive interventions. Such assessments are useful for policy makers in resource constraint country like India in changing the policy or implementation strategy of these interventions.

Indian government had launched a multiple-strategy community intervention to reduce MCH inequalities across socioeconomic, geographical and gender gradient known as the National 
Rural Health Mission (NRHM). It was started in 2005 in the $11^{\text {th }}$ health plan (2005 to 2012), and continued in $12^{\text {th }}$ health plan (2013 to 2017)] as National Health Mission at national level. The aim was to reduce health inequalities by improving the availability of and access to better-quality healthcare, especially for people residing in rural areas (to reduce geographical inequality), for the poor (to reduce socioeconomic inequality), and for women and children (to reduce gender inequality) [11. NRHM's health sector plans included health system strengthening, specific MCH strategies/schemes [under reproductive and child health program (RCH-II)], and communitization (delegating powers to and empowering the community to monitor the healthcare delivery system) [12]. Details of these plans are given in previously published study protocol [13].

Briefly, health system strengthening included strengthening the health infrastructure, providing free drugs and logistics and telemedicine facilities, availability of mobile medical units and patient transport services. MCH schemes included cash incentives for hospital deliveries (Janani Suraksha Yojna), free delivery services for pregnant women and treatment of neonatal illnesses in hospitals and reimbursements of travel cost to hospitals (Janani Shishu Suraksha Karyakaram), and appointing Accredited Social Health Activists (ASHAs) to promote the access to improved healthcare at household level in villages. The intention was to reduce the infant mortality rate to $30 / 1,000$ live births, and maternal mortality to $1 / 1,000$ live births.

The objective of this study is to quantify the extent of reduction in $\mathrm{MCH}$ inequality across geographical, socioeconomic and gender sectors by using the data of demographic health surveys, held pre (2003-04), during (2007-08) and post (2012-13) NRHM implementation in Haryana, North India. The added value of looking at the data during the implementation (District level Household Survey - 3, 2007-08) is to have information on the trend of MCH status and inequalities, since the implementation of NRHM health sector plans was gradual in 
the state. Referral transport services, human resources, drugs and logistics, ASHA scheme, and immunization were fully implemented, while all other schemes were only partially implemented. It took these schemes between 4 to 5 years to achieve full implementation [14]. The results of this study would inform the policy makers on the NRHM's plans that have been most effective in meeting its MCH goals. Funds could accordingly be allocated to those plans that have demonstrated highest adoption and effectiveness or conversely be directed to those that have suffered under-funding but are likely to be successful with proper financial support during the implementation of the second stage of the NRHM (2013-17).

\section{Materials and Methods}

\section{Ethics Statement}

Authors had received the ethical approval from Post Graduate Institute of Medical Education and Research (PGIMER), Chandigarh, India, to conduct this study.

\section{Setting}

The state chosen for this study was Haryana in North India, as it is representative of other North Indian states with similar socioeconomic development and sociocultural factors, such as the preference to have sons, female feticide, lower sex ratios and lower social status of women. At the same time, Haryana represents a unique context by being a prosperous state with a rising economy but with unequal distribution of resources, which has led to wide intrastate and inter-district differences. Despite being one of the richer states, reporting the highest per capita income in the country at INR 1,09,064 (USD 1947.6) during 2012-13, $\mathrm{MCH}$ indicators are not the best in the country [15]. The state is divided into 21 districts, with a total population of $2,53,53,081$ (70\% rural), reports a birth rate of 21.3 , a death rate of 6.3 per thousand mid-year population, and a total fertility rate of $2.3[5,6]$. The health care delivery system has been described in detail in chapter 2 [16]. 


\section{Data and Sample}

The source of data in this study was nationally representative demographic health survey known as District Level Household Survey (DLHS). DLHS provides consistent and reliable estimates of status of maternal health including antenatal care (ANC), natal and post natal care (PNC); child health care including immunization status; and utilization of $\mathrm{MCH}$ services at district level [17]. It also provides information on status of MCH services at different health facilities including sub center (SC), primary health center (PHC), community health center (CHC) and district hospital (DH). Till now four rounds of DLHS has been conducted by Ministry of Health and Family Welfare, Government of India though an external agency (International Institute for Population Sciences). Surveys were implemented through regional agencies by appointing a team of five persons, consisting of one supervisor, one field editor and three female investigators, who were at least graduates.

Because the second round (DLHS-2) was conducted during the year 2002-04, the third round (DLHS-3) in 2007-08 and the fourth round (DLHS-4) in 2012-13, the three waves of data collection reflected the situation before, during and after NRHM implementation, respectively. Hence, all data of these rounds of surveys were included in this study for analysis. DLHS-2 provided information on how well RCH-II program was performing, DLHS-3 on health facility's capacity and preparedness in terms of infrastructure when NRHM was being implemented so as to take corrective measures, and DLHS-4 on achievements and improvements after seven years of implementation of NRHM.

Detailed methodology of these surveys has been given in DLHS 2, 3 and 4 reports [18-21]. Briefly, a multi-stage stratified systematic sampling design was adopted in all the rounds to select 50 primary sampling units, which were census villages in rural areas and census enumeration blocks in urban areas in each district. Data was collected by using pretested structured questionnaires, namely, household, ever married woman, village and facility, 
which were typed in bilingual languages (regional and English). The same core sets of questionnaires were used in each survey so that comparisons could be drawn. The facility survey was conducted during DLHS-3 and 4 rounds only. Method of data collection was interview. Taking account of the multi-stage stratified systematic sampling, the DLHS researchers had applied weights to estimate the percentages of the $\mathrm{MCH}$ indicators. The percentages are then representative for the respective populations in Haryana in the different periods.

Background information of households during three surveys is given in Table 1. Data was collected from 18,796, 20,394, and 27,414 currently married women aged 15-49 years during DLHS 2 (aged 15-44 years), 3 and 4, respectively. About 990 and 1,046 health facilities were visited for facility survey during DLHS 3 and DLHS 4, respectively. The response rate varied from $85 \%$ to $95 \%$ for households and married women, respectively in all the surveys.

In addition to demographic health survey data, data of concurrent evaluation of NRHM in Haryana (held during 2012-13) was used for obtaining wealth quintile wise information on MCH indicators post NRHM, as this was unavailable in DLHS-4 report. Data of concurrent evaluation study was collected from 18,227 currently married women aged 15-49 years quarterly in all the districts in Haryana by School of Public health, PGIMER, post-NRHM, by using the same methodology as was used in DLHS, hence results were comparable [22]. The difference in concurrent study and DLHS is that data was collected on regular basis in concurrent study, while once in DLHS.

\section{Measures and Data Analysis}

List of independent and dependent variables considered in this study is given in Table 2 . Independent variables were socioeconomic variables i.e., standard of living (DLHS 2) / wealth index (DLHS 3), place of residence (rural or urban) and gender of the child (male or female), as available from survey data. 
Table 1. Background information of population and households surveyed and characteristics of women interviewed during DLHS round 2, 3 and 4 .

\begin{tabular}{|c|c|c|c|c|c|c|c|c|c|}
\hline \multirow{3}{*}{$\begin{array}{l}\text { Indicators } \\
\text { Sample Size }\end{array}$} & \multirow{2}{*}{\multicolumn{3}{|c|}{$\begin{array}{l}\text { Pre NRHM } \\
\text { DLHS-2 (2002-04) }\end{array}$}} & \multirow{2}{*}{\multicolumn{3}{|c|}{$\begin{array}{l}\text { During NRHM } \\
\text { DLHS-3 (2007-08) }\end{array}$}} & \multirow{2}{*}{\multicolumn{3}{|c|}{$\begin{array}{l}\text { Post NRHM } \\
\text { DLHS-4 (2012-13) }\end{array}$}} \\
\hline & & & & & & & & & \\
\hline & Total & Rural & Urban & Total & Rural & Urban & Total & Rural & Urban \\
\hline Households surveyed & 20,205 & 13,832 & 6,373 & 21,406 & 15,615 & 5,791 & 33,772 & 19,216 & 14,556 \\
\hline $\begin{array}{l}\text { Currently married women age 15-49 } \\
\text { years }\end{array}$ & 18,796 & 13,307 & 5,489 & 20,394 & 15,306 & 5,088 & 27,414 & 16,093 & 11,321 \\
\hline \multicolumn{10}{|l|}{ Profile of population } \\
\hline Literate age $7+$ years $(\%)$ & 70.9 & 66.1 & 81.9 & 73.4 & 70.2 & 82.7 & 77.7 & 73.5 & 85.5 \\
\hline Below age 15 years $(\%)$ & 12.2 & 12.4 & 11.6 & 32.2 & 33.1 & 29.3 & 26.7 & 27.7 & 24.8 \\
\hline Mean household size & 5.5 & 5.6 & 5.1 & 5.2 & 5.4 & 4.9 & 4.9 & 5.1 & 4.6 \\
\hline Sex ratio at birth & 113 & 113 & 113 & 110 & 109 & 112 & 113 & 112 & 114 \\
\hline \multicolumn{10}{|l|}{ (Males per 100 Females) } \\
\hline \multicolumn{10}{|l|}{ Percentage of households } \\
\hline Having electricity & 91.2 & 88.2 & 97.8 & 92.4 & 90.5 & 97.5 & 97.7 & 97.2 & 98.7 \\
\hline Improved source of drinking water & 91.7 & 78.5 & 98.8 & 96.0 & 94.7 & 99.5 & 99.1 & 98.9 & 99.4 \\
\hline $\begin{array}{l}\text { Having access to improved toilet } \\
\text { facility }\end{array}$ & 48.7 & 31.0 & 87.5 & 50.7 & 39.0 & 82.1 & 83.9 & 77.5 & 94.8 \\
\hline
\end{tabular}




\section{Education of currently married women aged 15-49 (15-45 years in DLHS 2) years (\%)}

$\begin{array}{llllllrrrr}\text { Illiterate } & 44.6 & 52.0 & 26.8 & 38.8 & 43.4 & 24.9 & 33.9 & 40.0 & 23.4 \\ \text { with 10 or more years of schooling } & 24.5 & 15.7 & 45.9 & 25.9 & 19.9 & 44.5 & 37.5 & 28.0 & 53.9\end{array}$


Standard of living index is a composite measure that was computed for classifying the households into low, medium and high standard on the basis of scores during DLHS 2. Scores were given after considering household amenities such as source of drinking water, type of house, source of lighting, fuel for cooking, toilet facility and ownership of durable goods. Wealth index is computed by combining the household amenities, assets and durables at the national level and then dividing into quintiles (lowest, second, middle, fourth and highest). It was computed in DLHS 3 and in concurrent evaluation study.

Table 2. List of independent and dependent variables.

\begin{tabular}{|c|c|c|}
\hline \multirow{2}{*}{$\begin{array}{l}\text { Independent } \\
\text { Variables } \\
\text { Geographical }\end{array}$} & \multicolumn{2}{|l|}{ Dependent Variables } \\
\hline & Maternal Health Indicators & MCH Tracer indicators \\
\hline Type of Locality & $\begin{array}{l}\text { Antenatal care: Pregnant women } \\
\text { who had }\end{array}$ & Antenatal Care \\
\hline Rural & & Three or more ANC \\
\hline Urban & Registration in the first trimester & Full ANC check up \\
\hline $\begin{array}{l}\text { Standard of living } \\
\text { index/Wealth quintile }\end{array}$ & $\begin{array}{l}\text { Three or more ANC } \\
\text { Full ANC check up }\end{array}$ & $\begin{array}{l}\text { Received two TT } \\
\text { injections }\end{array}$ \\
\hline Low/lowest quintile & At least one TT injection & $\begin{array}{l}\text { Consumed IFA for at } \\
\text { least } 3 \text { months }\end{array}$ \\
\hline Middle/Mid quintile & Consumed IFA for at least 3 months & Natal Care (\%) \\
\hline Second quintile & Natal Care (\%) & Institutional delivery rate \\
\hline High/Highest quintile & Institutional delivery rate & Post Natal Care (\%) \\
\hline Gender & Safe delivery & $\begin{array}{l}\text { Mothers who received } \\
\text { post natal care within } 2\end{array}$ \\
\hline Sex of child & $\begin{array}{l}\text { Post Natal Care }(\%) \text { : Mothers who } \\
\text { received post natal care within }\end{array}$ & $\begin{array}{l}\text { weeks of delivery } \\
\text { Immunization }(\%)\end{array}$ \\
\hline Male child & $\begin{array}{l}48 \text { hours of delivery } \\
2 \text { weeks of delivery }\end{array}$ & $\begin{array}{l}\text { Children age } 12-23 \\
\text { months who received }\end{array}$ \\
\hline & Child Health Indicators & Full vaccination \\
\hline & $\begin{array}{l}\text { Immunization (\%): Children age 12- } \\
23 \text { months who received }\end{array}$ & $\begin{array}{l}\text { Children with illness in } \\
\text { the last } 2 \text { weeks where }\end{array}$ \\
\hline & Full vaccination & $\begin{array}{l}\text { Mother gave ORS for } \\
\text { diarrhoea }\end{array}$ \\
\hline
\end{tabular}


No vaccination

BCG vaccination

DPT vaccine

OPV vaccine

\section{Breast Feeding Practices}

Women awareness about

Diarrhea management

ARI

Prevalence of Diarrhoea/ARI

Children with illness in the last 2 weeks where mother gave ORS for diarrhoea

\section{Impact Indicators}

Maternal Mortality Ratio

Infant Mortality Rate

\section{Geographical inequality}

Absolute difference in maternal and child health indicators between urban and rural areas

\section{Socioeconomic inequality}
Absolute difference in maternal and child health indicators between most advantaged and least advantaged socioeconomic groups (i.e., low vs high standard of living index, lowest vs highest quintile of wealth index)

From the list of various $\mathrm{MCH}$ indicators tracer indicators (dependent variables) were selected for the respective $\mathrm{MCH}$ situation, so as to have information on these selected indicators across geographical, socioeconomic and gender gradient. Tracer indicators were selected from the larger list because these were key indicators representative of each major aspect of maternal care and child preventive and treatment interventions. These indicators were similar to the ones chosen for tracking the progress for maternal, newborn and child survival as part 
of countdown to 2015 to meet the MCH millennium development goals for India [23]. Hence for maternal health, antenatal care indicators were: pregnant women who had three or more antenatal check ups, received two tetanus toxoid (TT) injection, consumed 100 iron folic acid (IFA) tablets, received full antenatal check-up. Natal care indicator was institutional delivery, while post-natal care indicator was post-natal check-up within two weeks of delivery. For child health, indicators were full immunization of a children aged between 12-23 months and children who received oral rehydration solution (ORS) for diarrhea management. Information on indicators on the distance and availability of health services for $\mathrm{MCH}$ was also obtained. Information on MMR and IMR were available at the state level and obtained from the Sample Registration System [5,6]. Information on MMR was not available across geographical or socioeconomic gradient, while IMR was available across geographical gradient from Sample Registration System [6]. Geographical, socioeconomic, and gender inequality in $\mathrm{MCH}$ was assessed by estimating the absolute differences (range) in $\mathrm{MCH}$ indicators between urban and rural areas, between the most advantaged and least advantaged socioeconomic groups (excluding maternal and child mortality indicators), and between male and female children.

Data was analyzed using Microsoft Excel and Statistical Package for Social Sciences (SPSS) version 16. Individual data of rounds 2 and 3 and aggregated data of round 4 of DLHS and concurrent evaluation study were used for analysis. Outcome variables and inequality measures were compared before, during and after the introduction of the NRHM, from 200204 to 2012-13, to assess improvements in $\mathrm{MCH}$ outcomes and inequalities in Haryana. Since the NRHM is implemented in all areas in Haryana, the situation during the pre-NRHM implementation period served as a control. It is expected that rate difference score either decreased or reached near to 0 post NHRM. The un-weighted numbers were available for the $\mathrm{MCH}$ indicators in each group (rural/urban, poor/rich, male/female) and for each respective time period (pre, during and post NRHM). The reported weighted percentages and the unweighted numbers allowed the reconstruction of cross-tabulations (e.g. rural-urban differences regarding three or more antenatal care visits) for the three separate periods. $\mathrm{Chi}^{2}$ 
tests then indicated whether there was a significant difference (e.g. rural-urban) within each period. Testing the statistical significance of the interaction between the inequality measures (e.g. urban-rural) and period (2002-2004, 2007-2008, and 2012-2013), logistic regression analyses indicated whether these differences changed across time (e.g. whether the urbanrural difference decreased between 2002-2004 and 2012-2013). A p-value of 0.05 was used.

\section{Results}

Overall improvements were observed in proportion of literate population of age 7 years and above from $70.9 \%$ to $77.7 \%$, currently married women with 10 or more years of schooling from $24.5 \%$ to $37.5 \%$, households with electricity from $91.2 \%$ to $97.7 \%$, access to improved toilet facilities from $48.7 \%$ to $83.9 \%$, wealth index from $19.3 \%$ in low rank to $9 \%$ in low \& second quintile. Nearly $70 \%$ of women were belonging to rural area and $90 \%$ of the households to Hindu religion. (Table 1).

\section{Maternal and child health outcomes}

Status of $\mathrm{MCH}$ indicators pre, during and post NRHM implementation in Haryana as per DLHS rounds 2, 3 and 4 is given in Table 3. Reference period for obtaining the MCH related history was three years preceding the respective surveys. The proportions of pregnant women having three or more ANCs increased significantly $(\mathrm{p}<0.05)$ from $43.1 \%$ to $74.5 \%$, at least one TT injection from $83.5 \%$ to $93.6 \%$, institutional delivery from $35.7 \%$ to $76.9 \%$, PNC within 2 weeks of delivery from $8.9 \%$ to $69.0 \%$; and children who received ORS for diarrhea from $32.3 \%$ to $44.8 \%$. MMR although had declined from 1.85 per thousand live births (200204) to 1.21 per thousand live births (2012-13) at state level, yet the decline was not significant. IMR had declined significantly $(\mathrm{p}<0.05)$ from 61 to 41 per thousand live births. 
Table 3. Status of maternal and child health indicators pre, during and post NRHM implementation in Haryana as per DLHS rounds 2, 3 and 4.

\begin{tabular}{|c|c|c|c|c|}
\hline Indicators & $\begin{array}{l}\text { Pre NRHM } \\
\text { (2002-2004) }\end{array}$ & $\begin{array}{l}\text { During } \\
\text { NRHM } \\
(\mathbf{2 0 0 7 - 2 0 0 8 )}\end{array}$ & $\begin{array}{l}\text { Post NRHM } \\
\text { (2012-2013) }\end{array}$ & P value \\
\hline Maternal Mortality Ratio & 1.86 & 1.53 & 1.21 & 0.13 \\
\hline Infant Mortality Rate & 61 & 55 & 41 & 0.09 \\
\hline \multicolumn{5}{|c|}{ Antenatal care (\%): Pregnant women } \\
\hline $\begin{array}{l}\text { Registered in the first } \\
\text { trimester }\end{array}$ & 13.7 & 55.1 & 82.1 & 0.00 \\
\hline With three or more ANC & 43.1 & 51.9 & 74.5 & 0.00 \\
\hline With full ANC check up & 11.8 & 13.3 & 21.8 & 0.06 \\
\hline $\begin{array}{l}\text { Who got at least one TT } \\
\text { injection }\end{array}$ & 83.5 & 86.1 & 93.6 & 0.04 \\
\hline Two TT injections & 77.5 & 79.4 & 58.1 & 0.05 \\
\hline $\begin{array}{l}\text { Who had at least } 100 \text { IFA } \\
\text { tablets }\end{array}$ & 16.5 & 29.0 & 29.5 & 0.00 \\
\hline \multicolumn{5}{|l|}{ Natal care $(\%)$} \\
\hline Institutional delivery rate & 35.7 & 46.9 & 76.9 & 0.00 \\
\hline $\begin{array}{l}\text { Safe deliveries (Deliveries } \\
\text { assisted by skilled birth } \\
\text { attendants) }\end{array}$ & 43.9 & 53.4 & 91.0 & 0.00 \\
\hline \multicolumn{5}{|c|}{ Post natal care (\%): Mothers who received post natal care within } \\
\hline 48 hours of delivery & NA & 48.8 & 67.2 & 0.01 \\
\hline 2 weeks of delivery & 8.9 & 49.5 & 69 & 0.07 \\
\hline
\end{tabular}

Child Health (\%): Children aged 12-23 months who received

$\begin{array}{lllll}\text { Full immunization } & 59.1 & 59.6 & 52.1 & 0.28 \\ \text { No vaccination } & 11.8 & 1.9 & 5.9 & 0.00 \\ \text { BCG vaccine } & 83.5 & 86.5 & 84.2 & 0.96 \\ \text { 3 doses of DPT vaccine } & 72.9 & 67.9 & 71.1 & 0.72 \\ \text { 3 doses of polio vaccine } & 73.6 & 69.0 & 72.7 & 0.83 \\ \text { Measles vaccine } & 65.4 & 69.0 & 70.0 & 0.53\end{array}$




\section{Breast feeding practices (\%)}

Exclusively breast fed for $\quad 33.0$

$\begin{array}{lll}5.7 & 27.4 & 0.00\end{array}$

atleast 6 months

Women awareness about

Diarrhoea Management

49.8

79.0

81.7

0.00

Danger signs of Acute

49.8

76.3

75.2

0.00

respiratory infection

Percentage of women whose child suffered from ${ }^{*}$

Diarrhoea

18.1

16.0

4.0

0.00

ARI

10.8

8.3

3.6

0.00

Childhood Diseases: Children with (illness reported in last two weeks)

\begin{tabular}{lcccc}
$\begin{array}{l}\text { Diarrhoea who received } \\
\text { ORS }\end{array}$ & 32.3 & 31.7 & 44.8 & 0.08 \\
$\begin{array}{l}\text { Diarrhoea who sought } \\
\text { advise/treatment }\end{array}$ & 78.4 & 82.0 & 68.7 & 0.05 \\
$\begin{array}{l}\text { Acute respiratory infection } \\
\text { who sought } \\
\text { advise/treatment }\end{array}$ & 78.0 & 88.1 & 85.5 & 0.5 \\
\hline
\end{tabular}

\section{Geographical inequalities}

The difference (Diff) between $\mathrm{MCH}$ indicators in urban and rural areas pre, during and post NRHM implementation as per DLHS rounds 2, 3 and 4 is given in Table 4. Significant $(\mathrm{p}<0.05)$ decline in difference of MCH indicators between urban and rural areas was observed for proportion of pregnant women who had three ANCs from 23\% to 5.4\%, full ANC check ups from $8.0 \%$ to $6.8 \%$, institutional delivery from $29.0 \%$ to $7.6 \%$, PNC with in 2 weeks of delivery from $2.8 \%$ to $1.5 \%$; children who received full vaccination (children age 12-23 months who have received all the primary vaccines i.e., Bacillus Calmitte Guerin (BCG) vaccine for tuberculosis; 3 doses of Diptheria pertussis and tetatnus vaccine (DPT), 3 doses of Oral Polio Vaccine (OPV) and measles vaccine) from $10.0 \%$ to $3.5 \%$ and ORS for diarrhea from $11.0 \%$ to $-2.2 \%$. $\mathrm{P}$ value shown in Table 4 indicates statistically significant difference in geographical inequality across time periods. The difference in urban and rural areas for 
proportion of pregnant women who had PNC with in two weeks of delivery, children with full vaccination and who received ORS became non significant in the post NRHM period.

Table 4. Geographical inequalities in maternal and child health indicators in rural and urban area during pre, during and post NRHM implementation (expressed as absolute difference in proportion of indicators in urban and rural area).

\begin{tabular}{|c|c|c|c|c|c|c|c|c|c|c|}
\hline \multirow[t]{2}{*}{ Indicators } & \multicolumn{3}{|c|}{$\begin{array}{l}\text { Pre NRHM (2002- } \\
\text { 2004) }\end{array}$} & \multicolumn{3}{|c|}{$\begin{array}{l}\text { During NRHM } \\
(2007-2008)\end{array}$} & \multicolumn{3}{|c|}{$\begin{array}{l}\text { Post NRHM (2012- } \\
\text { 2013) }\end{array}$} & \multirow[t]{2}{*}{$\begin{array}{l}\mathbf{P} \\
\text { value }\end{array}$} \\
\hline & $\mathbf{R}$ & $\mathbf{U}$ & Diff & $\mathbf{R}$ & $\mathbf{U}$ & Diff & $\mathbf{R}$ & $\mathbf{U}$ & Diff & \\
\hline \multicolumn{11}{|c|}{ Maternal Health: Women who had (\%) } \\
\hline $\begin{array}{l}\text { Three or more } \\
\text { ANC }\end{array}$ & 40.8 & 63.9 & $23.0^{*}$ & 47.2 & 66.1 & $18.9^{*}$ & 72.4 & 77.8 & $5.4^{*}$ & 0.00 \\
\hline $\begin{array}{l}\text { Full ANC } \\
\text { check up }\end{array}$ & 9.5 & 17.9 & $8.0 *$ & 10.2 & 22.6 & $12.4^{*}$ & 19.2 & 26.0 & $6.8^{*}$ & 0.00 \\
\hline $\begin{array}{l}\text { Received two } \\
\text { TT injections }\end{array}$ & 75.0 & 84.3 & $9.3 *$ & 76.9 & 87.0 & $10.1 *$ & 54.4 & 65.2 & $10.8 *$ & 0.02 \\
\hline $\begin{array}{l}\text { Consumed } \\
\text { IFA for at } \\
\text { least } 3 \text { months }\end{array}$ & 15.9 & 21.6 & $6.0 *$ & 28.1 & 31.7 & $3.6^{*}$ & 27.6 & 32.6 & $5.0^{*}$ & 0.08 \\
\hline $\begin{array}{l}\text { Institutional } \\
\text { delivery rate }\end{array}$ & 27.3 & 56.4 & $29.0 *$ & 42.2 & 61.4 & $19.2 *$ & 74.3 & 81.9 & $7.6^{*}$ & 0.00 \\
\hline $\begin{array}{l}\text { PNC with in } 2 \\
\text { weeks of } \\
\text { delivery }\end{array}$ & 9.6 & 6.8 & $2.8^{*}$ & 46.5 & 58.7 & $12.2 *$ & 68.5 & 70.0 & 1.5 & 0.00 \\
\hline \multicolumn{11}{|c|}{ Child Health (\%) } \\
\hline $\begin{array}{l}\text { Children age } \\
12-23 \text { months } \\
\text { who received } \\
\text { Full } \\
\text { vaccination }\end{array}$ & 56.7 & 66.3 & $10.0^{*}$ & 55.9 & 70.8 & $14.9^{*}$ & 51.0 & 54.5 & 3.5 & 0.00 \\
\hline $\begin{array}{l}\text { Children with } \\
\text { diarrhoea who } \\
\text { received ORS }\end{array}$ & 29.0 & 40.0 & $11.0^{*}$ & 28.3 & 44.2 & $15.9^{*}$ & 45.6 & 43.4 & -2.2 & 0.01 \\
\hline $\begin{array}{l}\text { Infant } \\
\text { Mortality Rate } \\
\text { (per thousand } \\
\text { live births) }\end{array}$ & 66.0 & 47.0 & $19.0 *$ & 60.0 & 44.0 & $16.0^{*}$ & 44.0 & 32.0 & $12^{*}$ & 0.09 \\
\hline
\end{tabular}

*p<0.05; R- Rural; U-Urban 


\section{Socioeconomic inequalities}

The difference between rich and poor was observed to be significantly $(\mathrm{p}<0.05)$ narrowed down for proportion of pregnant women who received 2 TT injection from $30.3 \%$ to $7.0 \%$, institutional deliveries from $48.2 \%$ to $13.0 \%$, fully immunized children from $48.3 \%$ to $14.0 \%$, proportion of children who received ORS for diarrhea from $40.7 \%$ to $5.0 \%$, in pre to post NRHM period. (Table 5). Although pregnant women who had three or more ANCs increased considerably among the least (16.8\% to $57.0 \%)$ and the highest socioeconomic group (17.0\% to $80.0 \%$ ), yet the improvement in this particular indicator was much more among those in the highest wealth quintile, resulting in increase in inequalities between lowest and highest wealth quintile groups post- NRHM implementation from $0.2 \%$ to $23.0 \%$. P value shown in Table 5 indicates statistically significant difference in the socioeconomic inequality across time periods.

\section{Gender inequalities}

Inequalities between male and female children was significantly $(\mathrm{p}<0.05)$ reversed for full immunization (5.7\% to $-0.6 \%$ ) and BCG immunization (1.9 to -0.9 points), and a significant $(\mathrm{p}<0.05)$ decrease was observed for oral polio vaccine $(4.6 \%$ to $0 \%)$ and measles vaccine (4.2\% to $0.1 \%$ ). (Table 6). $\mathrm{P}$ value shown in Table 6 indicates statistically significant difference in gender inequality across time periods.

There were certain indicators like the proportion of children fully immunized (from 59\% to $52 \%$ ) and exclusive breast-feeding rate for at least 6 months (from 33\% to 27.4\%), which had declined in the post NRHM period [Table 3]. However, geographical (from 10\% to $3.5 \%$ ), socioeconomic (from $48.3 \%$ to $14 \%$ ) and gender inequality (from $5.7 \%$ to $-0.6 \%$ ) for fully immunized children had shown a significant declining trend $(\mathrm{p}<0.05)$ in the post NRHM period. This was due to relatively higher decline in proportion of children with full immunization in urban areas (66.3\% to $54.5 \%)$ as compared to rural areas (56.7\% to $51 \%)$ [Table 4]; among males (62\% to 52\%) as compared to females (56\% to 52.5\%) [Table 6]; and 
Table 5. Trend of socioeconomic inequalities across various maternal and child health indicators in Haryana from pre to post NRHM.

\begin{tabular}{|c|c|c|c|c|c|c|c|c|c|c|}
\hline \multirow{3}{*}{$\begin{array}{l}\text { Maternal and Child Health } \\
\text { Indicators }(\%)\end{array}$} & \multirow{2}{*}{\multicolumn{3}{|c|}{$\begin{array}{l}\text { Pre NRHM (2002-04) } \\
\text { Standard of living } \\
\text { index }\end{array}$}} & \multirow{2}{*}{\multicolumn{3}{|c|}{$\begin{array}{l}\text { During NRHM (2007-08) } \\
\text { Wealth Index }\end{array}$}} & \multirow{2}{*}{\multicolumn{3}{|c|}{$\begin{array}{l}\text { Post NRHM (2012-13) } \\
\text { Wealth Index }\end{array}$}} & \multirow[t]{3}{*}{$\begin{array}{l}\mathbf{P} \\
\text { value }\end{array}$} \\
\hline & & & & & & & & & & \\
\hline & Low & High & Diff & Lowest & Highest & Diff & Lowest & Highest & Diff & \\
\hline \multicolumn{11}{|l|}{ Maternal Health: Women who had (\%) } \\
\hline Three or more ANC & 16.8 & 17.0 & 0.2 & 16.3 & 72.4 & $46.5^{*}$ & 57.0 & 80.0 & $23.0^{*}$ & 0.00 \\
\hline Full ANC check up & 3.6 & 20.1 & $16.5^{*}$ & 1.4 & 23.5 & $20.1 *$ & 20.0 & 36.0 & $16.0^{*}$ & 0.00 \\
\hline Received two TT injections & 58.5 & 88.5 & $30.3^{*}$ & 48.5 & 91.8 & $35.6^{*}$ & 77.0 & 84.0 & $7.0^{*}$ & 0.00 \\
\hline Consumed IFA for at least 3 months & 8.5 & 25.4 & $16.9^{*}$ & 2.2 & 28.1 & $22.3^{*}$ & 30.0 & 44.0 & $14.0^{*}$ & 0.00 \\
\hline Institutional delivery rate & 11.8 & 60.0 & $48.2 *$ & 14.8 & 70.9 & $52.5^{*}$ & 75.0 & 88.0 & $13.0^{*}$ & 0.00 \\
\hline PNC with in 2 weeks of delivery & 6.4 & 8.6 & $2.2 *$ & 26.9 & 66.7 & $39.8^{*}$ & 55.4 & 72.1 & $16.7^{*}$ & 0.00 \\
\hline \multicolumn{11}{|l|}{ Child Health (\%) } \\
\hline $\begin{array}{l}\text { Children (age } 12-23 \text { months) who } \\
\text { received Full vaccination }\end{array}$ & $\begin{array}{l}30 . \\
6\end{array}$ & 78.9 & $48.3^{*}$ & 28.5 & 74.4 & $44.4^{*}$ & 62.0 & 76.0 & $14.0^{*}$ & 0.00 \\
\hline $\begin{array}{l}\text { Children with diarrhoea who received } \\
\text { ORS }\end{array}$ & 7.8 & 48.5 & $40.7 *$ & 10.3 & 44.7 & $34.4 *$ & 32.0 & 37.0 & 5.0 & 0.00 \\
\hline
\end{tabular}


increase in proportion of children with full immunization among those belonging to lowest wealth quintile (30.6\% to $62 \%$ ) as compared to highest wealth quintile group (78.9 \% to 76\%). [Table 5].

Trend of availability and accessibility of health facilities from 2007-08 to 2012-13 in Haryana is presented in Table 7. Percentage of villages having ASHA's increased from $80.8 \%$ to 96.1\%. Accessibility of health facilities improved with proportion of villages with SCs center with in $3 \mathrm{~km}$ increased from $77.0 \%$ to $80.4 \%$ and PHCs with in $10 \mathrm{~km}$ from $82.3 \%$ to $87.3 \%$. Increase in availability of services observed for SCs with additional ANM (74.2\% to 83.5\%); PHCs functioning on $24 \times 7$ hours basis ( $39.2 \%$ to $79.3 \%$ ), having referral services for pregnancies/delivery on $24 \times 7$ hours basis ( $46.6 \%$ to $65.6 \%$ ), conducting at least 10 deliveries during last month on $24 \times 7$ hours basis ( $38.8 \%$ to $74.3 \%$ ); Community health centers (CHCs) having $24 \times 7$ hours normal delivery ( $88.1 \%$ to $100 \%)$, designated as first referral units $(44.1 \%$ to $71.7 \%$ ), having $24 \times 7$ new born care services (62.2\% to $91.5 \%)$; District hospitals having pediatrician $(77.7 \%$ to $95.2 \%)$, ultrasound facility (90.5\%), critical care area (44.4\% to $76.2 \%)$. 
Table 6. Child based gender inequalities in Haryana (expressed as absolute difference in proportion of indicators among male and female children).

\begin{tabular}{|c|c|c|c|c|c|c|c|c|c|c|}
\hline \multirow[t]{2}{*}{ Indicators (\%) } & \multicolumn{3}{|c|}{ Pre NRHM (2002-04) } & \multicolumn{3}{|c|}{ During NRHM (2007-08) } & \multicolumn{3}{|c|}{ Post NRHM (2012-13) } & \multirow{2}{*}{$\begin{array}{l}P \\
\text { value }\end{array}$} \\
\hline & $\begin{array}{l}\text { Male } \\
n=1221\end{array}$ & $\begin{array}{l}\text { Female } \\
n=993\end{array}$ & Diff & $\begin{array}{l}\text { Male } \\
\mathrm{n}=1178\end{array}$ & $\begin{array}{l}\text { Female } \\
\mathrm{n}=947\end{array}$ & Diff & $\begin{array}{l}\text { Male } \\
n=1142\end{array}$ & $\begin{array}{l}\text { Female } \\
n=896\end{array}$ & Diff & \\
\hline \multicolumn{11}{|c|}{ Children aged 12-23 months who received (\%) } \\
\hline $\begin{array}{l}\text { Full } \\
\text { Immunization }\end{array}$ & 61.8 & 56.1 & $5.7^{*}$ & 62.5 & 56.0 & $6.5^{*}$ & 51.9 & 52.5 & -0.6 & 0.00 \\
\hline No Vaccination & 11.3 & 12.7 & -1.4 & 1.7 & 2.1 & $-0.4^{*}$ & 6.5 & 6.8 & -0.3 & 0.00 \\
\hline BCG vaccine & 84.3 & 82.4 & 1.9 & 87.8 & 84.9 & $2.9^{*}$ & 83.8 & 84.7 & -0.9 & 0.00 \\
\hline $\begin{array}{l}3 \text { doses DPT } \\
\text { vaccine }\end{array}$ & 75.6 & 70.7 & 4.9 & 71.7 & 65.8 & $5.9^{*}$ & 72.2 & 73.5 & -1.3 & 0.00 \\
\hline $\begin{array}{l}3 \text { doses of OPV } \\
\text { vaccine }\end{array}$ & 74.7 & 70.1 & $4.6^{*}$ & 70.2 & 64.7 & $4.6^{*}$ & 71.1 & 71.1 & 0 & 0.00 \\
\hline Measles vaccine & 67.6 & 62.2 & $4.2^{*}$ & 70.9 & 66.7 & $5.4^{*}$ & 69.8 & 69.7 & 0.1 & 0.00 \\
\hline
\end{tabular}


Table 7. Trend of availability and accessibility of health facilities during and after NRHM implementation in Haryana.

\begin{tabular}{|c|c|c|}
\hline Indicator & $\begin{array}{l}\text { During NRHM } \\
(2007-08)\end{array}$ & $\begin{array}{l}\text { Post NRHM } \\
(2012-13)\end{array}$ \\
\hline Health programmes at village level & $\mathrm{N}=721$ & $\mathrm{~N}=708$ \\
\hline Percentage of villages having ASHA & 80.8 & 96.1 \\
\hline $\begin{array}{l}\text { Percentage of Villages having Village Health } \\
\text { Nutrition and Sanitation Committee }\end{array}$ & 68.2 & 43.5 \\
\hline \multicolumn{3}{|l|}{ Accessibility of health facility (\%) } \\
\hline Villages with Sub-Health Centre within $3 \mathrm{~km}$ & 77.0 & 80.4 \\
\hline Villages with PHC within $10 \mathrm{~km}$ & 82.3 & 87.3 \\
\hline $\begin{array}{l}\text { Availability of Health Infrastructure, Staff and } \\
\text { Services }(\%) \text { Sub-Health Centre }\end{array}$ & $N=625$ & $N=673$ \\
\hline Sub-Health Centre located in government building & 54.9 & 57.7 \\
\hline Sub-Health Centre with ANM & 92.3 & 90.6 \\
\hline Sub-Health Centre with male health worker & 51.8 & 58.2 \\
\hline $\begin{array}{l}\text { Sub-Health Centre with ANM residing in Sub- } \\
\text { Health Centre quarter where facility is available }\end{array}$ & 31.4 & 35.6 \\
\hline Sub-Health Centre with additional ANM & 74.2 & 83.5 \\
\hline Primary Health Centre (PHC) & $\mathrm{N}=\mathbf{2 6 3}$ & $N=246$ \\
\hline PHCs functioning on $24 \times 7$ hours basis & 39.2 & 79.3 \\
\hline PHCs having Lady Medical Officer & 30.8 & 34.2 \\
\hline PHCs with at least 4 beds & 64.3 & 75.7 \\
\hline $\begin{array}{l}\text { PHCs with AYUSH (Ayurveda, Unani, Sidha and } \\
\text { Homeopathy) doctor }\end{array}$ & 1.5 & 19.1 \\
\hline $\begin{array}{l}\text { PHCs having residential quarter for Medical } \\
\text { Officer }\end{array}$ & 43.0 & 47.9 \\
\hline $\begin{array}{l}\text { PHCs having new born care services on } 24 \times 7 \\
\text { hours basis }\end{array}$ & 94.2 & 91.1 \\
\hline $\begin{array}{l}\text { PHCs having referral services for } \\
\text { pregnancies/delivery on } 24 \times 7 \text { hours basis }\end{array}$ & 46.6 & 65.6 \\
\hline $\begin{array}{l}\text { PHCs conducted at least } 10 \text { deliveries during last } \\
\text { one month on } 24 \times 7 \text { hours basis }\end{array}$ & 38.8 & 74.3 \\
\hline
\end{tabular}




\begin{tabular}{lll}
\hline Community Health Centre (CHC) & $\mathbf{N = 8 4}$ & $\mathbf{N = 1 0 6}$ \\
CHCs having 24 X 7 hours normal delivery & 88.1 & 100 \\
services & & 13.2 \\
CHCs having Obstetrician/Gynaecologist & 13.1 & 8.5 \\
CHCs having Anesthetist & 10.7 & 46.2 \\
CHCs having functional Operation Theatre & 60.7 & 71.7 \\
CHCs designated as First referral units (FRUs) & 44.1 & 14.5 \\
CHCs designated as FRUs offering caesarean & 21.6 & 91.5 \\
section & & \\
CHCs having new born care services on 24 X 7 & 62.2 & $\mathbf{N = 2 1}$ \\
hours basis & & 95.2 \\
District Hospital (DH) & $\mathbf{N = 1 8}$ & 38.1 \\
DHs having Paediatrician & 77.7 & 38.1 \\
DHs having regular radiographer & 66.6 & 90.5 \\
DHs having 2D Echo facility & 22.2 & 100 \\
DHs having ultrasound facility & NA* & 76.2 \\
DHs having three phase connection & 100 & 100 \\
DHs having critical care area & 44.4 & 55.5 \\
DHs having suggestion and complaint box & & \\
\hline
\end{tabular}

*NA: information not available

\section{Discussion}

The results of the present study have highlighted that overall there is improvement in the broader social determinants of $\mathrm{MCH}$ (access to safe drinking water, sanitation facilities and clean fuel for cooking; literacy level of women), $\mathrm{MCH}$ coverage indicators, mortality statistics (maternal mortality ratio and infant mortality rate), and also reduction in geographical, socioeconomic and gender inequality, when compared with the situation before and after NRHM implementation. There is also improvement in accessibility and availability of health facilities after NRHM implementation. However, the coverage of MCH indicators and availability of health facilities is not yet $100 \%$. This indicates that the aim with which the NRHM was implemented i.e., to reduce $\mathrm{MCH}$ inequalities by improving the availability of 
and access to better-quality healthcare, especially for people residing in rural areas (to reduce geographical inequality), for the poor (to reduce socioeconomic inequality), and for women and children (to reduce gender inequality) has been achieved to some extent but not fully. That is why probably the goal to reduce the infant mortality rate to $30 / 1,000$ live births, maternal mortality to 1/1,000 live births could not be achieved till 2012-13.

Earlier studies that have used demographic health surveillance data in India to report MCH inequalities have shown marked inequalities during antenatal period, postnatal period and natal period regarding skilled birth attendance, which concentrated disproportionately among the rich [24-26]; and higher malnutrition burden among poor children coupled with a concomitant rise in economic inequalities [27]. Gender disparity in immunization programs favoring males has been reported in urban areas, developed states and Muslim communities in India [28]. Poor household economic status (46\%), mother's illiteracy (35\%) and rural residence $(15 \%)$ contributed to $96 \%$ of total socio-economic inequalities in child survival at the national level [29]. In addition to these factors mass media exposure were the critical pathways reported through which economic factors operate on $\mathrm{MCH}$ inequalities [30]. However, most of the earlier studies reflect the situation before NRHM implementation, which is similar to the situation observed during that period in this study also (2002-04). The strength of this study is that it documents the trend of $\mathrm{MCH}$ inequalities across geographical, socioeconomic and gender sectors in three time periods (pre-, during- and post-NRHM), so as to have better understanding of the dynamics of $\mathrm{MCH}$ inequalities and effectiveness of NRHM in reducing those.

Sanneving et al (2013) reviewed literature to use framework developed by Commission on social determinants of health to categorize and explain determinants of inequity in maternal and reproductive health in India, and concluded that economic status, gender, and social status are all closely interrelated when influencing use of and access to maternal and 
reproductive health care [31]. Therefore we had chosen to specifically to look into the status of these inequalities pre, during and post NRHM implementation.

Regarding the trend in $\mathrm{MCH}$ inequality in this study, it was observed that the initially $\mathrm{MCH}$ coverage indicators improved irrespective of area (rural or urban) or socioeconomic status (standard of living/wealth index) or gender (for children) after the launch of NRHM in the state. Since, in urban areas and among women who were at advantage due to their economic status or children due to being male, MCH indicators were better at the baseline (2002-04) as compared to their counterparts, hence $\mathrm{MCH}$ inequalities across these gradients increased during 2007-08. However, we witnessed that this gap reduced when MCH status reassessed during 2012-13.

This reduction of gap suggests that concerted efforts were done especially in rural areas and for the poor women to improve the $\mathrm{MCH}$ service coverage among them, probably after 200708. These efforts are reflected in the facility survey data (collected during DLHS 3 and 4), in the form of increased availability of ASHA's in almost all the villages, additional ANM in the SCs and accessibility of health facilities like sub centers with in $3 \mathrm{~km}$ and PHCs with in 10 $\mathrm{km}$ of villages. Additionally, availability of round the clock services at PHC level increased considerably. Since functional services at PHC's were provided close to villages, there was increase in proportion of PHCs with at least 10 deliveries in a month. This indirectly indicates increased utilization of functional services at PHCs in rural areas. Provisions of round the clock delivery and newborn care services also improved at CHC level (first referral units). This made the referral of complicated pregnancies/deliveries manageable. One possible reason for the noted coverage increases could be the simultaneous increase in the number and type of health facilities as shown by the data. High coverage of institutional delivery care with significant financial risk protection in the public sector has also been reported in a recent study in Haryana [32]. All these efforts jointly may have resulted in improvement in $\mathrm{MCH}$ 
indicators especially in rural areas and among least advantaged women and decline in geographical and socioeconomic inequalities post NRHM.

The present study probably the first one to document that there is bridging of $\mathrm{MCH}$ inequalities across geographical area, socioeconomic and gender gradient after NRHM implementation. Some of the indicators are even better in rural areas as compared to urban area like receiving ORS for diarrhea, and immunization among female children during 201213. In the time period covered (including the introduction of the NRHM), inequalities in MCH indicators may have decreased, but time-dependent changes (other than the introduction of the NRHM) may have occurred simultaneously (e.g. decreased income inequality, increased gross domestic product or other policies/regulations). We acknowledge that the inequalities improved in Haryana, but that more research is needed to know whether this is due to NRHM or a general economic progress in the background (improving everything including food and hygiene/sanitary situation, but also giving the country the possibility of implementing NRHM) in the same period. Moreover, causal relationships can never by fully proven with descriptive research. According to Mckeown, the improvements in the health indicators are less due to the human agency in the form of health-enhancing measures than to largely invisible economic forces that changed broad social conditions, that needs further exploration in this situation [33].

However, alternate explanations for reduction in inequalities may not account for, if we consider the logical framework analysis approach (input-process-output-outcome-impact analysis) for assessing the effectiveness of an intervention [34]. By applying this approach to explain the results of this study, it has been observed that after implementation of NRHM there has been considerable increase in inputs and processes (which has been presented in Table 7) that provides the causal link in improving the output in terms of improved MCH 
coverage indicators (Table 3) and ultimately outcomes and impact in terms of reduction in $\mathrm{MCH}$ inequalities and mortality (Tables 4 to 6). Evaluation of the program/intervention by comprehensively measuring the inputs, processes, outputs, outcomes, and impact over a longer time horizon is considered as a best available option when there is no control population for establishing the cause and effect relationship, as is the case in the present study [34]. WHO commission on social determinants of health does recognize the role of health systems in reducing inequalities as intermediary determinant [35]. Hence it can be stated that NRHM perhaps played a role through influencing health system in terms of improving access of $\mathrm{MCH}$ services, decreasing differential vulnerability and exposure to impact $\mathrm{MCH}$ inequalities.

During our analysis, we used absolute differences to measure the inequalities, which is considered more informative and useful to plan future interventions to reduce inequalities [36]. However, additional logistic regression analyses looked at the inequalities from a relative perspective, which added to the absolute perspective. The DLHS percentages indicated a general trend of reducing inequalities in Haryana. The logistic regression analyses were based on reconstructed cross-tabulations, using unweighted total numbers and weighted percentages. The testing for statistical significance (of reducing relative inequalities) should thus be interpreted cautiously. Also data on MMR might be fairly inconclusive because of wide uncertainty around the measure, particularly looking at per 1,000 births.

Declining exclusive breastfeeding rates as observed in this study are also documented by Chandhiok et al in India, Macias et al in Peru and in East Asia including China (28\%), Vietnam (20\%) and Thailand (5\%) by Unicef [37-39]. Barriers to exclusive breast feeding among mothers included female employment, perceived breast milk insufficiency, infant formula promotion in Peru, high mother education, mother aged $>=35$ years and living in 
urban areas in Indian study $[37,38]$. It was also observed that percentage of villages having village health nutrition and sanitation committee had declined from $68.2 \%$ to $43.5 \%$ in the post NRHM period. The reason for this could be improper implementation of this strategy at the village level, as is also observed in chapter 3 , table 2 . There was some decline in proportion of the PHC's having newborn care services $24 \times 7$ from $94 \%$ to $91 \%$, this might be either due to sampling variation in the two rounds of district level household survey or due to the implementation issues. This indicates that some of the indicators worsened after NRHM implementation, which could be because of different priority settings in the implementation of the NRHM's health sector plans in different year.

The results of this study have important public health implications globally as monitoring inequality is becoming an emerging priority for health post 2015 [40, 41]. The post 2015 sustainable development goals stress leaving no one behind and with goal ten focusing on inequality within and among countries. These results also have implications in terms of continuation of the program implementation in the rural areas with a special focus on poor women and children with same rigor in India. As we know that there are political preferences in what should be implemented or not at the national or state level, the program component, which is being implemented successfully, should be continued irrespective of political party in power at that moment [42]. This is quite pertinent to India as NRHM was implemented by the previous government as one of their major thrust area and also as part of commitment to meet Millennium development goals 4 and 5. The present government should take decisions or mend program implementation after carefully considering and deliberating upon what good the existing program has done in reducing maternal and child mortality statistics in future. The results of this study have shown that substantial gains were observed for schemes that aimed at increasing the institutional delivery rate among the poor and in rural areas. These schemes were free referral transport services, free hospital delivery, financial incentives for institutional delivery, improved access to delivery points and availability of ASHAs in the 
villages. Hence, these schemes should be further strengthened. While schemes aimed at improving child health like integrated management of neonatal and childhood illness needs more attention. We are on right path of improving $\mathrm{MCH}$ outcomes along with reduction in $\mathrm{MCH}$ geographical and socioeconomic inequalities to some extent, but the pace of achievement needs to be heightened to achieve sustainable development goals post 2015 . 


\section{References}

1. Gwatkin DR, Rutstein S, Johnson K, Suliman E, Wagstaff A, Amouzou A. Socio-economic differences in health, nutrition, and population within developing countries: an overview.World Bank. 2007.

2. Goldenberg RL, McClure EM. Disparities in interventions for child and maternal mortality. Lancet. 2012 Mar 31;379(9822):1178-80. doi: 10.1016/S0140-6736(12)60474-7.

3. Barros AJD, Ransman C, Axelon H, Loaiza E, Bertoldi AD, Franca GVA et al. Equity in maternal, newborn and child health interventions in countdown to 2015: a retrospective review of survey data from 54 countries. Lancet 2012;379:1225-33.

4. Countdown 2008 Equity Analysis Group, Boerma JT, Bryce J, Kinfu Y, Axelson H, Victora CG. Mind the gap: equity and trends in coverage of maternal, newborn, and child health services in 54 Countdown countries. Lancet. 2008; 12;371(9620):1259-67. doi: 10.1016/S0140-6736(08)60560-7.

5. Registrar General of India. Special Bulletin on Maternal Mortality in India. Sample Registration System 2011-13. Available at http://www.censusindia.gov.in/vital_statistics/mmr_bulletin_2011-13.pdf. Accessed on 20 September 2015.

6. Registrar General of India. Sample Registration System. Available http://www.censusindia.gov.in/vital_statistics/SRS_Bulletins/SRS\%20Bulletin\%20-

Sepetember\%202014.pdf . Accessed on 20 September 2015.

7. Ram F, Singh A, Ram U. Human rights approach to maternal \& child health: Has India fared well? Indian J Med Res. 2013;137(4): 721-727.

8. Pattinson R, Kerber K, Buchmann E, Friberg IK, Belizan M, Lansky S et al. Lancet's Stillbirths Series steering committee. Stillbirths: how can health systems deliver for mothers and babies? Lancet. 2011;377:1610-1623.

9. Bhutta ZA, Ali S, Cousens S, Ali TM, Haider BA, Rizvi A et al. Alma-Ata: Rebirth and Revision 6 Interventions to address maternal, newborn, and child survival: what difference can integrated primary health care strategies make? Lancet.2008;372(9642):972-989.

10. Schiffman J, Darmstadt GL, Agarwal S, Baqui AH. Community-based intervention packages for improving perinatal health in developing countries: a review of the evidence. Semin Perinatol. 2010;34:462-476.

11. Hota P, Dobe M. National Rural Health Mission. Indian J Public Health 2005; 49(3):107-10.

12. National Health Mission. Ministry of Health and Family Welfare. Government of India. Available [http://nrhm.gov.in/nhm/nrhm/nrhm-framework-for-implementation.html.] Accessed on 16 January 2014.

13. Gupta M, Angeli F, van Schayck OCP, Bosma H. 2015. Effectiveness of a multiple strategy community intervention to reduce maternal and child health inequalities in Haryana, North India: a mixed methods study protocol. Glob Health Action 8: 25987 http://dx.doi.org/10.3402/gha.v8.25987

14. Gupta M, Angeli F, Bosma H, Prinja S, Kaur M, Schayck OCP. Extent of implementation of a multiple-strategy community intervention for reducing maternal and child health inequalities in Haryana India. 2016. Unpublished

15. Department of Economic and Statistical Analysis Haryana: Economic Survey of Haryana. Government of Haryana. 2012-13. Available at http://web1.hry.nic.in/budget/Esurvey.pdf. Accessed on 16 July 2013. 
16. Pathak PK, Singh A. Trends in malnutrition among children in India: growing inequalities across different economic groups. Soc Sci Med 2011; 73(4):576-85.

17. International Institute of Population Sciences. District Level Household Surveys. Reproductive and Child Health Project. Ministry of Health and Family Welfare. New Delhi. India. Available at http://www.rchiips.org/ARCH-1.html. Accessed 10 July 2013.

18. International Institute of Population Sciences. District Level Household and Facility Survey-4. Reproductive and Child Health Project. Ministry of Health and Family Welfare. New Delhi. State Fact Sheet Haryana. 2012-13.

19. International Institute of Population Sciences. District Level Household and Facility Survey-4. Haryana. Reproductive and Child Health Project. Ministry of Health and Family Welfare. New Delhi. 2012-13.

20. International Institute of Population Sciences. District Level Household Survey-2. Reproductive and Child Health Project. Ministry of Health and Family Welfare. New Delhi. Haryana. 2002-04.

21. International Institute of Population Sciences. District Level Household and Facility Survey-3. Reproductive and Child Health Project. Ministry of Health and Family Welfare. New Delhi. Haryana. 2007-08.

22. School of Public Health. PGIMER. Concurrent Evaluation of National Rural Health Mission. Haryana. 2013-14.

23. Countdown to 2015. Maternal, Newborn and child survival. A decade of tracking progress for maternal, newborn and child survival. The 2015 report. Available at http://www.countdown2015mnch.org/documents/2015Report/India_2015.pdf. Accessed on 31 January 2016.

24. Singh A, Pallikadavath S, Ram F, Ogollah R. Inequalities in Advice Provided by Public Health Workers to Women during Antenatal Sessions in Rural India. PLoS One 2012; 7(9): e44931. doi: 10.1371/journal.pone.0044931

25. Singh A, Padmadas SS, Mishra US, Pallikadavath S, Johnson FA, Matthews Z. Socioeconomic inequalities in the use of postnatal care in India. PLoS One 2012; 7(5):e37037. doi: 10.1371/journal.pone.0037037. Epub 2012.

26. Pathak PK, Singh A, Subramanian SV. Economic inequalities in maternal health care: Prenatal care and skilled birth attendance in India, 1992-2006. PloS One. 2010;5(10): e13593. doi:10.1371/journal.pone.0013593.

27. Pathak PK, Singh A: Trends in malnutrition among children in India: growing inequalities across different economic groups. Soc Sci Med 2011; 73(4):576-85.

28. Prusty RK, Kumar A. Socioeconomic dynamics of gender disparity in childhood immunization in India, 1992-2006. Plos One. 2014;15:9(8):e104598. doi: 10.1371/journal.pone.0104598.

29. Pradhan J, Arokiasamy P. Socioeconomic inequalities in child survival in India: A decomposition $\quad$ analysis. Health 2010. doi: http://dx.doi.org/10.1016/j.healthpol.2010.05.010

30. Goli S, Doshi R, Arokiasamy P. Pathways of economic inequalities in maternal and child health in Urban India: A decompostition analysis. PloS One. 2013; 8(3): e58573. doi:10.1371/journal.pone. 0058573 
31. Sanneving L, Trygg N, Saxena D, Mavalankar D, Thomsen S. Inequity in india: the case of maternal and reproductive health. Glob Health Action 2013,6:19145 http://dx.doi.org/10.3402/gha.v6i0.19145

32. Prinja S, Bahuguna P, Gupta R, Sharma A, Rana SK, Kumar R. Coverage and financial risk protection for institutional delivery: how universal is provision of maternal health care in India? PLoS One. 2015;10(9):e0137315.

33. McKeown T, Brown RG, Record RG. An interpretation of the modern rise of population in Europe. Popul Stud. 1972;26:345-382.

34. Parkhurst JO. "What worked? the evidence challenges in determining the causes of HIV prevalence decline. AIDS Educ Prev. 2008; 20 : 275-83.

35. WHO. A conceptual framework for action on social determinants of health. Commission on social determinants of health. 2007.

36. Mackenbach JP. Should we aim to reduce relative or absolute inequalities in mortality? Eur J of Public Health. 2015;25(2): 185.

37. Chandhiol N, Singh J, Sahu D, Singh L, Pandey A. Changes in exclusive breastfeeding practices and its determinants in India, 1992-2006: analysis of national survey data. Int Breastfeed J. 2015; 10:34.

38. Macias YF, Marquis YF, Groleau D, Penny ME. Decline of exclusive breastfeeding: Practical advice and stronger policy compliance are needed in government health services in Lima, Peru. The FASEB Journal. 2012; 26(1): 806.5. Available at http://www.fasebj.org/content/26/1_Supplement/806.5.short.

39. Unicef rings alarm bells as breastfeeding rates plummet in East Asia. Available at http://www.unicef.org/media/media_62337.html. Accessed 5 August 2016.

40. Sustainable Development Goals. Available at https://sustainabledevelopment.un.org/topics. Accessed on 22 September 2015.

41. Hosseinpoor AR, Bergen N, Magar V. Monitoring inequality: an emerging priority for health post 2015. Bull World Health Organ. 2015;93:591-591A.

42. Colerbranber S, Birungi C, Mbonye AK. Consensus and contention in the priority setting process: Examining the health sector in Uganada. Health Policy Plan. 2015;30(5):555-65. 


\section{Chapter 5}

Qualitative study on the effectiveness of a multiple-strategy community intervention to reduce maternal and child health inequalities in Haryana, India.

Madhu Gupta, Hans Bosma, Federica Angeli, Manmeet Kaur, Venkatesan Chakarpani, Monica Rana, Onno CP van Schayck.

PLoS One. 2016. (submitted).

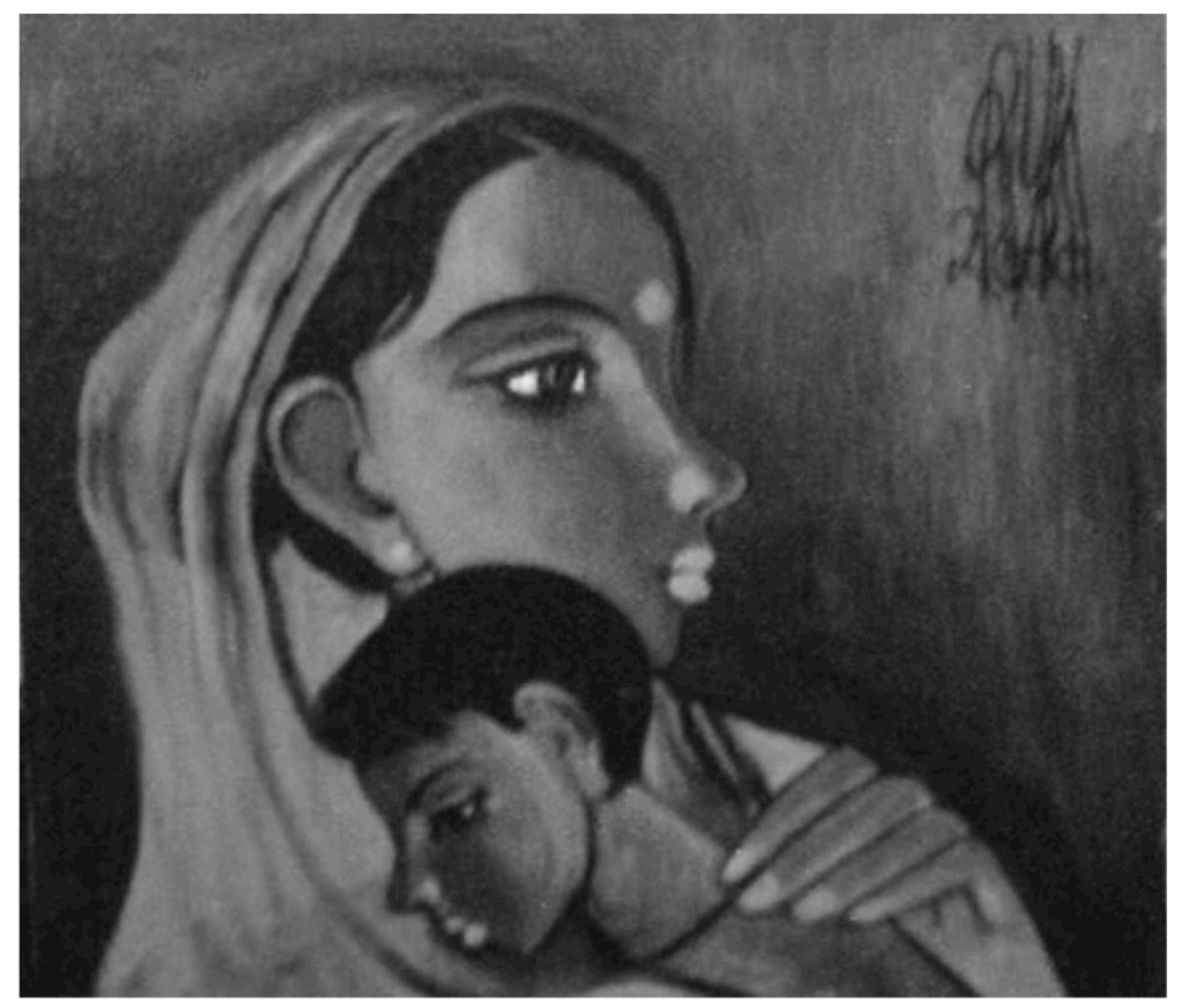




\begin{abstract}
A multiple strategy community intervention, known as National Rural Health Mission (NRHM), was implemented in India from 2005 to 2012. By improving the availability of and access to better-quality healthcare, the aim was to reduce maternal and child health (MCH) inequalities. This study was planned to explore the perceptions and beliefs of stakeholders about the effectiveness of NRHM's health sector plans in improving MCH status and reducing inequalities. A total of 33 in-depth interviews $(n=33)$ with program managers, community representatives, mothers and 8 focus group discussions $(n=42)$ with health service providers were conducted from September to December 2013, in Haryana post NRHM. Using NVivo software (version 9), an inductive applied thematic analysis was done based upon grounded theory, program theory of change and a framework approach. Almost all the participants reported that there was an improvement in overall health infrastructure through an increased availability of accredited social health activists, free ambulance services, and free treatment facilities in rural areas. This had increased the demand and utilization of $\mathrm{MCH}$ services, especially for those related to institutional delivery, even by the poor families. Service providers felt that acute shortage of human resources was a major health system level barrier. District-specific individual, community, and socio-political level barriers were observed in the implementation of the NRHM plans. Overall program managers, service providers and community representatives believed that NRHM had a role in improving $\mathrm{MCH}$ outcomes and in reducing geographical and socioeconomic inequalities, through the improvement in accessibility, availability and affordability of the MCH services in the rural areas and for the poor. Any reduction in gender-based inequalities, however, was linked to the adoption of small family sizes and an increase in educational levels.
\end{abstract}




\section{Introduction}

Large geographical and socioeconomic inequalities in maternal and child health ( $\mathrm{MCH})$ continue to persist in India and have even widened across states, between rural and urban areas and within communities [1]. Overall the maternal mortality ratio (MMR) in India is still as high as 1.67 maternal deaths per thousand live births [2] and the infant mortality rate (IMR) is 40 infant deaths per thousand live births [3]. IMR is higher in rural (44 per thousand live births) as compared to urban areas (27 per thousand live births) [3]. Socioeconomic $\mathrm{MCH}$ inequalities favoring the rich [4-6] and gender inequalities favoring male children [7] are also reported in India. To deal with $\mathrm{MCH}$ inequalities and improve $\mathrm{MCH}$, the government of India implemented a multiple-strategy community intervention known as the National Rural Health Mission (NRHM) from 2005-06 to 2012-13. NRHM's aim was to improve the availability of and access to better-quality healthcare, especially for people residing in rural areas (to reduce geographical inequality), for the poor (to reduce socioeconomic inequality), and for women and children (to reduce gender inequality) [8]. Its health sector plans were health system strengthening; communitization (delegating powers to and empowering the community to monitor the health care delivery system) and specific maternal and child healthcare strategies [9]. Details of these plans are given in a Chapter 1, and also in previously published study protocol [10]. NRHM aimed to reduce the IMR to 30 infant deaths /1000 live births, MMR to 1 maternal death /1000 live births.

This study is conducted in the state of Haryana in Northern India. It resembles other North Indian states in terms of socioeconomic development and sociocultural factors (like a strong preference for having sons, female feticide, a lower sex ratio, and a lower social status of women). At the same time, it provided a unique context by being a prosperous state with a rising economy, but with an unequal distribution of resources, leading to wide intra-state and inter-district differences in terms of the provision of basic infrastructure [11]. After the implementation of NRHM in Haryana, the MMR declined from 1.85 (2002-04) to 1.21 (201113) maternal deaths per thousand live births $[2,12]$ and the IMR from 59 (2002-04) to 40 
(2012-13) infant deaths per thousand live births in Haryana [12, 13]. Quantitatively, MCH indicators improved considerably [14] and $\mathrm{MCH}$ inequalities between geographical regions (urban and rural areas), between rich and poor women (class differences), and between male and female children post NRHM were reduced [15].

However, these improvements were not uniform in the state, with certain districts performing better than others. It was not clear why the same strategy was working in one district, but not in the other. Neither was it clear what the pathways of change were for the overall improvement in $\mathrm{MCH}$ outcomes and reduction in inequalities. Knowing the pathway of change is crucial to understand the preconditions that need to be met before reaching the ultimate goal and to better understand the barriers and facilitating factors for the preconditions. This information is paramount for the policy makers for an effective implementation of the NRHM health sector plans and meeting the intended goal of a reduction in maternal and child mortality and inequalities. NRHM is also continued in the second phase (2013-17) as part of National Health Mission [16]. There are limited studies estimating the effectiveness of interventions on equity in maternal or child health in low and middle-income settings [17]. Say and Raine (2007) highlighted the need to adequately grasp the contextual issues that must be addressed if inequalities in maternal health care use are to be reduced in developing countries [18]. Since such information cannot be obtained through quantitative surveys only, we planned a qualitative study.

To understand the contextual issues, barriers, facilitating factors, and pathways of change related to NRHM, the objective of this study was to explore the perceptions and beliefs of all the stakeholders involved in planning, monitoring, implementation, service provision, and use of NRHM health sector plans regarding the extent of implementation of NRHM health sector plans and the effectiveness of these plans in improving $\mathrm{MCH}$ outcomes and reducing geographical, socioeconomic and gender inequalities in MCH in Haryana. 


\section{Materials and Methods}

Study area

Haryana has 21 districts with a total population of $25,353,081$ ( $70 \%$ rural) and a birth rate of 21.3 per thousand mid-year population $[3,19]$. The health care delivery system in Haryana has been described in the previous protocol study [10]. To obtain a better contextual understanding of two extreme situations and to learn which scheme works better in a particular situation, extreme case purposive sampling [20] was used to select one wellperforming (district Ambala) [21] and one less well-performing district (district Mewat) [22] in terms of $\mathrm{MCH}$ indicators. Mewat is predominantly inhabited by Muslims, a religious minority in India [23-25]. From both Ambala and Mewat districts, we selected one village, one sub-center, one Primary Health Center (PHC), and one Community Health Center (CHC). As there was variability within the districts regarding $\mathrm{MCH}$ status, with certain blocks performing better than others, we purposively selected all well-performing and all poorly performing health facilities within the Ambala and Mewat district, respectively. Prior permission to conduct this study was obtained from the Mission Director, NRHM, Government of Haryana. The authors did not have any relation (like service providers) with those interviewed and the interviews were exclusively conducted for research purposes. The Ethics committee of the Post Graduate Institute of Medical Education and Research, Chandigarh, India approved the study.

\section{Study design}

The theoretical framework underpinning this study was both grounded theory, i.e., to build theories from the data [26], and theory of change [27]. Theory of change is essentially a comprehensive description and illustration of why and how a particular change is expected to happen in a particular context leading to the desired goals. It defines long term goals and then maps backward to identify necessary preconditions so as to understand the pathway of change [28-29]. 


\section{Study population and data collection}

The perceptions and beliefs of the participants were explored using pretested focus group discussion and in-depth interview guides. (Appendix 1). Focus group discussions were conducted separately with different MCH service providers: accredited social health activists, auxiliary nurse midwives, medical officers, or senior medical officers in each district. Each focus group discussion had about 4-10 participants. In-depth interviews were conducted with the Mission Director NRHM, MCH program managers at the state and district level, the community leaders and mothers at each level (ie., village, sub center, $\mathrm{PHC}, \mathrm{CHC}$ and district). Qualitative interactions were continued until data saturation. After obtaining written informed consent, all the interviews and discussions were audio and video-recorded and field notes prepared. Repeat interviews were conducted with program managers at the state level. The duration of the focus group discussions ranged from 60 minutes to 90 minutes and in-depth interviews ranged from 45 minutes to 60 minutes. Two female authors (a doctor with an MD in Community Medicine and a research scholar with a Master degree in Public Health), who were trained in qualitative research methods, collected the data from September to December 2013 (post-NRHM period). Focus group discussions and in depth interviews with the participants were conducted in their place of choice. Only authors, study staff, and respective participants were present at the time of data collection, so that participants were comfortable; privacy and confidentiality were ensured. No one refuse to participate in the study. However, one community representative could not be interviewed because of his unavailability at the time of data collection

\section{Data analysis}

Audio and video recorded focus group discussions and in depth interviews were transcribed in Hindi and translated into English. Two independent coders (authors) coded the translated text for grouping into categories. A conceptual framework of NRHM was used during the analysis. As per this framework, NRHM's health sector plans had four major pillars - health system strengthening, communitization, maternal health care strategies, and child health care 
strategies - to improve $\mathrm{MCH}$ and reduce $\mathrm{MCH}$ inequalities. (Figure 1). Fundamental were the behavior change communication of the community and the social status of women, as these were the determinants of $\mathrm{MCH}$ outcomes.

Figure 1. A conceptual framework of NRHM.

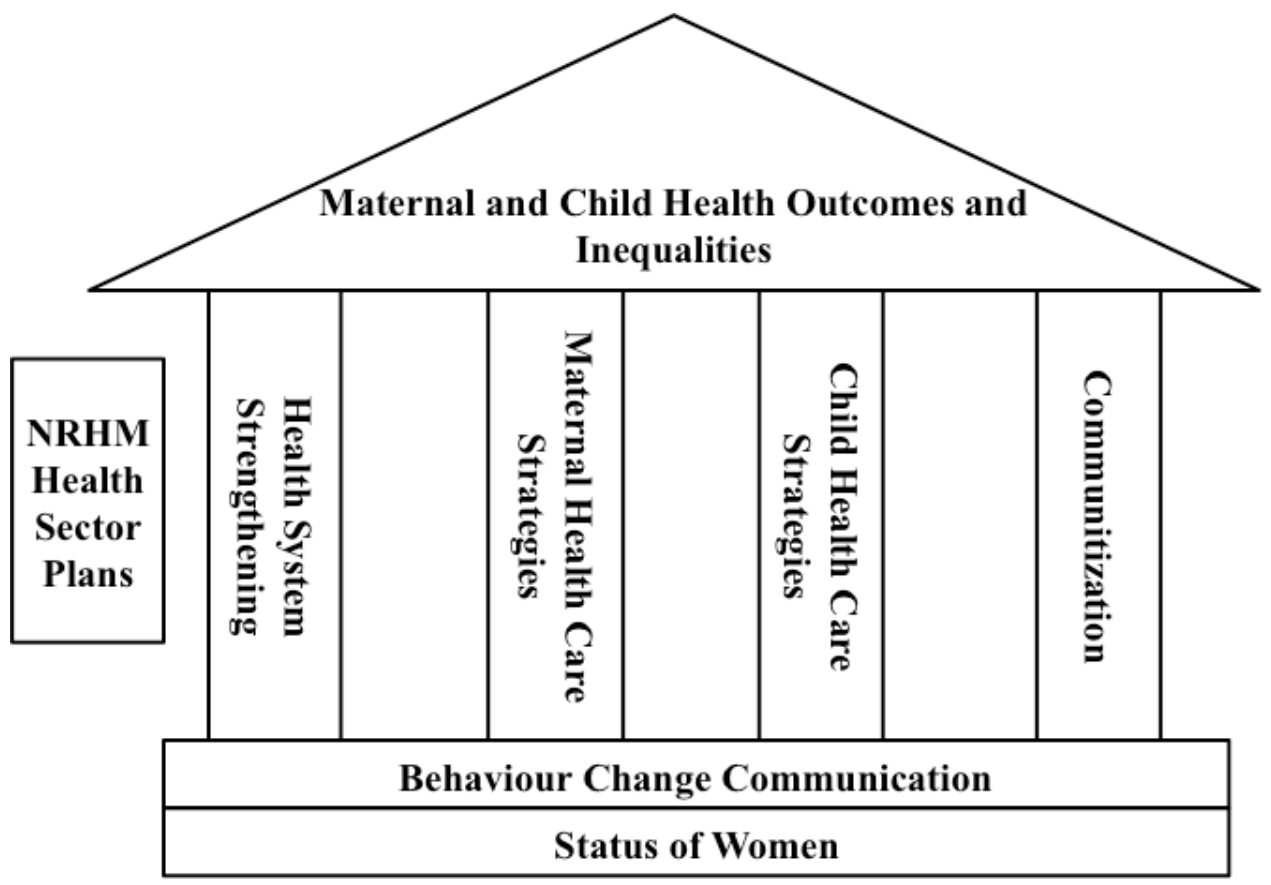

Using NVivo software (version 9), an inductive applied thematic analysis [30] was done based upon grounded theory [26], program theory of change [27] and framework approach [31]. In addition to the pre-determined codes (as listed in the focus group discussion/in-depth interview guide), codes emerged from the analysis of focus group discussion and in-depth interviews ('emergent codes'). Based on these codes, themes were identified. The framework approach was used to align the identified themes and codes as per the conceptual framework of NRHM. The program theory of change was applied to construct pathways of change by identifying the necessary preconditions that led to early, intermediate and long-term changes in the community (benefitting the NRHM goals). 


\section{Results}

A total of 33 in-depth interviews $(n=33)$ with program managers, community representatives and mothers, and 8 focus group discussions with service providers $(\mathrm{n}=42)$ were conducted. The background characteristics of the participants are given in Table 1. The participants' mean age was 34.8 years. Forty percent of the participants were between 20 and 29 years and $63 \%$ were females. Mean years of experience in the health system varied from 3 years for accredited social health activists to 10 years for auxiliary nurse midwives.

Table 1. Background characteristics of the participants of focus group discussions and indepth interviews.

\begin{tabular}{|c|c|c|c|}
\hline Characteristics & $\begin{array}{c}\text { Focus Group } \\
\text { Discussion } \\
\text { N=42 }(\%)\end{array}$ & $\begin{array}{c}\text { In-depth } \\
\text { Interviews } \\
\mathrm{N}=\mathbf{3 1}(\%)\end{array}$ & $\begin{array}{c}\text { Total } \\
\mathrm{N}=73(\%)\end{array}$ \\
\hline Mean age of participants & 35.4 years & 34.1 years & 34.8 years \\
\hline \multicolumn{4}{|l|}{ Age in years } \\
\hline $20-29$ & $14(33.3)$ & $15(48.4)$ & $29(39.7)$ \\
\hline $31-39$ & $14(33.3)$ & $3(9.7)$ & $17(23.3)$ \\
\hline $40-49$ & $9(21.4)$ & $11(35.5)$ & $20(27.4)$ \\
\hline $50-59$ & $5(11.9)$ & $1(3.2)$ & $7(8.5)$ \\
\hline \multicolumn{4}{|l|}{ Sex } \\
\hline Female & $24(57)$ & $22(71)$ & $46(63)$ \\
\hline Male & $18(43)$ & $9(29)$ & $27(37)$ \\
\hline \multicolumn{4}{|l|}{ Education } \\
\hline Illiterate & 0 & $4(12.9)$ & $4(5.5)$ \\
\hline Primary & $3(7)$ & $4(12.9)$ & $7(9.6)$ \\
\hline Middle & $2(4.8)$ & 0 & $2(2.7)$ \\
\hline Matric & $7(16.7)$ & $6(19.4)$ & $13(17.8)$ \\
\hline Senior Secondary & $5(11.9)$ & $1(3.2)$ & $6(8.2)$ \\
\hline Graduation and Post Graduation & $4(9.5)$ & $9(29)$ & $13(17.8)$ \\
\hline Professional & $21(50)$ & $7(22.6)$ & $28(38.4)$ \\
\hline
\end{tabular}




\section{Occupation}

Laborer

Housewife

Community leader

Auxiliary nurse midwife

Accredited social health activist

Doctor

Program Manager
$1(1.4)$

$15(48.4)$

$15(20.5)$

$6(19.4)$

10

11

(29)
$10(13.7)$

Mean years of experience in the health system

Auxiliary nurse midwife

Accredited social health activist

Doctors

Program Managers

The participants' mean age was 34.8 years. Forty percent of the participants were between 20 and 29 years and $63 \%$ were females. Mean years of experience in the health system varied from 3 years for accredited social health activists to 10 years for auxiliary nurse midwives. Themes, subthemes and codes are given in Table 2, and further described below.

Table 2: Themes and codes as per applied thematic analysis.

\begin{tabular}{llll}
\hline Themes & Code Family & $\begin{array}{l}\text { Code names } \\
\text { Predetermined } \\
\text { codes }\end{array}$ & Emergent codes \\
\hline $\begin{array}{l}\text { Health } \\
\text { system } \\
\text { strengthening }\end{array}$ & Infrastructure & $\begin{array}{l}\text { Health centers in } \\
\text { rural areas }\end{array}$ & $\begin{array}{l}\text { Well equipped health centers in rural } \\
\text { areas, non availability of waiting halls } \\
\text { for patients in the health facilities, } \\
\text { availability of clean health centers }\end{array}$ \\
& $\begin{array}{l}\text { Drugs and } \\
\text { Logistics }\end{array}$ & $\begin{array}{l}\text { Medicines in health } \\
\text { centers in rural areas }\end{array}$ & $\begin{array}{l}\text { Free availability of medicines in health } \\
\text { centers in rural areas; quality is an } \\
\text { issue; stock out of situations }\end{array}$ \\
& $\begin{array}{l}\text { Patient } \\
\text { Transport } \\
\text { Service }\end{array}$ & Ambulance service & $\begin{array}{l}\text { Free availability of ambulance service; } \\
\text { Issues with its maintenance, better } \\
\text { services with in the ambulance needed } \\
\text { at par with private, ambulance contact } \\
\text { number could not be reached possibly } \\
\text { due to frequent callers; late arrivals to }\end{array}$ \\
\hline
\end{tabular}




\begin{tabular}{|c|c|c|c|}
\hline & & & $\begin{array}{l}\text { the homes, inadequate number of } \\
\text { vehicles; linked to increase in } \\
\text { institutional delivery }\end{array}$ \\
\hline & $\begin{array}{l}\text { Human } \\
\text { resource }\end{array}$ & $\begin{array}{l}\text { Availability of } \\
\text { doctors, nurses, } \\
\text { midwives }\end{array}$ & $\begin{array}{l}\text { Acute shortage of manpower especially } \\
\text { specialist, contractual staff available } \\
\text { but quality of contractual staff is an } \\
\text { issue, salary of contractual staff not at } \\
\text { par with regular staff, negative attitude } \\
\text { of doctors, specialists not evenly } \\
\text { distributed with in the state }\end{array}$ \\
\hline & Untied funds & $\begin{array}{l}\text { Availability of untied } \\
\text { funds }\end{array}$ & $\begin{array}{l}\text { Availability of funds for upgrading } \\
\text { infrastructure as per the need, buying } \\
\text { drugs as per need, Availability of funds } \\
\text { for arranging refreshments for mothers } \\
\text { during mother meeting }\end{array}$ \\
\hline & $\begin{array}{l}\text { Mobile Medical } \\
\text { Units }\end{array}$ & $\begin{array}{l}\text { Availability of } \\
\text { mobile medical units }\end{array}$ & $\begin{array}{l}\text { Functional status of mobile medical } \\
\text { units an issue, non availability of } \\
\text { doctors, limited awareness of mobile } \\
\text { medical units in the villages }\end{array}$ \\
\hline $\begin{array}{l}\text { Communitiza } \\
\text { tion }\end{array}$ & $\begin{array}{l}\text { Accredited } \\
\text { Social Health } \\
\text { Activists }\end{array}$ & $\begin{array}{l}\text { Availability of } \\
\text { Accredited Social } \\
\text { Health Activists in } \\
\text { the villages }\end{array}$ & $\begin{array}{l}\text { Role in immunization of children and } \\
\text { pregnant women, improving } \\
\text { institutional delivery, generating } \\
\text { awareness about NRHM schemes \& } \\
\text { importance of institutional delivery } \\
\text { Accompanies the families while } \\
\text { travelling to the hospital; insufficient } \\
\text { number; educational qualification has a } \\
\text { bearing on recruitment of accredited } \\
\text { social health activists; well known in } \\
\text { the villages; good rapport with the } \\
\text { women, especially decision makers } \\
\text { (mother in laws); calls free ambulance; } \\
\text { Community Mobilizer }\end{array}$ \\
\hline
\end{tabular}

$\begin{array}{ll}\text { Village Health } & \text { Celebration of village } \\ \text { and Nutrition } & \text { health and nutrition } \\ \text { Day } & \text { days in the villages }\end{array}$

Village Health

Nutrition \&

Sanitation

Committee

Formation of Village Health Nutrition \& Sanitation Committee
Immunization sessions held on village health and nutrition days; mother meetings also held on these days; Known popularly as village health 'mela'; Not held regularly

Less awareness by mothers and community members, members are not involved in planning; village head would ask for bribe for utilizing the funds, funds remain unutilized; anganwadi worker involvement in funds handling leading to underutilization

$\begin{array}{lll}\text { Maternal } & \text { Janani } & \text { Financial incentive } \\ \text { Health Care } & \text { Suraksha Yojna } & \begin{array}{l}\text { for institutional } \\ \text { delivery }\end{array}\end{array}$

Funds remain unutilized; Delay in payment due to administrative reasons; Lack of knowledge imparted to the mothers about the scheme; Linked with opening of bank accounts leading to issue in delivering the benefits to women who do not have bank accounts; Proofs required to get the 
benefits; Linked with increase in institutional delivery

JananiShishu Free medicine and Free diet during hospital stay; Suraksha Yojna institutional delivery Implementation is partial due to lack of adequate manpower; Linked with increased institutional delivery

\begin{tabular}{lll}
\hline $\begin{array}{l}\text { Child health } \\
\text { care }\end{array}$ & Immunization & $\begin{array}{l}\text { All children getting } \\
\text { vaccines }\end{array}$ \\
strategies & &
\end{tabular}

Lack of sufficient auxiliary nurse midwives leads to partial implementation of immunization sessions; Cultural barrier are there for immunization of children especially in district Mewat; Fear of injections; accredited social health activists an catalyst in providing immunization in the form of mobilizing the community

Facility based Newborn care New born referred for treatment to newborn care services in government hospitals from private Government facilities health facilities as government new born facilities are better

$\begin{array}{ll}\begin{array}{l}\text { Integrated } \\ \text { management of } \\ \text { neonatal and } \\ \text { childhood }\end{array} & \begin{array}{l}\text { Treatment of sick } \\ \text { children as per }\end{array} \\ \text { illnesses } & \begin{array}{l}\text { Integrated } \\ \text { management of } \\ \text { neonatal and } \\ \text { childhood illnesses }\end{array}\end{array}$

Staff is trained in Integrated management of neonatal and childhood illnesses implementation; Community lack trust on government facilities for treatment of sick children so do not visit subcenters in villages for treatment (less demand at subcenter level); Lack of supervision; Poor implementation; Focus has been shifted from Integrated management of neonatal and childhood illnesses to home based post natal care;

\begin{tabular}{lll}
\hline MCH & Geographical & MCH inequalities in \\
Inequalities & Inequality & urban and rural areas
\end{tabular}

Increase in antenatal registrations in rural areas, gap is bridged with more villagers utilizing services than urban people due to NRHM. Awareness has improved and medicines are available in villages however facilities are still more in cities.

\begin{abstract}
Socioeconomic $\mathrm{MCH}$ inequalities Inequality between rich and poor
\end{abstract}

\section{Gender Inequality}

Socioeconomic inequalities have decreased to some extent because of availability of free ambulances, medicines, diet during hospital stay for the poor. Food security in general would reduce this.

NRHM has no scheme for targeting gender inequality; Small size of the families and increased educational status has led to the changes in gender inequality; Gender inequality is less seen in Mewat district 


\begin{tabular}{|c|c|c|c|}
\hline \multirow[t]{2}{*}{ Barriers } & Client level & - & $\begin{array}{l}\text { Poor awareness about schemes } \\
\text { provided under NRHM; Unmet basic } \\
\text { need (lack of food) of pregnant women } \\
\text { and mothers in rural areas; Lack of } \\
\text { faith in government health facilities; } \\
\text { Overriding household responsibilities } \\
\text { of mothers; Poor health seeking } \\
\text { behavior: Phobic towards } \\
\text { pills/medicines/operation }\end{array}$ \\
\hline & $\begin{array}{l}\text { Community } \\
\text { Level }\end{array}$ & - & $\begin{array}{l}\text { Mother-in-law and male spouse are the } \\
\text { potential influencers; Gender disparity } \\
\text { in providing child care; Negative image } \\
\text { among families about the quality of } \\
\text { free services; Community norm and } \\
\text { cultural belief; Lack of family planning } \\
\text { discourages ensuring child health; } \\
\text { Public attitude: Lack of willingness to } \\
\text { wait; Low social status of women in } \\
\text { the society }\end{array}$ \\
\hline
\end{tabular}

\section{Health systems strengthening}

Infrastructure strengthening

Almost all the participants reported that during the last 2-3 years of the NRHM period, the health infrastructure improved in terms of the availability of cleaner and well-equipped health centers providing $\mathrm{MCH}$ services.

"Infrastructure has improved a lot, earlier it was negligible. Only during NRHM, new born corners and stabilization units were established." (Program manager, Ambala)

However, there were still insufficient numbers of health facilities as per the population norms. It was reported that many centers lacked certain diagnostic facilities (in $\mathrm{CHCs}$ ) and waiting halls for patients (in sub centers and PHCs). According to some auxiliary nurses, the lack of toilets in some facilities posed a barrier to collect urine samples of pregnant women.

"There should be one CHC on one lakh population. We are running CHC at one lakh 45 thousand. There should be more PHCs to decrease the workload of CHC." (Medical officer, Ambala). 
"There is no facility of ultrasound and $x$-ray in the village. We are paying outside for these facilities. Only facility of normal delivery is here. I had a delivery in the 8th month through operation. At that time, they referred me to a private hospital from here [government] as there was no machine to keep the baby.” (Mother, Mewat)

\section{Drugs and logistics}

Service providers, program managers, and mothers believed that free medicines were available in the public health facilities during the NRHM implementation. As a result, the number of patients in the health facilities had increased. Not only this, but it had also improved the health of poor mothers and children.

"Free medicines have helped the poor mother and children in getting the treatment from the government hospitals; hence, they now remain healthy...." (Community leader, Ambala).

However, out of stock situations and less faith in medicines prescribed for to children in the government sector prevented its access.

\section{Patients Transport Service (Free ambulance service)}

The service providers and program managers perceived that the free ambulance service was a major factor contributing to the increase in institutional deliveries. The ambulance dial number was widely disseminated among the villagers in the district Ambala. According to the interviewees, through the accredited social health activists in the villages, the utilization of the ambulance by the mothers had also increased.

"The increase in institutional deliveries is all because of the ambulances. Earlier there were 5-7 deliveries at our CHC (in 2005) and then it was increased to 15 deliveries in 2011. Now today (2013) there are 45 plus deliveries (per month)." [Medical officer, Ambala]. 
"We dialed 102 and ambulance came to take us to hospital". [Mother, Ambala]

However, in the district Mewat, there was less awareness about the ambulance's free availability and the dial number. Also, there was either a delay in reaching the remotest areas, or it did not reach it at all, or the dial number could not be reached, possibly due to frequent callers. This resulted in less faith and more home deliveries.

\section{Human resources}

It was perceived by the senior medical officers, that the availability of doctors, auxiliary nurse midwives, staff nurses increased during the NRHM period, but simultaneously that the demand of services had increased manifold. This led to acute shortages of manpower. The shortages of doctors had also overburdened the existing staff and resulted in a poor access to health care services.

"There were earlier 10-15 patients in the outpatient department, now there are up to 150 patients in outpatient departments. In 2005, we (PHC) didn't have deliveries and in medical college (private medical college in the district); there used to be 150 deliveries, but now (year 2013) we have 600 and they have only 200 deliveries"(Medical officer, Ambala).

"Here, work of four people is done by one person. Then how can that person do so much work, and obviously his efficiency will suffer."(Auxiliary nurse, Ambala).

The lack of specialists had forced the non-specialist doctors to treat seriously ill patients. This compromised the quality of health care or led to referrals to other health facilities with additional health risks during transportation. It was also expressed that existing specialists were not meaningfully distributed with some districts having many specialists and others lacking them (e.g., district Mewat). The situation is even worse in the Mewat district, as 
ground level workers, such as the auxiliary nurse midwives, were not allegedly available in all the sub centers: hence, the provision of $\mathrm{MCH}$ services in such villages was not optimal.

"There are 86 sanctioned posts for medical officers in Mewat, but there are hardly 30-32 doctors." (Medical officer, Mewat).

"There is no surgeon here; no skin specialist is here, no radiologist here. ...Nobody is here." (Medical officer, Mewat).

"We have one auxiliary nurse on a population of 12,000; now there is one auxiliary nurse on a population of 16,000 and in some villages there are no such nurses at all." (Auxiliary nurse, Mewat).

A program manager at the Mewat district expressed his concerns about the frequent transfers of trained staff to their native districts in spite of getting extra financial incentives. This not only led to the loss of human resources, but also the loss of money and too much time invested in their trainings.

"The attrition rate is very high in Mewat. Doctors are not willing to join at the salary we are giving." (State-level NRHM officer).

There was a provision for hiring contractual staff to manage the acute shortage of staff. However, medical officers expressed that the contractual staff lacked proper training and skills to provide quality $\mathrm{MCH}$ services. They were also less paid as compared to regular staff, which demotivated them. Furthermore, as reported by village health activists, some pregnant women were afraid to go to PHCs for delivery due to the perceived lack of an adequate number of nurses, the negative and casual attitude of doctors, and the physical abuse of pregnant women in the labor room. 
"She delivered a baby girl, but after one hour she started bleeding; doctors then were having lunch and then they did not take care and she died." (Auxiliary nurse, Mewat)

\section{Untied funds}

Untied funds were perceived to be useful for upgrading the infrastructure and other needbased support by medical officers. However, participants expressed that the stringent accounting formalities and the lack of awareness regarding the accounting procedures were substantial barriers for an effective utilization of these funds.

\section{Medical mobile unit}

The medical mobile unit, intended to cater the $\mathrm{MCH}$ needs of the hard-to-reach areas in the Mewat district, was believed to be non-functional, possibly due to the lack of doctors.

"Medical Mobile Unit has zero role... There are no doctors in mobile units. Or they [authorities] could not appoint doctor. No service nothing... No man power is there." (Medical officer, Mewat)

\section{Communitization}

\section{Accredited Social Health Activists}

Of all the schemes under NRHM, the accredited social health activist's scheme was the most appreciated scheme by all the participants. Notably, some auxiliary nurses who were closely working with health activists at the sub-centers believed that these activists were educating the beneficiaries about $\mathrm{MCH}$ schemes and supporting them in conducting immunization sessions, mobilizing the children and pregnant women on the immunization session day, providing antenatal care, and motivating pregnant women for institutional deliveries. Similarly, many mothers stated that, primarily through the activists, they had understood about the importance of immunization, institutional delivery, and the possible adverse negative effects of home delivery. These activists had also supported them during delivery 
and assisted them in availing the free ambulance service, the treatment in the health facilities and the financial incentives for getting the institutional delivery. In particular, activists perceived to have played a vital role in convincing potential troublemakers in the families [often mother-in-laws] to ensure hospital care for pregnant mothers. They seemed to have established an excellent rapport with them.

"She has made me understand that delivering a baby at home is not good as the child might die during labor" (Mother, Mewat). "As far as the percentage of institutional delivery is concerned, presently it is $80 \%$ to $90 \%$. In promotion of these institutional deliveries, social health activists have played a major role." (State NRHM officer).

In Mewat, the program manager shared that large number of positions were vacant due to the lack of potential women candidates meeting the educational requirements even after the relaxation of the minimum education level from the $8^{\text {th }}$ to $5^{\text {th }}$ grade. However, medical officers reported that some activists faced challenges in understanding their job description possibly due to low educational status.

"For Mewat, we have have asked the district authority to relax the minimum qualification of activists from matric/eight to fifth class. But even after this, we were not able to recruit fifth passed activists because the illiteracy rate is very high in Mewat." (Program Officer, Mewat)

\section{Village Health Nutrition Day}

Although most mothers and community leaders did not know about this day, some were aware of the village health melas (fair), which were conducted along with the immunization camps. As reported by some medical officers and state-level NRHM officers, the village health nutrition days were not conducted regularly mainly due to the inadequate number of auxiliary nurses. 
"This day is combined with the immunization session. Auxiliary nurse midwives have lot of work on Wednesday, like vaccination etc. So I don't think she tells anything. She only ticks marks on papers." (Senior medical officer, Ambala)

\section{Village Health Nutrition and Sanitation Committee}

The medical officers shared that, although such committees were constituted in many villages, these were not involved in the planning and implementation of activities. A medical officer reported that some village heads [presidents] were expecting 'some money' [bribe] from the allocated committee funds (154 USD) for the infrastructure and program-related activities. As a result, auxiliary nurses were hesitant to withdraw the funds from the joint bank account and these remained unutilized. The involvement of grass-root worker from women and child development department (member) in the operationalization of the bank account was also a barrier in the utilization of funds, due to a lack of inter-sectoral coordination.

"The funds of the committee are not utilized properly from the time the account has been shifted to Anganwadi workers. Earlier it was with village health activists, but now it is with Anganwadi workers and they don't spend the budget of Rs 10,000 properly. So the account either should be with activists or with the auxiliary nurse. Implementation of this scheme is only around 30-40\%." (Senior medical officers, Ambala)

\section{Specific maternal and child health schemes}

Financial incentive scheme for institutional delivery (Janani Suraksha Yojana)

Many mothers and community leaders had an inadequate knowledge about this scheme and believed that some cash benefits were given to the poor mother for delivery. Almost all the participants had reported delayed payments to the mothers due to stringent administrative procedures, such as the need for the submission of several supportive documents (e.g., poverty line card, aadhar card - an unique identification number card). Most pregnant women 
did not have some of these documents (e.g., bank account in the name of the pregnant woman).

Free delivery and free treatment of pregnant women and infant in the public hospitals (Janani Shishu Suraksha Karyakaram)

Although most of the mothers and community leaders were not aware of this scheme's name, they were aware of the free delivery possibility and the free treatment of mothers and infants in public hospitals. Service providers believed that due to the facilities provided under this scheme, mothers preferred to go to the government hospitals for delivery and therefore the institutional deliveries had increased. Keeping them in the hospital for at least 48 hours after a normal delivery was, however, an issue, as mothers usually preferred to go back to their homes within 24 hours to meet their household responsibilities. In this relation, doctors were not able to motivate them, partly due to an inadequate number of post-partum beds. The medical officers believed that MCH services were now affordable for poor people and the shortage of human resources prevented the full implementation of this scheme.

\section{Immunization}

Many mothers reported that they usually get immunized during pregnancy and have their children immunized too. However, inadequate numbers of auxiliary nurse midwives for immunization, cultural barriers against immunization (not considered safe by some members in the community), and fear for injections (especially in the Mewat district) were expressed as barriers for immunization. The medical officers reported that the provision of alternate vaccine delivery (where there were no auxiliary nurse midwives) and the involvement of religious leaders to help deal with the cultural barriers in Mewat resulted in an improved immunization status.

Facility based newborn care 
Facility-based newborn care services in public hospitals were believed to have improved drastically during NRHM and they were considered better than those in private hospitals.

"All the districts now have sick new born care units, the infrastructure of which has been better than is available in the private sector. As a result many of sick new born are being referred to government hospitals for treatment." (State Child Health Officer)

\section{Integrated management of neonatal and childhood illnesses}

State program managers reported that, although medical officers and auxiliary nurse midwives were trained in the integrated management of neonatal and childhood illnesses, it was not implemented properly due to inadequate human resource and supervision.

\section{MCH Inequalities}

Regarding geographical MCH inequalities, most of the participants expressed that there was increase in the availability and access to health facilities, doctors, and medicines in rural areas during the NRHM period. Hence, they believed that $\mathrm{MCH}$ inequalities in urban and rural areas had reduced to some extent. However, regional differences remained between remote villages and urban areas. According to most study participants, the NRHM, through provision of free government services, had played a significant role in addressing socioeconomic inequalities between the rich and poor. Regarding gender inequality, it was reported that government alone could not deal with gender inequalities; it had to be dealt with at the societal level by changing the attitude of society towards female children, the adoption of small family sizes, and by increasing educational levels.

\section{Barriers in accessing MCH services}

As per service users and medical officers, the client-level barriers were: poor awareness of mothers about NRHM's schemes, overriding household responsibilities of mothers that 
prevented post-delivery care in the hospitals, phobia towards injections or operations that prevented access to seek immunization, and emergency obstetric care (especially in the Mewat), lack of faith in medicines supplied in government hospitals (especially for the treatment of sick children), and unmet basic needs like not having enough food for pregnant women and children from poor families. Community-level barriers were: low social status of women in the society (especially in the Mewat), lack of decision making power of the mothers to seek MCH care (as their mothers-in-law and spouses were the main decision makers), gender disparities in providing childcare with some families preferring male children's health care above female's health care, cultural barriers among some religious minority communities that discouraged institutional deliveries (possibly because of the lack of adequate female doctors), immunization, and the uptake of family-planning methods. The lack of willingness of the community members to wait for their turn to see a doctor in the government health facilities was another community-level barrier, although it is linked to inadequate human resources and high patient load in public hospitals. Program manager expressed that there was lack of political will to do the overall development in Mewat district, because they would not get additional grant of funds if its current status changed.

Overall, the perception of program managers, medical officers, auxiliary nurse midwives and accredited social health activists did not differ much regarding the implementation and effectiveness of the NRHM's health sector plans. However, although they often did not know the exact name of the schemes, community representatives and mothers were more aware of the visible benefits of the NRHM: health activists in the villages, ambulance services, free institutional deliveries, and free neonatal treatment in public hospitals.

\section{Discussion}

Starting from the four major pillars of the NRHM (health system strengthening, communitization, and specific maternal and child health strategies) to improve $\mathrm{MCH}$ and 
reduce $\mathrm{MCH}$ inequalities, service users and other stakeholders much appreciated the role of health systems strengthening, especially for the provision of free ambulance services and free medicines in public hospitals. Communitization efforts were also much appreciated, particularly for the availability of accredited social health activists at the village level. It was reported that, under specific $\mathrm{MCH}$ strategies, free $\mathrm{MCH}$ services, such as antenatal care, institutional deliveries, and the treatment of sick children, were also implemented better. This held particularly for the well-performing Ambala district. Stakeholders believed that overall $\mathrm{MCH}$ outcomes had improved during the NRHM implementation and that maternal and infant mortality had also declined, as had geographical and socioeconomic MCH inequalities. These perceptions correspond well with the quantitative data of the district-level household survey Haryana for the year 2012-13 [14] and a recent study on effectiveness of NRHM in reducing $\mathrm{MCH}$ inequalities [15].

The pathways for change, as derived from the theory of change, which might have led to the improvements are depicted in Figure 2. The NRHM's four pillars and corresponding interventions are depicted at the bottom. The arrows from the interventions lead to the boxes that represent the outputs. The weight of the arrows (dotted vs full) indicates the intensity of the effect of that intervention on the outputs. Weight is decided based upon the perceptions of the participants regarding an intervention. For example, the weight for accredited health activists is denoted by full arrow, as this intervention is perceived to be very effective in improving the $\mathrm{MCH}$ outcomes as compared to village health nutrition day (denoted as dotted arrow). The arrows from the outputs lead to the outcomes and finally to the impact at the top. 
Figure 2. The pathways of change as derived from theory of change.

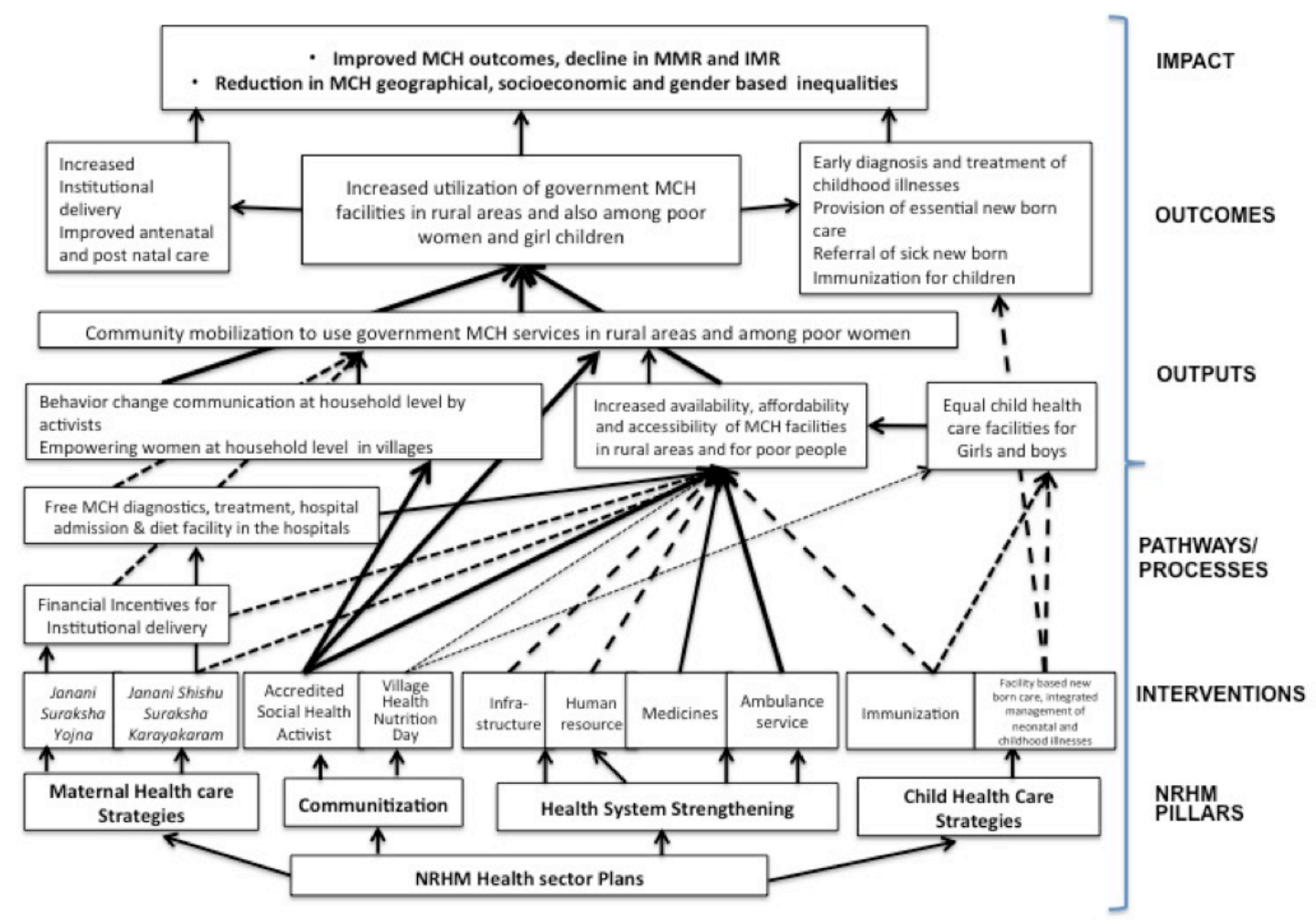

As per the theory of change, NRHM's interventions are the preconditions (inputs) to produce the outputs, the outcomes, and the impact, respectively. The outputs are relatively immediate effects that are expected to happen after inputs and processes that add more details in relation to the product of the activity e.g., number of persons trained in sick child management. Outcome indicators refer more specifically to the objectives of an intervention, that is its 'results' e.g., management of sick child; and impact indicators refer to the health status of the target population that do not show progress over relatively short periods of time like child mortality rate [32].

An important precondition to achieve the NRHM's goal of reduction in IMR and MMR and $\mathrm{MCH}$ inequalities was the delivery by skilled birth attendants, especially in rural areas and for poor women. Delivery by skill birth attendants was ensured by the institutional deliveries. The pathways for change, which might have led to the increase in institutional deliveries, included the availability of accredited social health activists in the villages, who did behavior 
change communication with mothers and potential influencers in the family. This empowered the pregnant women with enough knowledge regarding the health sector plans of NRHM (free ambulance services, free hospital deliveries, free neonatal treatment, and financial incentives for hospital deliveries) and enabled them to take decisions regarding institutional delivery. She acted as a bridge between the community and public hospitals. As a result, the community was mobilized to use the $\mathrm{MCH}$ facilities in rural areas. These factors, along with the availability of health facilities and doctors in rural areas and the free ambulance service, free medicines further improved the accessibility and affordability of $\mathrm{MCH}$ services and benefitted poor pregnant women and children. The pathways of change constructed in this study can be supported by various other studies. Nonyane et al (2015), reported that community-based interventions delivered by female community health volunteers can be instrumental in improving equity in levels of facility delivery and other newborn care behaviours [33]. Brazier et al (2015) reported that building the capacity of community-level cadres to promote maternity care-seeking by women in their villages is an important complement to facility-level interventions when increasing the availability, quality and utilization of essential maternal health services [34]. Bridging inequalities through an analytical framework, Jacob et al (2011) reported that the combination of interventions in NRHM is required to tackle barriers in health care access [35]. Parkhurst and Ssengooba (2009) reported that if the mothers are properly counseled and mobilized and given the enabling environment, in terms of the ambulance service and the accompanied person for the institutional delivery, they will go to the local functional health facility and not bypass it [36]. In a systematic review by Yuan et al (2014), it was concluded that interventions that were effective in reducing inequity included the improvement of health care delivery by outreach methods, using human resources in local areas, using services in the community nearest to the residents, and providing financial incentives or knowledge support to the demand side [17].

The preconditions in the pathway of change, however, were not fully met in the Mewat district. This was due to health system barriers, like the inadequate number of accredited 
social health activists for community mobilization, the lack of auxiliary nurse midwives and doctors in the hospitals to provide $\mathrm{MCH}$ services, and a poor ambulance service to improve the access. This was compounded by the presence of client and cultural barriers for accessing $\mathrm{MCH}$ services. An acute shortage of manpower was perceived as the major health system barrier in accessing quality MCH services. Shaw et al (2015) also reported that lack of health extension workers is the most common barrier to the utilization of sick child care services [37]. The underlying reason for the poor $\mathrm{MCH}$ status in the Mewat district was also the perceived lack of political will to improve the basic socioeconomic conditions (structural determinants of health inequalities), despite the special status granted to the district and extra financial contributions by the government of India [38]. Interventions, that are otherwise well designed, therefore, might not have work. An enabling environment at the structural, political and cultural level is an important precondition. Thus, as depicted in Diderichsen's model, the health system acts as an intermediary determinant of health inequalities [39]. Structural determinants in the social and political context (giving rise to unequal socioeconomic positions, income, education, power) are the major social determinants of health inequalities [40]. These need to be tackled to reduce health inequalities. Pallikadavath et al (2013) reported that districts that provide good connectivity by roads, better educational facilities for children, and recreational facilities have better retention of human resources for $\mathrm{MCH}$ care (compared with districts providing financial incentives) [41]. Fleuren et al (2004) in their review on determinants of innovation in health care organization reported that characteristic of organizations, the users adopting the innovation, the innovation, and the socio-political context are the important determinants of a successful implementation of an innovation [42]. Hence, it can be learnt from the Mewat experience that, for an effective implementation of $\mathrm{MCH}$ plans, the overall socio-economic development in sectors such as education, employment, infrastructure development, and social welfare also need to be addressed.

Based on the participants' perspectives, NRHM did not seem to have contributed much to the reduction in gender inequalities, except for the measures related to immunization. The better 
immunization status of girls than boys as observed by Gupta et al (2016) was not because the community cared more for the girls, but because injections were not generally perceived to be safe for children, so they would let girls have them rather than boys [15]. Several client and community level barriers were thus observed in this study. These have to be addressed appropriately for an effective implementation of the NRHM health sector plans. Similarly, at the ground level, NRHM schemes were sometimes considered poorly visible indicating an information gap between service providers and users. Perhaps lessons can be learned from Taleb et al (2015) study in Bangladesh, where the maternal and newborn health improved by a focused and dedicated bridging of the information gap through community-based programs that influenced knowledge levels and practices of women [43].

Similar results as in our study are reported in some of qualitative studies done on the effective role of accredited social health activists in improving MCH in Uttar Pradesh [44], on barriers in the financial incentive scheme (like the need for having identity documents by pregnant women) in Madhya Pradesh [45], and on the poor functional status of village health nutrition and sanitation committees in Maharashtra [46] in India. However, gender-based barriers by the female health workers as observed by Mumtaz et al (2003) in Pakistan were not reported in this study [47].

The strength of this study is its integrated approach and holistic review of NRHM's MCH plans. This provides contextual information on what works and what does not work and identifies modifiable barriers at the health system, client and community level in the implementation of the $\mathrm{MCH}$ program. This information is crucial for a better planning and effective implementation of the program, not only in Haryana, but also in other states of India, and possible also in the second phase of NRHM (2013-17) as part of the National Health Mission [16]. To make a policy a success apparently is complex and, as was observed in the Mewat district, dependent on many interrelated factors, like political, economic and sociocultural factors. The policy implications of this study are that, along with the 
implementation of the specific $\mathrm{MCH}$ schemes, the structural determinants of health inequalities (education, occupation, income, socioeconomic status) and the basic socioeconomic development of the district need also to be addressed. Unless that is done, the extent and effectiveness of implementation of $\mathrm{MCH}$ plans runs the risk of remaining only a partial success. It is also recommended that MCH plans needs to be scaled up through an extensive availability of human resources, a reduction in the information gap between service providers and users, and an effective planning and implementation of the targeted interventions to deal with client and community-level barriers. 


\section{References}

1. Ram F, Singh A, Ram U. Human rights approach to maternal \& child health: Has India fared well? Indian J Med Res. 2013. 137(4): 721-727.

2. Registrar General of India. Special Bulletin on Maternal Mortality in India. Sample Registration System. 2011-13. Available at http://www.censusindia.gov.in/vital_statistics/mmr_bulletin_2011-.pdf. Accessed 20 September 2015.

3. Registrar General of India. Sample Registration System Bulletin. 2014. Available at http://www.censusindia.gov.in/vital statistics/SRS Bulletins/SRS\%20 Bulletin\%20Sepetember\%202014.pdf . Accessed 20 September 2015.

4. Singh A, Padmadas SS, Mishra US, Pallikadavath S, Johnson FA, Matthews Z. Socioeconomic inequalities in the use of postnatal care in India. PLoS One. 2012; 7(5):e37037. doi: 10.1371/journal.pone.0037037. Epub 2012.

5. Singh A, Pallikadavath S, Ram F, Ogollah R. Inequalities in Advice Provided by Public Health Workers to Women during Antenatal Sessions in Rural India. PLoS One. 2012; 7(9): e44931. doi: 10.1371/journal.pone.0044931

6. Pathak PK, Singh A. Trends in malnutrition among children in India: growing inequalities across different economic groups. Soc Sci Med. 2011; 73(4):576-85.

7. Prusty RK, Kumar A. Socioeconomic dynamics of gender disparity in childhood immunization in India, 1992-2006. Plos One. 2014; 15:9(8):e104598. doi: 10.1371/journal.pone.0104598.

8. Hota P, Dobe M. National Rural Health Mission. Indian J Public Health. 2005 ; 49(3):107-10.

9. Ministry of Health and Family Welfare. National Rural Health Mission. Framework for implementation. Government of India. New Delhi. 2005-12. Available at http://nrhm.gov.in/nhm/nrhm/nrhm-framework-for implementation.html. Accessed 16 January 2016.

10. Gupta M, Angeli F, van Schayck OCP, Bosma H. Effectiveness of a multiple startegy community intervention to reduce maternal and child health inequalities in Haryana, North India: a mixed methods study protocol. Glob Health Action. 2015; 8: 25987 -

11. Economic Survey of Haryana. Department of Economic and Statistical Analysis Haryana. Government of Haryana. 2012-13. Available at http://web1.hry.nic.in/budget/Esurvey.pdf. Accessed 16 July 2015.

12. Registrar General of India. Maternal and Child Mortality and Total Fertility Rates. Sample Registration System Bulletin 2004-06, 2007-09. Available at http://www.censusindia.gov.in/vital_statistics/SRS_Bulletins/MMR_release_070711.pdf. Accessed 22 December 2015.

13. Registrar General of India. Sample Registration System Bulletin. 2005. Available at http://www.censusindia.gov.in/vital statistics/SRS Bulletins/SRS\%20 Bulletin\%20Sepetember\%2005.pdf. Accessed 20 September 2015.

14. International Institute of Population Sciences. District Level Household and Facility Survey-4. Haryana Report. Reproductive and Child Health Project. Ministry of Health and Family Welfare. New Delhi. 2012-13.

15. Gupta M, Angeli F, Bosma H, Rana M, Prinja S, Kumar R et al. Effectiveness of multiplestrategy community intervention in reducing geographical, socioeconomic and gender inequalities in maternal and child health outcomes in Haryana, India. PLoS One. 2016;11(3):e0150537.

16. Ministry of Health and Family Welfare. Government of Inida. National Health Mission. 2013. Available at http://nrhm.gov.in/. Accessed 23 November 2015.

17. Yuan B, Malqvist M, Trygg N, Qian X, Ng Nawi, Thomsen S. What interventions are effective on reducing inequalities in maternal and child health in low and middle income 
settings? A systematic review. BMC Public Health. 2014;14:634. doi: 10.1186/1471-2458-14634.

18. Say L, Raine R. A systematic review of inequalities in the use of maternal health care in developing countries: examining the scale of the problem and importance of the context. Bull World Health Organ. 2007; 85(10):812-9.

19. Census 2011. Haryana. India. Available at http://censusindia.gov.in/2011census/censusinfodashboard/index.html. Accessed on 16 July 2015.

20. Patton M. Qualitative evaluation and research methods. Beverly Hills, CA: Sage; 1990.

21. International Institute of Population Sciences. District Level Household and Facility Survey-4. Fact Sheet District Ambala. Reproductive and Child Health Project. Ministry of Health and Family Welfare. New Delhi. 2012-13.

22. International Institute of Population Sciences. District Level Household and Facility Survey-4. Fact Sheet District Mewat. Reproductive and Child Health Project. Ministry of Health and Family Welfare. New Delhi. 2012-13.

23. Institute for Human Development. Ministry of Minority Affairs, Government of India and Indian Council of Social Science Research. A baseline survey of minority concentration districts of India. 2008. Available at http://www.minorityaffairs.gov.in/msdp. Accessed 20 September 2015.

24. Niti Ayog. Government of India. Identifying backwardness of Mewat region in Haryana: A block level analysis. 2015 Available at http://niti.gov.in/mgov file/Identifying\%20Backwardness\%20of\%20Mewat\%20Region\%20in \%20Haryana\%20A\%20Block\%20Level\%20Analysis_final.pdf. Accessed 12 November, 2015.

25. Census. Mewat District. Haryana. India. 2011. Available at http://www.census2011.co.in/census/district/226-mewat.html. Accessed on 16 July 2015.

26. Strauss A, Corbin J. Basics of Qualitative Research: Techniques and Procedures for Developing Grounded Theory. Thousand Oaks, CA: Sage; 1998.

27. Ritchie J, Lewis J. Qualitative research practices: a guide for social science students and researchers. London: Sage; 2003.

28. Center for theory of Change. Theory of Change. 2015. Available at http://www.theoryofchange.org/what-is-theory- of-change/how-does-theory-of-changework/. Accessed 17 October 2015.

29. Anderson A. The community builder's approach to theory of change: A practical guide to theory and development. New York: The Aspen Institute Roundtable on Community Change; 2005.

30. Guest G, MacQueen KM, Namey EE. Applied Thematic Analysis. Thousand Oaks, CA: Sage; 2012.

31. Ritchie J, Spencer L. Qualitative data analysis for applied policy research. In: Bryman A, Burgess RG, editors. Analysing Qualitative Data. London: Routledge; 1994. pp. 172-194.

32. WHO. Indicators. Research and Evaluation. Child Health and Development. Available at http://www.emro.who.int/child-health/research-and-evaluation/indicators/All-Pages.html. Accessed 17 March 2016.

33. Nonyane BAS, Ashish KC, Jennifer A, Koru C, Guenther T. Equity improvements in maternal and newborn care indicators: results from the Bardiya district of Nepal. Health Policy Plan. 2015. doi: 10.1093/heapol/czv077

34. Brazier E, Fiorentino R, Barry MS, Diallo M. The value of building health promotion capacities with in communities: evidence from a maternal health intervention in Guinea. Health Policy Plan. 2015; 30 (7): 885-894.

35. Jacob B, Ir P, Bigdeli M, Annear PL, Damme WV. Addressing access barriers to health services: an analytical framework for selecting appropriate interventions in low-income Asian countries. Health Policy Plan. 2011; 27 (4):288-300. 
36. Parkhurst OJ, Ssengooba F. Assessing access barriers to maternal health care: measuring bypassing to identify health center needs in rural Uganda. Health Policy Plan.2009; 24 (5):377-384.

37. Shaw B, Amouzou A, Miller NP, Tafesse M, Bryce J, Surkan PJ. Access to integrated community case management of childhood illnesses services in rural Ethiopia: a qualitative study of the perspectives and experiences of caregivers. Health Policy Plan. 2015. doi: $10.1093 /$ heapol/czv115.

38. Ministry of Minority Affairs. Government of India. Guidelines for implementation of Multisectoral Development Program during 12 ${ }^{\text {th }}$ five year plan. 2013-17. Available at http://www.minorityaffairs.gov.in/. Accessed 30 October 2016.

39. Diderichsen F, Evans T, Whitehead M. The Social Basis of Disparities in Health. In: Diderichsen F, Evans T, Whitehead M, Bhuiya A and Wirth M, editors. Challenging Inequities in Health: From Ethics to Action. Oxford: Oxford University Press; 2001.

40. Diderichsen F. Understanding Health Equity in Populations- Some Theoretical and Methodological Considerations. In: Pares B A, editors. Promoting Research on Inequality in Health. Stockholm: Swedish Council for Social Research; 1998.

41. Pallikadavath S, Singh A, Ogollah R, Dean T, Stones W. Human Resource inequalities at the base of India's public health care system. Health Place.2013; 23:26-32. doi:10.1016/j.healthplace.2013.05.003. Epub 2013 May 22.

42. Fleuren M, Wiefferink K, Paulussen Theo. 2004. Determinants of innovation with in health care organizations: Literature review and Delphi study. Int J Qual Health Care. 2004; 16(2):107-23.

43. Taleb F, Perkins J, Ali NA, Capello C, Ali Muzahid, Santarelli C et al.. Transforming maternal and newborn health social norms and practices to increase utilization of health services in rural Bangladesh: a qualitative review. BMC Pregnancy and Childbirth. 2015; 15:75.DOI10.1186/s 12884-015-0501-8.

44. Jain N, Srivastava NK, Khan AM, Dhar N, Adish V, Menon S et al.. Assessment of functioning of ASHA under NRHM in Uttar Pradesh. Health and Population: Perspective and Issues. 2008; 31(2): 132-140.

45. Chaturvedi S, Costa De Ayesha, Raven J. Does the Janani Suraksha Yojna cash transfer program to promote facility births in India ensure skilled birth attendance? A qualitative study of intrapartum care in Madhya Pradesh. Global Health Action. 2015; 8: 27427. http://dx.doi.org/10.3402/gha.v8.27427

46. Sah PK, Raut AV, Maliya CH, Gupta SS. Performance of village health, nutrition and sanitation committee: A qualitative study from rural Wardha, Maharashtra. The Health Agenda. 2013;1(4):112-117.

47. Mumtaz Z, Salway S, Waseem M, Umer N. Gender based barriers to primary health care provision in Pakistan: the experience of female providers. Health Policy Plan. 2003;18(3); 261-69. 


\section{Chapter 6}

Effectiveness of a multiple-strategy community intervention to reduce maternal and child health inequalities in Northern India: mixed method study.

Madhu Gupta, Hans Bosma, Federica Angeli, Manmeet Kaur, Venkatesan Chakarpani, Monica Rana, Onno C.P. van Schayck

Journal of Mixed Method Research. 2016. (submitted)

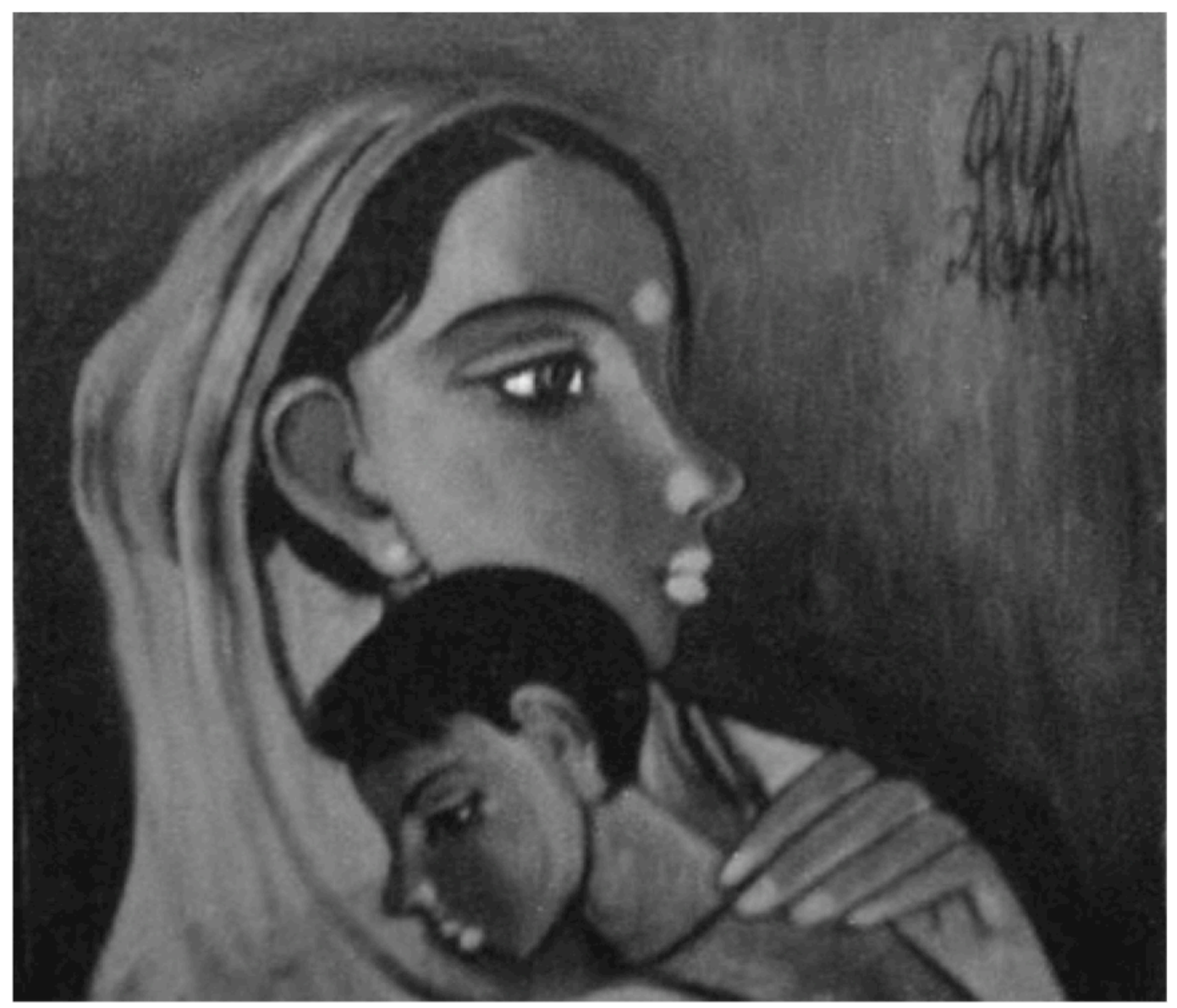




\begin{abstract}
A multi-strategy community intervention, known as National Rural Health Mission (NRHM), was implemented by Indian government to reduce geographical, socioeconomic and genderbased maternal and child health $(\mathrm{MCH})$ inequalities in India. A sequential mixed method study was conducted to assess effectiveness of NRHM's plans by comparing demographic health surveys data held before (2002-04), during (2007-08), and after (2012-13) the implementation of NRHM, and exploring the perceptions and beliefs of stakeholders regarding extent and effectiveness of NRHM in Haryana. There was significant improvement in $\mathrm{MCH}$ outcomes and reduction in geographical, socioeconomic and gender-based inequalities. Better health infrastructure, accredited social health activists, free ambulance services and treatment in hospitals in rural areas were reported to have improved the $\mathrm{MCH}$ outcomes and reduced inequalities.
\end{abstract}




\section{Introduction}

Maternal and child health (MCH) inequalities across socioeconomic, geographical and gender gradient is a public health concern worldwide and more so in developing countries [1]. There are several safe motherhood campaigns implemented in developing countries with limited success in reducing these inequalities, mainly due to lack of rigorous analysis of existing data on inequalities and in-adequate grasp of contextual factors to deal with these inequalities [1]. In India, the maternal mortality ratio (MMR) is still as high as 167 per hundred thousand live births [2] and the infant mortality rate (IMR) is 40 deaths per thousand live births [3]. There is geographical inequality in MCH outcomes, like IMR is higher in rural (44 per thousand live births) as compared to urban areas (27 per thousand live births) [3]. The persistence of $\mathrm{MCH}$ inequalities indicates the need to assess how the existing national health programs on $\mathrm{MCH}$ are being implemented and for studies presenting evidence on the effectiveness of these programs, as these are highly resource-intensive interventions. Since implementing a national health program at state and district level is a complex phenomenon, hence to report on its effectiveness the assessment needs to be done from the government (supply side) as well as societal (demand side) perspective. Kaur (2016) suggested that mono-methods of assessments may not yield desired results as only quantitative methods may miss contextual information and only qualitative methods may miss to quantify the inequalities [4]. Hence, mixed methods study design, as described by Creswell, 2015, is better study design in such situations [5].

A multiple-strategy community intervention known as the National Rural Health Mission (NRHM) was implemented from 2005-06 to 2012-13, with an aim to reduce $\mathrm{MCH}$ inequalities by improving the availability of and access to better-quality healthcare, especially for people residing in rural areas (to reduce geographical inequality), for the poor (to reduce socioeconomic inequality), and for women and children (to reduce gender inequality) in India [6]. Details of NRHM's health sector plans are given in previously published study protocol [7]. Briefly these included health system strengthening (improving the health infrastructure, 
free drugs, mobile medical units and patient transport services); specific MCH schemes like cash incentives for hospital deliveries, free delivery services for pregnant women and treatment of neonatal illnesses in hospitals; and appointing accredited social health activists to promote the access to improved healthcare at household level in villages as part of communitization etc. [8]. The intention was to reduce the infant mortality rate to $30 / 1,000$ live births, and maternal mortality to 1/1,000 live births. Most of the earlier evaluations of NRHM were mainly quantitative in nature that lack thorough exploration to identify context specific causes of variable use of MCH care $[9,10]$.

This study was conducted in the state of Haryana in Northern India. It resembles other North Indian states in terms of socioeconomic development and sociocultural factors (like a strong preference for having sons, female feticide, a lower sex ratio, and a lower social status of women). At the same time, it provided a unique context by being a prosperous state with a rising economy, but with an unequal distribution of resources, leading to wide intra-state and inter-district differences in terms of provision of basic infrastructure [11]. This mixedmethods study was designed, to quantify the extent of implementation of NRHM's maternal and child health-related plans in the healthcare sector, to quantify NRHM's effectiveness in terms of reducing geographical, socioeconomic, and gender inequalities and improving the overall $\mathrm{MCH}$ outcomes, as well as to qualitatively ascertain the extent to which $\mathrm{MCH}$ strategies in the NRHM were implemented and were effective in tackling the inequalities and outcomes, and to formulate evidence-based recommendations for bridging the health inequalities in Haryana state. The purpose of mixed method study design is to enhance or validate the findings of the quantitative study using qualitative study, provide explanation for the findings of quantitative study and identify contextual factors for the improvement in $\mathrm{MCH}$ outcomes and reduction in $\mathrm{MCH}$ inequalities. Such explanations are paramount in understanding of the complex implementation process of a national health program at the state and district level, which will guide the policy makers in the effective implementation of the program so as to reach the intended goal of improving the maternal and child survival and 
reducing inequalities, as second phase of NRHM (2013-2017) is continue as part of National Health Mission [12]

\section{Methods}

\section{Study design}

An explanatory sequential mixed methods design was used in this study [5]. [Figure 1]. It falls under partially mixed sequential equal status design as per Leech and Onwuegbuzie (2009) typology [13]. Partially mixed design implies that mixing of qualitative and quantitative data was done at the interpretation level (i.e. the quantitative data was linked to and explained by qualitative results); sequential means that the qualitative data was collected after the quantitative data collection; and equal status denoted that both qualitative and quantitative data was given the same importance at the time of interpretation.

Figure 1. Explanatory sequential mixed method study design.

\section{Explanatory Sequential Mixed Method Study Design}

\section{Quantitative study $\longrightarrow$ Qualitative study}

Extent of Implementation of NRHM (2005-12)

- Review of annual state records and financial monitoring reports of Haryana

- Budget utilization rate for each NRHM's plan estimated

\section{Effectiveness of NRHM} strategies

- Secondary level analysis of District Level Household Surveys [DLHS 2 (2002-04), the DLHS 3 (2007-08), and the DLHS 4 (2012-13).
Study Period: September to

December, 2013

Study districts: Ambala and Mewat

Focus group discussions with service providers i.e., accredited social health activists, auxiliary nurse midwives, medical officers

In-depth interviews with program managers of $\mathrm{MCH}$ at the state and district level, the community leaders, and mothers
Mixed

Method

Integration at

Interpretation

Level 


\section{Setting}

Haryana has 21 districts, and has a population of 25,353,081 (70\% rural), a birth rate of 21.6 and a mortality rate of 6.4 deaths per thousand mid-year populations. Health care delivery system of Haryana has been described in Chapter 2 and previously published protocol [7].

\section{Quantitative study}

\section{Data}

The annual proportion of budget left unspent under each NRHM's health plan was used to measure the extent of utilization of budget to implement the health plans, which indirectly assessed the extent of implementation of the plans [14]. For assessing the effectiveness of NRHM plans in improving the MCH outcomes and reducing the geographical, socioeconomic and gender based $\mathrm{MCH}$ inequalities, information on the status of $\mathrm{MCH}$ indicators was obtained from the District Level Household Surveys (DLHS). DLHS round 2 (2002-04) represented the situation before, DLHS round 3 (2007-08) that during and DLHS round 4 (2012-13) that after NRHM implementation. Detailed methodology of these surveys is given in the respective DLHS reports [15-18]. Briefly, a multi-stage stratified systematic sampling design was adopted in all the rounds to randomly select 50 primary sampling units, which were census villages in rural areas and census enumeration blocks in urban areas in each district. Interview method was used to collect data using pretested structured questionnaires, namely, household, ever married woman, village and facility. The same core sets of questionnaires were used in each survey so that comparisons could be drawn. The facility survey was conducted during DLHS-3 and 4 rounds only. Data was collected from 18796, 20394, and 27414 currently married women aged 15-49 years during DLHS 2 (aged 15-44 years), 3 and 4, respectively. About 990 and 1,046 health facilities were visited for facility survey during DLHS 3 and DLHS 4, respectively. Maternal and infant mortality rates at the Haryana state level was obtained from the Sample Registration System [2, 3]. This 
methodology is in line with the earlier studies on extent and effectiveness of NRHM plans in Haryana, and described in Chapters 3 and 4 [19, 20].

\section{Data Analysis}

The implementation status of the overall NRHM plans was based upon the status of individual health sector plans, and categorized into fully implemented, partially implemented, or not at all implemented, depending upon the utilization of the budget for implementation of that plan at the end of 2013. If all the plans were fully implemented, the overall NRHM plans was also considered to be fully implemented, if partially then partial, if not implemented at all then not at all.

The MCH indicators were compared before, during and after the introduction of the NRHM using DLHS data (2002-04, 2007-08 and 2012-13) to assess the improvements in $\mathrm{MCH}$ outcomes in Haryana. Implementation variables were NRHM health sector measures; sociodemographic variables were geographical area, gender of the child and wealth index/quintiles (as available from demographic surveys); and outcome variables were $\mathrm{MCH}$ indicators and inequalities across the geographical, socioeconomic and gender gradients. Impact indicators like mortality rates (maternal mortality ratio and child mortality rates) were compared at state level for Haryana. Geographical, socioeconomic, and gender inequality in $\mathrm{MCH}$ was assessed by estimating the absolute differences in $\mathrm{MCH}$ indicators between urban and rural areas, between the most advantaged and least advantaged socioeconomic groups (excluding maternal and child mortality indicators), and between male and female children. Overall rates and inequalities expressed in terms of rate differences were compared across the relevant time period before, during, and after the NRHM. Data was analyzed using Excel and SPSS version 16. The chi square test was applied and the P-value was considered significant at $95 \%$ confidence intervals. 


\section{Qualitative study}

Qualitative study was done after the completion of NRHM (2005-06 to 2012-13) phase I, from September to December 2013. To obtain a better contextual understanding of two extreme situations and to learn which scheme works better in a particular situation, extreme case purposive sampling was used to select one well-performing (district Ambala) [21] and one less well-performing district (district Mewat) [22] in terms of MCH indicators. From both these districts we had selected a village, a sub-center, a Primary Health Center and a Community Health Center. As there was variability within the districts regarding MCH status, with certain blocks performing better than others, we purposively selected all well-performing and all poorly performing health facilities within the Ambala and Mewat district, respectively. Forty-one qualitative interactions with 73 participants, including 8 focus group discussions with service providers (medical officers, nurses, accredited social health activists) and 33 indepth interviews with state and district program managers, community representatives and mothers, were conducted until data saturation, using pretested guides. The perceptions and beliefs of participants were explored regarding the extent of implementation of NRHM plans, the affordability and accessibility of healthcare services, and the extent of improvement in geographical, socioeconomic, and gender differences in $\mathrm{MCH}$ outcomes.

Focus group discussions and in-depth interviews were audio-video recorded after obtaining written informed consent, so that verbal and non-verbal responses could be recorded. This methodology is in line with earlier study on qualitative assessment of extent and effectiveness of NRHM in Haryana, and described in detail in chapter 5 [23].

\section{Data analysis}

Data obtained from the focus group discussions and in-depth interviews were first transcribed in Hindi language using the audio-video and the manual recordings. The transcribed version was then translated into English. Two independent coders (authors) who were trained in 
qualitative analysis identified the codes. A conceptual framework of NRHM was used during the analysis. As per this framework, NRHM's health sector plans had four major pillars health system strengthening, communitization, maternal health care strategies, and child health care strategies - to improve $\mathrm{MCH}$ and reduce $\mathrm{MCH}$ inequalities. (Figure 1, Chapter 5). Fundamentals were the behavior change communication of the community and the social status of women, as these were the determinants of $\mathrm{MCH}$ outcomes. Applied thematic analysis of the content was done to identify the patterns using grounded theory, theory of change and framework approach, in NVivo statistical software version 9.

\section{Mixed methods integration}

The findings of the quantitative and qualitative parts of study were combined during the interpretation stage so as to explain the results of the quantitative study. Joint display of quantitative and qualitative findings was done for side-by-side comparisons.

\section{Results}

Quantitative findings

\section{Extent of implementation of NRHM health sector plans}

The total amount of budget sanctioned and spent under the health system strengthening, specific MCH care strategies/schemes (RCH-II), and communitization from the year 2005-06 to 2011-12 is given in Table 1, Chapter 3. There was increase in number of community health centers (from 81 to 110 ), primary health centers (from 408 to 440 ) and sub centers in the rural areas (from 2433 to 2630) during NRHM implementation in Haryana. Scheme wise financial monitoring reports of NRHM's implementation were available from the year 200708 onwards. Yearly allocation of funds, expenditure incurred and proportion of budget left unspent under each scheme from financial year 2007-08 to 2012-13 is presented in Table 2, Chapter 3. 
Based upon the budget sanctioned and spent on various maternal and child health schemes, the extent of implementation of NRHM's plans is summarized in Table 5, Chapter 3. The patients' referral transport services, human resources and provision of drugs and logistics under health system strengthening; the accredited social health activists in the villages and patient welfare committee (Rogi Kalyan Samities) schemes in the health facilities under communitization; and immunization and home based post natal care under child health care strategies were fully implemented. Nutrition rehabilitation center scheme was only minimally implemented hence placed in not implemented category and all other schemes were partially implemented.

\section{Effectiveness of NRHM health sector plans}

It was observed that after implementation of NRHM, there were significant improvements in all MCH indicators $(\mathrm{p}<0.05)$. [Table 3, Chapter 4]. The MMR had declined from 1.86 (200204) to 1.21 (2012-13) maternal deaths per thousand live births, and the IMR from 59 (200204) to 40 (2012-13) infant deaths per thousand live births in Haryana [24, 2, 3]. The geographical and socioeconomic differences between urban and rural areas, and between rich and poor were significantly $(\mathrm{p}<0.05)$ reduced for pregnant women who had an institutional delivery (geographical difference declining from $22 \%$ to $7.6 \%$; socioeconomic from $48.2 \%$ to $13 \%)$, post-natal care within 2 weeks of delivery $(2.8 \%$ to $1.5 \% ; 30.3 \%$ to $7 \%$ ); and for children with full vaccination (10\% to $3.5 \%, 48.3 \%$ to $14 \%$ ) and who received oral rehydration solution (ORS) for diarrhea ( $11 \%$ to $-2.2 \%$; $41 \%$ to $5 \%)$. Inequalities between male and female children were significantly $(\mathrm{p}<0.05)$ reversed for full immunization $(5.7 \%$ to $-0.6 \%)$ and BCG immunization (1.9 to -0.9 points), and a significant $(\mathrm{p}<0.05)$ decrease was observed for oral polio vaccine $(4.0 \%$ to $0 \%)$ and measles vaccine $(4.2 \%$ to $0.1 \%)$. [Tables 4 6, Chapter 4]. 
Trend of availability of and accessibility of health facilities during and after implementation in Haryana is given in Table 7, Chapter 4.

Qualitative findings

Forty-one qualitative interactions with 73 participants, including 8 focus group discussions with service providers (medical officers, nurses, accredited social health activists) and 33 indepth interviews with program managers, community representatives and mothers, were conducted until data saturation, using pretested guides in Haryana. Detailed qualitative findings are in line with previous paper [23] and given in chapter 5. Themes and subthemes are presented in Table 2, Chapter 5. Briefly the applied thematic analysis revealed that there was improvement in overall health infrastructure like availability of clean, well-equipped health centers and free medicines in the villages. Acute shortage of manpower was perceived at all levels of service delivery, which hampered the availability and accessibility of quality of $\mathrm{MCH}$ services. The barriers of manpower, especially in the district Mewat, reported were frequent transfers of the staff to other districts, unwillingness of the staff to work in rural areas due to lack of facilities like educational, recreational, road connectivity etc, less financial incentives for the doctors, no financial incentives for the paramedical staff, Mewat was perceived to be a punishment posting by the health care providers.

Accredited social health activists, free referral transport facilities and treatment facilities in rural areas were perceived to have increased the demand and utilization of $\mathrm{MCH}$ services especially institutional delivery, even by the poor families. Village Health Nutrition Day and Village Health Nutrition and Sanitation Committee scheme was not reported to be implemented well. A medical officer reported that few village heads [presidents] were expecting 'some money' [bribe] from the allocated committee funds (about 154 USD) for the infrastructure and program-related activities. As a result, auxiliary nurses were hesitant to withdraw the funds from the joint bank account and these remained unutilized. Involvement of grass-root worker from women and child development department (member) in the 
operationalization of bank account was also a barrier in the utilization of funds, due to lack of inter-sectoral coordination. Overall it was believed that NRHM has a role in improving $\mathrm{MCH}$ outcomes and reduction in geographical and socioeconomic inequalities, but reduction in gender-based inequalities was linked to adoption of small family size and increase in educational status.

The pathways for change, as derived from theory of change, which might have led to these improvements are depicted in Figure 2, Chapter 5. The NRHM's four pillars and its interventions are depicted at the bottom. The arrows from the interventions lead to the boxes that represent the outputs. The weight of the arrows indicates the intensity of the effect of that intervention on the outputs. The arrows from outputs lead to the outcomes and finally to the impact at the top. As per theory of change, NRHM's interventions are the preconditions to produce outputs, outputs to the outcomes and outcomes to the impact. An important precondition to achieve the NRHM's goal of reduction in IMR and MMR and MCH inequalities was the delivery by skilled birth attendants, especially in rural areas and for poor women. Delivery by skill birth attendant was ensured by institutional delivery. The pathways for change which might have led to increase in institutional delivery included availability of accredited social health activists in the villages, who did behavior change communication with mothers and potential influencers in the family, empowered the pregnant women with enough knowledge regarding health sector plans of NRHM (like free ambulance service, free hospital delivery, free neonatal treatment, financial incentives for hospital delivery) and enabled them to take decision regarding institutional delivery. She acted as a bridge between the community and public hospitals. As a result, the community was mobilized to use the $\mathrm{MCH}$ facilities in rural areas. These factors, along with the availability of health facilities and doctors in rural areas and the free ambulance service, further improved the accessibility and affordability of MCH services and benefitted poor pregnant women and children. 
However, several client and community level barriers were observed in implementing NRHM's plans during qualitative interviews. Client level barriers were poor awareness about NRHM's schemes, overriding household responsibilities of mothers that prevent them to access immediate postnatal care in the hospitals, phobia towards injections or operations especially in district Mewat, lack of faith in medicines in government supply especially for children, and unmet basic needs like food. Community level barriers were low social status of women, lack of decision making power of the mothers, gender disparities in providing childcare, cultural barriers among some religious minority communities that discouraged institutional deliveries, immunization and uptake of family-planning methods, lack of willingness of the community members to wait for their turn to see a doctor in public health facilities. These were especially more in district Mewat as compared to district Ambala.

Stakeholders (medical officers, program managers and community representatives) suggested several recommendations to overcome the barriers like opening of bank account of pregnant women at zero balance, career incentives to doctors working in rural/ difficult areas, financial incentives to all paramedical staff working in difficult areas, maintenance of ambulances on regular basis, availability of more ambulances, alternative doctors (Ayuervedic/Homeopathic) to be recruited in mobile medical units, financial incentives of accredited health activists should be increased as per performance.

Mixed methods findings

The extent of implementation and effectiveness of NRHM' health sector plans in improving the $\mathrm{MCH}$ outcomes and reducing geographical, socioeconomic and gender based $\mathrm{MCH}$ inequality are discussed below using the results of quantitative and qualitative study. Joint display of these findings is given in Table 1. 
Table 1. Joint display of quantitative and qualitative findings regarding extent of implementation and effectiveness of NRHM's plans in Haryana.

\begin{tabular}{|c|c|c|c|}
\hline \multirow[t]{2}{*}{ NRHM's plans } & \multicolumn{3}{|c|}{ Extent of implementation } \\
\hline & \multicolumn{2}{|c|}{ Quantitative findings } & \multirow[t]{2}{*}{ Qualitative findings } \\
\hline $\begin{array}{l}\text { Health System } \\
\text { Strengthening }\end{array}$ & $\begin{array}{l}\text { Proportion } \\
\text { of budget left } \\
\text { unspent }\end{array}$ & Status & \\
\hline $\begin{array}{l}\text { Patient transport } \\
\text { service/referral } \\
\text { services }\end{array}$ & $-11.5 \%$ & $\begin{array}{l}\text { Fully } \\
\text { implemented }\end{array}$ & $\begin{array}{l}\text { Free availability of ambulance service; issues } \\
\text { with its maintenance, better services with in the } \\
\text { ambulance needed at par with private, } \\
\text { ambulance contact number could not be reached } \\
\text { possibly due to frequent callers; late arrivals to } \\
\text { the homes, inadequate number of vehicles; } \\
\text { linked to increase in institutional delivery }\end{array}$ \\
\hline $\begin{array}{l}\text { Infrastructure } \\
\text { development and } \\
\text { strengthening }\end{array}$ & $50.2 \%$ & $\begin{array}{l}\text { Partially } \\
\text { implemented }\end{array}$ & $\begin{array}{l}\text { Well equipped health centers in rural areas, non } \\
\text { availability of waiting halls for patients in the } \\
\text { health facilities, availability of clean health } \\
\text { centers }\end{array}$ \\
\hline Human resources & $-10.8 \%$ & $\begin{array}{l}\text { Fully } \\
\text { implemented }\end{array}$ & $\begin{array}{l}\text { Acute shortage of manpower especially } \\
\text { specialist, contractual staff available but quality } \\
\text { of contractual staff is an issue, salary of } \\
\text { contractual staff not at par with regular staff, } \\
\text { negative attitude of doctors, specialists not } \\
\text { evenly distributed with in the state }\end{array}$ \\
\hline $\begin{array}{l}\text { Drugs and } \\
\text { logistics }\end{array}$ & $-71.0 \%$ & $\begin{array}{l}\text { Fully } \\
\text { implemented }\end{array}$ & $\begin{array}{l}\text { Free availability of medicines in health centers } \\
\text { in rural areas; quality is an issue; stock out of } \\
\text { situations }\end{array}$ \\
\hline $\begin{array}{l}\text { Mobile medical } \\
\text { units }\end{array}$ & $44.9 \%$ & $\begin{array}{l}\text { Partially } \\
\text { implemented }\end{array}$ & $\begin{array}{l}\text { Functional status of mobile medical units an } \\
\text { issue, non availability of doctors, limited } \\
\text { awareness of mobile medical units in the } \\
\text { villages }\end{array}$ \\
\hline \multicolumn{4}{|l|}{ Communitization } \\
\hline $\begin{array}{l}\text { Accredited } \\
\text { Female Health } \\
\text { Activist }\end{array}$ & $-32.2 \%$ & $\begin{array}{l}\text { Fully } \\
\text { implemented }\end{array}$ & $\begin{array}{l}\text { Role in immunization of children and pregnant } \\
\text { women, improving institutional delivery, } \\
\text { generating awareness about NRHM schemes \& } \\
\text { importance of institutional delivery } \\
\text { Accompanies the families while travelling to } \\
\text { the hospital; insufficient number; educational } \\
\text { qualification has a bearing on recruitment of } \\
\text { accredited social health activists; well known in } \\
\text { the villages; good rapport with the women, } \\
\text { especially decision makers (mother in laws); } \\
\text { calls free ambulance; Community Mobilizer }\end{array}$ \\
\hline
\end{tabular}




\begin{tabular}{|c|c|c|c|}
\hline $\begin{array}{l}\text { Village health and } \\
\text { sanitation } \\
\text { committees }\end{array}$ & $59.2 \%$ & $\begin{array}{l}\text { Partially } \\
\text { implemented }\end{array}$ & $\begin{array}{l}\text { Immunization sessions held on village health } \\
\text { and nutrition days; mother meetings also held } \\
\text { on these days; Known popularly as village } \\
\text { health 'mela'; Not held regularly }\end{array}$ \\
\hline $\begin{array}{l}\text { Village health and } \\
\text { nutrition days }\end{array}$ & $0 \%$ & $\begin{array}{l}\text { Partially } \\
\text { implemented }\end{array}$ & $\begin{array}{l}\text { Less awareness by mothers and community } \\
\text { members, members are not involved in } \\
\text { planning; village head would ask for bribe for } \\
\text { utilizing the funds, funds remain unutilized; } \\
\text { anganwadi worker involvement in funds } \\
\text { handling leading to underutilization }\end{array}$ \\
\hline
\end{tabular}

Maternal health care strategies

Janani Suraksha $\quad 19.8 \% \quad$ Partially $\quad$ Funds remain unutilized; Delay in payment due Yojna implemented to administrative reasons; Lack of knowledge imparted to the mothers about the scheme; Linked with opening of bank accounts leading to issue in delivering the benefits to women who do not have bank accounts; Proofs required to get the benefits; Linked with increase in institutional delivery

\begin{tabular}{|c|c|c|c|}
\hline $\begin{array}{l}\text { Janani Shishu } \\
\text { Suraksha } \\
\text { Karyakaram }\end{array}$ & $48.4 \%$ & $\begin{array}{l}\text { Partially } \\
\text { implemented }\end{array}$ & $\begin{array}{l}\text { Free diet during hospital stay; Implementation } \\
\text { is partial due to lack of adequate manpower; } \\
\text { Linked with increased institutional delivery }\end{array}$ \\
\hline
\end{tabular}

\section{Child health care strategies}

Facility based new $\quad 69.1 \%$ born care

Integrated

management of

childhood

illnesses
Partially implemented

Partially implemented neonatal and childhood illnesses implementation; Community lack trust on government facilities for treatment of sick children so do not visit subcenters in villages for treatment (less demand at subcenter level); Lack of supervision; Poor implementation; Focus has been shifted from Integrated management of neonatal and childhood illnesses to home based post natal care

\begin{tabular}{lcll}
$\begin{array}{l}\text { Infant and young } \\
\text { child feeding }\end{array}$ & $43.6 \%$ & $\begin{array}{l}\text { Partially } \\
\text { implemented }\end{array}$ & Not reported \\
$\begin{array}{l}\text { Nutrition } \\
\begin{array}{l}\text { Rehabilitation } \\
\text { Centers }\end{array}\end{array}$ & $99.4 \%$ & $\begin{array}{l}\text { Not } \\
\text { implemented }\end{array}$ & Not reported \\
Immunization & $-5.4 \%$ & $\begin{array}{l}\text { Fully } \\
\text { implemented }\end{array}$ & $\begin{array}{l}\text { Lack of sufficient auxiliary nurse midwives } \\
\text { leads to partial implementation of immunization } \\
\text { sessions; Cultural barrier are there for }\end{array}$ \\
\hline
\end{tabular}




\begin{tabular}{|c|c|c|c|}
\hline & & & $\begin{array}{l}\text { immunization of children especially in district } \\
\text { Mewat; Fear of injections; accredited social } \\
\text { health activists an catalyst in providing } \\
\text { immunization in the form of mobilizing the } \\
\text { community }\end{array}$ \\
\hline $\begin{array}{l}\text { Effectiveness of } \\
\text { NRHM's plans }\end{array}$ & $\begin{array}{l}P \text { value for } \\
\text { difference in } \\
\text { the inequality } \\
\text { across time } \\
\text { periods }\end{array}$ & & \\
\hline $\begin{array}{l}\text { Geographical } \\
\text { inequality } \\
\text { between urban } \\
\text { and rural areas }\end{array}$ & 0.00 & $\begin{array}{l}\text { Significant } \\
\text { decline }\end{array}$ & $\begin{array}{l}\text { Increase in antenatal registrations in rural areas, } \\
\text { gap is bridged with more villagers utilizing } \\
\text { services than urban people due to NRHM. } \\
\text { Awareness has improved and medicines are } \\
\text { available in villages however facilities are still } \\
\text { more in cities. }\end{array}$ \\
\hline $\begin{array}{l}\text { Socioeconomic } \\
\text { inequality } \\
\text { between rich and } \\
\text { poor }\end{array}$ & 0.00 & $\begin{array}{l}\text { Significant } \\
\text { decline }\end{array}$ & $\begin{array}{l}\text { Socioeconomic inequalities have decreased to } \\
\text { some extent because of availability of free } \\
\text { ambulances, medicines, diet during hospital } \\
\text { stay for the poor. Food security in general } \\
\text { would reduce this. }\end{array}$ \\
\hline $\begin{array}{l}\text { Gender inequality } \\
\text { between male and } \\
\text { female child }\end{array}$ & 0.00 & $\begin{array}{l}\text { Significant } \\
\text { decline }\end{array}$ & $\begin{array}{l}\text { NRHM has no scheme for targeting gender } \\
\text { inequality; Small size of the families and } \\
\text { increased educational status has led to the } \\
\text { changes in gender inequality; Gender inequality } \\
\text { is less seen in Mewat district }\end{array}$ \\
\hline
\end{tabular}

\section{Health system strengthening}

It was observed from the quantitative study that this component was partially implemented.

About $50 \%$ of the sanctioned budget was spent annually for infrastructure development (Web

Table 2). Although, there had been increase in number of community health centers, primary health centers and sub centers in the rural areas during NRHM implementation in Haryana as per quantitative findings, yet the requirement was much more as per the population norms according to qualitative study. It was also reported that many centers lacked certain diagnostic facilities (in community health centers) and waiting halls for patients (in sub centers and primary health centers). 
It was observed that budget on the drugs and logistics was exhausted fully and this component was fully implemented during NRHM implementation, quantitatively. This finding was validated qualitatively. It was reported that free medicines were available in the public health facilities after the NRHM implementation, which had benefitted the poor patients maximally. Patient transport service that was launched during 2008-09, was fully implemented as per the data on budget spent on implementing this activity in Haryana. This was also evident from the qualitative study. The ambulance dial number was widely disseminated among the villagers in the district Ambala. The service providers and program managers perceived the free ambulance service as the major factor contributing to the increase in institutional deliveries in the rural areas. However, qualitatively it was reported that ambulances were slowly breaking down and there was no maintenance or repair of broken down ambulances.

There was gradual increase in budget expenditure on human resources during NRHM implementation. Overall, this component was fully implemented. Qualitatively, it was reported that the availability of doctors, auxiliary nurse midwives, staff nurses increased during the NRHM period, but simultaneously that the demand of services had increased manifold leading to acute shortages of manpower. Shortages of doctors had also overburdened the existing staff and resulted in a poor access to health care by patients. Implementation of Mobile Medical Units was partial in the state, which is also evident from the results of qualitative study. The medical mobile unit, intended to cater the $\mathrm{MCH}$ needs of the hard-to-reach areas in the Mewat district, was believed to be non-functional, possibly due to the lack of doctors.

\section{Communitization}

Accredited Social Health Activists scheme was fully implemented quantitatively, and was also the most appreciated scheme by all the participants, qualitatively. According to the interviewees, utilization of the ambulance and health facilities by the mothers had also 
increased through the accredited social health activists in the villages. The implementation of Village Health Nutrition Day and Village Health Nutrition and Sanitation Committee schemes was partial, quantitatively. Qualitative findings provided the reasons for the partial implementation of these schemes, like low priority for implementation of these schemes at the state level, poor monitoring and supervision of these schemes, shortage of auxiliary nurses for celebrating Village Health Nutrition Day every month; lack of inter-sectoral coordination for utilization of committee's funds.

\section{Maternal and child health schemes}

Quantitatively, it was observed that implementation status of all the maternal and child health schemes (Janani Suraksha Yojna, Janani Sishu Suraksha Yojna) was partial except for home based post-natal care and immunization. During the qualitative interviews it was observed that although increase in institutional deliveries was linked with the implementation of schemes like financial incentives for institutional deliveries (Janani Suraksha Yojna) and free hospital delivery and free treatment in the hospitals (Janani Sishu Suraksha Yojna), however funds remained unutilized under financial incentive schemes. This was because of linking of funds disbursement with opening of bank accounts of pregnant women, which had lead to issue in delivering the benefits to women who do not have bank accounts. Also proofs were required to get these benefits. Implementation of free hospital delivery scheme was partial due to lack of adequate manpower. In addition recommended stay in the hospital for a minimum of 48 hours after hospital delivery was not possible by many postnatal women, inspite of the guidelines, due to insufficient number of hospital beds and overriding household responsibilities of the women. Qualitatively, immunization scheme was not fully implemented especially in district Mewat, due to barriers like inadequate number of auxiliary nurse midwives, cultural barriers, fear of injections. 


\section{MCH indicators and inequalities}

Both quantitative and qualitative study results provided evidence that there had been marked improvement in $\mathrm{MCH}$ indicators and reduction in geographical and socioeconomic inequalities in $\mathrm{MCH}$. Qualitatively, the reason for reduction of $\mathrm{MCH}$ inequalities was reported to be due to more awareness regarding $\mathrm{MCH}$ services, availability of medicines and health facilities and increased utilization of $\mathrm{MCH}$ services in rural areas and availability of free ambulances, medicines, diet during hospital stay for the poor.

While quantitative data shows that there has been reduction in gender-based inequality in immunization status of male and female children, the qualitative study provide insight into this change. Injections given for immunization of children were not perceived to be very safe for children; hence, care providers (especially in the Mewat district) would let girls have it rather than the boys.

\section{Discussion}

This mixed method study has presented the holistic and in-depth review of the extent and effectiveness of NRHM's MCH plans i.e., health system strengthening, communitization, maternal and child health care strategies in Haryana, quantitatively and qualitatively. Both quantitative and qualitative study reported overall partial implementation of NRHM's MCH plans in Haryana. Quantitative results of improved $\mathrm{MCH}$ outcomes and reduction in geographical and socioeconomic $\mathrm{MCH}$ inequality were enhanced and validated by the qualitative study. However, the qualitative explanation for improved immunization status among girls than boys as observed in quantitative study was quite a revelation. It was perceived that immunization was unsafe and hence would rather let the girl children get it than the boys (especially in district Mewat). Wesely (2010) have reported that mixed methods research can be uniquely revealing, and it can accommodate multiple theoretical frameworks 
[25]. The results of the qualitative study also proffered the explanation for the improved $\mathrm{MCH}$ outcomes and reduction in inequalities through the construction of pathways of change, and how these could not work in district Mewat, as all the preconditions were not met.

Regarding extent of implementation of NRHM's health sector plans various circumstantial and contextual factors are identified in this mixed methods study especially in district Mewat, like acute shortage of human resources at all levels of health care delivery system, cultural barriers in accepting immunization/injection etc. Barriers that are reported to prevent the availability of health care providers in this study pointed towards the fact that policies regarding human resource management need a revamping in the state. The local residents from the respective district should be empowered, educated and qualified enough to work in their respective districts. Health care providers should be offered the place of posting of their native area. Similar status and inequality in distribution of human resources is reported at the base of health care delivery system, by Pallikadavath et al (2013) in India [26]. The contextual factors reported in their study were the percentages of villages connected with allweather roads and having primary schools. Mukherjee et al (2010) had interviewed 100 rural doctors from the states of Orissa, Assam, Jharkhand and Chattisgarh and observed similar inefficiencies in terms of infrastructure and human resource provision as observed in this study [10].

The fact that poor patients are maximally benefitted through provision of free medicines as part of health system strengthening is substantiated by the fact that the trend of utilization of public hospitals is changing in India. A study by Prinja et al (2013) has reported that in contrast to previous studies, India's poor reported using hospital services in the public sector at a higher rate than the wealthy. In Haryana, hospitalization rate among lowest wealth quintile group was $32.3 / 1000$ persons as compared to $29.6 / 1000$ persons among highest wealth quintile group in that study [27]. The role of accredited social health activists as a 
catalyst in improving the institutional delivery rate, immunization rate and utilization of various MCH schemes in rural areas was also observed in Uttar Pradesh [28] and Manipur in India [29]. Such role of indigenous community health workers in improving $\mathrm{MCH}$ is also reported in countries other developing countries like Bangladesh [30] and developed countries like Canada among vulnerable groups [31]. Increase in utilization of antenatal care and delivery by skilled birth attendants following implementation of financial incentive scheme (Janani Suraksha Yojna) is also reported by Kingkaew et al (2016) in Myanmar [32]. However, similar barriers in utilizing funds under financial incentive scheme like the need for having identity documents by pregnant women are also reported by Chaturvedi et al (2015) in Madhya Pradesh [33]. Priedman et al (2013) suggested that if service use is uniformly low then a performance based financing program that incentivizes select services, such as facility deliveries, may improve service use overall [34]. However, if the equity gap is extreme, then performance based financing program without equity targets will do little to alleviate disparities. Sah et al (2013) have reported similar low functional status of village health nutrition and sanitation committees in Maharashtra, India as observed in this study [35]. At the ground level, NRHM schemes were sometimes considered poorly visible indicating an information gap between service providers and users. Perhaps lessons can be learnt from Taleb et al (2015) study in Bangladesh, where the maternal and newborn health improved by a focused and dedicated bridging of the information gap through community-based programs that influenced knowledge levels and practices of women [36]. Qualitative findings had also pointed towards the overall socio-political context of a district, especially in district Mewat, in improving $\mathrm{MCH}$. There was less political will to develop district Mewat, probably because of increased allocation of funds to this district due to its underdeveloped status [37, 38].

The planning commission of India had the NRHM schemes evaluated in seven states (Uttar Pradesh, Madhya Pradesh, Jharkhand, Orissa, Assam, Jammu and Kashmir and Tamil Nadu) during the fourth year of its implementation (2009-10) using quantitative and qualitative 
study. They observed some improvements in the availability and utilization of MCH services in rural areas, and recommended further strengthening of health facilities [9]. However, their evaluation was limited by the lack of assessment of the extent of implementation of NRHM schemes, the lack of comparison of results with the situation before the implementation of the NRHM, the lack of measurement of maternal and child health inequalities, and the lack of interpretation of quantitative data and qualitative data by a mixed-methods approach. These limitations are overcome by this study.

Reviews of data on maternal and child health inequalities in India have shown marked maternal and child health inequalities during antenatal, natal or postnatal period to the disadvantage of the poor [39-46]. However, most of the earlier studies reflect the situation before NRHM implementation, which is similar to the situation observed during that period in this study also (2002-04). Since this study compared the MCH status and inequalities pre, during and post NRHM, this is perhaps the first study that not only documents partial bridging of $\mathrm{MCH}$ inequalities across geographical, socioeconomic and gender domains, but also provides the explanation for such findings. Further since state-specific information is necessary, as each state is different, having its own unique cultural, social, and demographic backgrounds and problems, this study also provides some of the solutions to further bridge the gaps which are tailor-made to Haryana (especially district Mewat), as is also suggested by Pathak et al [42]. However, the lessons learnt from this study are applicable to other states in India as well.

The strength of this study is the mixed methods study design, as quantitative surveys assessed peoples' needs based on the providers' understanding of people's needs, which in this study was complimented by assessing the felt needs of the health service users as well through conducting qualitatively study. Thus a mixed methods approach brought the users' perspective to the fore [4-6]. Joint display of quantitative and qualitative data helped us in understanding how mixed methods design provided new insight into the implementation 
process of NRHM's MCH plans [47, 49]. Owing to the complex issues underlying research into community health mixed methods research is an effective method of enquiry for community health research and is a foundation for primary care research $[50,51]$. This is probably the first study that has evaluated the national program using mixed methods approach in Indian settings, and has provided useful insight and explanations for the findings of the quantitative study.

Having said so, there is definitely a scope for improvement in future for carrying out such studies. In-depth review of how funds are being spent on implementing the NRHM's scheme in the district, right to the village level, can give us better understanding of the process of budget expenditure on implementing programs at various health care delivery levels. This information will bring further clarification on barriers and facilitating factors to improve the implementation. We also acknowledge that the budget left unspent may not indicate true implementation status of a given NRHM plan, because the reasons why it could not be spent fully might be due to more efficient use of funds or too high estimation on the forehand, hence this aspect was investigated qualitatively as well so as to have better insight of how spending of the money is appreciated and judged by the key persons involved.

The causal association between NRHM implementation and MCH outcomes and inequalities however, cannot be established, as there was no control region (without NRHM). There might have been other (confounding) developments in the same time period (e.g. improving socioeconomic conditions in general) that brought up the positive changes.

The results of this study has an implication for policy makers on the way the program is implemented during the second phase of NRHM as part of National Health Mission. What we have learnt from the first phase is that, substantial gains are observed for schemes that have aimed at increasing the institutional delivery rate among the poor women and in rural areas. 
These schemes were free referral transport services, free hospital delivery, financial incentives for institutional delivery, improved access to delivery points and availability of accredited social health activists in the villages linking the community with the health care delivery system. Hence it is recommended that these schemes should be further strengthened. Reported bottle necks for the implementation of these schemes were insufficient number of ambulances per district especially district Mewat, non existent maintenance mechanisms for the ambulances, insufficient human resource (auxiliary nurse midwives, doctors and accredited social health activists), administrative delays in providing incentives to the pregnant women. While schemes aimed at improving child health like integrated management of neonatal and childhood illness needs more attention at the implementation level. Hence during the implementation of second phase of NRHM these bottlenecks should be targeted, and improved planning and implementation should be done after carefully considering the recommendations suggested in this study. A structured mixed methods approach in the initial development of a rigorous community-based participatory research program to develop culturally tailored and community-based health interventions for vulnerable populations (especially for district Mewat) will be better approach for designing future interventions [52]. Overall it can be said that Haryana is on the right track for achieving the sustainable development goals of reducing maternal and child health inequalities. The results of this study may also be useful for other states in India that are now implementing the second phase of the NRHM. 


\section{References}

1. Say L, Raine R. (2007). A systematic review of inequalities in the use of maternal health care in developing countries: examining the scale of the problem and importance of the context. Bull World Health Organ. 2007; 85(10): 812-9.

2. Registrar General of India. Special Bulletin on Maternal Mortality in India. Sample Registration System 2011-13. Available at http://www.censusindia.gov.in/vital_statistics/mmr_bulletin_2011-13.pdf. Accessed 10 September 2015.

3. Registrar General of India. Sample Registration System. Available http://www.censusindia.gov.in/vital_statistics/SRS_Bulletins/SRS\%20Bulletin\%20Sepetember\%202014.pdf .

4. Kaur M. Application of mixed method research in Public Health. Indian J Comm Medicine. 2016; 41(2): 93-97.

5. Creswell J W. A concise introduction to mixed methods research. Thousand Oaks, CA: Sage Publications; 2015.

6. Hota P, Dobe M. National Rural Health Mission. Indian J Public Health. 2005; 49(3): 10710.

7. Gupta M, Angeli F, van Schayck OC, Bosma H. Effectiveness of a multiple strategy community intervention to reduce maternal and child health inequalities in Haryana, North India: a mixed methods study protocol. Glob Health Action. 2015; 8: 25987. http://dx.doi.org/10.3402/gha.v8.25987

8. Ministry of Health and Family Welfare. National Rural Health Mission. Framework for implementation. Government of India. New Delhi. 2005. Available at http://nrhm.gov.in/nhm/nrhm/nrhm-framework-for implementation.html. Accessed 10 September 2015.

9. Planning Commission. Evaluation study of National Rural Health Mission (NRHM) in seven states. Programme Evaluation Organisation. Government of India. 2011. Available at http://planningcommission.nic.in/reports/peoreport/peoevalu/peo_2807.pdf. Accessed 10 September 2015.

10. Mukherjee S. A study on effectiveness of NRHM in terms of reach and social marketing initiatives in rural India. European Journal of Scientific Research. 2010; 42(4): 573.

11. Economic Survey of Haryana. Department of Economic and Statistical Analysis Haryana. Government of Haryana. 2012-13. Available at http://web1.hry.nic.in/budget/Esurvey.pdf. Accessed 10 September 2015.

12. Ministry of Health and Family Welfare. Government of India. National Health Mission. 2013. Available at http://nrhm.gov.in/. Accessed 22 October 2015.

13. Leech N L, Onwuegbuzie A J. A typology of mixed method research designs. Qual Quant. 2009; 43: 265-275.

14. National Rural Health Mission. Record of Proceedings to approve PIP of Haryana. Government of Haryana. India. 2005-12. Available at http://www.nrhmharyana.gov.in/files/ROP\%202009-10.pdf. Accessed on 6 April 2015.

15. International Institute of Population Sciences. District Level Household and Facility Survey-2. Haryana Report. Reproductive and Child Health Project. Ministry of Health and Family Welfare. New Delhi. 2002-04.

16. International Institute of Population Sciences. District Level Household and Facility Survey-3. Haryana Report. Reproductive and Child Health Project. Ministry of Health and Family Welfare. New Delhi. Haryana. 2007-08. 
17. International Institute of Population Sciences. District Level Household and Facility Survey-4. State Fact Sheet Haryana. Reproductive and Child Health Project. Ministry of Health and Family Welfare. New Delhi. 2012-13.

18. International Institute of Population Sciences. District Level Household and Facility Survey-4. Haryana Report. Reproductive and Child Health Project. Ministry of Health and Family Welfare. New Delhi. 2012-13.

19. Gupta M, Angeli F, Bosma H, Prinja S, Kaur M, van Schayck OC. Extent of implementation of a multiple-strategy community intervention for reducing maternal and child health inequalities in Haryana India. 2016. (Unpublished paper).

20. Gupta M, Angeli F, Bosma H, Rana M, Prinja S, Kumar R, van Schayck OC et al. Effectiveness of multiple-strategy community intervention in reducing geographical, socioeconomic and gender inequalities in maternal and child health outcomes in Haryana, India. PLoS one. 2016. 11(3): e0150537. doi:10.1371/journal.pone.0150537.

21. International Institute of Population Sciences. District Level Household Surveys. Fact Sheet District Ambala. Reproductive and Child Health Project. 2012-13.

22. International Institute of Population Sciences. District Level Household Surveys. Fact Sheet District Mewat. Reproductive and Child Health Project. Ministry of Health and Family Welfare. New Delhi. India. 2012-13. Available at http://www.rchiips.org/ARCH-1.html. Accessed on 20 October 2015.

23. Gupta M, Bosma H, Angeli F, Kaur M, Chakarpani V, Rana M, van Schayck OC. Qualitative study on the effectiveness of a multiple-strategy community intervention to reduce maternal and child health inequalities in Haryana, India. 2016. (unpublished paper).

24. Registrar General of India. Maternal and Child Mortality and Total Fertility Rates. Sample Registration System. 2004-06, 2007-09. Available at http://www.censusindia.gov.in/vital_statistics/SRS_Bulletins/MMR_release_070711.pdf. Accessed 20 October 2015.

25. Wesely P M. Language learning motivation in early adolescents. J Mix Methods Res. 2010; 4(4): 295-312.

26. Pallikadavath S, Singh A, Ogollah R, Dean T, Stones W. Human resource inequalities at the base of India's public healthcare system. Health Place. 2013; 23: 26-32.

27. Prinja S, Kumar MI, Pinto AD, Jan S, Kumar R. Equity in hospital service utilization in India. Economic and Political Weekly. 2013; 48:52-58.

28. Jain N, Srivastava NK, Khan AM, Dhar N, Adish V, Menon S, et al. Assessment of functioning of ASHA under NRHM in Uttar Pradesh. Health and Population: Perspective and Issues. 2008; 31(2): 132-140.

29. Sapril L, Richards E, Kokho P, Theobald, S. Community health workers in rural India: analysing the opportunities and challenges Accredited Social Health Activists (ASHAs) face in realizing their multiple roles. Hum Resour Health. 2015; 9(13): 95.

30. Rahman M, Jhohura F T, Mistry SK, Chowdhury T R, Ishaque T, et al. Assessing Community Based Improved Maternal Neonatal Child Survival (IMNCS) Program in Rural Bangladesh. PLoS One. 2015; 10(9),e0136898, doi: 10.1371/journal.pone.0136898. eCollection 2015.

31. Smylie J, Krist M, McShane K, Firestone M, Wolfe S, O'Campo P. Understanding the role of Indigenous community participation in Indigenous prenatal and infanttoddler health promotion programs in Canada: A realist review. Soc Sci Med. 2016;150:12843.

32. Kingkaew $\mathrm{P}$, Werayingyong $\mathrm{P}$, Aye SS, Tin N, Singh A, et al. An ex-ante economic evaluation of the Maternal and Child Health Voucher Scheme as a decision-making tool in Myanmar. Health Policy Plan. 2016; 31(4): 482-92. 
33. Chaturvedi S, Costa De Ayesha, Raven J. Does the Janani Suraksha Yojna cash transfer program to promote facility births in India ensure skilled birth attendance? A qualitative study of intrapartum care in Madhya Pradesh. Global Health Action. 2015. 8: 27427. http://dx.doi.org/10.3402/gha.v8.27427

34. Priedeman S M, Curtis S L, Basinga P, Angeles G. An equity analysis of performance-based financing in Rwanda: are services reaching the poorest women? Health Policy Plan. 2013; 28(8): 825-37, doi: 10.1093/heapol/czs 122 .

35. Sah PK, Raut AV, Maliya CH, Gupta SS. Performance of village health, nutrition and sanitation committee: A qualitative study from rural Wardha, Maharashtra. The Health Agenda. 2013; 1(4):112-117.

36. Taleb F, Perkins J, Ali NA, Capello C, Ali Muzahid, Santarelli C et al. Transforming maternal and newborn health social norms and practices to increase utilization of health services in rural Bangladesh: a qualitative review. BMC Pregnancy and Childbirth; 15:75.DOI10.1186/s12884-015-0501-8.

37. Institute for Human Development. Ministry of Minority Affairs, Government of India and Indian Council of Social Science Research. A baseline survey of minority concentration districts of India. Available at http://www.minorityaffairs.gov.in/msdp. Accessed on 20 September 2015.

38. Niti Ayog. Government of India. Identifying backwardness of Mewat region in Haryana: A block level analysis. 2015. Available at http://niti.gov.in/mgov_file/Identifying\%20Backwardness\%20of\%20Mewat\%20Region\%20in \%20Haryana\%20A\%20Block\%20Level\%20Analysis_final.pdf. Accessed on 20 September 2015.

39. Singh A, Pallikadavath S, Ram F, Ogollah R. Inequalities in Advice Provided by Public Health Workers to Women during Antenatal Sessions in Rural India. PLoS One. 2012; 7(9): e44931, doi: 10.1371/journal.pone.0044931.

40. Singh A, Padmadas S S, Mishra U S, Pallikadavath S, Johnson F A, Matthews Z. Socioeconomic inequalities in the use of postnatal care in India. PLoS One. 2012; 7(5): e37037. doi: 10.1371/journal.pone.0037037. Epub 2012.

41. Goli S, Doshi R, Arokiasamy P. Pathways of economic inequalities in maternal and child health in Urban India: A decompostition analysis. PloS One. 2013; 8(3): e58573. doi:10.1371/journal.pone.0058573

42. Pathak P K, Singh A, Subramanian S V. Economic inequalities in maternal healthcare: prenatal care and skilled birth attendance in India, 1992-2006. PLoS One. 2010; 5(10): e13593. doi: 10.1371/journal.pone.0013593.

43. Pathak P K, Singh A, Subramanian SV. Economic inequalities in maternal health care: Prenatal care and skilled birth attendance in India, 1992-2006. PloS One. 2015; 5(10); e13593. doi:10.1371/journal.pone.0013593.

44. Pathak PK, Singh A. Trends in malnutrition among children in India: growing inequalities across different economic groups. Soc Sci Med. 2011; 73(4): 576-85.

45. Prusty RK, Kumar A. Socioeconomic dynamics of gender disparity in childhood immunization in India, 1992-2006. Plos One. 2014; 9(8): e104598. doi: 10.1371/journal.pone.0104598.

46. Pradhan J, Arokiasamy P. Socioeconomic inequalities in child survival in India: A $\begin{array}{llll}\text { decomposition } & \text { analysis. } & \text { Health }\end{array}$ doi: http://dx.doi.org/10.1016/j.healthpol.2010.05.010 
47. Ostlund U, Kidd L, Wengstrom Y, Rowa-Dewar N. Combining qualitative and quantitative research with in mixed methods research designs: a methodological review. Int J Nurs Stud. 2011; 48(3): 369-83.

48. Creswell JW, Plano ClarkV L. Designing and Conducting Mixed Methods Research. 2nd ed. Thousand Oaks, CA: Sage; 2011.

49. Guetterman TC, Fetters MD, Creswell JW. Integrating quantitative and qualitative results in health science mixed methods research through joint displays. Ann Fam Med. 2015;13(6):55461.

50. Andrew S, Halcomb E J. Mixed methods research is an effective method of enquiry for community health research. Contemp Nurse. 2006; 23(2), 145-53.

51. Jefferey M B. Mixed methods studies: A foundation for primary care Research. Ann Fam Med. 2004; 2(1), 4-6.

52. Windsor LC. Using concept mapping in community-based participatory research: a mixed methods approach. J Mix Methods Res. 2013; 7(3), 274-293. 


\section{Chapter 7}

General Discussion

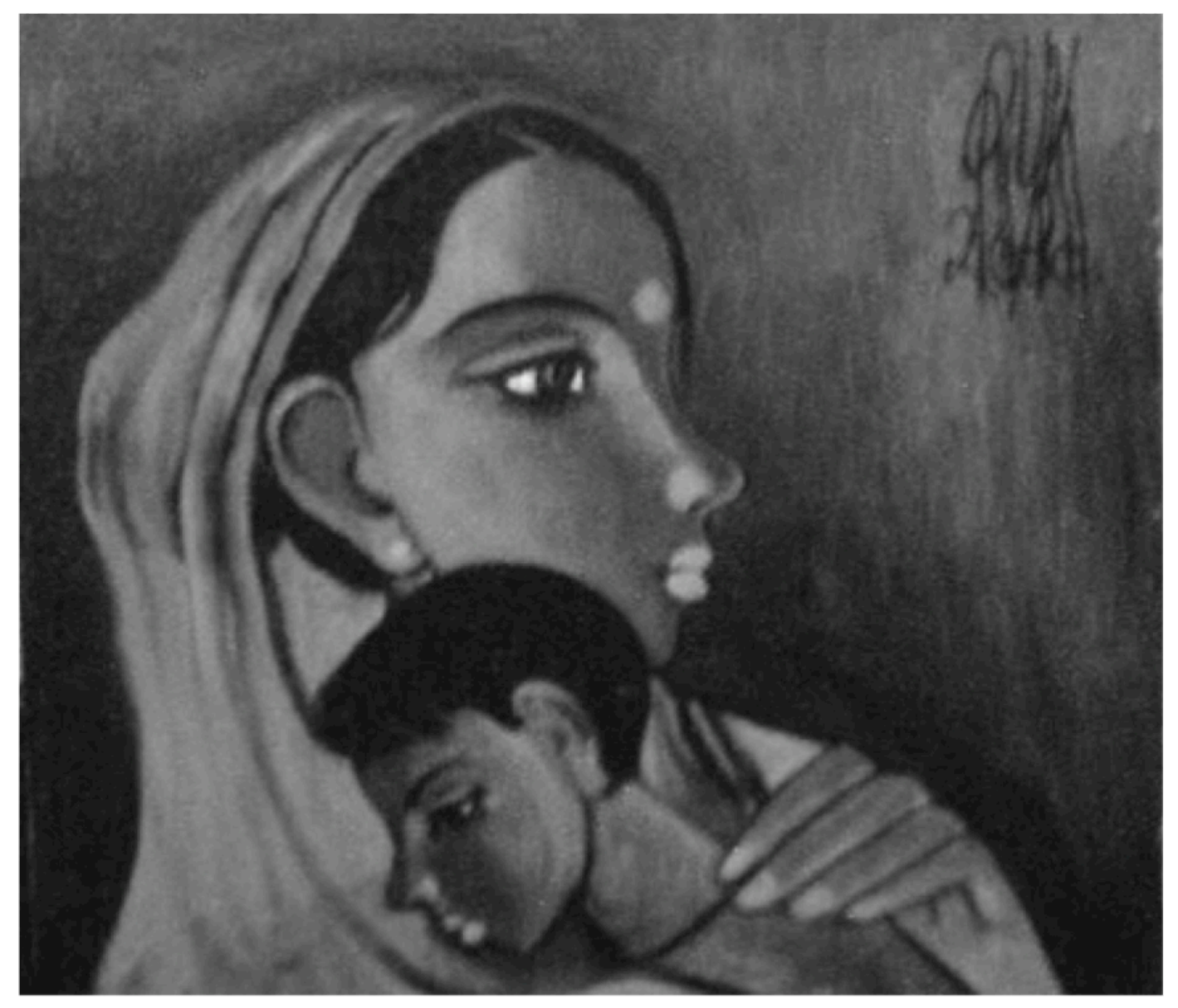




\section{Introduction}

The Ministry of Health and Family Welfare, Government of India launched a national multiple-strategy community intervention known as the National Rural Health Mission (NRHM), during 2005 [1]. It aimed to improve maternal and child health (MCH) and reduce health inequalities by improving the availability of and access to better-quality healthcare especially for people residing in the rural areas (to reduce geographical inequality), for the poor (to reduce socioeconomic inequality) and women and children (to reduce gender inequality). NRHM was started in the $11^{\text {th }}$ health plan (2005-06 to 2012-13) and continued in the $12^{\text {th }}$ health plan (2012 to 2017) as National Health Mission. NRHM's had four major health sector plans including health system strengthening, maternal health care strategies, child health care strategies, and communitization. Health system strengthening included the availability of improved health facilities, increased human resources, free referral transport services for patients, especially for pregnant women and sick children, mobile medical units, free medicines etc. Specific maternal and child health care schemes were financial incentives for institutional deliveries and treatment of sick infants, etc. Communitization (delegating powers to and empowering the community to monitor the healthcare delivery system) included the appointment of female accredited social health activists at the household level in villages, the formation of village health and sanitation committees, and the celebration of village health and nutrition days [2]. The intention of NRHM was to reduce the infant mortality rate to $30 / 1,000$ live births and the maternal mortality to $1 / 1,000$ live births.

This sequential, explanatory mixed methods study was conducted with the first aim to quantify the extent of implementation of NRHM's maternal and child health-related plans in the healthcare sector in Haryana, India from 2005-06 to 2012-13. The second objective was to quantify NRHM's effectiveness in terms of improving the overall maternal and child health outcomes and reducing the geographical, socioeconomic, and gender inequalities in Haryana in the same period. The third objective was to qualitatively ascertain the extent to which maternal and child health strategies in the NRHM were implemented and were effective in tackling the $\mathrm{MCH}$ inequalities and improving the outcomes in two districts, one well performing (district Ambala) and another low performing district (district Mewat), during 2013 (after the completion of the first phase of NRHM). MCH indicators as per the District Level Household Survey, round 3 (2007-08), were used to label the district as well or low performing [3]. Fourth, this study also aimed to formulate evidence-based recommendations for bridging the health inequalities in Haryana state. In the current chapter the main findings of the study are discussed and public health implications as well as future research possibilities are elaborated upon. 


\section{Reflection of the main findings}

\section{Extent of implementation of NRHM}

It was observed in the quantitative study that overall the budget sanctioned for implementation of the maternal and child health sector plans of the NRHM had increased from USD 6.6 million (2005-06) to USD 66.7 million (2012-13). The budget utilization rate for the NRHM's maternal and child health schemes in the Haryana state had also increased from $20.6 \%$ (2007-08) to $89 \%$ (2012-13). Funds were overspent for implementing schemes like the patient referral transport services (111.5\%), human resources (110.8\%), drugs and logistics (171\%), the accredited social health activists scheme (132.2\%), patient welfare committees (105\%) and immunization (105.4\%). The reason for the more than $100 \%$ budget utilization rate was due to grant of additional funds from the state health budget. Hence, it was considered that these schemes were fully implemented, while all other schemes, based upon their low budget utilization rate, were only partially implemented. Overall, the extent of implementation of the NRHM maternal and child health plans was considered to be partial in Haryana.

Based upon the amount of budget spent in implementing the activities, we have indirectly reported the extent of implementation of NRHM plans. However, we have to acknowledge that less spending on implementing the health sector plans may not always mean a poor implementation. Less spending may also happen when the system is more efficient in planning and implementing the plans or when more than sufficient budget is sanctioned, while the actual cost of implementing the plan was lower than estimated beforehand. Hence, to validate and enhance the findings of the quantitative study, we also explored this particular issue during the qualitative study.

From the thematic analysis of qualitative data, it became clear that almost all the stakeholders (program managers, medical officers, auxiliary nurse midwives, accredited social health activists, mothers, and community representatives) believed that there was improvement in the overall health infrastructure (e.g. availability of clean, well-equipped health centers and free medicines in the villages). Hence, these findings confirmed the quantitative results on the status of the implementation. At the same time, additional information was obtained. For example, from the quantitative study, it was observed that there was an increase in the number of health facilities (community health centers, primary health centers or sub-centers in the rural areas) during the NRHM period. However, the qualitative findings indicated that the increase was not sufficient enough to meet the planned norms for a health center based upon 
the size of its catering population (like one sub-center for a population of 5,000 , one primary health center for a population of 30,000 and one community health center for a population of $100,000)$. It became also clear that many health centers lacked certain diagnostic facilities (in community health centers) and waiting halls for patients (in sub-centers and primary health centers).

The gradual increase in the budget expenditure on human resources during the NRHM implementation was validated in the qualitative study by the reported increase in the availability of doctors, auxiliary nurse midwives, and staff nurses during the NRHM period (mainly on a contractual basis). But the simultaneous large increase in the demand of services still led to acute shortages of human resources. The availability of free medicines in the public health facilities increased the number of patients seeking treatment in these health facilities. The quantitative findings indicated that the accredited social health activists scheme and patient welfare committees were fully implemented. This was also confirmed by the qualitative study findings. In the interviews, it was observed that the increase in institutional deliveries was linked with the implementation of schemes that provided financial incentives for institutional deliveries (Janani Suraksha Yojna), free hospital deliveries, and free treatment in hospitals (Janani Sishu Suraksha Yojna). However, part of the funds remained under-utilized, as women needed a unique identification number card or an individual bank account; many poor pregnant women did not have such a card or account. This observation is similar to a study by Chauturvedi et al in Madhya Pradesh in India [4]. The implementation of the free hospital delivery scheme was partial, due to the lack of adequate manpower. Other schemes under the communitization strategy, like the celebration of village health and nutrition days and the installment of village health nutrition and sanitation committees, were also reported to be partially implemented. This is similar to a study of Sah et al (2013). They also reported a poor functional status of village health nutrition and sanitation committees in Maharashtra in India [5].

An estimation of the extent of implementation of $\mathrm{MCH}$ plans according to NRHM is not available from earlier reviews of NRHM [6,7]. Most of the earlier program reviews provided information on the outputs of the programs, like the number of women utilizing health facilities for delivery etc,. In this study, we have looked at both the extent of implementation and the resulting outputs. This provides a more holistic review of NRHM's plans. The fully implemented interventions (free patient referral transport services, human resources, free drugs and logistics, accredited social health activists) in Haryana are already proven key strategies for improving $\mathrm{MCH}$ outcomes and inequalities in other studies [8-12]. However, 
the central or local government also need to place more emphasis on the infrastructure development and strengthening, putting in place 24 hours delivery services, treatment of sick children at health facilities, and implementing infant and young child feeding, village health and sanitation committees, and village health and nutrition day celebrations. This will allow an effective implementation of NRHM as to reach the intended goal of reducing infant and maternal mortality and related inequalities.

Several studies have reported on the importance of health financing for improved health outcomes. Singh (2014) in his systematic review on the relationship between public health spending and population health outcomes concluded that financial investments in public health have the potential to improve community health [13]. Bekemeier et al (2012) pointed out that need-based allocations of the funds for programs on $\mathrm{MCH}$ are better for improving services [14]. Farag et al (2013) examined the relationship between a country's health spending and child health (infant and child mortality) among low- and middle-income countries and observed that government health spending has a significant effect on reducing infant and child mortality [15]. A direct correlation between the level of public health spending and an improving equitable utilization of health services has also been shown in Haryana, India [16]. The present study also provides evidence on public health spending on implementing $\mathrm{MCH}$ plans at the state level and on effectiveness of these plans in improving $\mathrm{MCH}$ outcomes and reducing inequalities. This evidence further strengthens the role of health financing and public health spending in improving maternal and child health and reducing inequalities.

Effectiveness of NRHM in improving the Maternal and Child Health outcomes and reducing inequalities

The quantitative results showed that, after the implementation of NRHM, there were significant $(\mathrm{p}<0.05)$ improvements in most MCH indicators. The MMR had declined from 1.86 (2002-04) to 1.21 (2012-13) maternal deaths per thousand live births and the IMR from 59 (2002-04) to 40 (2012-13) infant deaths per thousand live births in Haryana [17-19]. However, the intended goal of a reduction of MMR to 1/1000 live births and of IMR to $30 / 1000$ live births could not be achieved by 2012-13. The geographical and socioeconomic differences between urban and rural areas and between rich and poor women were significantly $(\mathrm{p}<0.05)$ reduced regarding the percentage of pregnant women having institutional deliveries (the geographical difference declined from $22 \%$ to $7.6 \%$ and the socioeconomic from $48.2 \%$ to $13 \%$ ), regarding post-natal care within 2 weeks of delivery 
( $2.8 \%$ to $1.5 \% ; 30.3 \%$ to $7 \%$ ), regarding children with full vaccination (10\% to $3.5 \%, 48.3 \%$ to $14 \%$ ), and regarding children who received the oral rehydration solution (ORS) for diarrhea ( $11 \%$ to $-2.2 \% ; 41 \%$ to $5 \%$ ). Inequalities between male and female children were even significantly $(\mathrm{p}<0.05)$ reversed for full immunization $(5.7 \%$ to $-0.6 \%)$ and BCG immunization (1.9 to -0.9 points) and a significant $(\mathrm{p}<0.05)$ decrease was observed for oral polio vaccine (4.0\% to $0 \%$ ) and measles vaccine ( $4.2 \%$ to $0.1 \%$ ) [20]. The negative values are because of higher proportion of girls immunized as compared to boys.

The qualitative findings provided insight into the pathways for change that might have led to these changes. This research was based upon grounded theory, program theory of change, and a framework analysis. It was observed that the pathway for the increase in institutional deliveries in rural areas was through the availability of accredited social health activists in the villages. They initiated behavior change communication with mothers and potential influencers in the family, empowered the pregnant women with enough knowledge regarding health sector plans of NRHM (like the free ambulance service, free hospital deliveries, free neonatal treatment, and financial incentives for hospital deliveries) and enabled them to take decisions regarding an institutional delivery. She acted as a bridge between the community and public hospitals. As a result, the community was mobilized to use the $\mathrm{MCH}$ facilities in rural areas. These factors, along with the availability of health facilities and doctors in rural areas and the free ambulance services further improved the accessibility and affordability of $\mathrm{MCH}$ services in rural areas and particularly benefitted the poor pregnant women and children. This might have resulted in the reduction of $\mathrm{MCH}$ inequalities across geographical and socioeconomic sectors. From the provider's perspective, facilitating factors for the NRHM's implementation was the availability of untied funds for meeting the local needs of the health facilities. From the program manager's perspective, the facilitating factor was the flexible financing of the NRHM's health sector funds. This flexibility in spending the NRHM's health sector funds enabled them to direct the funds to those areas where these were most needed (e.g., human resources, accredited social health activists, drugs and logistics, or immunization). As per the commitment nationally, they had to keep the minimum amount earmarked for the other disease control programs as well.

However, not all these preconditions were met fully in district Mewat (low-performing district) as opposed to district Ambala (well-performing district). While quantitative data had shown that there was a reduction in the gender-based inequality in immunization status of 
male and female children, the qualitative study provided insight into this change. The injections given for the immunization were not perceived safe. Caretakers (especially in the Mewat district) would therefore let girls have it rather than the boys. Also individual (like a low awareness of NRHM's schemes) and community-level barriers (like cultural factors) were more often encountered in district Mewat. That may be the reason for the district's lower performance in terms of $\mathrm{MCH}$ outcomes. The individual and community-level barriers in accessing $\mathrm{MCH}$ care were similar to other studies in India [21-23]. The experience of district Mewat in this study has shown that both economic and cultural factors are relevant and need to be addressed holistically to improve the $\mathrm{MCH}$. The economic factors influence the income levels and affordability of $\mathrm{MCH}$ services. Economic factors were addressed by providing free institutional delivery and treatment and referral services Cultural factors influence the status of women in society and the educational status of the community. Especially female education has a direct correlation with a better understanding of the $\mathrm{MCH}$ care needs by the population and the demand of and access to $\mathrm{MCH}$ services. By involving the local community leaders, the cultural factors need to be addressed carefully and with increased sensitivity. Cultural factors were perhaps not much taken care of during the NRHM's implementation in Haryana.

The role of accredited social health activists as a catalyst in improving the institutional delivery rate, the immunization rate, and the utilization of various $\mathrm{MCH}$ schemes in rural areas (through the behavior change communication with the mothers and family members in the villages) was also observed in Uttar Pradesh [24] and Manipur in India [25]. However, because of a poor health care delivery system, in terms of an inadequate infrastructure and limited knowledge of activists, the activists' full impact on improving $\mathrm{MCH}$ could not be seen in Manipur. Prinja et al (2014) reported a positive effect of the referral transport service on increasing institutional deliveries and suggested that it needed to be backed up with adequate supply of basic and emergency obstetric care at health facilities in Haryana [26]. Internationally, Rahman et al (2015) observed an improvement in maternal, newborn and child survival after implementing an intervention through community health workers who were trained in providing essential maternal, neonatal, and child health care services in Rural Bangladesh [27]. Kingkaew et al (2016) reported a significant increase in the utilization of antenatal care and delivery by skilled birth attendants following the implementation of a $\mathrm{MCH}$ voucher scheme in Myanmar; this schema is similar to the impact of the financial incentive scheme on the institutional delivery (Janani Suraksha Yojna) in the current study [28]. Smylie et al (2016) observed that an indigenous community investment-ownership- 
activation was an important pathway for success in indigenous prenatal and infant-toddler health programs in Canada [29]. Similarly, Priedeman et al (2013) suggested that, when the service use is uniformly low, a performance-based financing program that incentivizes select services, such as facility deliveries, may improve service use. However, when the equity gap is extreme, a performance-based financing program without equity targets will do little to alleviate disparities [30].

Another important point to be discussed is the role of local governments (Panchayati Raj institutions) in managing health care in public health facilities. It was observed in this study that members of the Panchayati Raj institutions were perhaps actively involved in the appointments of accredited social health activists in the villages. However, their role in the implementation of other strategies under communitization, like patient welfare committees in the hospitals, was mainly passive. It was also observed that they were less actively engaged in formulating village health action plans through the village health nutrition and sanitation committees in the villages in Haryana. Role of Panchayati Raj leaders was reported to be unfair in study by Kumar et al [31]. Less involvement of Panchayati Raj institutions in management of health care services was also observed in Odisha [32]. However, several advantages of these institutions in managing health care are documented from other states in India like Kerela and Karnatka. It is reported that with proper orientation and training of the members of Panchayati Raj institutions, these were in a position to actively involve them in monitoring the functioning of health care institutions for the benefit of the poor. [33, 34]. Another study have reported that Panchayati Raj institutions play an important role in healthcare provision; however, their involvement is ineffective due to their partial capabilities and approach, which creates a non-conducive environment, which is similar to the findings of this study [35].

Overall, our hypothesis that the budget utilization according to the NRHM's maternal and child health sector plans would result in an increased implementation of those schemes and consequently in improved maternal and child health outcomes has been confirmed by our data and analyses. The schemes for which the budget utilization was maximum (like the patients' referral transport services, human resources, drugs and logistics, the accredited social health activists, the patient welfare committees in the health facilities and immunization) were implemented well and contributed to the improvement of the maternal and child health outcomes and to the reduction of inequalities during the NRHM's implementation [20]. 
However, the wide inter-district variations and non-uniform improvements in $\mathrm{MCH}$ outcomes also point to the relevance of the socio-political context within districts for influencing the budget utilization for various maternal and child health schemes and their levels of implementation. Findings also indicated various client and cultural-level barriers in the implementation (like the low awareness of $\mathrm{MCH}$ schemes, the fear for injections/operations, the negative image among families about the quality of free services, and the low status of women etc.). Such barriers differently affect the effectiveness of NRHM across districts and states.

\section{Maternal and child health policies and programs/interventions in other countries}

Overall, low and middle-income countries have more or less similar maternal and child health policies, programs and strategies, as NRHM's maternal and child health strategies in India. The reason for this similarity could be the similar involvement of international organizations, like the WHO, UNICEF etc. These international organizations not only provide technical support to the government bodies in formulating evidence-based policies, but also support these nations financially so that policies are being implemented appropriately and effectively. The differences lie in the scale of the program implementation (India being a very large country with a large number of mothers and children), in the proportion of gross domestic product (GDP) dedicated to health, in the way the program is implemented, in the simultaneous improvements in other sectors (like education, especially for females, road networks/connectivity in rural areas, the availability of electricity, sanitation facilities and the use of new technology in health (m-health) like in Bangladesh), and in the varying levels of political commitment or willingness to improve $\mathrm{MCH}$ outcomes and related inequalities. Health services (curative and preventive) can be provided using two modes of delivery: horizontal and vertical [36]. In India, $\mathrm{MCH}$ programs were previously implemented vertically. After the launch of NRHM in 2005, it was implemented horizontally under the overarching umbrella of NRHM. In other neighboring countries like Nepal, $\mathrm{MCH}$ programs are implemented as vertical programs. Horizontal programs imply that services are delivered through public financed health systems and are commonly referred as comprehensive primary care [37]. Horizontal programs are the older of the two modes of delivery. These were derived from primary health care and originated as part of the WHO/UNICEF declaration in Alma Ata in 1978. A vertical delivery of health services implies a selective targeting of specific interventions and is not fully integrated in the health system $[38,39]$. 
Maternal and child health policies and programs have been extensively reviewed in about 146 low and middle-income countries. By closely working with the Ministries of Health in these countries, the review aims to understand how some countries show an accelerated progress to reduce preventable maternal and child deaths. This is part of the countdown to the Millennium Development Goals, 2015, by the Partnership for Maternal Newborn and Child Health [40]. It was observed that there are 10 fast-track countries i.e., Bangladesh, Nepal, Cambodia, China, Egypt, Ethiopia, Lao PDR, Peru, Rwanda and Vietnam [41]. These fasttrack countries have invested in high-impact health interventions, such as quality care at birth, immunization and family planning. This is very similar to NRHM's strategies. In each country, the mix of policies and programs has been different, depending on the local context and local priorities. Like in Nepal, cash incentives for pregnant women in difficult geographical terrain for institutional delivery have improved maternal health outcomes. This is comparable to the financial incentive scheme implemented under NRHM [42]. In Bangladesh, the under five mortality was reduced due to an improved immunization; this is also comparable to the universal immunization program in India. Bangladesh also had a widespread and increasing use of mobile phone technology at all levels of society. That offered an effective vehicle for health system strengthening, health promotion, and communication between health professionals and patients, making this unique for this country [43]. By prioritizing community-based primary care and deploying almost 40,000 health extension workers, Ethiopia found a way of delivering essential maternal and child health interventions, such as antenatal care and contraception, to women and children in rural communities. This is comparable to appointing accredited social health activists in villages in India [44]. Vietnam, faced with different challenges in the aftermath of war, also relied on an effective delivery of the $\mathrm{MCH}$ interventions through village health workers [45]. Peru recognized that cultural barriers were as important as geographical ones in promoting women's access to antenatal and delivery services. This is comparable to our study. New affordable ways were found in Peru to deliver modern maternity and newborn care in a culturally sensitive context [46]. Cambodia exploited the reach of mass media to launch a campaign promoting exclusive breastfeeding, which even included a TV soap opera [47]. China identified subsidies as a way to encourage women to deliver their babies in hospitals and supported this with referral networks for high-risk pregnancies [48]. These countries all practiced flexibility in implementing the strategies, depending upon the need. This is comparable to the implementation of various schemes under NRHM in India.

Strategies such as performance-driven financing in countries, such as Rwanda [49], Peru [46] 
and Nepal [42], helped to reduce inequities in access to maternal and child health services. In relation to bridging the inequalities through the availability of community mobilizers, i.e., accredited social health activists in the villages and performance based incentives in India, this is in line with the findings of our study. Egypt is also looking at options to move towards universal health care and equitable access to quality services and financial risk protection. Another key mechanism is the collection of timely, robust health data to inform policymaking and increase accountability [50]. In Lao PDR, locally generated data have informed the policy shift towards free care for pregnant women and the under-fives [51]. In Bangladesh, the development of information communication and technology in the health sector is driving the collection of real-time health data on pregnant women and the underfives and the creation of an online registration system for births and deaths [43]. During the NRHM implementation in India, a routine health management information system was developed and used for collecting the data and sending reports in India. However, its use in taking decisions was limited mainly due to quality issues with the data. [52].

Fast-track countries have also recognized the role played by sectors outside the health domain, like education, sanitation and water supply, and employment, in creating and sustaining an environment that supports the work of health systems and health partners. Ethiopia shows how investments in education can benefit women and children by giving girls the same educational opportunities as boys [44]. Likewise, the Community Schools initiative in Egypt has increased access to primary education in remote areas, especially for girls [50]. Cambodia offers an example of non-health investments that create health-sustaining environments, through its policies targeting economic growth and giving people that live in poverty, including women, more opportunities for paid work [47]. Likewise, China and Vietnam demonstrated the benefits of upgrading infrastructure for drinking water and sanitation to serve all levels of society [45, 48]. Large-scale systemic transformations within countries are rarely achieved without sustained political will by governments and politicians. However, political stability helps but is not a prerequisite for progress, as shown by Nepal [42]. There the Ministry of Health, supported by harmonized international donor funding, has kept health improvements on track despite political instability and rapid turnover in leadership. Good governance is also important for accountability, effective policymaking and efficient use of resources. Rwanda has introduced policies that include an annual Governance Scorecard, zero tolerance of corruption and a programme of health-sector decentralization [49]. 
Studies in Malaysia and Srilanka provide the most comprehensive and detailed analysis available on the factors behind the decline in maternal mortality in these countries over the past 50 to 60 years and the magnitude of health system expenditures on maternal health [5355]. Both countries devoted special attention to providing geographical and financial access to education and health services for the rural poor, and both countries declared early that maternal and child health were national priorities. The strategies in these countries were almost similar to the ones implemented in other fast-track countries. The key factors behind the progress made in Malaysia and Sri Lanka was the planning of transport measures that improved the access to higher levels of health care facilities, well established free preventive care system and facilities which are accessible to all the citizens and high literacy rate of the population (male 97\% and female 95\%) [53].

So to summarize, effective implementation of the key strategies like high quality maternal and child interventions especially around birth, availability of community link worker, immunization, good governance, political will, referral services and use of routine health management information system has helped in improving the $\mathrm{MCH}$ in above mentioned countries. These countries have also improved the sectors like education especially of women, economic growth etc. All these key strategies were part of NRHM's MCH plans in India, however, the overall extent of implementation of these strategies was observed to be partial in Haryana. Although there was improvement in the overall $\mathrm{MCH}$ outcomes and a positive effect on bridging of geographical, socioeconomic and gender inequalities in Haryana, these achievements showed a marked inter-district variation.

Maternal and child health in high-income countries is already secured and is considered as basic right. There are large differences in pregnancy outcome between high- income countries and many middle- and low-income countries. In fact, maternal, fetal and neonatal mortality rates in many low-income countries approximate those that were seen in high-income countries nearly a century ago. Goldenberg and colleagues document the very substantial reductions in maternal, fetal and neonatal mortality rates in high-income countries over the last century and explores the likely reasons for those reductions [56]. It is reported that universal access to good quality antenatal, natal and post natal care including basic emergency obstetric care and emergency obstetric care along with improved and responsive health system is the key to improve maternal and child health. The problem with low- and middle-income countries is that such care is either not available fully or of inadequate quality 
if available [56]. Perry et al have systematically mapped out the community-based interventions for improving maternal health and for reducing maternal health inequalities in high-income countries as part of the EU-funded project 'Multilateral Association for Studying health inequalities and enhancing north-south and south-south Cooperation' (MASCOT) [57]. They have reported that studies on breastfeeding assistance and promotion, preventing and treating post-natal depression, interventions to support and build capacity around parenting and child care, antenatal interventions preparing women for birth, postnatal planning of future births and randomized control trials around changing maternal behaviors were conducted in community based settings in high-income countries. The home was used as the most common setting to implement these interventions and health professionals accounted for the largest group of intervention providers. The results of their study open the opportunity for further studies on interventions' effectiveness and knowledge transfer to low- and middleincome countries' settings. The current community-based interventions in low and middle income countries' settings mainly include recruiting a village health worker (like accredited social health activists in India) to mobilize women towards institutional delivery and immunization of children in the outreach session in the villages.

Studies about the effectiveness of interventions on equity in maternal or child health are limited. A systematic review of about 22 studies was conducted by Yuvan et al (2014), to collect evidence about the differential effects of interventions on different socio-demographic groups in order to identify interventions that were effective in reducing maternal or child health inequalities in low and middle income countries across socioeconomic status (Brazil, Bangladesh, Philippines, Tanzania), asset/wealth (India, Nepal, Indonesia, Bangladesh), gender (Guinea- Bissau, Nepal, Bangladesh, Gender), education (Bangladesh), ethnicity (South Africa), place of residence like urban/rural (Philippines, Guinea-Bissau), distance to health facilities (Zambia), caste (India) [58]. It was concluded that the interventions that were effective in reducing inequity included the improvement of health care delivery by outreach methods (like organizing outreach immunization sessions and celebration of village health and nutrition days in the villages in this study), using human resources in local areas or provided at the community level nearest to residents (like having accredited social health activists in the village under communitization component of NRHM) and the provision of financial or knowledge support to demand side (financial incentives for institutional delivery, knowledge imparted by social health activists at household level in the villages). It was also reported that the included interventions may be more effective in improving maternal or child health in disadvantaged groups. The results of this systematic review support the findings of 
the present study that demonstrate the pathway of change for reducing maternal and child health inequalities during NRHM implementation.

\section{Cost-effectiveness of maternal and child health interventions}

Adam et al (2005) reported that preventive interventions at the community level for newborn babies and at the primary care level for mothers and newborn babies are extremely costeffective, but needs universal access [59]. These were the community based newborn care package, followed by antenatal care (tetanus toxoid, screening for pre-eclampsia, screening and treatment of asymptomatic bacteriuria and syphilis); skilled attendance at birth, offering first level of maternal and neonatal care around childbirth; and emergency obstetric and neonatal care around and after birth. Screening and treatment of maternal syphilis, community based management of neonatal pneumonia, and steroids given during the antenatal period were relatively less cost effective. Scaling up all of the included interventions to $95 \%$ coverage would halve neonatal and maternal deaths. Prinja et al (2016) also reported that integrated management of neonatal and childhood illnesses in district Faridabad, Haryana was cost effective in India [60]. A systematic review was undertaken on the cost-effectiveness of strategies to improve the demand and supply of maternal and newborn health care in lowincome and lower-middle-income countries [61]. There was reasonably strong evidence for the cost-effectiveness of the use of women's groups, home-based newborn care using community health workers and traditional birth attendants, adding services to routine antenatal care, a facility-based quality improvement initiative to enhance compliance with care standards, and the promotion of breastfeeding in maternity hospitals. The NRHM health sector plans which were implemented at the national level, were decided based upon the existing evidence on their effectiveness in improving $\mathrm{MCH}$ outcomes and also cost effectiveness $[8,9,62-64]$.

Data from Sri Lanka show that government spends about $2 \%$ of GDP on health and $0.23 \%$ on maternal health and it is able to reduce the maternal and infant mortality to a significant level, hence its MCH policies appear efficient and cost effective [48]. In Bangladesh expenditure on health increased from 7.6\% (as a percentage of total government expenditure) in 2000 to $8.9 \%$ in 2011. South Asia saw smaller increases over the same period, from $6.7 \%$ to $7.5 \%$ [65]. To be more effective in improving maternal and child health, proportion of GDP spend on health should be increased from current $1 \%$ to at least $3 \%$ in India, as is already done by its neighboring countries. WHO has suggested that at least an additional US\$5 billion 
annually by 2010 - increasing to an additional US $\$ 10$ billion by 2015 - is needed in the region. This additional investment of less than US $\$ 3$ per person per year can make a significant contribution towards achieving millennium development goals 4 and 5, now as part of sustainable development goals [66].

\section{Methodological considerations}

The literature review revealed that no national maternal and child health program has ever been evaluated through a mixed method approach. This study is perhaps the first one to use a mixed methods approach to determine the effectiveness of NRHM. The mixed-methods approach used for this study promoted the use of quantitative as well as qualitative methods to not only estimate the extent of implementation and effectiveness of the multiple strategy intervention in reducing maternal and child health inequalities in Haryana (quantitative study findings) but also to explain the possible causes of these results (on the basis of the qualitative study findings). The partially mixed sequential equal status design afforded us the flexibility to use existing quantitative data from demographic surveys held before, during, and after the NRHM implementation [DLHS 2 (2004-05), DLHS 3 (2007-08), DLHS 4 (2012-13)] for trend analysis. The qualitative study was performed last (2013-14), so as to ascertain the status of implementation of NRHM at its flag end. Inclusion in the qualitative study of one well performing district (District Ambala) and one low performing district (District Mewat) in terms of status of $\mathrm{MCH}$ indicators in Haryana had allowed us to document the circumstances and contextual factors that might moderate the successful implementation of the national program at the district level and influence the maternal and child health outcomes and inequalities.

Earlier evaluations of NRHM are limited by the lack of assessment of the extent of implementation of NRHM schemes, the lack of a longitudinal perspective that appreciates the situation before and after the implementation of NRHM, the lack of measurement of maternal and child health inequalities, and the lack of an interpretation that combines quantitative data and qualitative data through a mixed-methods approach [6,7]. These limitations are overcome by this study. The planning commission of India had the NRHM schemes evaluated in seven states (Uttar Pradesh, Madhya Pradesh, Jharkhand, Orissa, Assam, Jammu and Kashmir and Tamil Nadu) during the fourth year of its implementation (2009-10) using quantitative and qualitative techniques, but not mixed methods approach. The commission had observed some improvements in the availability and utilization of maternal and child 
health services in rural areas, and recommended further strengthening of health facilities [6]. Existing studies on $\mathrm{MCH}$ inequalities in India are all quantitative in nature and conducted in pre-NRHM period. These have reported marked $\mathrm{MCH}$ inequalities during antenatal, natal or postnatal period to the disadvantage of the poor during pre NRHM implementation, which is similar to the situation observed during that period in this study also (2002-04) [67-73].

Hence the strength of this study lies in its mixed methods design. Previous quantitative surveys assessed peoples' needs based on the providers' understanding of people's needs. This study complements this perspective by assessing the felt needs of the health service users as well through the qualitatively study. Thus a mixed methods approach brought the users' perspective to the fore [74-76]. Joint display of quantitative and qualitative data helped us in understanding how mixed methods design provided new insights into the implementation process of NRHM's MCH plans [77,78]. Andrew and Halcomb (2006) and Jeffry (2004) have also suggested that owing to the complex issues underlying research into community health, mixed methods research is an effective method of enquiry for community health research and is a foundation for primary care research $[79,80]$.

We looked at the surrogate parameter budget spent for maternal and child health care, while it would have been better to evaluate the actual care delivered. An alternative method to measure the extent of implementation of NRHM's maternal and child health sector plans is a field survey, which, however, is costly and time-consuming. The advantage of using our indirect method is the feasibility and the ease with which existing information can be used for evaluation and ultimately for having a better implementation of health plans in the future. The causal association between NRHM implementation and $\mathrm{MCH}$ outcomes and inequalities however, cannot be established, as there was no control region (without NRHM). There might have been other (confounding) developments in the same time period (e.g. improving socioeconomic conditions in general) that determined the positive changes. Another potential confounding element relates to the relative increase of urban households included in the sample of DLHS round 3 (rural: urban population ratio in DLHS round 2 (2004-06) and round 3 (2007-08) was about 70:30, while in round $4(2012-13)$ it was 57:43). This was because sampling in first two waves was based on census 2001 and last wave on census 2011 [81]. Because urban households benefit on average from better healthcare access, the observed positive changes could therefore be related also to the relative overrepresentation of urban population in the last round with respect to previous rounds. However, it should be noted that 
the potential confounding bias relates only to the total population. Because analyses performed on the rural group separately (Table 4 and Table 7, Chapter 4), the confounding concern related to sampling differences is partially mitigated.

Alternate explanations for reduction in inequalities may not have been accounted for if we consider the logical framework analysis approach [82]. By applying this approach to explain the results of this study, it has been observed that after implementation of NRHM there has been considerable increase in inputs and processes (which has been presented in Table 3, Chapter 3; and Table 7, Chapter 4). This provides the causal link between NRHM, improved MCH coverage indicators (Table 3, Chapter 4) and ultimately outcomes and impact in terms of reduction in $\mathrm{MCH}$ inequalities and mortality (Tables 4 to 6, Chapter 4). Evaluation of the program/intervention by comprehensively measuring the inputs, processes, outputs, outcomes, and impact over a longer time horizon is considered as the best available option for establishing the cause and effect relationship when there is no control population, as is the case in the present study [82]. WHO commission on social determinants of health does recognize the role of health systems in reducing inequalities as intermediary determinant [83]. Hence it can be stated that NRHM perhaps played a role through influencing the health system in terms of improving access to $\mathrm{MCH}$ services, decreasing differential vulnerability and exposure to $\mathrm{MCH}$ inequalities. These facts are also supported by the changes in the health system, such as availability of medicines, health care providers, free ambulances and treatment services during NRHM implementation as reported in the qualitative study.

\section{Implications of the Results and Future direction}

This mixed methods study has presented a holistic and in-depth review of the extent and effectiveness of NRHM's MCH plans i.e., health system strengthening, communitization, maternal and child health care strategies in Haryana, India. There is evidence of an increased utilization of funds throughout the NRHM implementation period (from 2005-12) and a decline in maternal and child mortality and reduction in inequalities, but the decline was not as intended (which was a decrease to a maternal mortality ratio of less than 1 per 1,000 live births and a decrease of infant mortality rate to 30/1000 live births). The results of this study have important implications for policymakers, to inform the second phase of NRHM implementation as part of National Health Mission. What we have learnt from the first phase is that substantial gains are observed for schemes that have aimed at increasing the 
institutional delivery rate among the poor women and in rural areas (like free referral transport services, free hospital delivery, financial incentives for institutional delivery, accredited social health activists in the villages). Hence it is recommended that these schemes should be further strengthened. Bottle necks (like insufficient number of ambulances, no maintenance mechanisms for the ambulances, insufficient human resource, administrative delays in providing incentives to the pregnant women) for the implementation of these schemes should be tackled effectively. Schemes aimed at improving child health (like integrated management of neonatal and childhood illness) need to be strengthened by improving the supportive supervision of health care providers involved in implementation of this scheme and providing adequate logistics. Hence, during the implementation of the second phase of NRHM these bottlenecks should be targeted, and improved planning and implementation should be ensured after carefully considering the recommendations suggested in this study.

Also, to make a policy an apparent success is complex and, as was observed in the Mewat district, dependent on many interrelated factors, including political, economic and sociocultural aspects. Other policy implications of this study are that, along with the implementation of the specific $\mathrm{MCH}$ schemes, the structural determinants of health inequalities (education, occupation, income, socioeconomic status) and the basic socioeconomic development of the district need also to be addressed. Unless that is done, the extent and effectiveness of implementation of $\mathrm{MCH}$ plans runs the risk of remaining only a partial success. It is also recommended that $\mathrm{MCH}$ plans need to be scaled up through extensive availability of human resources, a reduction in the information gap between service providers and users, and an effective planning and implementation of the targeted interventions to deal with client and community-level barriers.

There is definitely room for improvement for future studies. In-depth review of how funds are being spent on implementing the NRHM's scheme in the district, right to the village level, can give us better understanding of the process of budget expenditure in implementing programs at various health care delivery levels. This information will bring further clarification on barriers and facilitating factors to improve the implementation. Also research designs that include control area or information on background socioeconomic indicators should be considered, in order to better control for confounders in the causal association between the intervention and the outcomes. Future studies should also take into account existing monitoring processes in place to monitor the progress of NRHM's health sector plans, as these have implications on the effective implementation of the NRHM. 
Other Indian states and low and middle-income countries can definitely benefit by the lessons learnt in the implementation of maternal and child health plans of NRHM in Haryana. The results of this study may be generalizable to other Indian states, as socio, economic and political context of each state is similar to some extent. However, the cultural context may vary from state to state. Also as health primarily is a state subject, each state needs to conduct its own review to know the extent of implementation of its $\mathrm{MCH}$ plans and their effectiveness in improving the $\mathrm{MCH}$ indicators and reducing inequalities across geographical, socioeconomic and gender sectors, maybe by using the same methodology as is used in this study. The quantitative and qualitative methodology used in this thesis is not only robust but also simple and can be used by any researcher to measure $\mathrm{MCH}$ inequalities in any other state in India using demographic health survey data and qualitative techniques.

The results of this study clearly indicate that improved, strengthened, affordable, accessible and available public health care delivery systems to provide maternal and child health care services, along with effective community mobilization through village health workers, can not only improve maternal and child health status but can also bridge inequalities across geographical, socioeconomic and gender sectors. These results provide strong evidence and add to the current debate in favor of implementation of universal health coverage in India. Such effective public health systems are the need of the hour, and future $\mathrm{MCH}$ policies should include universal health coverage. At the same time it is clear that health sector alone cannot bring all the improvements and reduction of inequalities, and other sectors like education, water supply and sanitation, information technology and employment also has an important role to play in improving maternal and child health.

\section{Conclusion}

It can be concluded that NRHM's health sector plans have succeeded in improving the MCH outcomes and in reducing geographical and socioeconomic inequalities in Haryana by successfully implementing accredited social health activists scheme, free referral transport scheme, free medicines and availability of health facilities in the rural areas and for the poor. However, the decline did not reach the intended goal (which was a decrease to a maternal mortality ratio of less than 1 per 1,000 live births and a decrease of infant mortality rate to 30/1000 live births) may be due to partial implementation of NRHM's schemes. Genderbased inequalities are linked to increased education level and adoption of small family norms. Overall it can be said that Haryana is on the right track for achieving the sustainable 
development goals of reducing maternal and child health inequalities. The results of this study may also be useful for other states in India that are now implementing the second phase of the NRHM. 


\section{References}

1. Hota P, Dobe M. National Rural Health Mission. Indian J Public Health. 2005; 49(3):107-10.

2. National Health Mission. Available at http://nrhm.gov.in/nhm/nrhm/nrhm-framework-forimplementation.html. Accessed on 16 January 2014.

3. International Institute of Population Sciences. District Level Household and Facility Survey-3. Reproductive and Child Health Project. Ministry of Health and Family Welfare. New Delhi. Haryana. 2007-08.

4. Chaturvedi S, Costa De Ayesha, Raven J. Does the Janani Suraksha Yojna cash transfer program to promote facility births in India ensure skilled birth attendance? A qualitative study of intrapartum care in Madhya Pradesh. Global Health Action. 2015; 8: 27427. http://dx.doi.org/10.3402/gha.v8.27427

5. Sah PK, Raut AV, Maliya CH, Gupta SS. Performance of village health, nutrition and sanitation committee: A qualitative study from rural Wardha, Maharashtra. The Health Agenda. 2013; 1(4): 112-117.

6. Planning Commission. Evaluation study of National Rural Health Mission (NRHM) in seven states. Programme Evaluation Organisation. Government of India. 2011. Available at http://planningcommission.nic.in/reports/peoreport/peoevalu/peo_2807.pdf. Accessed 1 May 2016.

7. Mukherjee S. A study on effectiveness of NRHM in terms of reach and social marketing initiatives in rural India. European Journal of Scientific Research 2010; 42(4):573.

8. Campbell OM, Graham WJ, Lancet Maternal Survival Series, steering group. Strategies for reducing maternal mortality: getting on with what works. Lancet 2006;368(9543):1284-99.

9. Jones G, Steketee RW, Black RE, Bhutta ZA, Morris SS, Bellagio Child Survival Study Group. How many child deaths can we prevent this year? Lancet 2003;362: 65-71.

10. Mosley WH, Chen LC. Child Survival: strategies for research. Popul Dev Rev 1984; 10: (Suppl).

11. Rustein OS. In: Setty-Venugopal V, Upadhyay UD, eds. Birth spacing: three to five saves lives. Population Reports, 2002 Series L (13). Baltimore: Johns Hopkins Bloomberg School of Public Health, Population Information Program. 2002.

12. Rustein OS. Factors associated with trends in infant mortality in developing countries during 1990s. Bull World Health Organ 2000;78: 1256-68.

13. Singh SR. Public health spending and population health: a systematic review. Am J Prev Med. 2014;47(5):634-40. doi: 10.1016/j.amepre.2014.05.017. Epub 2014: 29.

14. Bekemeier B, Dunbar M, Bryan M, Morris ME. Local health departments and specific maternal and child health expenditures: relationships between spending and need. J Public Health Manag Pract. 2012;18(6):615-22.

15. Farag $\mathrm{M}^{1}$, Nandakumar AK, Wallack $\mathrm{S}$, Hodgkin $\mathrm{D}$, Gaumer $\mathrm{G}$, Erbil $\mathrm{C}$. Health expenditures, health outcomes and the role of good governance. Int J Health Care Finance Econ 2013; 13(1): 33-52. doi: 10.1007/s10754-012-9120-3.

16. Prinja S, Kumar M, Pinto AD, Jan S, Kumar R. Equity in Hospital Services Utilization in India. Economic and Political Weekly. 2013; XLVIII (2): 52-58.

17. RGI. Registrar General of India. Maternal and Child Mortality and Total Fertility Rates. Sample Registration System Bulletin 2004-06, 2007-09. Available at http://www.censusindia.gov.in/vital_statistics/SRS_Bulletins/MMR_release_070711.pdf. Accessed 22 December 2015.

18. RGI. Registrar General of India. Special Bulletin on Maternal Mortality in India. Sample Registration $\quad$ System. 2011-13. Available at http://www.censusindia.gov.in/vital_statistics/mmr_bulletin_2011- 13.pdf. Accessed 20 September 2015. 
19. RGI. Registrar General of India. Sample Registration System Bulletin. 2014. Available at http://www.censusindia.gov.in/vital_statistics/SRS_Bulletins/SRS\%20 Bulletin\%20Sepetember\%202014.pdf . Accessed 20 September 2015.

20. Gupta M, Angeli F, Bosma H, Rana M, Prinja S, Kumar R et al. Effectiveness of multiplestrategy community intervention in reducing geographical, socioeconomic and gender inequalities in maternal and child health outcomes in Haryana, India. PLoS One. 2016; 11(3): e0150537. http://dx.doi.org/10.1371/journal.pone.0150537.

21. Pandey N. Perceived barriers to utilization of maternal health and child health services: Qualitative insights from rural Uttar Pradesh, India. International Institute of Population Sciences. India. Available at http://paa2011.princeton.edu/papers/111751. Accessed 3 June 2016.

22. Khan Z, Mehnaz S, Ansari MA, Khalique N, Siddiqui AR. Existing practices and barriers to avail of maternal health care services in two slums of Aligarh. Health and Population: Perspectives and Issues. 2009; 32:113-123.

23. Singh S, Remez L, Ram U, Moore AM, Audam S. Barriers to safe motherhood in India. Available at https://www.guttmacher.org/sites/default/files/report_pdf/safe-motherhoodindia.pdf. Accessed on 4 June 2016.

24. Jain N, Srivastava NK, Khan AM, Dhar N, Adish V, Menon S et al. Assessment of functioning of ASHA under NRHM in Uttar Pradesh. Health and Population: Perspective and Issues. 2008; 31(2): 132-140.

25. Sapril L, Richards E, Kokho P, Theobald S. Community health workers in rural India: analysing the opportunities and challenges Accredited Social Health Activists (ASHAs) face in realizing their multiple roles. Hum Resour Health. 2015; 9(13): 95.

26. Prinja S, Jeet S, Kaur M, Aggarwal AK, Manchanda N, Kumar R. Impact of referral transport system on institutional deliveries in Haryana, India. Indian J Med Res. 2014; 139(6): 883-891.

27. Rahman M, Jhohura F T, Mistry S K, Chowdhury T R, Ishaque T et al. Assessing Community Based Improved Maternal Neonatal Child Survival (IMNCS) Program in Rural Bangladesh. PLoS One. 2015; 10(9): e0136898, doi: 10.1371/journal.pone.0136898. eCollection 2015.

28. Kingkaew P, Werayingyong P, Aye SS, Tin N, Singh A et al. An ex-ante economic evaluation of the Maternal and Child Health Voucher Scheme as a decision-making tool in Myanmar. Health Policy Plan. 2016; 31(4): 482-92.

29. Smylie J, Krist M, McShane K, Firestone M, Wolfe S, O'Campo P. Understanding the role of Indigenous community participation in Indigenous prenatal and infanttoddler health promotion programs in Canada: A realist review. Soc Sci Med 2016; 150:12843.

30. Priedeman S M, Curtis S L, Basinga P, Angeles G. An equity analysis of performance-based financing in Rwanda: are services reaching the poorest women? Health Policy Plan. 2013; 28(8): 825-37. doi: 10.1093/heapol/czs122.

31. Kumar V, Mishra AJ, Verma S. Health planning through village health sanitation and nutrition. Int J Health Care Qual Assur. 2016; 29;(6):703-15.].

32. Catalysing the role of Panchayati Raj institutions in health care delivery in Odisha. Odisha Review. 2016. Available at http://www.orissa.gov.in/e-magazine/Orissareview/2016/FebMar/engpdf/19-22.pdf.].

33. John J. A study on effectiveness of Panchayati Raj institutions in health care system in the state of Kerela. Planning Commission. Government of India. Available at http://planningcommission.nic.in/reports/sereport/ser/ser_kds1803.pdf. Accessed on 8 August 2016.

34. Rout SK, Nallala S. Sekher, T.V. (2001). Administrative Review of the Department of Health and Family Welfare. In Karnataka administrative reforms commission functional review reports (pp. 433-543) Bangalore: Government of Karnataka and Ford Foundation. 
35. Kumar V, Jayanta Mishra A. Healthcare under the Panchayati Raj Institutions (PRIs) in a decentralised health system. Leadersh Health Serv (Bradf Engl). 2016;29(2):151-67.

36. Msuya J. Horizontal and vertical delivery of health services: what are the trade offs? Available at http://files.givewell.org/files/DWDA\%202009/Interventions/maternal-and-neonatal-tetanuselimination/Msuya\%202004.pdf. Accessed on 17 June 2016.

37. WHO. Primary Health Care: report of the International conference on primary health care, Alma-Ata. 1978; Health for All series: number 1.

38. Banerji D. Primary Health Care: selective or comprehensive? World Health Forum 1984;5:312-315.

39. Rifkin SB, Walt G. Why health improves: defining the issues concerning 'comprehensive primary health care' and 'selective primary health care'. Social Science Medicine 1986; 23(6): 559-566.

40. Partnership for Maternal Newborn and Child Health. Available athttp://www.who.int/pmnch/en/. Accessed 5 June 2016.

41. Success factors for women and children's health. Policy and program highlights from 10 fasttrack countries. Available at http://www.who.int/pmnch/knowledge/publications/success_factors_highlights.pdf?ua=1. Accessed 3 June 2016.

42. Success factors for women and children's health. Ministry of Health and population. Nepal. Available http://www.who.int/pmnch/knowledge/publications/nepal_country_report.pdf?ua=1. Accessed 18 June 2016.

43. Success factors for women and children's health. Ministry of Health and Family Welfare. Bangladesh. Available at http://www.who.int/pmnch/knowledge/publications/bangladesh_country_report.pdf?ua=1. Accessed 18 June 2016.

44. Success factors for women and children's health. Ministry of Health. Ethiopia. Available at http://www.who.int/pmnch/knowledge/publications/ethiopia_country_report.pdf?ua=1. Accessed 18 June 2016.

45. Success factors for women and children's health. Ministry of Health. Vietnam. Available at http://www.who.int/pmnch/knowledge/publications/vietnam_country_report.pdf?ua=1. Accessed 18 June 2016.

46. Success factors for women and children's health. Ministry of Health. Peru. Available at http://www.who.int/pmnch/knowledge/publications/peru_country_report.pdf?ua=1. Accessed 18 June 2016.

47. Success factors for women and children's health. Ministry of Health. Cambodia. Available at http://www.who.int/pmnch/knowledge/publications/cambodia_country_report.pdf?ua=1. Accessed 18 June 2016.

48. Success factors for women and children's health. National Health and Planning Commission. China. Available http://www.who.int/pmnch/knowledge/publications/china_country_report.pdf?ua=1. Accessed 18 June 2016. 
49. Success factors for women and children's health. Ministry of Health. Rwanda. Available at http://www.who.int/pmnch/knowledge/publications/rwanda_country_report.pdf?ua=1.

Accessed 18 June 2016.

50. Success factors for women and children's health. Ministry of Health and Population. Egypt. Available http://www.who.int/pmnch/knowledge/publications/egypt_country_report.pdf?ua=1. Accessed 18 June 2016.

51. Success factors for women and children's health. Ministry of Health. Lao PDR. Available at http://www.who.int/pmnch/knowledge/publications/lao_country_report.pdf?ua=1. Accessed 18 June 2016.

52. Sharma A, Rana SK, Prinja S, Kumar R. Quality of health management information system for maternal and child health care in Haryana state, India. PLoS One. 2016; 11(2): e0148449.

53. Accessing maternal and child health services in Sri Lanka and Malaysia. Available at https://www.ssatp.org/en/page/accessing-maternal-and-child-health-services-sri-lanka-andmalaysia

54. Pathmanathan I, Liljestrand J, Martins, J M, Rajapaksa LC, Silva AD, Selvaraju S, Singh PJ. Investing in Maternal Health. Learning from Malaysia and Sri Lanka. Human Development Network. The World Bank. Washington DC. 2003

55. National Maternal and Child Health Policy. Family Health Bureau. Ministry of Health and indeginous Medicine. SriLanka. Available at http://fhb.health.gov.lk/web/index.php?option=com_content $\& v i e w=a r t i c l e \& i d=175$ :maternaland-child-health-policy-framework-directives\&catid=10:policyframework\&Itemid=120\&lang=en\#national-strategic-plan---maternal-and-newborn-health. Published online 2016 Feb 12.

56. Goldenberg RL, Elizabeth MM. Maternal, fetal and neonatal mortality: lessons learnt from historical changes in high income countries and their potential application to low-income countries. Maternal Health, Neonatology and Perinatology. 2015. doi: 10.1186/s40748-0140004-z

57. Perry M, Becerra F, Kavanagh J, Serre A, Vargas E, Becerril V. Community-based interventions for improving maternal health and for reducing maternal health inequalities in high-income countries: a systematic map of research. Globalization and Health. 2015. 10:63. Doi: 10.1186/s12992-014-0063-y

58. Yuan et al, Malqvist M, Trygg N, Qian X, Ng Nawi, Thomsen S. What interventions are effective on reducing inequalities in maternal and child health in low- and middle-income settings? A systematic review. BMC Public Health. 2014 14:634. doi: 10.1186/1471-2458-14634

59. Adam $\mathrm{T}^{1}$, Lim SS, Mehta S, Bhutta ZA, Fogstad H, Mathai M, Zupan J, Darmstadt GL. Cost effectiveness analysis of strategies for maternal and neonatal health in developing countries. BMJ. 2005 Nov 12;331(7525):1107.

60. Prinja S, Bahuguna P, Mohan P, Mazumder S,Taneja S, Bhandari N etal. Cost Effectiveness of Implementing Integrated Management of Neonatal and Childhood Illnesses Program in District Faridabad, India. PLoS One. 2016; 11(1): e0145043. doi: 10.1371/journal.pone.0145043

61. Jefferies LM, Pitt C, Cousens S, Mills A, Schellenberg J. Cost-effectiveness of strategies to improve the utilization and provision of maternal and newborn health care in low-income and lower-middle-income countries: a systematic review. BMC Pregnancy and Childbirth. 201414:243. doi: 10.1186/1471-2393-14-243

62. Hill Z, Kirkwood, B.R. and Edmond, K. Family and community practices that promote child survival, growth and development: a review of the evidence. Geneva: World Health Organization; 2004. 
63. Darmstadt GL, Bhutta ZA, Cousens S, Adam T, Walker N, de Bernis L. Evidence-based, costeffective interventions: how many newborn babies can we save? Lancet. 2005 Mar 1218;365(9463):977-88.

64. Bhutta ZA, Ahmed T, Black RE, Cousens S, Dewey K, Giugliani E, et al. What works? Interventions for maternal and child undernutrition and survival. Lancet. 2008 Feb 2;371(9610):417- 40

65. World Development Indicators. World Bank, Washington DC, 2013. http://data.worldbank.org/data-catalog/world-development-indicators

66. Investing in maternal, newborn and child health. The case for Asia and the Pacific. Available at http://www.who.int/pmnch/topics/investinginhealth.pdf. Accessed on 4 June 2016.

67. Singh A, Pallikadavath S, Ram F, Ogollah R. Inequalities in Advice Provided by Public Health Workers to Women during Antenatal Sessions in Rural India. PLoS One. 2012; 7(9): e44931. doi:10.1371/journal.pone.0044931.

68. Singh A, Padmadas SS, Mishra US, Pallikadavath S, Johnson FA, Matthews Z. Socioeconomic inequalities in the use of postnatal care in India. PLoS One. 2012; 7(5): e37037. doi: 10.1371/journal.pone.0037037.

69. Pathak PK, Singh A, Subramanian SV. Economic inequalities in maternal healthcare: prenatal care and skilled birth attendance in India, 1992-2006. PLoS One. 2010; 5(10), e13593. doi: 10.1371/journal.pone.0013593.

70. Pathak PK, Singh A. Trends in malnutrition among children in India: growing inequalities across different economic groups. Soc Sci Med. 2011; 73(4): 576-85.

71. Prusty RK, Kumar A. Socioeconomic dynamics of gender disparity in childhood immunization in India, 1992-2006. Plos One. 2014:19(8); e104598. doi: 10.1371/journal.pone.0104598.

72. Pradhan J, Arokiasamy P. Socioeconomic inequalities in child survival in India: A decomposition analysis. Health Policy. 2010; 98(2-3): 114-20. doi: http://dx.doi.org/10.1016/j.healthpol.2010.05.010

73. Goli S, Doshi R, Arokiasamy P. Pathways of economic inequalities in maternal and child health in Urban India: A decompostition analysis. PloS One. 2013; 8(3): e58573. doi:10.1371/journal.pone.0058573

74. Kaur M. Application of mixed method research in Public Health. Indian J Comm Medicine. 2016; 41(2): 93-97.

75. Creswell J W. A concise introduction to mixed methods research. Thousand Oaks, CA: Sage Publications. 2015

76. Ostlund U, Kidd L, Wengstrom Y, Rowa-Dewar N. Combining qualitative and quantitative research with in mixed methods research designs: a methodological review. Int J Nurs Stud. 2011; 48(3): 369-83.

77. Creswell JW, Plano Clark VL. Designing and Conducting Mixed Methods Research. 2nd ed. Thousand Oaks, CA: Sage; 2011

78. Guetterman TC, Fetters MD, Creswell JW. Integrating quantitative and qualitative results in health science mixed methods research through joint displays. Ann Fam Med. 2015; 13(6): 554-61.

79. Andrew S, Halcomb EJ. Mixed methods research is an effective method of enquiry for community health research. Contemp Nurse. 2006; 23(2): 145-53. 
80. Jefferey MB. Mixed methods studies: A foundation for primary care Research. Ann Fam Med. 2004; 2(1): 4-6.

81. Census 2011. [http://censusindia.gov.in/2011census/censusinfodashboard/index.html.] Accessed on Accessed on 16 July 2013.

82. Parkhurst JO. "What worked? the evidence challenges in determining the causes of HIV prevalence decline. AIDS Educ Prev. 2008; 20: 275-83.

83. WHO. A conceptual framework for action on social determinants of health. Commission on social determinants of health. 2007. 


\section{Summary}

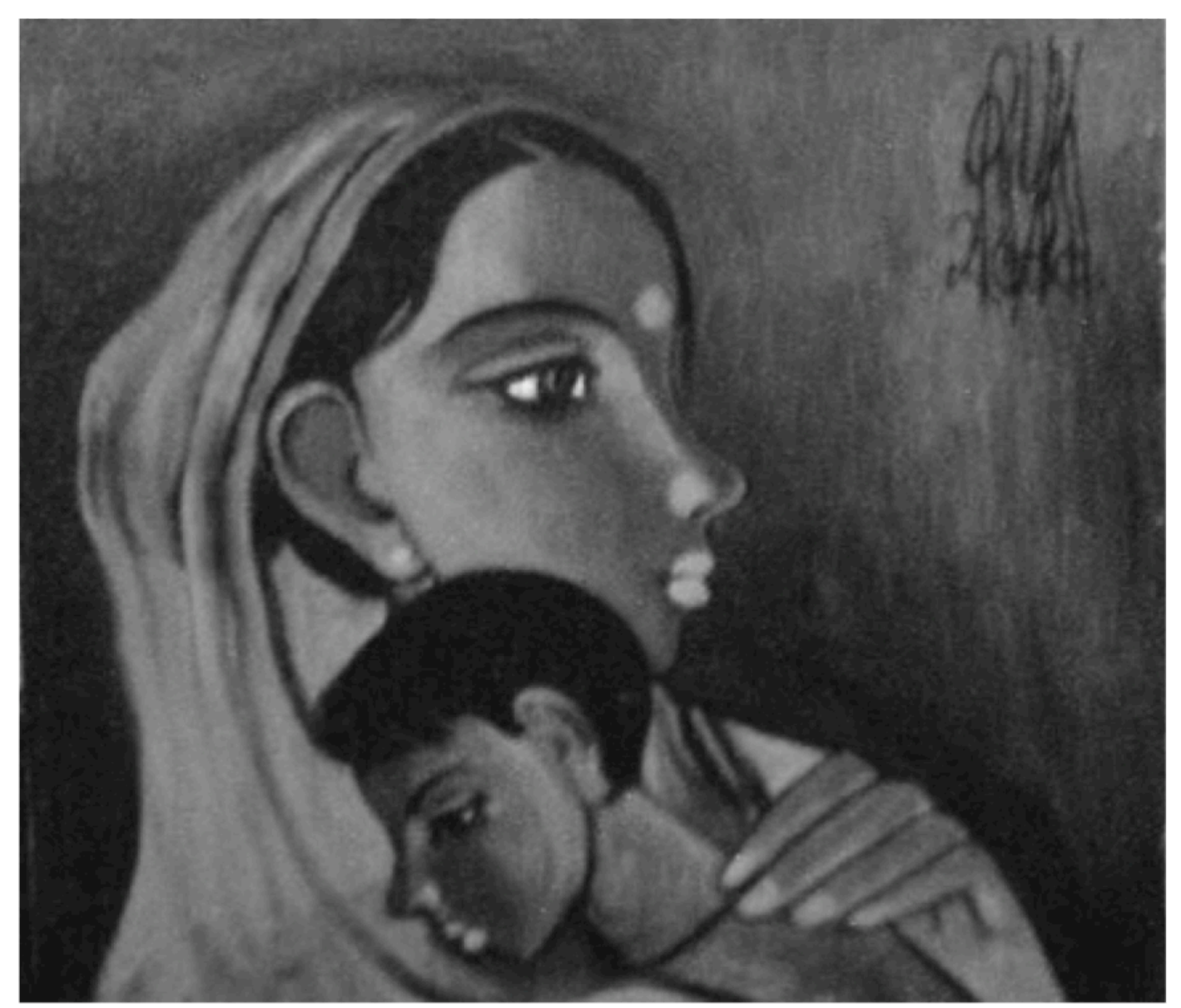




\section{Summary}

India contributes to about $22 \%$ of all maternal deaths and to $20 \%$ of all under five deaths globally. Public health interventions to improve maternal and child health outcomes in India have been implemented since 1950, such as National Family Welfare Program (1952), Acute Diarrheal Disease Control Program (1978), Acute Respiratory Infections Control Program (1978), Universal Immunization Program (1985), Safe Childhood and Safe Motherhood Program (1992), Reproductive and Child Health Program (RCH-1997-2005). However, the pace of improvement of maternal and child health outcomes has been slow. The maternal mortality rate (MMR) until 2005 was still as high as 3 maternal deaths per thousand live births and the infant mortality rate (IMR) was equal to 60 infant deaths per thousand live births. In addition, not much emphasis has been given on reducing the maternal and child health $(\mathrm{MCH})$ inequalities. To address this gap in the implementation, enhance the pace of improvement, and meet the millennium development goals, a multiple-strategy communitybased intervention known as National Rural Health Mission (NRHM) was implemented in India from 2005 to 2012 by the central government. The aim of the NRHM was to improve the availability of and access to better quality health care especially for poor mothers and children. Organizational improvements in the health care delivery system were initiated, so as to reduce the maternal and child health inequalities and improve the overall maternal and child health status. To meet this aim, four major NRHM's health sector plans were implemented. These plans were health system strengthening, specific maternal health care strategies, child health care strategies/schemes, and communitization (empowering the community to perform and monitor the healthcare delivery system). The objectives of this $\mathrm{PhD}$ research was to ascertain the extent of implementation of NRHM's health sector plans and its effectiveness in improving the maternal and child health outcomes and reducing geographical, socio-economical and gender based MCH inequalities in Haryana, North India. General introduction of the topic and its relevance, the need to conduct this study and NRHM's maternal and child health plans are described in Chapter 1. 
Chapter 2 describes the detailed study protocol. To meet the objectives of this research a novel methodological approach was used in this study that could overcome the shortcomings of previous research. An explanatory sequential mixed-methods approach was adopted, in which the quantitative study was followed by a qualitative study that could provide explanation for the quantitative findings. Mixing of the results was done at the interpretation level. As part of the quantitative study, total funds sanctioned and spent under each maternal and child health sector plans of NRHM in a given financial year were obtained from state records and financial monitoring reports to assess the extent of the implementation of NRHM's plans. The proportion of unspent budget and budget utilization rate of each health plan was calculated to measure the extent of utilization of budget and to have an indirect estimation of the extent of implementation of the planned activity. The implementation status of the NRHM's health sector plans categorized into fully implemented, partially implemented, or not at all implemented, depending upon the utilization rate of the budget sanctioned for implementation of that plan at the end of financial year 2012-13. Data on maternal and child health indicators was obtained from district-level household surveys held before (2002-04), during (2007-08), and after (2012-13) the implementation of first phase of the NRHM (2005 to 2012). These were used for quantifying the extent of reduction in maternal and child health inequalities pre- and post-NRHM. Geographical, socioeconomic and gender inequalities in maternal and child health were assessed by estimating the absolute differences in MCH indicators between urban and rural areas, between the most advantaged and least advantaged socioeconomic groups and between male and female children. Logistic regression analyses were done to observe significant differences in these inequalities between 2005 and 2012. For the qualitative study, a total of 33 in-depth interviews $(n=33)$ with program managers, community representatives, mothers and 8 focus group discussions $(n=42)$ with health service providers were conducted from September to December 2013 (post NRHM period), in two districts of Haryana. To obtain a better contextual understanding of two extreme situations and to learn which scheme works better in a particular situation, we 
had selected a well (district Ambala) and a low performing district (district Mewat) in terms of maternal and child health status to conduct qualitative study. Using NVivo software (version 9), an inductive applied thematic analysis was done based upon grounded theory, program theory of change and a framework approach. Ethical approval was obtained from the Ethics Committee of the Post Graduate Institute of Medical Education and Research.

The results of this study are described in Chapters 3, 4, 5 and 6. Chapter 3 reports on the extent of implementation of NRHM's maternal and child health sector plans, including health system strengthening, maternal and child health care strategies, and communitization from 2005 to 2012 in Haryana, India. It was observed that the overall budget for maternal and child health sector plans increased from USD 6.6 million (2005-06) to USD 66.7 million (2012-13). Budget utilization rate increased from $20.6 \%$ (2007-08) to $89 \%$ (2012-13). Funds were overspent for patient referral services (111.5\%), human resources (110.8\%), drugs and logistics (171\%), Accredited Social Health Activists (ASHA) [132.2\%] and immunization (105.4\%). Additional budget on implementing these activities was obtained from state health budget. However, a large amount of the budget is instead left unspent under the village health and sanitation scheme (98\% in 2011-12 and 59\% in 2012-13) scheme. About $44 \%$ of the budget remained unutilized for strengthening delivery points with 24 hours services during 2011-12. Unspent funds dedicated for financial incentive scheme for institutional delivery decreased from $100 \%$ to $20 \%$ from 2007-08 to 2012-13. The unspent budget decreased from 100 to $62.9 \%$ for implementation integrated management of neonatal and childhood illnesses, $100 \%$ to $43.6 \%$ for implementing infant young child feeding from 2005-06 to 2012-13.

Overall the extent of implementation of NRHM maternal and child health plans was partial in Haryana. Referral services, human resources, drugs, ASHA scheme, and immunization were fully implemented; and all other schemes were only partially implemented. 
Chapter 4 presents the extent of reduction of maternal and child health $(\mathrm{MCH})$ inequalities across geographical, socioeconomic and gender categories pre- and post-NRHM in Haryana, North India. It was observed that there were significant improvements in all $\mathrm{MCH}$ indicators $(\mathrm{p}<0.05)$. The geographical and socioeconomic differences between urban and rural areas, and between rich and poor were significantly $(\mathrm{p}<0.05)$ reduced for pregnant women who had an institutional delivery (geographical difference declining from $22 \%$ to $7.6 \%$; socioeconomic from $48.2 \%$ to $13 \%$ ), post-natal care within 2 weeks of delivery ( $2.8 \%$ to $1.5 \%$ and $30.3 \%$ to $7 \%$, respectively); and for children with full vaccination (10\% to $3.5 \%$ and $48.3 \%$ to $14 \%$, respectively) and who received oral rehydration solution (ORS) for diarrhea (11\% to $-2.2 \%$ and $41 \%$ to $5 \%$, respectively). Inequalities between male and female children were significantly $(\mathrm{p}<0.05)$ reversed for full immunization $(5.7 \%$ to $-0.6 \%)$ and BCG immunization (1.9 to -0.9 points), and a significant $(\mathrm{p}<0.05)$ decrease was observed for oral polio vaccine ( $4.0 \%$ to $0 \%)$ and measles vaccine $(4.2 \%$ to $0.1 \%)$. Geographical, socioeconomic, and gender inequality in $\mathrm{MCH}$ was measured by estimating the absolute differences in $\mathrm{MCH}$ indicators between urban and rural areas, between the most advantaged and least advantaged socioeconomic groups (excluding maternal and child mortality indicators), and between male and female children. The negative estimates are as a result of higher coverage of immunization among females as compared to males. Overall it is stated that the implemented multiple-strategy community intervention National Rural Health Mission (NRHM) between 2005 and 2012 might have resulted in significant reductions in geographical, socioeconomic and gender inequalities in $\mathrm{MCH}$ in Haryana. However, causal relationships are difficult to establish with descriptive research, and studies without comparison with a control region (without NRHM being implemented), as socioeconomic improvements also could have contributed to a reduction in inequalities.

In Chapter 5, the qualitative perceptions and beliefs of stakeholders about the effectiveness of NRHM's health sector plans in improving $\mathrm{MCH}$ status and reducing inequalities are 
described. Almost all the participants reported that there was an improvement in overall health infrastructure through an increased availability of accredited social health activists, free ambulance services, and free treatment facilities in rural areas. This had increased the demand and utilization of $\mathrm{MCH}$ services, especially for those related to institutional delivery, even by the poor families. Service providers felt that acute shortage of human resources was a major health system level barrier. District-specific individual, community, and socio-political level barriers were observed in the implementation of the NRHM plans. Overall program managers and service providers believed that NRHM had a role in improving $\mathrm{MCH}$ outcomes and in reduction of geographical and socioeconomic inequalities. Any reduction in gender-based inequalities, however, was linked to the adoption of small family sizes and an increase in educational levels. It was concluded from the qualitative study that better health infrastructure, availability of accredited social health activists, and free ambulance services and treatment in hospitals in rural areas were considered to have resulted in the improvement of $\mathrm{MCH}$ outcomes and decline of geographical and socioeconomic inequalities.

Chapter 6 presents the results from the integration of quantitative and qualitative findings using a mixed methods approach. It was observed that budget on the drugs and logistics was exhausted fully and this component was fully implemented during the actual execution of NRHM. This finding was validated qualitatively. It was reported that free medicines were available in the public health facilities after the NRHM implementation, which had benefitted the poor patients maximally. Patient transport service was fully implemented according to the budget spent on implementing this activity in Haryana. This was confirmed by the qualitative study. There was gradual increase in budget expenditure on human resources during NRHM implementation, and overall this component was fully implemented in quantitative terms. However, qualitatively, it was reported that the availability of doctors, auxiliary nurse midwives, staff nurses increased during the NRHM period, but simultaneously that the demand of services had increased manifold leading to acute shortages of manpower. 
Accredited Social Health Activists scheme was fully implemented quantitatively, and was also the most appreciated scheme by all the participants, qualitatively. Reduction in genderbased inequality in immunization status of male and female children was found to be due to the perception that the injections given for immunization of children were not very safe for children; hence, care-takers (especially in the Mewat district) would let girls have it rather than the boys. Both quantitative and qualitative study results have provided evidence that there had been marked improvement in $\mathrm{MCH}$ outcome indicators and reduction in geographical and socioeconomic inequalities. Mixed methods study not only validated the findings of the quantitative study but also provided the explanations for the quantitative findings. The reasons for reduction of these $\mathrm{MCH}$ inequalities was reported to be due to more awareness regarding $\mathrm{MCH}$ services in rural areas by accredited social health activists, availability of free medicines, free ambulance service, free diet during hospital stay for the poor families, increase in number of health facilities and utilization of $\mathrm{MCH}$ services in rural areas.

The General Discussion reflecting on the main findings, barriers and facilitating factors for implementing NRHM's health sector plans, methodological considerations, public health implications of this study and future directions is reported in Chapter 7. The impact of NRHM in reducing maternal and child health inequalities is elaborated upon. This multi-strategy community intervention was innovative in providing the flexible financing system to the states, which enabled them to implement the schemes in accordance to the needs of the state. Another successful innovation was the communitization, where one of the community member (accredited social health activists) was delegated the health related responsibility in the villages and financial incentives were linked to the performance of this person. This initiative with simultaneous strengthening of health systems in terms of availability of delivery facilities for the pregnant women, free medicines, free transport to the health facilities and availability of health care providers increased the utilization of health facilities 
in rural areas even by poor families. However, non-uniform improvement in the state with wide inter-district differences was observed. To make a policy a success apparently is complex and, as was observed in the Mewat district, dependent on many interrelated factors, like political, economic and sociocultural factors. The policy implications of this study are that, along with the implementation of the specific $\mathrm{MCH}$ schemes, the structural determinants of health inequalities (education, occupation, income, socioeconomic status) and the basic socioeconomic development of the district need also to be addressed. Unless that is done, the extent and effectiveness of implementation of $\mathrm{MCH}$ plans runs the risk of remaining only a partial success. Overall it can be said that Haryana is on the right track for achieving the sustainable development goals of reducing maternal and child health inequalities. The results of this study may also be useful for other states in India that are now implementing the second phase of the NRHM. 


\section{Valorization}

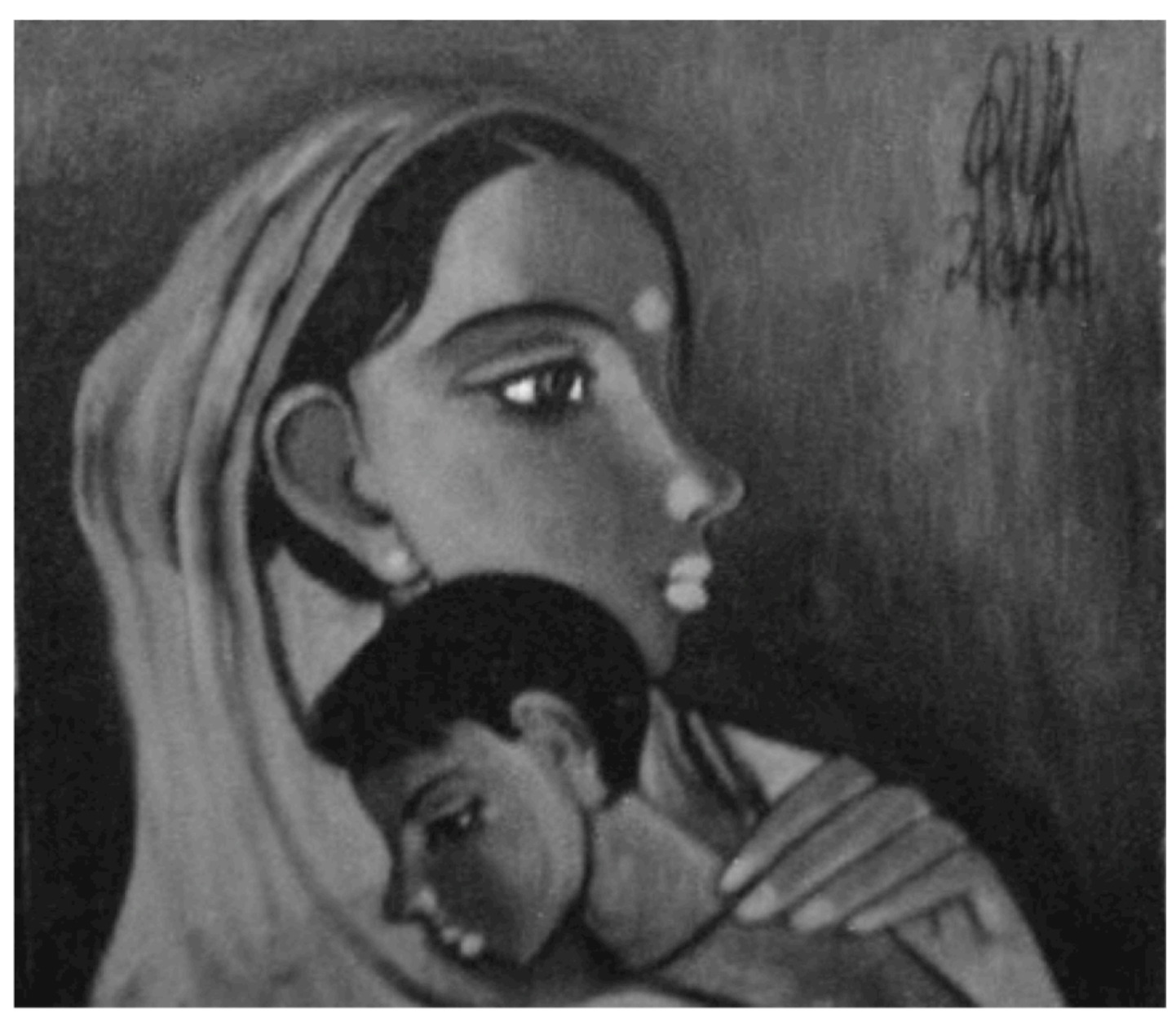




\section{Valorization}

The research conducted with in the scope of this PhD trajectory has not only led to scientific output, but has also contributed in offering new knowledge about the way the national maternal and child health programs (NRHM) are assessed holistically by using a mixed methods approach. This approach has comprehensively provided information on the extent of implementation of NRHM's health sector plans and its effectiveness in improving $\mathrm{MCH}$ outcomes and reducing the inequalities across geographical, socioeconomic and gender gradients in Haryana state in India (quantitative study), and also given explanation to these findings (qualitative study). In this chapter the relevance of this study and the recommendations for the program implementers, managers and policy makers are given. Lastly, future directions for effective implementation of national maternal and child health programs are also dwelled upon.

\section{Relevance}

Maternal and child health $(\mathrm{MCH})$ inequalities across socioeconomic, geographical and gender gradient is a public health concern worldwide and more so in developing countries [1]. In India, the maternal mortality ratio (MMR) is still as high as 167 per hundred thousand live births [2] and the infant mortality rate (IMR) is 40 deaths per thousand live births [3]. There is geographical inequality in MCH outcomes, like IMR is higher in rural (44 per thousand live births) as compared to urban areas (27 per thousand live births) [3]. The persistence of $\mathrm{MCH}$ inequalities indicates the need to assess how the existing national health programs on $\mathrm{MCH}$ are being implemented and for studies presenting evidence on the effectiveness of these programs, as these are highly resource-intensive interventions. Government of India had launched a multiple-strategy community intervention known as National Rural Health Mission in the year 2005, to provide primary health care to all and to carry out necessary organizational changes in the basic health care delivery system. The aim of NRHM was to improve the availability of and access to quality health care by people, especially for those 
residing in rural areas (to reduce geographical inequality), the poor (to reduce socioeconomic inequality), women and children (to reduce gender inequality) [4]. NHRM was implemented till 2012 and later continued as part of National Health Mission to cover urban poor (2013 to 2017) [5]. The objective of this $\mathrm{PhD}$ research was to ascertain the extent of implementation of NRHM's health sector plans and its effectiveness in improving the maternal and child health outcomes and reducing geographical, socio-economical and gender based $\mathrm{MCH}$ inequalities in Haryana, North India by using a mixed method approach. In the previous chapters the advantage of using this approach for program assessment and its results are described in detail. Recommendations based upon holistic program assessments are likely to deliver a more complete and complex picture, and hence to be more relevant for policy making.

\section{Target Groups}

The results presented in this thesis are of relevance to several sectors/groups in the society. Of course, first of all to the implementers (medical officers, auxiliary nurse midwives or accredited social health activists) of the program themselves so that they know about the interventions that are delivered effectively by them and the ones that needs to be improved. Secondly, to the program managers who are responsible for getting the program implemented in the district and at the state level. Thirdly, to the policy makers who are involved in the five year strategic planning for improving the maternal and child health and reducing $\mathrm{MCH}$ inequalities in the state so as to achieve the intended goals.

\section{Program implementers}

Program implementers include accredited social health activists at the village level, auxiliary nurse midwife at the subcenter level and medical officers at primary and secondary health care facility level. For the accredited social health activists, this study provides the evidence that their work is deeply appreciated by their seniors (doctors and nurses). It's due to their counseling and behavior change communication with the mothers and pregnant women that women are increasingly utilizing the public health facilities for $\mathrm{MCH}$ services like 
immunization and institutional delivery. They are the major catalyzing factors for increasing the institutional delivery rate. However, they need to provide complete information regarding the $\mathrm{MCH}$ schemes, as there was information gap regarding the knowledge of schemes between mothers and health care providers. For auxiliary nurse midwives, this study provide the evidence that community is linked with them through accredited social health activists in the villages, and they are the first point of contact at the health facilities. Hence, they should be well prepared for delivering the services like immunization and antenatal care. Also, that government health schemes related to $\mathrm{MCH}$ are accepted by the community, hence these are utilized more. She should plan her activities in close coordination with accredited social health activists. However, awareness about village health nutrition days among women is low, and also funds allocated to the functioning for village health and sanitation committee remains unutilized. Therefore she should involve the accredited social health activists in mobilizing the pregnant women and mothers for attending the village health and nutrition days. Also she should plan the village health need based activities to utilize the funds under the committee along with other members from the village. For the medical officers, this study provide the evidence that people in rural areas are increasingly mobilized to utilize the $\mathrm{MCH}$ services, and hence the number of patients are increasing in the health facilities. Access to the health facilities is also increased through availability of free ambulances. Therefor they should prepare the health facilities with adequate logistics like drugs and medicines, functioning equipments and availability of supportive staff and along with referral facility for smooth functioning of health facility and uninterrupted delivery of $\mathrm{MCH}$ services. It also provides them with information on the implementation status of various $\mathrm{MCH}$ schemes of NRHM.

\section{Program Managers and Policy Makers}

This study provide useful information for the program managers regarding extent of implementation of various MCH health sector plans of NRHM, and also about the barriers and facilitating factors of these plans. Under health system strengthening component of 
NRHM, the schemes like provision of ambulance services and drugs and logistics were implemented fully in the state, and as a result utilization of maternal and child health services had increased considerably. However, there was insufficient number of ambulances per district especially in Mewat. There was no system of repair or maintenance of existing ambulances. Human resources were inadequate. There was acute shortage of health care providers. Although there was provision of hiring the contractual staff to fill the gap in human resources, however this was not enough to meet the requirement of the health care facilities due to increase in number of patients. Hence effective measures need to be adopted to increase the number of health care providers at all health care delivery levels. Some of these measures are suggested by the stakeholders in this study like appointment of health care providers from the local area, redistribution of human resources in relation to the need of the area, career incentives to doctors working in rural/ difficult areas, financial incentives to all paramedical staff working in difficult areas, etc. Mobile Medical Units were observed to be non functional. To make these functional it was suggested, by district program managers in the study, that AYUSH (Ayuerveda, Sidha, Unani and Homeopathy) doctors in alternate medicine can be deployed in these mobile units in the absence of availability of allopathic doctors for increasing the access in difficult areas.

Under communitization, accredited social health activists scheme and patient welfare committee schemes were fully implemented and rest of the schemes were partially implemented like, celebration of village health nutrition days and formation of village health and sanitation committees. The financial incentives of the social health activists may be increased, as was also desired by them, to further strengthen this scheme. Nutrition days in the villages were not celebrated monthly due to shortage of staff and lack of monitoring. Those involved in providing alternate vaccine delivery may be involved in celebrating these days in the villages and close monitoring and supervision of these days by the concerned medical officers needs to be done. Funds under the village health and sanitation committee 
remained underutilized due to lack of coordination among the members. Hence, simpler coordination mechanisms should be there between grass root level workers and village heads to utilize these funds.

All the maternal health care strategies were partially implemented. Financial incentive scheme (Janani Suraksha Yojna) was implementing quite well, but after the administrative hitch in disbursement of funds to the pregnant ladies like linking of benefits with having an unique identification number or bank account of pregnant woman, the funds remained only partially utilized under this scheme. Stakeholders (medical officers, program managers and community representatives) had suggested opening of bank accounts of pregnant women at zero balance. Scheme for free hospital delivery and treatment for infant sickness in the hospitals (Janani Sishu Suraksha Karyakaram) was not fully implemented due to shortage of medical officers or staff nurses. Both these schemes however did motivate the pregnant women to go to institute for delivery. Child health Care strategies were also partially implemented. All these efforts have led to decline in maternal and child mortality in Haryana during NRHM implementation period, but it still lags behind the intended goal of reducing these mortalities. Concerted efforts to increase the availability of maternal and child health services and communitization in the villages have led to reduction in geographical and socioeconomic inequalities.

Overall the NRHM's maternal health schemes that had aimed at increasing the institutional delivery rate among the poor women and in rural areas was implemented well and effectively during the evaluation period of NRHM from 2005-06 to 2012-13. These schemes were free referral transport/ambulance services, free hospital delivery, financial incentives for institutional delivery, improved access to delivery points and availability of accredited social health activists in the villages linking the community with the health care delivery system. 
Hence it is recommended that these schemes should be further strengthened. While schemes aimed at improving child health like integrated management of neonatal and childhood illness needs more attention at the implementation level in terms of strengthening the health system to provide the necessary logistics like weighing scales to measure weight of the child etc., and supportive supervision of the health care providers. Reported bottlenecks should especially be targeted, and improved planning and implementation should be done after carefully considering the recommendations suggested in this study, during the implementation of NRHM in the second phase (2013-14 to 2017-18). These results also have implications in terms of continuation of the program implementation in the rural areas with a special focus on poor women and children with the same rigor in India during the second phase of NRHM from 2013-14 to 2017-18.

A policy brief was submitted to Haryana state officials and policy makers after the completion of this study so as to take immediate actions. Consequently the Haryana government had decided to delink the disbursements of the financial incentives to the pregnant woman with the unique identification number and had also started the bank account at zero balance for the pregnant woman. State also has taken control of running the mobile medial units and these were managed centrally at the state level (for the qualitative interview with the Mission Director, NRHM). Ambulance services were strengthened with maintenance services and additional purchases. More accredited social health activists were recruited especially in district Mewat. A separate division to strengthen communitization component of NRHM was created at the state level, which included monitoring and supervision of celebration of village health and nutrition days and village health and sanitation committees (for the qualitative interview with the Mission Director, NRHM). 


\section{Future Directions}

The results of this study have important public health implications globally since, monitoring inequality is becoming an emerging health priority post 2015 [6, 7]. The post 2015 sustainable development goals stress leaving no one behind and focus on inequalities within and among countries. The results of this study also have implications in terms of continuation of the program implementation in the rural areas with a special focus on poor women and children with the same thoroughness as was done during the evaluation period. As we know that there are political preferences in what should be implemented or not at the national or state level, the program component, which is being implemented successfully, should be continued irrespective of political party in power at that moment [8]. This is quite pertinent to India as NRHM was implemented by the previous government as one of their major thrust area and also as part of commitment to meet Millennium Development Goals 4 and 5. The present government should take decisions or mend program implementation after carefully considering and deliberating upon what good the existing program has done in reducing maternal and child mortality statistics in future.

Based upon the results of this study it is recommended that defined annual targets regarding budget expenditures on maternal and child health interventions should be set at the state level and, regular monitoring and evaluation by an independent agency should be done to strengthen the program implementation at the state level. Since the major barrier in the implementation of NRHM schemes was the acute shortage of the health care providers, the existing policies regarding human resource management should be reviewed and revised accordingly. The results of this study have provided following suggestions in managing human resource crunch. The local residents from the respective districts should be empowered, educated and qualified enough to work in their respective health systems in the districts. There should be a state policy to offer the health care providers the place of posting 
of their native area. This will not only increase the number of local health care providers but also reduce attrition rate among them. Since overall socio-economic development of the district was observed to be an important determinant of maternal and child health (from district Mewat's experience), health policy makers should take this aspect into account while framing future policies related to maternal and child health.

Overall it can be said that Haryana is on the right track for improving $\mathrm{MCH}$ outcomes along with reduction in $\mathrm{MCH}$ geographical and socioeconomic inequalities to some extent, but the pace of achievement needs to be heightened to achieve sustainable development goals post 2015. Results of the this study indicates that increasing the pace of the achievement will be possible by not merely focusing on spending more budget on the implementation of the NRHM's scheme from the government's side, but also by improving the basic underlying socioeconomic conditions of the mother and children and further increasing the demand and utilization of maternal and child health services. 


\section{References}

1. Say L, Raine R. (2007). A systematic review of inequalities in the use of maternal health care in developing countries: examining the scale of the problem and importance of the context. Bull World Health Organ. 2007; 85(10): 812-9.

2. Registrar General of India. Special Bulletin on Maternal Mortality in India. Sample Registration System 2011-13. Available at http://www.censusindia.gov.in/vital_statistics/mmr_bulletin_2011-13.pdf. $\quad$ Accessed 10 September 2015.

3. Registrar General of India. Sample Registration System. Available http://www.censusindia.gov.in/vital_statistics/SRS_Bulletins/SRS\%20Bulletin\%20Sepetember\%202014.pdf .

4. Ministry of Health and Family Welfare. National Health Mission. [http://nrhm.gov.in/nhm/nrhm/nrhm-framework-for-implementation.html.] Accessed on 16 January 2014.

5. Ministry of Health and Family Welfare. NRHM mission document. Available at http://www.mohfw.nic.in/NRHM/Documents/Mission_Document.pdf. Accessed on 16 January 2014.

6. Sustainable Development Goals. Available at https://sustainabledevelopment.un.org/topics. Accessed on 22 September 2015.

7. Hosseinpoor AR, Bergen N, Magar V. Monitoring inequality: an emerging priority for health post 2015. Bull World Health Organ. 2015;93:591-591A.

8. Colerbranber S, Birungi C, Mbonye AK. Consensus and contention in the priority setting process: Examining the health sector in Uganada. Health Policy Plan. 2015;30(5):555-65. 


\section{Acknowledgement}

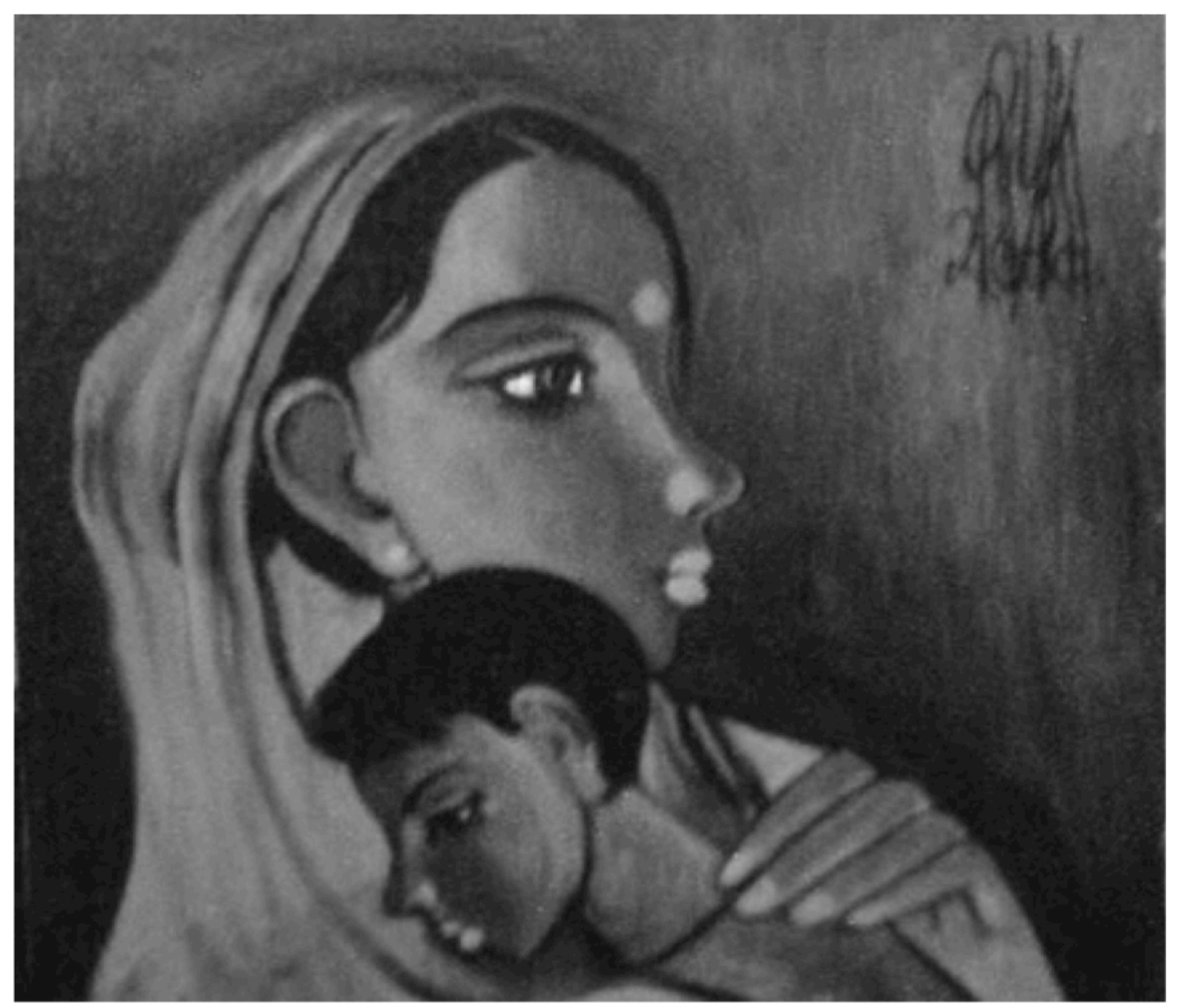




\section{Acknowledgement}

I remember the day when Prof. Dr. Onno C.P. van Schayck with his team had visited the Post Graduate Institute of Medical Education Research (PGIMER), Chandigarh in India in 2011. He had made an impressive presentation about CAPHRI, Maastricht University in Netherlands (PGIMER), especially about the research work. So was the impact of his presentation on me that despite of my regular position as faculty in PGIMER, I got motivated to enroll as a PhD student in CAPHRI. I expressed my desire to do PhD to Prof. Dr. Rajesh Kumar, Head of School of Public Health at PGIMER. He immediately agreed and suggested to write a proposal. He also talked to Prof. Dr. Onno C.P. van Schayck regarding that, who also encouraged me to submit the proposal. The proposal got accepted. It was like my dream coming true. I am thankful to Prof. Dr. Onno C.P. van Schayck for agreeing to promote me in conducting the $\mathrm{PhD}$ as an external student. He had also got me in touch with Prof. Dr. Hans Bosma as co promoter, and Dr. Federica Angeli as supervisor. Finally I got the approval of Dean, Maastricht University. However, it was a challenge to get the approval from Dean, PGIMER, Chandigarh, India, as there was no such precedence in our Institute, where faculty was enrolled as a $\mathrm{PhD}$ student from a University in abroad. After couple of meetings with the administration and Dean, I could pass through this hurdle too and finally got the approval.

Little did I know where I was heading? It was like climbing up a big mountain, and the journey was long and tiresome. However, now I realize that, that climb was not at all futile, as it has led me to explore my cognitive potential. This journey has transformed me completely and has made an everlasting impact on my mind regarding how to conduct good quality research. This would not have been possible without the constant support and guidance of my supervisors. It is very difficult to express my gratitude towards my supervisors in simple words, as no words can fully express my feelings of thankfulness and gratitude. And with the kind of quality supervision I have received from my supervisors from across the oceans, it is pertinent to say that the term DISTANCE seems immaterial!

I am extremely grateful to Prof. Dr. Onno C.P. van Schayck, for entrusting faith in me. His constant words of encouragement had kept me motivated through out this journey. His knowledge and ability of critically analyzing the work, has expanded my thinking process. I 
remember the warm welcome extended to me when I had come to meet him in his office in 2012. He has taught me how to stay focus on the work and perseverance. I feel indebted to him, and lucky to have been supervised me. I am extremely thankful to him for promoting me to conduct this $\mathrm{PhD}$ work.

I express my heartfelt gratitude to Prof. Dr. Hans Bosma. I am thankful to him for promoting and supervising me. He is like my mentor. I have learnt meticulous planning and organization of the work from him. He has holded my hand in analyzing the large data set. It was a great learning experience to work under the guidance of Prof. Dr. Hans Bosma. His keen and dedicated supervision of my $\mathrm{PhD}$ work has led to timely completion of my work. Not only this I am grateful to him for taking care of me when I had visited Maastricht University in April 2011.

I am also grateful to Dr. Federica Angeli for guiding and supervising my $\mathrm{PhD}$ work. Her knack of thoroughly reviewing the $\mathrm{PhD}$ work has improved the quality of my work to a great extent. I had always looked forward to her comments and suggestions, as those were the opportunities to learn more from her. I am extremely grateful to her for editing English language in the manuscripts, which has helped me in publishing my papers. She was instrumental in getting my thesis approved from the assessment committee. I am sincerely thankful to her for providing extra care and effort.

I would also like to express my gratitude to the members of the assessment committee Prof. Dr. Ruwaard (voorzitter), Prof. Dr. F. Feron, Dr. A. Krumeich, Prof. Dr. S. Zodpey and Prof. Dr. B.S. Garg for their suggestions to improve the content of the thesis and finally approving the thesis.

I would like to extend my heartfelt gratitude to Prof Rajesh Kumar, Head of School of Public Health, PGIMER, Chandigarh, India. With his constant support during this period, I could have faith in myself in completing this work. He was always there to discuss any problem related to procuring the data or analysis, and had suggested the most practical and useful solutions. 
I am also thankful to Dr Manmeet Kaur, Additional Professor, School of Public Health, PGIMER, for holding my hand especially while conducting qualitative study. I am thankful to her for building my capacity to conduct the qualitative study, especially the mixed methods research.

I am also thankful to Dr Shankar Prinja, Associate Professor, School of Public Health, PGIMER, for his inputs and sharing his data of socioeconomic MCH inequalities in Haryana in 2012-14.

I am obliged to Dr Rakesh Gupta, IAS, Mission Director, NRHM, Haryana for not only allowing me to conduct the research in Haryana, but also sanctioning the grant to do this research.

I am also grateful to secretarial support offered to me by Mrs Sandrein Wansink, Mrs Karin Vaessen and Mrs Isel van Noppen. I am thankful to Mrs Isel van Noppen for assisting me during my travel and stay in Maastricht in 2012; and Mrs Karin Vaessen in 2016.

I am also thankful to the project staff including Dr Monica Rana, Mrs Nisha Rana, Nareinder Duggal for assisting me in data collection in the field in Haryana.

In the end, I would like to mention that this journey would not have been possible without the support of my family. My husband's, Dr Vivek Gupta, constant support, patience and understanding has led me to complete this task, and my kids', Anirudh Gupta and Saanvi Gupta's, love has kept me going. 


\section{Curriculum Vitae}

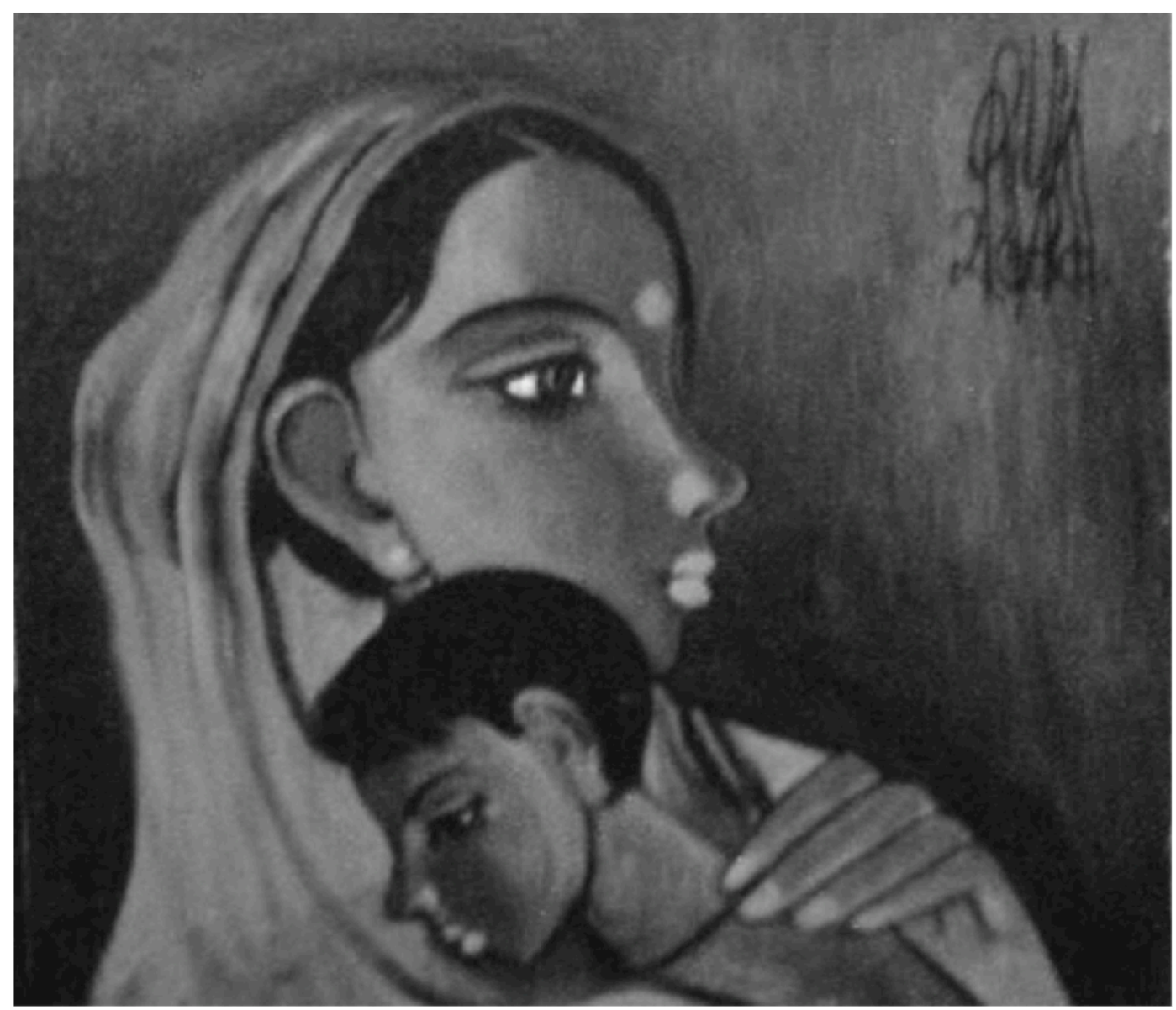




\section{Curriculum Vitae}

Madhu Gupta was born on 21 April 1974 in Khetri Nagar, Rajasthan, India. In 1997 she graduated as a Bachelor of Medicine and Bachelor of Surgery (MBBS), and in 2003 she post graduated as a Doctor of Medicine (MD in Community Medicine) from Indira Gandhi Medical College, Shimla, Himachal Pradesh, India. She had also worked as an intern in Government Multi Specialty Hospital in Chandigarh during

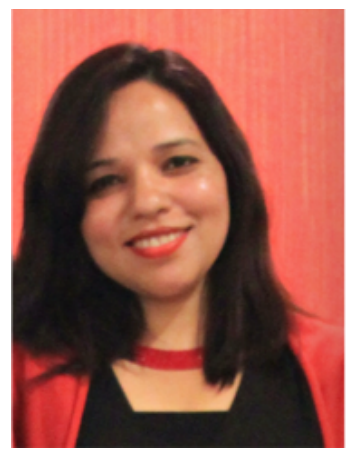
1998. Her MD thesis was on estimating prevalence of ocular morbidity among school children in Shimla, Himachal Pradesh. It got published in indexed journal and has been cited about 50 times. She had joined the department of Community Medicine, School of Public Health, Post Graduate Institute of Medical Education and Research (PGIMER), Chandigarh, India (an Institute of National Importance) as Senior Resident in 2003. During her residency period she had developed interest in maternal and child health and inequalities. She had worked as medical Research Scientist in a collaborative project of Indian Council of Medical Research, New Delhi India, John Hopkins's Bloomberg School of Public Health, USA and Global Alliance of Vaccine Initiatives entitled 'Estimating the Preventable Burden of Haemophilus influenzae type b Meningitis and Pneumonia in India-Part A' from 2006 to 2008. During 2008 she had joined as an Assistant Professor of Community Medicine in School of Public Health, PGIMER Chandigarh. Her research provided evidence on significant reproductive and child health inequalities among urban, rural and slum population in Union Territory, Chandigarh, North India in 2008. She also has a keen interest in Vaccinology and involved in conducting vaccine trials on pentavalent vaccine and rotavirus vaccine so as to make these vaccines available at affordable cost for Indian children. She got promoted to Associate Professor of Community Medicine in 2011 and to Additional Professor of Community Medicine in 2014 in PGIMER. She has conducted about 29 research projects mainly on maternal and child health issues, which are funded by various national and international organizations like UNICEF, WHO, ICMR, USAID, European Commission etc. She has published about 45 articles on maternal and child health issues in national and international indexed journals till date. In 2011, she began her work as a PhD student at the School of Public Health and Primary Care (CAPHRI), Maastricht, The Netherlands. Since then she is also working as External Technical Consultant with Haryana and Chandigarh Government in India. She is also a member of State Expert Committee on Adverse Events Following Immunization in Haryana, and State Task Force on Improving Maternal and Child Health in Chandigarh, Union Territory. She is living with Vivek Gupta and they have a daughter named Saanvi and a son named Anirudh. 


\section{Indexed}

Blencowe H, Cousens S, Jassir FB, Say L, Chou D, Mathers C, Lancet Still Birth Investigator Group et al. National, regional and worldwide estimates of stillbirth rates in 2015, with trends from 2000. Ending preventable still births series global epidemiology paper series.

Joy E Lawn, Blencowe H, Waiswa P, Amouzou A, Matehers C, Hagan D, Lancet Stillbirth Epidemiology investigator group. Stillbirths:rates, risk factors and acceleration towrads 2030 .

Prinja S, Gupta M, Singh A, Kumar R. Effectiveness of planning and management interventions for improving ageappropriate immunization in rural India.

Saluja T, Sharma SD, Gupta M, Kundu R, Kar S, Dutta A et al. A multicenter prospective hospital based surveillance to estimate the burden of rotavirus gastroenteritis in children less than five years of age in India.

MS Dhingra, Kundu R, Gupta M, Kanungo S, Ganguly N, Singh M et al. Phase I/II Evaluation of Safety and

Vaccine.

$\underline{\text { M, Sharma SD, Bavdekar SB, Jayanth MV, Ravinuthala }}$

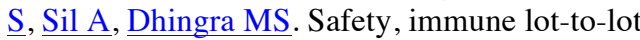
consistency and non-inferiority of a fully liquid pentavalent DTwP-HepB-Hib vaccine in Healthy Indian Toddlers and Infants

Gupta M, Angeli F, Bosma H, Rana M, Prinja S, Kumar $\mathrm{R}$, van Schayck OCP. Effectiveness of multiple-strategy community intervention in reducing geographical, socioeconomic and gender inequalities in maternal and child health outcomes in Haryana, India.

Gupta M, Prinja S, Kumar R and Kaur M. Costeffectiveness of Haemophilus influenzae type b (Hib) vaccine introduction in the universal immunization schedule in Haryana State, India.

Hum Vaccin 18:0. doi:10.1080/21645515.2 015.1100779 .

PLoS One. 2016; 11(3): $\mathrm{e} 0150537$.

doi:10.1371/journal.pon e.0150537.

Health Policy and

Sardana M, Goel S, Gupta M, Singh BS. Is exposure to Tobacco Advertising, Promotion and Sponsorship (TAPS) associated with initiation of tobacco use among current tobacco users in youth in India?

Asia Pacific Journal of

Gupta M, Thakur JS, Kumar R. Reproductive and child health inequity in Chandigarh, Union Territory of India.

2015;16(15):6299-6302.

Journal of Urban

Health. 2008; 86(2):291-99. 
intervention to reduce maternal and child health inequalities in Haryana, North India: a mixed methods study protocol.

Prinja S, Rani R, Gupta A, Bahuguna P, Thakur JS, Gupta M, Singh T. Impact assessment and Cost effectiveness of $\mathrm{m}$-Health application used by community health workers for maternal, newborn and child health care $(\mathrm{MNCH})$ services in a rural area of Uttar Pradesh, India - Study Protocol.

Gupta M, Prinja S, Shekhar S, Chakarborti A, Singh A, Singhi S, Kumar R. Feasibility of Pneumonia and Meningitis Surveillance in a District of Northern India.

Prinja S, Gupta M, Singh A, Kumar R. Improving Age Appropriate Immunization: Experience from Rural North India.

Smith ND, Gupta M, Kaur M, Kumar R. Determinants of persistent anemia in poor, urban pregnant women of Chandigarh city, North India: a mixed method approach.

Gupta M, Singh A. Pattern of treatment compliance among

eye patients in North Indian town.

Jeyashree K, Gupta M, Kathirvel S, Singh A. Home deliveries in Chandigarh, the beautiful city of India: a tug of war between culture and science.

Kaur M, Sukhbir, Gupta M, Pankaj. Inequity in Access to Health Services between Migrants and Natives of Chandigarh, India.

\section{National}

Singh M, Gupta M, Grover S. Prevalence and factors associated with depression among school going adolescents in Chandigarh, North India.

Singh MP, Kaur M, Gupta N, Kumar A, Goyal K, Sharma A, Majumdar M, Gupta M, Ratho K. Prevalence of high risk human papilloma virus types and cervical smear abnormalities in female sex workers in Chandigarh, India.

Gupta M, Kumar R, Deb AK, Bhattacharya SK, Bose A, John J et al. Multi-center surveillance for pneumonia \& meningitis among children $(<2 \mathrm{yr})$ for Hib vaccine probe trial preparation in India.

Mathew BS, Fleming DS, Gupta M, Kumar R, Kumar D, Chandy SJ et al. An objective measure of antibiotic use for febrile illness in a rural paediatric population using high performance liquid chromatography.

Gupta M, Prinja S, Kumar D, Kumar R. Introducing pentavalent vaccine in EPI in India: A counsel for prudence in interpreting scientific literature.

Singh MP, Kumar A, Gautam N, Khurana J, Gupta M, Ratho RK. Rubella outbreak in the Union Territory of http://dx.doi.org/10.340

2/gha.v8.25987

Global Health Action.

2016. (Ahead of print).

Int J Infect Dis.

2008;12(Spp 1):e69.

(Abstract).

Int J Infect Dis.

2008;12(Spp 1):e154-

55. (Abstract).

Food and nutrition

Bulletin. 2016; DOI:

10.1177/037957211663

7721.

Annali italiani di

Chirurgia. 2007; 78: 1-

4.

BMJ Case Reports

2013. doi: $10.1136 / \mathrm{bcr}-$

2012-007904.

International Journal of Migration, Health and

Social Care.

2015;11(2):147-155.

Indian Journal of Medical Research. 2016. (Ahead of print).

Indian Journal of

Medical Research. 2016. (Ahead of print).

Indian J Med Res

2010;131: 649-658.

Indian J Med Res 2010:131; 723-725.

Indian J Med Res 2011;133(5):560-62.

J Med Virol. 
Venkatachalam J, Aggarwal AK, Gupta M, Sathya GR. Evaluation of IMNCI practices among health care providers in a district of North India.

Singhi S, Gupta M, Kumar D, Kumar R. Outcome of meningitis among less than 2-year-old children in Haryana.

Kumar R, Gupta M, Prinja S. Illness burden, care seeking, and treatment cost among $<2$-year-old children in a rural area of Haryana.

Gupta M, Gupta BP, Chauhan A, Bhardwaj A. Ocular morbidity prevalence among school children in Shimla, Himachal, North India.

Singh SK, Kaur R, Gupta M, Kumar R. Is National Rural Health Mission having any Impact on Perinatal Mortality in Rural India?

Bhatnagar N, Kaur R, Gupta M. Introducing combined Measles, Mumps and Rubella (MMR) vaccine in Chandigarh (India): Issues and Concerns

Madhanraj K, Singh N, Gupta M, Singh MP, and Ratho RK. An Outbreak of Rubella in a Union Territory of Northern India.

Gupta M, Singh MP, Guglani V, Mahajan KS, Pandit S. Hospital based surveillance of rotavirus diarrhoea among under five children in Chandigarh.

Singh MP, Chandran C, Sarwa A, Kumar A, Gupta M, Raj A, Ratho RK. Outbreak of chicken pox in a Union Territory of North India.

Chakarborti A, Sekhar S, Singhi S, Kumar D, Prinja S, Gupta M, Kumar R. Feasibility of Laboratory-Based Surveillance for Childhood Pneumonia and Meningitis in District Hospitals.

Gupta M, Aggarwal AK. Feasibility study of IMNCI guidelines on effective breastfeeding in North Indian rural area.

J Venkatachalem, Kumar D, Gupta M, Aggarwal AK. Knowledge and skills of primary health care worker on IMNCI:Follow up assessment three years after training.

Dikid T, Gupta M, Kaur M, Goel S, Aggarwal AK, Caravotta J. Maternal and perinatal death inquiry and response project implementation review in India.

Venkatachalam J, Kumar D, Gupta M, Aggarwal AK. Development of One day Refresher Training Course for Primary Health Care Workers on Integrated Management of Neonatal and Childhood Illness (IMNCI).

Gupta M, Venkatachalam J, Goyal N, Kaur R, Goel S, Kaur M et al. Models of Supportive Supervision for IMNCI Implementation in Selected Districts of Bihar,
Journal of Dental and

Medical Sciences.

2012;1(6):45-60.

Indian Journal of

Paediatrics.

2012;79(12):1651-3.

Indian Journal of

Paediatrics.

2014;81(12):1347-52.

Indian Journal of

Ophthalmology. 2009; 57:133-138.

Indian Pediatrics.

2012;49(2):136-8.

Indian Paediatrics.

1.01

2014;51(6):441-3.

Indian Paediatrics.

2014;51(11):897-99.

Indian Paediatrics

Accepted March 2015.

Indian Journal of

Medical Microbiology. 2015;33(4);524-527.

J Commun Dis. 2013; 45(3\&4) : 125-36.

Indian Journal of

Community Medicine. 2008;33(3):201-203

Indian Journal of Public Health. 2011;55(4):289302.

Journal of Obstetrics and Gynaecology of India. 2013;63:101-107.

Indian Journal of Public Health Research and Development. 2012;4(1):221-223.

Indian Journal of Public Health Research and Development. 
Orissa and Rajasthan in India.

Gupta M, Tripathy JP. Psychosocial problems among young high school adolescents in Chandigarh, North India.

Gupta M, Bhatnagar N, Bahugana P. Inequity in awareness and utilization of adolescent reproductive and sexual health services in Union Territory, Chandigarh, North India.

Khumukcham T, Singh T, Kaur M, Gupta M, Kumar R. Factors Influencing the Choice of a Public or Private Health Institution for Childbirth in Chandigarh.

Gupta M, Tripathy JP, Jamir L, Sarwa A, Sinha S, Bhag C. Improving quality of home based postnatal care by microteaching of multipurpose workers in rural and urban slum areas of Chandigarh, India: a pilot study.

Kaur M, Aggarwal AK, Gupta M. Audit maternal deaths to save mothers.

Venkatachalam J, Aggarwal AK, Gupta M. Treatment Seeking Practices of Parents of Under-Fives' in IMNCI Implemented district of North India.
2012;4(1):224-228.

Indian Journal of Public

Health Research and

Development.

2015;6(1):11-15.

Indian Journal of Public

Health. 2015;59(1):9-

17.

Indian J Comm Health. 2015; 27, 1: 86-94.

Advances in Medical Education and Practice. 2016. (Ahead of print).

\section{Non Indexed}

Manthan. 2009;13(2):3

International Journal of Contemporary Medicine. 2014;2(1):3338. 


\section{Appendices}

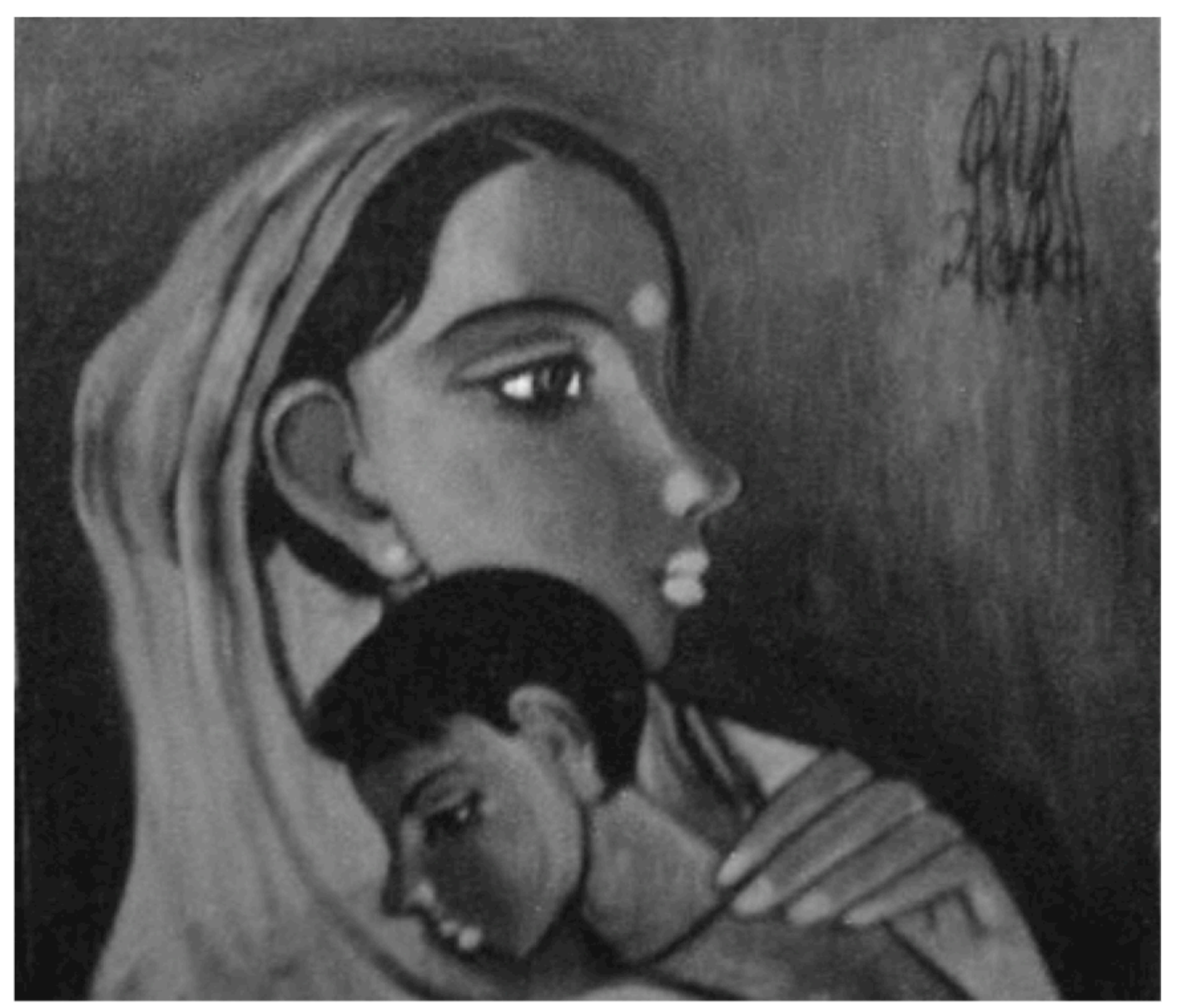




\section{Appendix 1}

\section{In-depth Interview/Focus Group Guide}

Title: Effectiveness of a Multiple-Strategy Community Intervention to Reduce Maternal and Child Health Inequalities in Haryana, North India.

Section 1: Informed consent

Section 2: Introduction to study (study information sheet provided to the participants)

Section 3: Extent of implementation of NRHM health sector plans for maternal and child health

- What is your opinion on NRHM plans/schemes for maternal and child health?

- What do you think is the status of various schemes implemented to improve maternal and child health under the NRHM?

Section 4: Status of maternal health strategies under NRHM implementation

- What do you think about the implementation status of the existing maternal health strategies under the NRHM?

- Do you think that after the implementation of the NRHM plans, the maternal health has improved compared to the status before its implementation? If yes, how?

- Has the death rate among mothers decreased after the implementation of the NRHM? If yes, by how much?

Section 5: Status of child health strategies under NRHM implementation

- What do you think about the implementation status of the existing child health strategies under the NRHM?

- What is the immunization status among children? Are all children getting all vaccinations in time? Do you think the NRHM has helped in improving the immunization status of children?

- Do you think that neonatal (newborn) care has improved after the implementation of NRHM? Could you describe how?

- Do you think that after the implementation of the NRHM plans, child health has improved compared to the status before their implementation?

Section 6: Accessibility, availability, and affordability of maternal and child health services

- Availability: Do you think that the implementation of NRHM schemes and the maternal and child health services were able to reach rural areas, poor women and children, and disadvantaged groups? 
- Accessibility: Do you think that there is improvement in the accessibility of maternal and child health services after the implementation of NRHM schemes in rural areas/ for poor women and children/for disadvantaged groups?

- Affordability: In your opinion, are people satisfied with the existing NRHM schemes? Have NRHM schemes done anything to make maternal and child health services affordable for people, especially for people in rural areas and for poor families?

Section 7: Status of maternal and child health inequalities after NRHM implementation

- Do you think that health sector plans implemented under the NRHM influenced these inequalities in any way? If yes, how?

- Do you think that this inequality with respect to maternal and child health between rich and poor still exists?

- Has there been any improvement in these inequalities after the introduction of the NRHM?

- Do you think there are differences in health status between male and female children?

\section{Section 8:}

- Are people accepting the NRHM and its schemes?

- According to you, are people satisfied with existing NRHM schemes?

- Do you think there are barriers to implementing NRHM schemes that aim to reduce the geographic, socioeconomic, and gender health inequalities in the district?

- If yes, what in your opinion are the possible solutions to overcome these?

- What do you think is the key to success of the NRHM schemes? 


\section{Appendix- 2}

\section{Informed Consent Form}

Title: Effectiveness of a Multiple-Strategy Community Intervention to Reduce Maternal and Child Health Inequalities in Haryana, North India.

\section{Name of Principal Investigator: Dr Madhu Gupta}

Name of the Institution: School of Public Health, Post Graduate Institute of Medical Education and Research, Chandigarh, India; and CAPHRI, Maastricht University, The Netherlands

This is to inform you that I, Dr. Madhu Gupta, Assistant Professor of Community Medicine in School of Public Health, Department of Community Medicine, PGIMER, Chandigarh, am conducting a study to ascertain the Effectiveness of National Rural Health Mission on health inequalities in Haryana, North India as a part of my PhD thesis.

The proposed study is in the interest of society at large and it will help understanding whether National Rural Health Mission in Haryana is able to bridge the gaps in terms of better maternal and child health outcomes in different geographical area and socioeconomic groups. In this study a focus group discussion will be conducted with the residents from study area regarding implementation status of schemes under national rural health mission, barriers in implementation of NRHM schemes and possible solutions offered to solve these barriers. Also in depth interviews will be done with community leaders and programme managers to ascertain their view on the above-mentioned issue.

This is to emphasize, that participation of residents of selected areas in the study will be voluntary. They will be free to withdraw from the study at any stage if they wish to do so. Participants will also be free to refuse to participate in the study and refusal shall not have any negative consequences for them. All the information provided by participants in the study shall remain confidential.

Dr. Madhu Gupta

Mob: 9914208226

I have been explained the purpose of the study. I consent voluntarily to participate in this study. I understand that I have the right to withdraw from the study at any time.

Name of participant

Signature of participant:

Date:

Place: 


\section{Appendix 3}

\section{Participant Information Sheet}

This study will be done to ascertain the effectiveness of National Rural Health Mission on maternal and child health inequalities in Haryana, North India.

The goal of National Rural Health Mission is to improve the availability of and access to quality health care by people, especially for those residing in rural areas, the poor, women and children. Aim is to reduce in Infant Mortality Rate (IMR) and Maternal Mortality

Ratio (MMR); provide universal access to public health services such as women's health, child health, water, sanitation \& hygiene, immunization, and Nutrition; prevent and control of communicable and non-communicable diseases, including locally endemic diseases, access to integrated comprehensive primary healthcare, population stabilization, gender and demographic balance, revitalize local health tradition, promotion of healthy life styles. Main strategies to achieve these goals include train and enhancing capacity of Panchayati Raj Institutions (PRIs) to own, control and manage public health services, promote access to improved healthcare at household level through the female accredidated health activist (ASHA), health Plan for each village through Village Health Committee of the Panchayat, strengthening sub-centre through an untied fund to enable local planning and action and more Multi Purpose Workers (MPWs), strengthening existing PHCs and CHCs, and provision of 30-50 bedded CHC per lakh population for improved curative care to a normative standard. Special emphasis will be given to strengthen the health infrastructure in underserved areas.

This study will include conducting focus group discussions with the residents from study area regarding implementation status of schemes under national rural health mission, barriers in implementation of NRHM schemes and possible solutions offered to solve these barriers and in depth interviews with community leaders and programme managers to ascertain their view on the above-mentioned issue. 